\title{
Templated electrodeposition of functional nanostructures
}

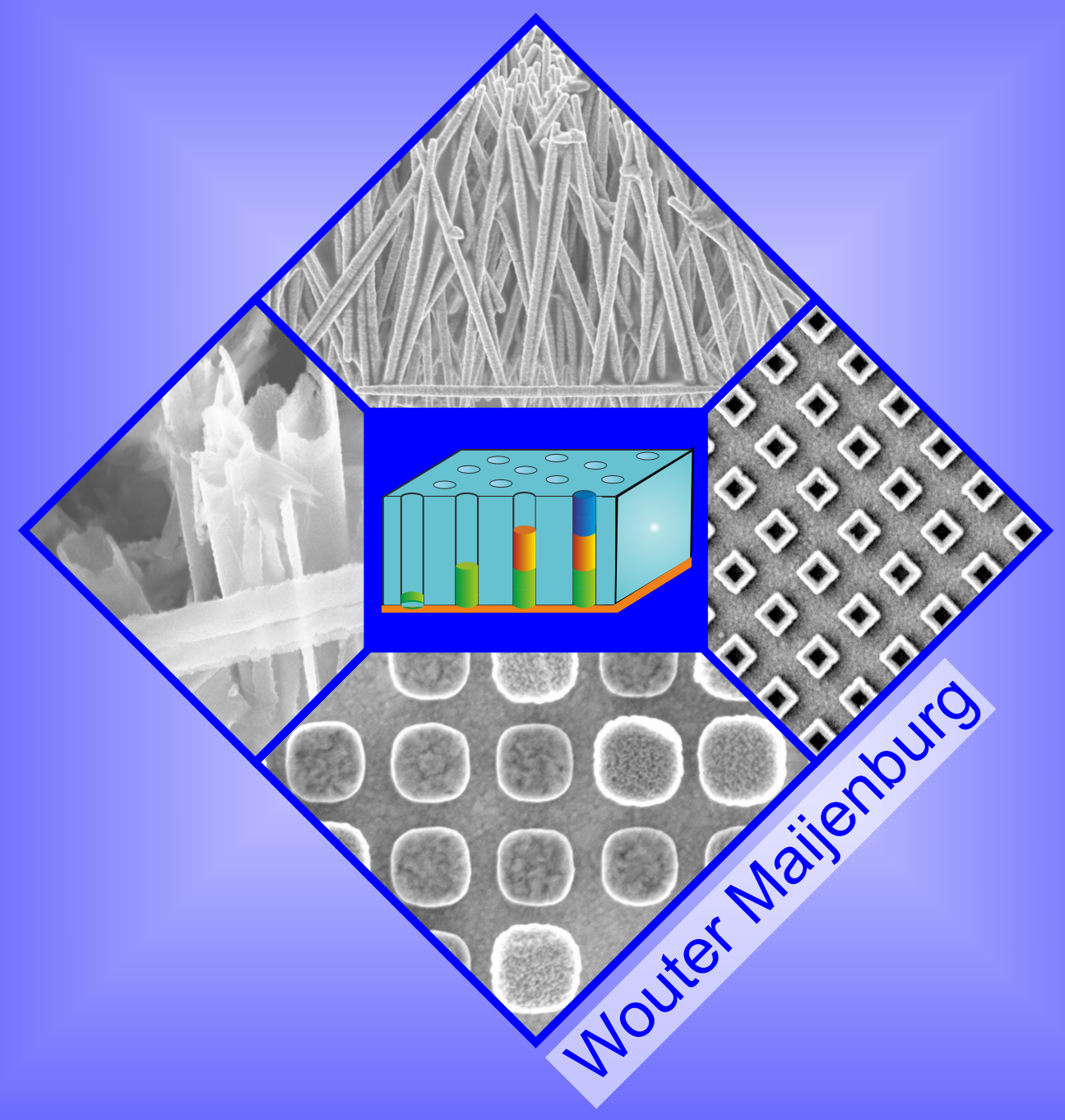

Nanowires, nanotubes and nanocubes 



\title{
Templated electrodeposition of functional nanostructures:
} nanowires, nanotubes and nanocubes

\author{
Wouter Maijenburg
}




\section{PhD committee}

Chairman and secretary:

Prof. dr. G. van der Steenhoven University of Twente

Supervisors:

Prof. dr. ir. J.E. ten Elshof

University of Twente

Prof. dr. ing. D.H.A. Blank

University of Twente

Members:

Prof. dr. K. Nielsch

University of Hamburg

Prof. dr. F.M. Mulder

Delft University of Technology

Prof. dr. G. Mul

University of Twente

Prof. dr. J. Huskens

University of Twente

Referent:

Dr. M.E. Toimil-Molares

GSI Institute for heavy ion irradiation

Cover: A selection of SEM images showing different types of nanostructures made by templated electrodeposition as presented in this thesis: Ni nanowires (top), $\mathrm{TiO}_{2}$ nanotubes (left), $\mathrm{Ni} \mid \mathrm{p}-\mathrm{Cu}_{2} \mathrm{O}$ nanocubes (bottom) and $\mathrm{Ni}$-Au nanoboxes (right).

The work described in this thesis was carried out at the Inorganic Materials Science group at the faculty of Science and Technology, and the MESA+ Institute for Nanotechnology, University of Twente, P.O. Box 217, 7500 AE Enschede, The Netherlands. Part of this research was carried out in the group of prof. Kyoung-Shin Choi at Purdue University (IN, USA).

This research was financially supported by the Chemical Sciences division of the Netherlands Organization for Scientific Research (NWO-CW) in the framework of the TOP program, and partly by the Fulbright Center in The Netherlands.

A.W. Maijenburg

Templated electrodeposition of functional nanostructures:

nanowires, nanotubes and nanocubes

PhD Thesis, University of Twente, Enschede, The Netherlands

ISBN: 978-90-365-3603-5

DOI: $10.3990 / 1.9789036536035$

Printed by: Gildeprint drukkerijen (Enschede, The Netherlands)

Copyright (c) 2014 by A.W. Maijenburg

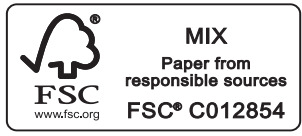




\title{
TEMPLATED ELECTRODEPOSITION OF FUNCTIONAL NANOSTRUCTURES: \\ NANOWIRES, NANOTUBES AND NANOCUBES
}

\author{
PROEFSCHRIFT \\ ter verkrijging van \\ de graad van doctor aan de Universiteit Twente, \\ op gezag van de rector magnificus, \\ prof. dr. H. Brinksma, \\ volgens besluit van het College voor Promoties \\ in het openbaar te verdedigen \\ op vrijdag 17 januari 2014 om 14.45 uur
}

door

Albert Wouter Maijenburg

geboren op 21 mei 1985

te Nieuwegein 
Dit proefschrift is goedgekeurd door de promotoren:

Prof. dr. ir. J.E. ten Elshof Prof. dr. ing. D.H.A. Blank 


\section{Table of contents}

Chapter 1 - Introduction $\quad 11$

1.1) Electrodeposition 12

1.2) Photocatalysis 19

1.3) Thesis scope and outline 25

$\begin{array}{ll}1.4) & \text { References } \\ & 28\end{array}$

Chapter 2 - Preparation and use of photocatalytically active $\mathbf{3 3}$ segmented $\mathrm{Ag} \mid \mathrm{ZnO}$ and coaxial $\mathrm{TiO}_{2}-\mathrm{Ag}$ nanowires made by templated electrodeposition

2.1) Abstract $\quad 34$

2.2) Introduction $\quad 35$

2.3) Procedure 40

2.3.1) Segmented $\mathrm{Ag} \mid \mathrm{ZnO}$ nanowire formation in PCTE 40 membranes

2.3.2) Coaxial $\mathrm{TiO}_{2}-\mathrm{Ag}$ nanowire formation in AAO membranes 43

2.3.3) $\mathrm{H}_{2}$ formation experiments 46

2.4) Representative results 48

2.5) Discussion $\quad 52$

2.6) Conclusions $\quad 55$

2.7) References $\quad 55$

Chapter 3 - Electrodeposition of micropatterned Ni|Pt multilayers $\mathbf{6 3}$ and segmented $\mathrm{Ni}|\mathrm{Pt}| \mathrm{Ni}$ nanowires

3.1) Abstract 64

3.2) Introduction $\quad 64$

3.3) Experimental details 66

3.4) Results and discussion 68

2.4.1) Thin film deposition 68

2.4.2) Nanowires and patterning $\quad 71$

3.5) Conclusions $\quad 75$

3.6) References $\quad 75$ 
Chapter 4 - Hydrogen generation from photocatalytic silver|zinc oxide nanowires

4.1) Abstract $\quad 82$

4.2) Introduction $\quad 82$

4.3) Experimental details 83

4.4) Results and discussion 85

4.5) Conclusions 90

4.6) References 90

Chapter 5 - Electrochemical synthesis of coaxial $\mathrm{TiO}_{2}$-Ag nanowires $\mathbf{9 5}$ and their application in photocatalytic water splitting

5.1) Abstract 96

5.2) Introduction 96

5.3) Experimental details 101

5.4) Results and discussion 104

5.5) Conclusions 115

5.6) References 116

Chapter 6 - Photoelectrochemical diodes consisting of axially 123 segmented $\mathrm{Cu}_{2} \mathrm{O}$ nanowires with $\mathrm{p}$ - and $\mathrm{n}$-type segments for autonomous $\mathrm{H}_{2}$ formation

6.1) Abstract 124

6.2) Introduction 124

6.3) Experimental details 127

6.4) Results and discussion 130

6.5) Conclusions 136

6.6) References 137 
Chapter $\mathbf{7}-\mathrm{Ni}$ and $\mathrm{p}-\mathrm{Cu}_{2} \mathrm{O}$ nanocubes with a small size distribution by templated electrodeposition, and their characterization by photocurrent measurement

7.1) Abstract

7.2) Introduction

7.3) Experimental details 144

7.4) Results and discussion 147

7.5) Conclusions 157

7.6) References

Chapter $8-\mathrm{MoS}_{2}$ nanocube structures as catalysts for 165 electrochemical $\mathrm{H}_{2}$ evolution from acidic aqueous solutions

8.1) Abstract 166

8.2) Introduction 166

8.3) Experimental details 169

8.4) Results and discussion 171

8.5) Conclusions 181

8.6) References 182

Summary 185

Samenvatting 191

Epilogue 197

Dankwoord

203 



\section{List of publications}

[1] K. M. Pondman, A. W. Maijenburg, F. B. Celikkol, A. A. Pathan, U. Kishore, B. ten Haken, and J. E. ten Elshof, "Au coated $\mathrm{Ni}$ nanowires with tuneable dimensions for biomedical applications", Journal of Materials Chemistry B, 2013,

[2] A. W. Maijenburg, A. N. Hattori, M. De Respinis, C. M. McShane, K.-S. Choi, B. Dam, H. Tanaka, and J. E. ten Elshof, "Ni and p- $\mathrm{Cu}_{2} \mathrm{O}$ nanocubes with a small size distribution by templated electrodeposition and their characterization by photocurrent measurement", ACS Applied Materials \& Interfaces, 2013, vol. 5, pp. 10938-10945.

[3] A. W. Maijenburg, A. George, D. Samal, M. Nijland, R. Besselink, B. Kuiper, J. E. Kleibeuker, and J. E. ten Elshof, "Electrodeposition of micropatterned Ni|Pt multilayers and segmented $\mathrm{Ni}|\mathrm{Pt}| \mathrm{Ni}$ nanowires", Electrochimica Acta, 2012, vol. 81, pp. 123-128.

[4] A. Hovestad, H. Rendering, and A. W. Maijenburg, "Patterned electrodeposition of interconnects using microcontact printing", Journal of Applied Electrochemistry, 2012, vol. 42, pp. 753-761.

[5] E. J. B. Rodijk, A. W. Maijenburg, M. G. Maas, D. H. A. Blank, and J. E. ten Elshof, "Templated electrodeposition of $\mathrm{Ag}_{7} \mathrm{NO}_{11}$ nanowires with very high oxidation states of silver", Materials Letters, 2011, vol. 65, pp. 3374-3376.

[6] A. W. Maijenburg, E. J. B. Rodijk, M. G. Maas, M. Enculescu, D. H. A. Blank, and J. E. ten Elshof, "Hydrogen generation from photocatalytic silver|zinc oxide nanowires: Towards multifunctional multisegmented nanowire devices", Small, 2011, vol. 7, pp. 2709-2713.

[7] A. W. Maijenburg, M. G. Maas, E. J. B. Rodijk, W. Ahmed, E. S. Kooij, E. T. Carlen, D. H. A. Blank, and J. E. ten Elshof, "Dielectrophoretic alignment of metal and metal oxide nanowires and nanotubes: A universal set of parameters for bridging prepatterned microelectrodes", Journal of Colloid and Interface Science, 2011, vol. 355, pp. 486-493.

[8] M. G. Maas, E. J. B. Rodijk, A. Wouter Maijenburg, D. H. A. Blank, and J. E. ten Elshof, "Microstructure development in zinc oxide nanowires and iron oxohydroxide nanotubes by cathodic electrodeposition in nanopores", Journal of Materials Research, 2011, vol. 26, pp. 2261-2267. 
[9] A. George, A. W. Maijenburg, M. D. Nguyen, M. G. Maas, D. H. A. Blank, and J. E. ten Elshof, "Nanopatterning of functional materials by gas phase pattern deposition of self-assembled molecular thin films in combination with electrodeposition", Langmuir, 2011, vol. 27, pp. 12760-12768.

[10] A. George, A. W. Maijenburg, M. G. Maas, D. H. A. Blank, and J. E. ten Elshof, "Electrodeposition in capillaries: Bottom-up micro- and nanopatterning of functional materials on conductive substrates", ACS Applied Materials and Interfaces, 2011, vol. 3, pp. 3666-3672.

[11] A. George, A. W. Maijenburg, M. G. Maas, D. H. A. Blank, and J. E. ten Elshof, "Patterning functional materials using channel diffused plasma-etched self-assembled monolayer templates", Langmuir, 2011, vol. 27, pp. 12235-12242.

[12] M. G. Maas, E. J. B. Rodijk, W. Maijenburg, J. E. ten Elshof, and D. H. A. Blank, "Photocatalytic segmented nanowires and single-step iron oxide nanotube synthesis: Templated electrodeposition as all-round tool," in MRS Proceedings, Boston, MA, 2010, pp. 1-6.

[13] X. Y. Ling, I. Y. Phang, W. Maijenburg, H. Schönherr, D. N. Reinhoudt, G. J. Vancso, and J. Huskens, "Free-standing 3D supramolecular hybrid particle structures", Angewandte Chemie International Edition, 2009, vol. 48, pp. 983-987.

[14] A. W. Maijenburg, J. Veerbeek, R. de Putter, S. A. Veldhuis, M. G. C. Zoontjes, G. Mul, J. M. Montero, K. Nielsch, H. Schäfer, M. Steinhart, and J. E. ten Elshof, "Electrochemical synthesis of coaxial $\mathrm{TiO}_{2}$-Ag nanowires and their application for photocatalytic water splitting", Accepted in Journal of Materials Chemistry A,

[15] A. W. Maijenburg, E. J. B. Rodijk, M. G. Maas, and J. E. ten Elshof, "Preparation and use of photocatalytically active segmented $\mathrm{Ag} \mid \mathrm{ZnO}$ and coaxial $\mathrm{TiO}_{2}-\mathrm{Ag}$ nanowires made by templated electrodeposition", Accepted in Journal of Visualized Experiments, 


\section{1. \\ Introduction}

This thesis is comprised of a selection of functional nanostructures (nanowires, nanotubes and nanocubes) made by templated electrodeposition. To introduce the main subjects that will be presented and discussed in the rest of the thesis, the theoretical aspects of both electrodeposition (which is the method used to make the nanostructures) and photocatalysis (which is the main functionality discussed in this thesis) will be explained in this introduction. 


\subsection{Electrodeposition}

Using electrodeposition, a wide range of metals, metal oxides, semiconductors and conductive polymers can be deposited. Due to the possibility of electrodeposition to operate at room temperature or temperatures near room temperature $\left(<100{ }^{\circ} \mathrm{C}\right)$ and at ambient pressure, electrodeposition is an easy and cost-effective technique. The mostly used setup for electrodeposition is the three-electrode electrochemical cell as shown in Figure 1.1. In this configuration, a working electrode (WE), a counter electrode (CE) and a reference electrode (RE) are placed in an electrolyte containing the ions of interest [1].

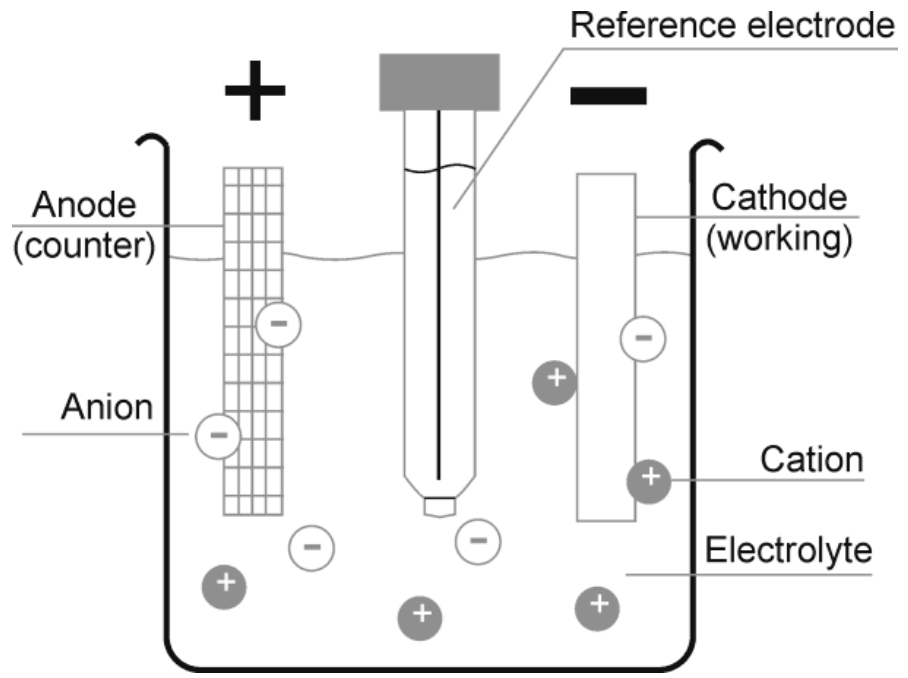

Figure 1.1: Schematic representation of a three-electrode electrochemical cell.

When operated in the potentiostatic mode, a potential is applied to the WE with respect to the RE. Since the RE has a fixed potential, the potential applied to the WE will be reproducible in every experiment. In the case of an $\mathrm{Ag} / \mathrm{AgCl}(3 \mathrm{M} \mathrm{KCl}) \mathrm{RE}$ at room temperature, the potential is fixed at $0.2223 \mathrm{~V}$ with respect to the standard hydrogen reaction. When the applied potential is different from the open circuit potential (OCP), which is the potential difference between the WE and RE at equilibrium, a current will flow between the WE and the CE for compensation of the potential 
difference. In the case of electrodeposition, typically a potential more negative than the OCP is applied to the WE and electrons are transported from the CE (also known as anode) to the WE (also known as cathode). The potential difference between the applied potential and the OCP is called the overpotential. For a simple metal deposition, these electrons will reduce ions in the solution and form a solid phase at the WE according to the following reaction $[1,2]$ :

$\mathrm{M}^{\mathrm{n}+}+\mathrm{ne}^{-} \rightarrow \mathrm{M}(\mathrm{s})$

Instead of direct electrodeposition in which a metal is deposited from its respective ions, an indirect approach in which the $\mathrm{pH}$ is locally increased at the WE by nitrate reduction is also possible. This approach is often used for electrodeposition of metal oxides as shown in Chapter 4 for the deposition of $\mathrm{ZnO}$ nanowires at $60-90^{\circ} \mathrm{C}$ following the reactions [3, 4]:

$\mathrm{NO}_{3}^{-}+\mathrm{H}_{2} \mathrm{O}+2 \mathrm{e}^{-} \rightarrow \mathrm{NO}_{2}^{-}+2 \mathrm{OH}^{-}$and

$\mathrm{Zn}^{2+}+2 \mathrm{OH}^{-} \rightarrow \mathrm{ZnO}+\mathrm{H}_{2} \mathrm{O}$.

Instead of direct formation of a metal oxide by nitrate reduction, it is also possible to create a gel containing the desired metal oxide as a oxyhydroxide with crystal water. Upon annealing, this gel can be transformed into the desired metal oxide. In Chapter 5, the electrochemically induced sol-gel method was used for the deposition of $\mathrm{TiO}_{2}$ nanotubes via a $\mathrm{TiO}(\mathrm{OH})_{2} \cdot \mathrm{xH}_{2} \mathrm{O}$ gel:

$$
\begin{aligned}
& \mathrm{TiOSO}_{4}+\mathrm{H}_{2} \mathrm{O}_{2} \rightarrow \mathrm{Ti}\left(\mathrm{O}_{2}\right) \mathrm{SO}_{4}+\mathrm{H}_{2} \mathrm{O}, \\
& \mathrm{NO}_{3}^{-}+\mathrm{H}_{2} \mathrm{O}+2 \mathrm{e}^{-} \rightarrow \mathrm{NO}_{2}^{-}+2 \mathrm{OH}^{-}, \\
& \mathrm{Ti}\left(\mathrm{O}_{2}\right) \mathrm{SO}_{4}+2 \mathrm{OH}^{-}+(\mathrm{x}+1) \mathrm{H}_{2} \mathrm{O} \rightarrow \\
& \mathrm{TiO}(\mathrm{OH})_{2} \cdot \mathrm{xH}_{2} \mathrm{O}+\mathrm{H}_{2} \mathrm{O}_{2}+\mathrm{SO}_{4}^{2-} \text { and }
\end{aligned}
$$


$\mathrm{TiO}(\mathrm{OH})_{2} \cdot \mathrm{xH}_{2} \mathrm{O} \rightarrow \mathrm{TiO}_{2}+(\mathrm{x}+1) \mathrm{H}_{2} \mathrm{O}$.

Since the introduction of this method for the preparation of $\mathrm{TiO}_{2}$, several other materials, e.g. $\mathrm{SiO}_{2}$ and $\mathrm{ZrO}_{2}$, have also been made via the same principle [5-12].

During electrodeposition, the electron flow is measured by the potentiostat, and can be visualised in a chronoamperogram ( $l-t$ curve). The most important advantage of using the potentiostatic mode is that one can aim for a specific reaction or product, since a different reaction or stoichiometry will dominate at a different potential. The theoretical potential needed for an electrochemical reaction to take place can be calculated using the Nernst equation:

$E=E_{0}+\frac{R T}{z F} \ln \left(\frac{a_{\text {reactants }}^{a}}{a_{\text {products }}^{b}}\right)$

where $E$ is the cell potential (V), $E_{0}$ is the standard redox potential at $298 \mathrm{~K}$ and $1 \mathrm{~atm}(\mathrm{~V}), R$ is the gas constant $(8.3145 \mathrm{~J} / \mathrm{mol} \cdot \mathrm{K}), T$ is the temperature $(\mathrm{K}), z$ is the unit-less valence of the deposited atoms, $F$ is Faraday's constant $\left(9.64853 \cdot 10^{4} \mathrm{C} / \mathrm{mol}\right), a_{\text {reactants }}$ is the total activity of the reactants or oxidants, $a_{\text {products }}$ is the total activity of the products or reductants, and $a$ and $b$ describe the stoichiometric relationship between the reactants and the products [13-15].

It is also possible to operate the system in the galvanostatic mode. In this case, the current flow between the WE and CE is fixed and the potential difference between the $\mathrm{WE}$ and $\mathrm{RE}$ will be measured in a chronopotentiogram ( $V$ - $t$ curve). The most important advantage of using the galvanostatic mode is that the reaction rate can be optimized, since the amount of deposited material is directly related to the current via Faraday's law:

$w=\frac{I t M}{z F}$, 
where $w$ is the weight of the deposited material $(\mathrm{g}), I$ is the measured current (A), $t$ is the passed time (s), and $M$ is the molecular weight $(\mathrm{g} / \mathrm{mol})$ [13-15].

When the standard redox potential of material $A$ (which is usually a less noble metal) is much more negative than that of material $B$ (a more noble metal), material A could be replaced by material $B$ in a solution containing ions of material B. For this method called galvanic replacement or transmetalation, there is no need for an external voltage or current supply. Replacement reactions are often used for deposition of tiny layers of expensive catalyst material on a support of the less noble metal [16-20]. In Chapter 3, a method for the suppression of such replacement reaction is investigated to open up the possibility of depositing a more noble metal on top of a less noble metal by electrodeposition.

In 1987, Penner and Martin were the first to publish their results making nanowires by templated electrodeposition in polycarbonate membranes [21]. Since then, many more researchers started using templated electrodeposition for the synthesis of nanowires with different dimensions using either polycarbonate track-etched membranes (PCTE) or anodized aluminium oxide (AAO) membranes and templates [22]. Advantages of using templated electrodeposition for nanowire synthesis are its cost-effective nature, its possibility of forming nanowires from either metals, semiconductors and polymers, and its ability to create an exact negative replica of the template used [22]. Furthermore, when both phases would form a nanowire after single component deposition, axially segmented nanowires can be formed by sequential deposition of two or more different phases. An example of a multisegmented nanowire containing six different segments capable of three different functionalities can be found in Section 1.3. On the other hand, when templated electrodeposition of one of the two phases would result in a nanotube, coaxial nanowires containing two different phases can be created. An example of a coaxial nanowire consisting of a $\mathrm{TiO}_{2}$ shell and an $\mathrm{Ag}$ core can be found in Chapter 5 . 
In Equation (1.9) it was already explained that the observed current during electrodeposition is a direct measure for the amount of material deposited. By constraining the performed electrodeposition inside a template and knowledge of the template shape, it is possible to follow the deposition inside the template by looking at the chronoamperogram. An example of a chronoamperogram for the templated electrodeposition of Ni nanowires in a cigar-shaped PCTE membrane with an outer pore diameter of $50 \mathrm{~nm}$ and an inner pore diameter of $150 \mathrm{~nm}$ is shown in Figure 1.2. Since the current is indirectly related to the surface area of deposition, also the cigar-shape of these PCTE membranes can be observed in the $l-t$ curve. The first stage of every electrodeposition experiment is charging of the electrical double layer, which is accompanied by a sudden increase in current ${ }^{*}$ that slowly decreases as the electrical double layer reaches its equilibrium. The electrical double layer is the area around an electrode in which the ions in the electrolyte are influenced by the applied potential as species of opposite charge are attracted by the electrode. In the second stage, the current increases as the surface area of deposition increases, leading to deposition of more material at the same time, and faster supply of reactants since the surface of the nanowire gets closer to the entrance of the membrane pores. In the third stage, the change in surface area is minimal, leading to a smaller slope of increasing current since only the effect of faster reactant supply is visible in this stage. The decrease in current in the fourth stage is induced by the decrease in surface area of deposition. Finally, a quick increase in current can be observed in stage 5, indicating a fast increase in surface area of the deposited material due to growth of mushroom-shaped material on top of the membrane as the pores are completely filled [23].

* please note that the current always has a negative sign in electrodeposition as electrons are transported from the CE to the WE 


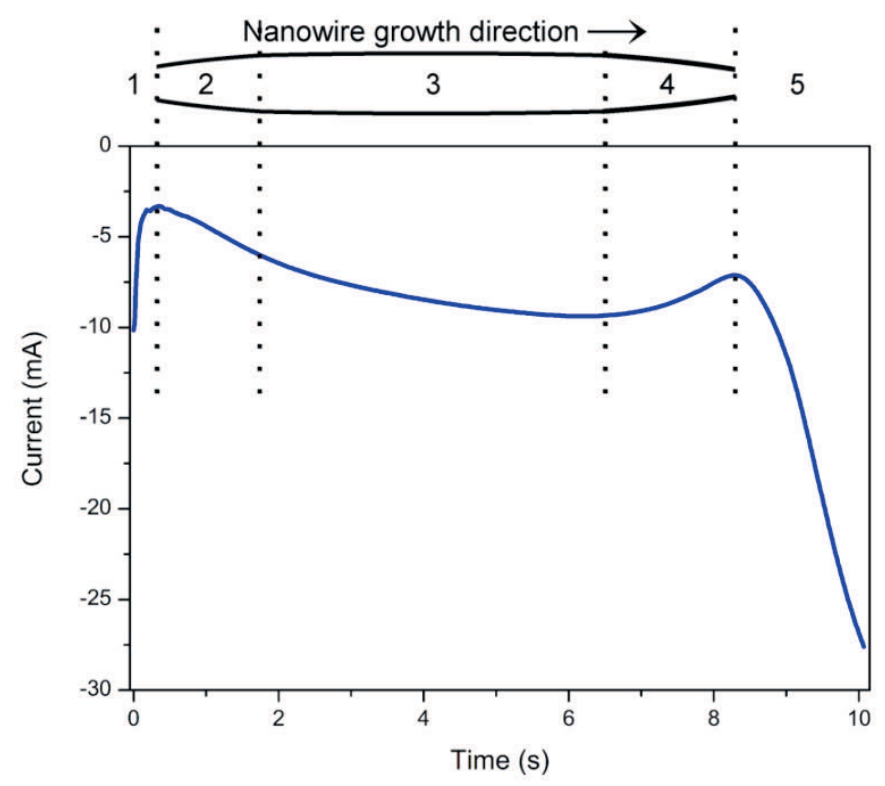

Figure 1.2: Chronoamperogram of $\mathrm{Ni}$ nanowire electrodeposition at $-1.0 \mathrm{~V}$ vs. $\mathrm{Ag} / \mathrm{AgCl} \mathrm{RE}$ inside a cigar-shaped PCTE template with a pore diameter of 50-150 $\mathrm{nm}$ and a pore length of $6 \mu \mathrm{m}$ including stages of nanowire growth; stage 1 represents charging of the electrical double layer, stage 2 represents nonlinear filling at the bottom of the nanopores, stage 3 represents linear filling of the nanopores, stage 4 represents nonlinear filling at the top of the nanopores, and stage 5 represents mushrooming on top of the membrane surface.

Templated electrodeposition is mostly associated with the afore mentioned electrodeposition of nanowires inside a hard template of PCTE or AAO membranes. But since the introduction of this type of templated electrodeposition, different types of templates have been created that are either related or unrelated to the PCTE and AAO membranes. Next to PCTE or AAO, also polyethylene terephthalate and polyimide templates have been created by heavy ion beam irradiation and filled by electrodeposition $[24,25]$. Next to the use of polycarbonate templates for synthesizing straight or cigar-shaped nanowires, also nanocones and interconnected nanowire network structures have been created inside PCTE templates [26-28]. Also for AAO templates, synthetic routes for creating different pore shapes and interconnected structures have been developed over the years [29-31]. 
But also several methods of templated electrodeposition are developed that are unrelated to the well-known PCTE or AAO membranes. For this, the main substrate limitations for templated electrodeposition, the availability of a conductive part for the start of the electrodeposition and stability of the template in the electrolyte solution, need to be taken into account. A popular application of templated electrodeposition is filling of through silicon vias (TSV) by e.g. Cu for 3D packaging of two or more chips in integrated circuits. In this area, a lot of research is performed on complete filling of the vias by either adding additives for smooth deposition or adjusting the deposition parameters like potential or the use of pulsed plating $[32,33]$. A completely different approach is the lithographically patterned nanowire electrodeposition (LPNE) technique developed by Penner and co-workers. In this technique, a horizontal trench is created with a sacrificial $\mathrm{Ni}$ electrode inside, from which horizontal nanowires from a wide variety of materials can be created using electrodeposition [34-36]. Another approach related to templated electrodeposition has recently been investigated in our group by Antony George and co-workers and combines the field of soft-lithography with electrodeposition. Several approaches have been developed that range from direct electrodeposition within a template formed by a PDMS stamp on top of a conductive substrate [37], to selective deactivation of a conductive substrate by a patterned self-assembled monolayer (SAM) [38, 39]. In this thesis (Chapter 7 and 8), new methods are developed for templated electrodeposition of nanocubes within either a negative PMMA template containing squared holes made by nano imprint lithography (NIL) (Chapter 7), or on top of a positive template containing arrays of Au nanocubes made by a combination of NIL and side-wall deposition (Chapter 8). 


\subsection{Photocatalysis}

Every day, more solar energy reaches the earth than is consumed globally in 7.5 years [40]. In nature, plants use sunlight to convert $\mathrm{CO}_{2}$ and $\mathrm{H}_{2} \mathrm{O}$ into sugar and $\mathrm{O}_{2}$, which are essential for all forms of life on our planet. This process is called photosynthesis. Within the last decades, researchers also found semiconducting materials that are capable of using sunlight for the generation of fuels, electricity or both. With the use of these semiconductors, one can either create electricity by using them as a solar cell (also called photovoltaic cell) or one can create fuels by using the semiconductors in a photoelectrochemical cell as a photocatalyst. In principle, also electricity can be generated by a photoelectrochemical cell, but a solar cell configuration is often more efficient for electricity generation.

The physical property that allows a semiconductor to be used as a photocatalyst or solar cell is its band gap energy $\left(E_{g}\right)$. This band gap energy is the energy difference between the top of the valence band $\left(E_{v b}\right)$ and the bottom of the conduction band $\left(E_{c b}\right)$ (Figure 1.3a). In analogy to the HOMO-LUMO gap in conjugated polymers, the valence band is the highest occupied orbital band and the conduction band is the lowest unoccupied orbital band. The band gap energy is basically the minimum energy an electron should gain from photons in order to pass the band gap and travel to the conduction band. When an electron is excited and inserted into the conduction band, a hole will remain in the valence band. This process creates an electron-hole pair [41-43]. 


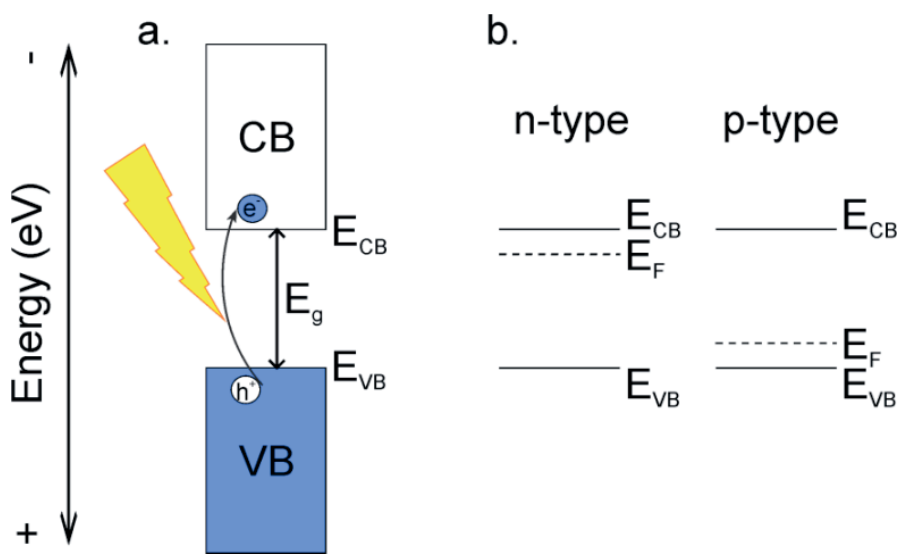

Figure 1.3: Schematic representation of (a) the band structure of a semiconductor and (b) the location of the Fermi level in an n-type or p-type semiconductor. For simplicity, the CB and VB are often depicted as a single horizontal line at the bottom position of the $C B$ and the top position of the $V B$, respectively.

Intrinsic doping is very common for semiconductors as even a small impurity concentration can have a profound effect on the electrical properties. Depending on whether the material is doped with an electron donor or electron acceptor, the material will respectively obtain either n-type or p-type semiconductivity. These types are defined as such because an electron donor will make the semiconductor slightly negatively charged, and an electron acceptor will make the semiconductor slightly positively charged. Another important property of a semiconductor is its Fermi level $\left(E_{F}\right)$, which is defined as the energy level at which the probability of finding an electron is $50 \%$. For an intrinsic semiconductor, the Fermi level lies exactly in between the valence and conduction band, but for an n-type semiconductor with electron donors, the Fermi level will shift towards the conduction band (Figure 1.3b) since the chance of finding an electron is higher near the conduction band. In the same way, the Fermi level will shift towards the valence band in a p-type semiconductor [43].

When a semiconductor is immersed in solution, the Fermi level of the semiconductor will align with the level of the electrochemical potential of the solution $\left(E_{A / A}\right)$. Since the position of the conduction and valence bands are fixed at the semiconductor-liquid interface, band bending will occur in 
both bands in order to return to the original distance between both bands and the Fermi level in the bulk of the semiconductor. This process is schematically depicted in Figure 1.4 for an n-type semiconductor. The initial

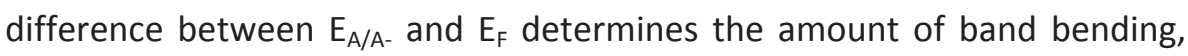
and the amount of band bending necessary to obtain equilibrium between $E_{A / A}$ and $E_{F}$ determines the speed with which electrons will flow from the semiconductor to the solution or vice versa. It is important to note that electrons will always flow towards a more positive energy level, which is determined as downwards in an energy diagram, and holes will flow towards a more negative energy level [43].

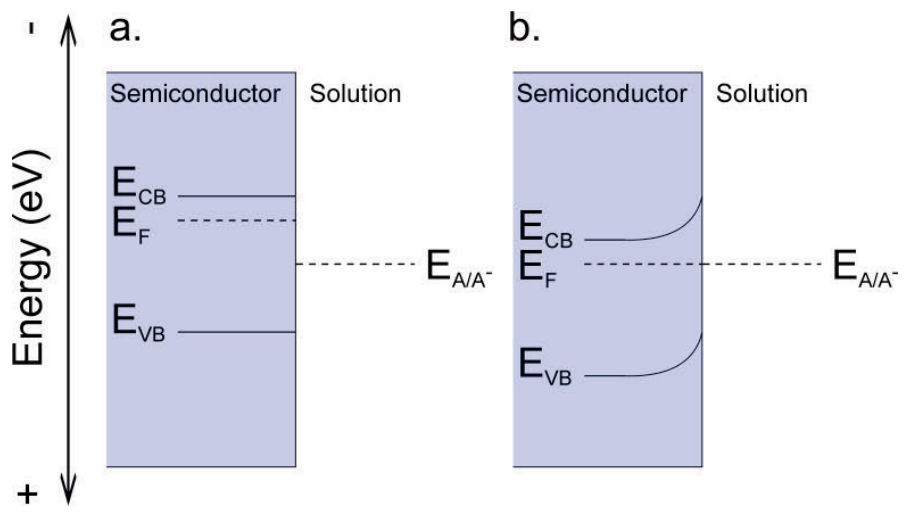

Figure 1.4: Band bending diagram for an $n$-type semiconductor in solution (a) before and (b) after equilibrium.

Sunlight is composed of photons with a lot of different energies. Most photons that reach the earth's surface possess an energy of $\sim 0.75 \mathrm{eV}$, and their amount slowly decreases towards higher photon energies (Figure 1.5). As mentioned earlier, an electron can only cross the band gap and enter the conduction band if it is hit by a photon with an energy higher than the band gap energy. This means that a material with a smaller band gap will be capable of using more photons for the excitation of electrons to the conduction band. On the other hand, in order to split water into $\mathrm{H}_{2}$ and $\mathrm{O}_{2}$ 
gas, the photon energy needs to be larger than the theoretical energy difference between both oxidation and reduction reactions:

$\mathrm{H}_{2} \mathrm{O}+2 \mathrm{~h}^{+} \rightarrow 2 \mathrm{H}^{+}+1 / 2 \mathrm{O}_{2}$ and

$2 \mathrm{H}^{+}+2 \mathrm{e}^{-} \rightarrow \mathrm{H}_{2}$

which is $1.23 \mathrm{eV}$. But unfortunately, any photocatalytic cell will be subject to energy losses caused by e.g. electron-hole recombination, polarization within the cell, electrode resistance, resistance at electrical connections and voltage losses at the contacts. It is estimated that these energy losses attribute to $\sim 0.77 \mathrm{eV}$, which means that the practical energy available for photocatalytic water splitting is $\sim 2 \mathrm{eV}$ and higher. At the moment, most semiconductors used for water splitting possess a band gap of $\sim 3 \mathrm{eV}$ while a band gap of $\sim 2 \mathrm{eV}$ with the band positions around the standard redox potentials for reactions (1.10) and (1.11) would provide a higher efficiency as more photons are captured. The efficiency of a photocatalytic cell is often represented by the incident photon to current conversion efficiency (IPCC) as

$I P C C=\frac{1250 \mathrm{~J}}{\lambda \Phi}$

where 1250 is the unit conversion factor, $J$ is the photocurrent density $\left(\mu \mathrm{A} / \mathrm{cm}^{3}\right), \lambda$ is the wavelength ( $\left.\mathrm{mm}\right)$, and $\Phi$ is the photon flux $\left(\mathrm{W} / \mathrm{m}^{2}\right)$ [44]. 


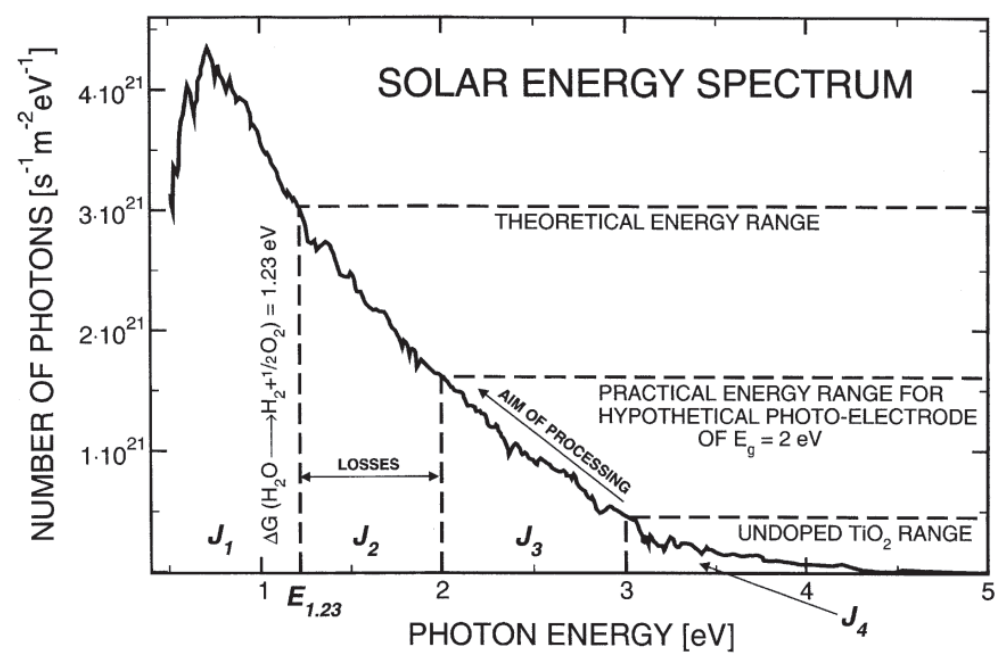

Figure 1.5: Solar energy spectrum at AM 1.5, which is the average spectrum at the earth's surface. Reprinted with permission from reference [44].

As mentioned in the previous section, electron-hole recombination is accountable for a big part of the energy losses in photocatalytic materials. In photocatalyst research, several strategies are employed for efficient electron-hole separation. One of these strategies is the use of a co-catalyst with a work function more positive than the conduction band of the semiconductor. In this way, excited electrons are transferred to the metal while the holes stay in the semiconductor and efficient electron-hole separation is realized. Another strategy is the use of nanoparticles as photocatalyst material. Since the electrons and holes reach the particle surface much faster in a smaller photocatalytic particle, electron-hole recombination is less likely to occur in smaller particles. Even though smaller photocatalytic particles will be more efficient in terms of electron-hole separation, a trade-off has to be made between smaller particles for efficient electron-hole separation and larger particles for efficient light absorption. The amount of light absorbed by a solid is expressed as

$$
A=\ln \frac{I_{0}}{I}=\alpha l
$$


where $I$ is the transmitted light intensity, $I_{0}$ is the incident light intensity, $\alpha$ is the absorption coefficient, and $l$ is the optical path length. Higher crystallinity also has a positive effect on diminished electron-hole recombination as boundaries and defects in the crystal lattice of a photocatalytic material are typical traps and recombination centers [41-43].

Overall splitting of water into hydrogen and oxygen gas is the holy grail of photocatalyst research. Because overall water splitting is a very tough reaction, not every photocatalytic material is capable of direct water splitting, so a few strategies have been realized to evaluate the capabilities of a specific material for water splitting. One of these strategies is the use of sacrificial reagents for either the oxidation or reduction reaction. Alcohols (e.g. methanol) and sulfide ions are often used as hole scavengers or electron donors and carry out the oxidation half reaction, while the formation of $\mathrm{H}_{2}$ gas in the reduction half reaction (reaction (1.11)) is still carried out by the photocatalyst. On the other hand, oxidizing reagents as $\mathrm{Ag}^{+}$and $\mathrm{Fe}^{3+}$ can act as electron acceptors or electron scavengers to carry out the reduction half reaction, while the formation of $\mathrm{O}_{2}$ gas (reaction (1.10)) is still carried out by the photocatalyst [41, 42].

As mentioned before, the use of a photocatalyst with a smaller band gap is beneficial because it is capable of capturing a larger amount of the solar spectrum. But the band positions of semiconductors with a small band gap are usually not ideal for water splitting, as water splitting requires the conduction band to lie well above the equilibrium potential for the reduction half reaction (reaction (1.11)) and the valence band is required to lie well below the equilibrium potential for the oxidation half reaction (reaction (1.10)). Three strategies have been realized to overcome this inconvenience: band engineering, the so-called Z-scheme system and spectral sensitization. In band engineering, the valence and conduction bands of a single photocatalyst are altered in such a way that both bands enclose the two half reactions for water splitting. A Z-scheme photocatalytic system consists of a combination of multiple photocatalysts in which one of the photocatalysts is responsible for the reduction half reaction and the other for the oxidation half reaction. A disadvantage of 
this system is the use of multiple photons which reduces the overall efficiency of the system. A third option is the use of spectral sensitization in analogy with dye-sensitized solar cells. In this method, the semiconductor is infiltrated with a dye with a small band gap for efficient photon capture. The generated electrons and holes are directly separated as the electron is transferred to the metal oxide where the reduction reaction takes place, while the hole stays in the sensitizer for the oxidation reaction $[41,42]$.

Even though a semiconductor might have a suitable band gap with the appropriate band positions for overall water splitting, this is not a guarantee for efficient water splitting. Unfortunately, a lot of suitable semiconductors are sensitive to degradation reactions at the solid/liquid interface like electrochemical corrosion, photocorrosion or dissolution. A material is susceptible to photocorrosion if the free enthalpy of reduction and/or oxidation of the semiconductor material lies inside its band gap and in between the equilibrium potentials of both half reactions for water splitting (reactions (1.10) and (1.11)) [44]. An example of a material that is resistant to photocorrosion is $\mathrm{TiO}_{2}$, and the use of $\mathrm{TiO}_{2}$ nanotubes for photocatalytic water splitting will be presented in Chapter 5. Examples of materials that are not resistant to photocorrosion are $\mathrm{ZnO}$ and $\mathrm{Cu}_{2} \mathrm{O}$, and the use of these materials as photocatalytic nanowires will be presented in Chapters 4 and 6, respectively.

\subsection{Thesis scope and outline}

This thesis is comprised of a selection of studies on functional nanostructures (nanowires, nanotubes and nanocubes) made by templated electrodeposition. The general experimental procedures used for making $\mathrm{Ag} \mid \mathrm{ZnO}$ segmented nanowires, $\mathrm{TiO}_{2}$ nanotubes and $\mathrm{TiO}_{2}-\mathrm{Ag}$ coaxial nanowires are presented in Chapter 2. The method used for detection of $\mathrm{H}_{2}$ evolved from $\mathrm{Ag} \mid \mathrm{ZnO}$ nanowires with a $\mathrm{Pd}$-based $\mathrm{H}_{2}$ sensor is also presented in this chapter. 
A very special nanowire is shown in Figure 1.6. It is $20 \mu \mathrm{m}$ long with a diameter of $450 \mathrm{~nm}$ and contains six segments: $\mathrm{Pt}|\mathrm{Au}| \mathrm{Pt}|\mathrm{Ni}| \mathrm{Ag} \mid \mathrm{ZnO}$, that are responsible for three functions: (1) The $\mathrm{Pt} \mid \mathrm{Au}$ segments are electrochemically active in aqueous solutions containing a 'fuel' such as hydrogen peroxide, and the resulting reaction can propel the nanowire to move autonomously through the solution as a nanomotor [45, 46]; (2) The Ni segment is ferromagnetic, so that an external force can be imposed on the nanowire in solution via an external magnetic field [46]; and (3) The $\mathrm{Ag} \mid \mathrm{ZnO}$ segments are photocatalyticaly active as will be shown in Chapter 4 [47]. This six-segment nanowire was made by sequential electrodeposition of the respective phases in nanopores, which shows the versatility of templated electrodeposition for the construction of multifunctional nanowires.

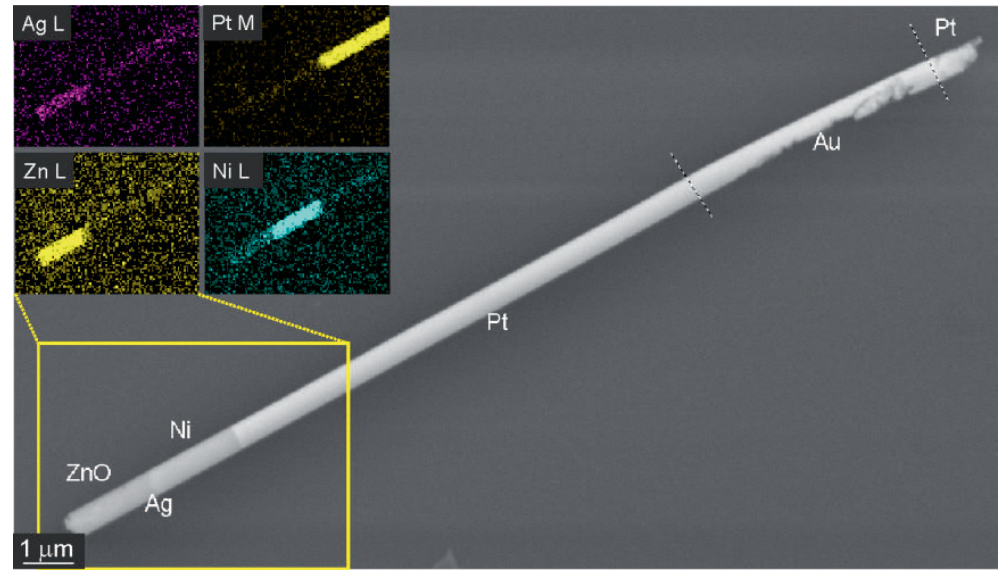

Figure 1.6: Multifunctional nanowire composed of six segments: $\mathrm{Pt}|\mathrm{Au}| \mathrm{Pt}|\mathrm{Ni}| \mathrm{Ag} \mid \mathrm{ZnO}$. The inset gives energy dispersive X-ray (EDX) spectroscopy maps indicating the distribution of the metallic elements $\mathrm{Ag}, \mathrm{Zn}, \mathrm{Pt}$ and $\mathrm{Ni}$ in the part of the nanowire at the bottom left corner of the figure [47].

In fact, it is noted that it was initially intended to form an extra Ni segment instead of the Pt segment on the right-hand side, but the first Ni segment was replaced by $\mathrm{Pt}$ during deposition of the $\mathrm{Pt}$ segment, resulting in the formation of two Pt segments. Since the possibility to deposit Pt on top of $\mathrm{Ni}$ by electrodeposition would be beneficial for a wide range of applications 
in which these phases have to be deposited sequentially, it was investigated whether it would be possible to suppress this galvanic replacement reaction. The developed method is presented in Chapter 3.

The photocatalytic properties of several kinds of nanowires and nanotubes, like the $\mathrm{ZnO} \mid \mathrm{Ag}$ combination on the left-hand side of Figure 1.6 are presented in more detail in Chapters 4, 5 and 6 for $\mathrm{ZnO}, \mathrm{TiO}_{2}$ and $\mathrm{Cu}_{2} \mathrm{O}$, respectively. Chapter 4 presents the first (segmented) nanowire system in which both redox reactions needed for hydrogen formation from a water/methanol mixture are carried out by a single nanowire. This is accomplished by the formation of segmented $\mathrm{Ag} \mid \mathrm{ZnO}$ nanowires in which a Schottky barrier was created at the interface.

Since $\mathrm{TiO}_{2}$ is a material that is well-studied for its photocatalytic properties, Chapter 5 presents a method for the templated electrodeposition of $\mathrm{TiO}_{2}$ nanotubes via the electrochemically induced sol-gel method. The formation of $\mathrm{TiO}_{2}$ nanotubes within AAO membranes was investigated, as well as the influence of the location and shape of $\mathrm{Ag}$ as co-catalyst on the efficiency of these nanowire/nanotube systems for water splitting.

The possibility of using electrodeposition for the formation of both $\mathrm{p}$ - and n-type doped $\mathrm{Cu}_{2} \mathrm{O}$ makes this system ideal for the investigation of the influence of the number of $p$-n junctions within a segmented nanowire on its efficiency for water splitting. The concept of $p-n$ homojunction nanowires and the investigation of the influence of the number of $\mathrm{p}$-n homojunctions on the efficiency is presented in Chapter 6 .

In Chapter 7, a method for the templated electrodeposition of a new kind of nanostructure, a nanocube, is introduced. With this method, it is either possible to create an ordered array of nanocubes with arbitrary composition on a substrate for e.g. property measurements, or these nanocubes can be dispersed in solution after dissolving the substrate for e.g. self-assembly. 
Instead of using a negative template with cubic holes for the formation of nanocubes, also a template with PMMA-Au nanocube structures on top of a substrate can be used as positive template for electrodeposition. As presented in Chapter $\mathbf{8}$ for the case of $\mathrm{MoS}_{2}$ electrodeposition, the use of Au nanocubes as template results in the deposition of a smooth $\mathrm{MoS}_{2}$ layer perfectly replicating the pattern used. Since $\mathrm{MoS}_{2}$ is a layered compound, more edges are available for $\mathrm{H}_{2}$ evolution when electrodeposited on top of a PMMA-Au nanocube pattern.

\subsection{References}

[1] A. J. Bard and L. R. Faulkner, "Chapter 1: Introduction and overview of electrode processes," in Electrochemical methods: Fundamentals and applications, second ed: John Wiley \& Sons, Inc., 2001, pp. 1-43.

[2] M. Paunovic and M. Schlesinger, "Chapter 1: An overview," in Fundamentals of electrochemical deposition, First ed: John Wiley \& Sons, Inc., 1998, pp. 1-6.

[3] S. Otani, J. Katayama, H. Umemoto, and M. Matsuoka, "Effect of bath temperature on the electrodeposition mechanism of zinc oxide film from zinc nitrate solution", Journal of the Electrochemical Society, 2006, vol. 153, pp. C551-C556.

[4] T. Yoshida, D. Komatsu, N. Shimokawa, and H. Minoura, "Mechanism of cathodic electrodeposition of zinc oxide thin films from aqueous zinc nitrate baths", Thin Solid Films, 2004, vol. 451-452, pp. 166-169.

[5] J. Bünsow, J. Petri, and D. Johannsmann, "Preparation of hydrogelsilica composite films by electrochemically triggered deposition", Macromolecular Symposia, 2009, vol. 275-276, pp. 250-256.

[6] T. M. Harrell, B. Hosticka, M. E. Power, L. Cemke, R. Hull, and P. M. Norris, "Selective deposition of biocompatible sol-gel materials", Journal of Sol-Gel Science and Technology, 2004, vol. 31, pp. 349-352.

[7] R. Shacham, D. Mandler, and D. Avnir, "Electrochemically induced sol-gel deposition of zirconia thin films", Chemistry - A European Journal, 2004, vol. 10, pp. 1936-1943. 
[8] X. Wang, R. Xiong, and G. Wei, "Preparation of mesoporous silica thin films on polystyrene substrate by electrochemically induced sol-gel technique", Surface and Coatings Technology, 2010, vol. 204, pp. 2187-2192.

[9] D. Xu, Y. Yu, M. Zheng, G. Guo, and Y. Tang, "Electrochemical fabrication of one-dimensional silica nanostructures", Electrochemistry Communications, 2003, vol. 5, pp. 673-676.

[10] S. Karuppuchamy, D. P. Amalnerkar, K. Yamaguchi, T. Yoshida, T. Sugiura, and $\mathrm{H}$. Minoura, "Cathodic electrodeposition of $\mathrm{TiO}_{2}$ thin films for dye-sensitized photoelectrochemical applications", Chemistry Letters, 2001, pp. 78-79.

[11] S. Karuppuchamy, K. Nonomura, T. Yoshida, T. Sugiura, and $\mathrm{H}$. Minoura, "Cathodic electrodeposition of oxide semiconductor thin films and their application to dye-sensitized solar cells", Solid State lonics, 2002, vol. 151, pp. 19-27.

[12] C. Natarajan and G. Nogami, "Cathodic electrodeposition of nanocrystalline titanium dioxide thin films", Journal of the Electrochemical Society, 1996, vol. 143, pp. 1547-1550.

[13] M. Paunovic and M. Schlesinger, "Chapter 5: Equilibrium electrode potential," in Fundamentals of electrochemical deposition, First ed: John Wiley \& Sons, Inc., 1998, pp. 51-71.

[14] P. H. Rieger, "Chapter 6: Electrolysis," in Electrochemistry, First ed: Prentice-Hall, Inc., 1987, pp. 379-438.

[15] P. Ramasamy, "Chapter 16: Kinetics of electrocrystallization," in Handbook of crystal growth: 16 Fundamentals: Transport and stability, First ed: North-Holland, 1993, pp. 1123-1205.

[16] S. R. Brankovic, J. McBreen, and R. R. Adžić, "Spontaneous deposition of $\mathrm{Pd}$ on a Ru(0001) surface", Surface Science, 2001, vol. 479, pp. L363-L368.

[17] S. R. Brankovic, J. McBreen, and R. R. Adžić, "Spontaneous deposition of $\mathrm{Pt}$ on the $\mathrm{Ru}(0001)$ surface", Journal of Electroanalytical Chemistry, 2001, vol. 503, pp. 99-104.

[18] S. R. Brankovic, J. X. Wang, and R. R. Adžić, "Metal monolayer deposition by replacement of metal adlayers on electrode surfaces", Surface Science, 2001, vol. 474, pp. L173-L179.

[19] G. Kokkinidis, A. Papoutsis, D. Stoychev, and A. Milchev, "Electroless deposition of Pt on $\mathrm{Ti}$ - catalytic activity for the hydrogen evolution reaction", Journal of Electroanalytical Chemistry, 2000, vol. 486, pp. 48-55. 
[20] G. Kokkinidis, D. Stoychev, V. Lazarov, A. Papoutsis, and A. Milchev, "Electroless deposition of Pt on Ti: Part II. Catalytic activity for oxygen reduction", Journal of Electroanalytical Chemistry, 2001, vol. 511, pp. 20-30.

[21] R. M. Penner and C. R. Martin, "Preparation and electrochemical characterization of ultramicroelectrode ensembles", Analytical, 1987, vol. 59, pp. 2625-2630.

[22] S. J. Hurst, E. K. Payne, L. Qin, and C. A. Mirkin, "Multisegmented one-dimensional nanorods prepared by hard-template synthetic methods", Angewandte Chemie - International Edition, 2006, vol. 45, pp. 2672-2692.

[23] M. E. Toimil Molares, V. Buschmann, D. Dobrev, R. Neumann, R. Scholz, I. U. Schuchert, and J. Vetter, "Single-crystalline copper nanowires produced by electrochemical deposition in polymeric ion track membranes", Advanced Materials, 2001, vol. 13, pp. 62-65.

[24] L. E. Khotseng, S. Feng, G. Vaivars, and V. Linkov, "Nickel/carbon nanostructured electrodes synthesized using template method", Integrated Ferroelectrics, 2008, vol. 103, pp. 72-79.

[25] X. Li, E. Koukharenko, I. S. Nandhakumar, J. Tudor, S. P. Beeby, and N. M. White, "High density p-type $\mathrm{Bi}_{0.5} \mathrm{Sb}_{1.5} \mathrm{Te}_{3}$ nanowires by electrochemical templating through ion-track lithography", Physical Chemistry Chemical Physics, 2009, vol. 11, pp. 3584-3590.

[26] F. Jordan, P. Serbun, A. Navitski, D. Lützenkirchen-Hecht, G. Müller, I. Alber, M. E. Toimil-Molares, and C. Trautmann, "Optimization of ion-track etching and electrochemical $\mathrm{Cu}$ nanocone deposition for field emission cathodes," 25th International Vacuum Nanoelectronics Conference, 2012, pp. 58-59.

[27] M. Rauber, I. Alber, S. Muöller, R. Neumann, O. Picht, C. Roth, A. Schoökel, M. E. Toimil-Molares, and W. Ensinger, "Highly-ordered supportless three-dimensional nanowire networks with tunable complexity and interwire connectivity for device integration", Nano Letters, 2011, vol. 11, pp. 2304-2310.

[28] P. Serbun, F. Jordan, A. Navitski, G. Müller, I. Alber, M. E. Toimil-Molares, and C. Trautmann, "Copper nanocones grown in polymer ion-track membranes as field emitters", EPJ Applied Physics, 2012, vol. 58,

[29] Q. Xu, G. Meng, F. Han, X. Zhao, M. Kong, and X. Zhu, "Controlled fabrication of gold and polypyrrole nanowires with straight and branched morphologies via porous alumina template-assisted approach", Materials Letters, 2009, vol. 63, pp. 1431-1434. 
[30] H. Xing, L. Zhiyuan, W. Kai, and L. Yi, "Fabrication of three dimensional interconnected porous carbons from branched anodic aluminum oxide template", Electrochemistry Communications, 2011, vol. 13, pp. 1082-1085.

[31] C. Shuoshuo, L. Zhiyuan, H. Xing, Y. Hui, and L. Yi, "Competitive growth of branched channels inside AAO membranes", Journal of Materials Chemistry, 2010, vol. 20, pp. 1794-1798.

[32] T. P. Moffat and D. Josell, "Extreme bottom-up superfilling of through-silicon-vias by damascene processing: Suppressor disruption, positive feedback and turing patterns", Journal of the Electrochemical Society, 2012, vol. 159, pp. D208-D216.

[33] B. Kim, C. Sharbono, T. Ritzdorf, and D. Schmauch, "Factors affecting copper filling process within high aspect ratio deep vias for 3D chip stacking," San Diego, CA, 2006, pp. 838-843.

[34] E. J. Menke, M. A. Thompson, C. Xiang, L. C. Yang, and R. M. Penner, "Lithographically patterned nanowire electrodeposition", Nature Materials, 2006, vol. 5, pp. 914-919.

[35] C. Xiang, S. C. Kung, D. K. Taggart, F. Yang, M. A. Thompson, A. G. Güell, Y. Yang, and R. M. Penner, "Lithographically patterned nanowire electrodeposition: A method for patterning electrically continuous metal nanowires on dielectrics", ACS Nano, 2008, vol. 2, pp. 1939-1949.

[36] C. Xiang, M. A. Thompson, F. Yang, E. J. Menke, L. M. C. Yang, and R. M. Penner, "Lithographically patterned nanowire electrodeposition", Physica Status Solidi (C) Current Topics in Solid State Physics, 2008, vol. 5, pp. 3503-3505.

[37] A. George, A. W. Maijenburg, M. G. Maas, D. H. A. Blank, and J. E. ten Elshof, "Electrodeposition in capillaries: Bottom-up micro- and nanopatterning of functional materials on conductive substrates", ACS Applied Materials and Interfaces, 2011, vol. 3, pp. 3666-3672.

[38] A. George, A. W. Maijenburg, M. G. Maas, D. H. A. Blank, and J. E. ten Elshof, "Patterning functional materials using channel diffused plasma-etched self-assembled monolayer templates", Langmuir, 2011, vol. 27, pp. 12235-12242.

[39] A. George, A. W. Maijenburg, M. D. Nguyen, M. G. Maas, D. H. A. Blank, and J. E. ten Elshof, "Nanopatterning of functional materials by gas phase pattern deposition of self-assembled molecular thin films in combination with electrodeposition", Langmuir, 2011, vol. 27, pp. 12760-12768. 
[40] Hessian Ministry of Economy, Transport, Urban and Regional Development, Application of nanotechnologies in the energy sector, 2008, www.hessen-nanotech.de

[41] A. Kudo and Y. Miseki, "Heterogeneous photocatalyst materials for water splitting", Chemical Society Reviews, 2009, vol. 38, pp. 253-278.

[42] K. Maeda, "Photocatalytic water splitting using semiconductor particles: History and recent developments", Journal of Photochemistry and Photobiology C: Photochemistry Reviews, 2011, vol. 12, pp. 237-268.

[43] M. X. Tan, P. E. Laibinis, S. T. Nguyen, J. M. Kesselman, C. E. Stanton, and N. S. Lewis, "Principles and applications of semiconductor photoelectrochemistry," in Progress in inorganic chemistry. vol. 41, K. D. Karlin, Ed., ed: John Wiley \& Sons, Inc., 1994, pp. 21-144.

[44] T. Bak, J. Nowotny, M. Rekas, and C. C. Sorrell, "Photo-electrochemical hydrogen generation from water using solar energy. Materials-related aspects", International Journal of Hydrogen Energy, 2002, vol. 27, pp. 991-1022.

[45] W. F. Paxton, K. C. Kistler, C. C. Olmeda, A. Sen, S. K. St. Angelo, Y. Cao, T. E. Mallouk, P. E. Lammert, and V. H. Crespi, "Catalytic nanomotors: Autonomous movement of striped nanorods", Journal of the American Chemical Society, 2004, vol. 126, pp. 13424-13431.

[46] T. R. Kline, W. F. Paxton, T. E. Mallouk, and A. Sen, "Catalytic nanomotors: Remote-controlled autonomous movement of striped metallic nanorods", Angewandte Chemie - International Edition, 2005, vol. 44, pp. 744-746.

[47] A. W. Maijenburg, E. J. B. Rodijk, M. G. Maas, M. Enculescu, D. H. A. Blank, and J. E. ten Elshof, "Hydrogen generation from photocatalytic silver|zinc oxide nanowires: Towards multifunctional multisegmented nanowire devices", Small, 2011, vol. 7, pp. 2709-2713. 


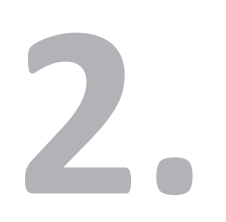

Preparation and use of photocatalytically active segmented $\mathrm{Ag} \mid \mathrm{ZnO}$ and coaxial $\mathrm{TiO}_{2}-\mathrm{Ag}$ nanowires made by templated electrodeposition

In this chapter, the experimental procedures are outlined that were used in other chapters for the preparation of segmented and coaxial nanowires via templated electrodeposition in nanopores. As examples, axially segmented nanowires consisting of $\mathrm{Ag}$ and $\mathrm{ZnO}$ segments (Chapter 4), and coaxial nanowires consisting of a $\mathrm{TiO}_{2}$ shell and a $\mathrm{Ag}$ core (Chapter 5) were made. The $\mathrm{Ag} \mid \mathrm{ZnO}$ nanowires were used in photocatalytic hydrogen formation experiments that require minimal capital investments.

This chapter is accepted as:

A.W. Maijenburg, E.J.B. Rodijk, M.G. Maas, and J.E. ten Elshof, "Preparation and use of photocatalytically active segmented $\mathrm{Ag} \mid \mathrm{ZnO}$ and coaxial $\mathrm{TiO}_{2}-\mathrm{Ag}$ nanowires made by templated electrodeposition", Journal of Visualized Experiments. 


\subsection{Abstract}

Photocatalytically active nanostructures require a large specific surface area with the presence of many catalytically active sites for the oxidation and reduction half reactions, and fast electron (hole) diffusion and charge separation. Nanowires present suitable architectures to meet these requirements. Axially segmented $\mathrm{Ag} \mid \mathrm{ZnO}$ and radially segmented (coaxial) $\mathrm{TiO}_{2}$-Ag nanowires with a diameter of $200 \mathrm{~nm}$ and a length of 6-20 $\mu \mathrm{m}$ were made by templated electrodeposition within the pores of polycarbonate track-etched (PCTE) or anodized aluminium oxide (AAO) membranes, respectively. In the photocatalytic experiments, the $\mathrm{ZnO}$ and $\mathrm{TiO}_{2}$ phases acted as photoanodes, and $\mathrm{Ag}$ as cathode. No external circuit is needed to connect both electrodes, which is a key advantage over conventional photo-electrochemical cells. For making segmented $\mathrm{Ag} \mid \mathrm{ZnO}$ nanowires, the $\mathrm{Ag}$ salt electrolyte was replaced after formation of the $\mathrm{Ag}$ segment to form a $\mathrm{ZnO}$ segment attached to the Ag segment. For making coaxial $\mathrm{TiO}_{2}-\mathrm{Ag}$ nanowires, a $\mathrm{TiO}_{2}$ gel was first formed by the electrochemically induced sol-gel method. Drying and thermal annealing of the as-formed $\mathrm{TiO}_{2}$ gel resulted in the formation of crystalline $\mathrm{TiO}_{2}$ nanotubes. A subsequent $\mathrm{Ag}$ electrodeposition step inside the $\mathrm{TiO}_{2}$ nanotubes resulted in formation of coaxial $\mathrm{TiO}_{2}-\mathrm{Ag}$ nanowires. Due to the combination of an $n$-type semiconductor $\left(\mathrm{ZnO}\right.$ or $\left.\mathrm{TiO}_{2}\right)$ and a metal $(\mathrm{Ag})$ within the same nanowire, a Schottky barrier was created at the interface between the phases. To demonstrate the photocatalytic activity of these nanowires, the $\mathrm{Ag} \mid \mathrm{ZnO}$ nanowires were used in a photocatalytic experiment in which $\mathrm{H}_{2}$ gas was detected upon UV illumination of the nanowires dispersed in a methanol/water mixture. After 17 minutes of illumination, approximately 0.2 vol\% $\mathrm{H}_{2}$ gas was detected from a suspension of $\sim 0.1 \mathrm{~g}$ of $\mathrm{Ag} \mid \mathrm{ZnO}$ nanowires in a $50 \mathrm{~mL} 80$ vol\% aqueous methanol solution. 


\subsection{Introduction}

Owing to their small dimensions and large surface-to-volume ratio, nanowires are very promising one-dimensional objects that can be used in a wide range of biomedical and nanotechnological applications [1]. In the literature, many nanowires containing a single component with functional properties have been reported [2-7]. But when multiple materials (metals, polymers and metal oxides) are incorporated sequentially within a single nanowire, multifunctional nanowires can be made $[8,9]$. When several segments are connected inside a single nanowire, functional properties may appear that were not present when only the individual segments were used. For instance, nanomotors containing $\mathrm{Au}$ and $\mathrm{Pt}$ segments within a single nanowire were reported that moved autonomously when placed in hydrogen peroxide [4]. Suitable techniques for the formation of multisegmented nanowires are infiltration and templated electrodeposition $[8,9]$.

In 1987, Penner and Martin were the first to publish the use of templated electrodeposition for the formation of $\mathrm{Au}$ nanowires in polycarbonate membranes [10]. Since then, many other researchers have started using templated electrodeposition for the synthesis of nanowires with different dimensions, using either polycarbonate track-etched membranes (PCTE) or anodized aluminium oxide (AAO) membranes and templates [11]. The advantages of using templated electrodeposition for nanowire synthesis are its cost-effective nature as electrodeposition is usually performed under mild conditions, the possibility to form nanowires from either metals, metal oxides and/or polymers, and its ability to create an exact negative replica of the template used [11]. Furthermore, segmented nanowires can be formed by sequential deposition of two or more different phases, and when a nanotube of one of the two phases can be made by templated electrodeposition, coaxial nanowires containing two different phases can be made. 
Metal oxides can be electrodeposited when the respective metal ions are insoluble in aqueous solutions at high $\mathrm{pH}$. For the necessary oxygen, three different precursors can be used, i.e. nitrate ions [12-15], hydrogen peroxide $[13,16,17]$, and molecular oxygen [18]. With the use of nitrate ions, as in this protocol, application of a potential more negative than $-0.9 \mathrm{~V}$ vs. $\mathrm{Ag} / \mathrm{AgCl}$ leads to a locally increased $\mathrm{pH}$ by reduction of nitrate at the cathode $[19,20]$ :

$\mathrm{NO}_{3}^{-}+\mathrm{H}_{2} \mathrm{O}+2 \mathrm{e}^{-} \rightarrow \mathrm{NO}_{2}^{-}+2 \mathrm{OH}^{-}$.

When the electrolyte solution is heated to $60-90{ }^{\circ} \mathrm{C}, \mathrm{ZnO}$ nanowires will form from precipitated zinc hydroxide:

$\mathrm{Zn}^{2+}+2 \mathrm{OH}^{-} \rightarrow \mathrm{ZnO}+\mathrm{H}_{2} \mathrm{O}$.

Upon application of a potential to the working electrode, which is positioned at the pore bottom in templated electrodeposition, the $\mathrm{pH}$ inside the pore is locally increased resulting in local nanowire formation. Since $\mathrm{ZnO}$ is an $n$-type semiconductor, reactions (2.1) and (2.2) can continue at the $\mathrm{ZnO} /$ electrolyte interface, resulting in the formation of a crystalline and dense $\mathrm{ZnO}$ nanowire $[21,22]$.

Several methods exist for the synthesis of $\mathrm{TiO}_{2}$ nanotubes, but for the formation of a coaxial structure using a sequential electrodeposition process, the electrochemically induced sol-gel method is most suitable. This method for cathodic electrodeposition of $\mathrm{TiO}_{2}$ films was first introduced by Natarajan et al. in 1996 [23], and was further improved by Karuppuchamy et al. in 2001 [19, 24]. Using this method, titanium oxysulfate $\left(\mathrm{TiOSO}_{4}\right)$ powder is dissolved in an aqueous solution of hydrogen peroxide $\left(\mathrm{H}_{2} \mathrm{O}_{2}\right)$ upon the formation of a peroxotitanate complex $\left(\mathrm{Ti}\left(\mathrm{O}_{2}\right) \mathrm{SO}_{4}\right)$ :

$\mathrm{TiOSO}_{4}+\mathrm{H}_{2} \mathrm{O}_{2} \rightarrow \mathrm{Ti}\left(\mathrm{O}_{2}\right) \mathrm{SO}_{4}+\mathrm{H}_{2} \mathrm{O}$. 
At potentials more negative than $-0.9 \mathrm{~V}$ vs. $\mathrm{Ag} / \mathrm{AgCl}$, the $\mathrm{pH}$ at the electrode surface is increased by reduction of nitrate (reaction (2.1)), forming a titanium hydroxide gel $[19,20]$ :

$\mathrm{Ti}\left(\mathrm{O}_{2}\right) \mathrm{SO}_{4}+2 \mathrm{OH}^{-}+(\mathrm{x}+1) \mathrm{H}_{2} \mathrm{O} \rightarrow$

$\mathrm{TiO}(\mathrm{OH})_{2} \cdot \mathrm{xH}_{2} \mathrm{O}+\mathrm{H}_{2} \mathrm{O}_{2}+\mathrm{SO}_{4}^{2-}$.

Natarajan et al. used differential thermal analysis to find that water is removed from the gel around $283{ }^{\circ} \mathrm{C}$ during thermal annealing, which results in the formation of an amorphous $\mathrm{TiO}_{2}$ phase [23]. For a planar film, crystallization into the anatase phase occurs when the temperature is increased above $365{ }^{\circ} \mathrm{C}[23,25]$, while crystallization occurs at a temperature between 525 and $550^{\circ} \mathrm{C}$ when an AAO template is used [26]:

$\mathrm{TiO}(\mathrm{OH})_{2} \cdot \mathrm{xH}_{2} \mathrm{O} \rightarrow \mathrm{TiO}_{2}+(\mathrm{x}+1) \mathrm{H}_{2} \mathrm{O}$.

The pore diameter of the AAO template used determines whether a solid nanowire or open nanotube will be formed. Deposition in a template with a small pore diameter $(\sim 50 \mathrm{~nm})$ results in nanowire formation $[20,27]$, while applying the same method inside a pore with larger diameter $(\sim 200 \mathrm{~nm})$ results in nanotube formation [26]. This is because gel collapse can take place upon removal of excess water.

In the early 1970s, Fujishima and Honda were the first to publish a system for direct water splitting under UV light, which was accomplished by a rutile electrode coupled to a platinum electrode $[28,29]$. Since then, over 130 semiconductor materials were identified as photocatalysts [30-32]. Of these, titanium dioxide [33-37], zinc oxide [38-41], and iron oxide $[42,43]$ are among the most intensively studied materials. The surface-to-volume ratio of these materials can be increased drastically when nanoparticles or nanowires are used, leading to improved photocatalytic efficiencies [30, 31, 44-50]. 
For the construction of photocatalytic $\mathrm{Ag} \mid \mathrm{ZnO}$ nanowires, $\mathrm{ZnO}$, which is a photoactive $n$-type semiconductor, was connected with Ag via sequential electrodeposition inside the same template [51]. Within such a single nanowire, the $\mathrm{ZnO}$ photoanode and $\mathrm{Ag}$ cathode are directly coupled without the need of an external circuit connecting the electrodes, which is in contrast to the situation in conventional photo-electrochemical cells. This simplifies device architecture considerably and increases the efficiency by reduction of Ohmic losses in the system. $\mathrm{ZnO}$ and $\mathrm{Ag}$ segments were coupled since the electron affinity of $\mathrm{ZnO}(4.35 \mathrm{eV}$ vs. vacuum) is very close to the work function of $\mathrm{Ag}$ ( $4.26 \mathrm{eV}$ vs. vacuum). This induces the formation of a Schottky barrier between both phases [52], which allows excited electrons in the conduction band of $\mathrm{ZnO}$ to flow to $\mathrm{Ag}$, but not vice versa, thus prohibiting the chance of electron-hole recombination [53]. The active wurtzite phase of $\mathrm{ZnO}$ can be formed already at $60-90{ }^{\circ} \mathrm{C}$, which provides an easy and cost effective way of nanowire formation. This is in contrast to most other photoactive oxides that require an intermediate annealing step at high temperatures when made via cathodic electrodeposition.

The conversion of methanol and water into hydrogen and carbon dioxide was used as a model reaction to demonstrate the use of a segmented nanowire containing a metal and a metal oxide phase for autonomous $\mathrm{H}_{2}$ formation under the influence of UV light. In this experiment, methanol is used as a hole scavenger which is oxidized to $\mathrm{CO}_{2}$ at the $\mathrm{ZnO}$ segment, following the net reaction

$\mathrm{CH}_{3} \mathrm{OH}+\mathrm{H}_{2} \mathrm{O}+6 \mathrm{~h}^{+} \rightarrow \mathrm{CO}_{2}+6 \mathrm{H}^{+}$,

where $\mathrm{h}^{+}$represents an electron hole. The protons formed at the $\mathrm{ZnO}$ segment are reduced to $\mathrm{H}_{2}$ at the Ag surface, following the reaction

$2 \mathrm{H}^{+}+2 \mathrm{e}^{-} \rightarrow \mathrm{H}_{2}$. 
Since the total energy required for reactions (2.6) and (2.7) is much smaller than the band gap of $\mathrm{ZnO}(0.7$ and $3.2 \mathrm{eV}$, respectively), this process can take place without the need for an external power source. This process is schematically illustrated in Figure 2.1.

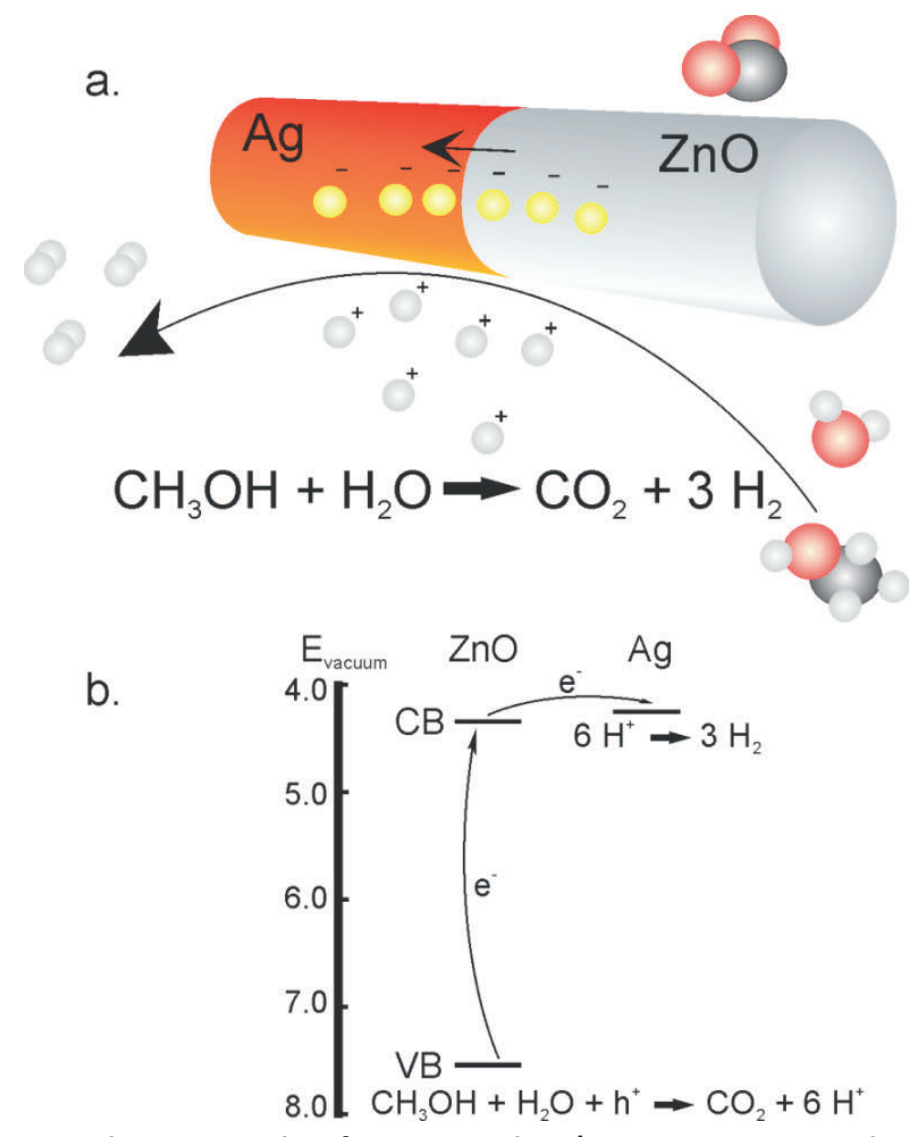

Figure 2.1: Working principle of segmented $\mathrm{Ag} \mid \mathrm{ZnO}$ nanowire in photocatalytic water splitting: (a) schematic representation, and (b) energy diagram. When UV light is absorbed by the $\mathrm{ZnO}$ segment, an electron-hole pair is formed. The as-formed electrons flow to the $\mathrm{Ag}$ phase where they are consumed in an electrochemical reduction half-reaction. The hole stays in the $\mathrm{ZnO}$ segment where it is consumed in an oxidative half-reaction. 
In this chapter, the experimental procedures of templated electrodeposition for the formation of segmented and coaxial nanowires containing both a metal and a semiconductor phase are explained. A procedure for the formation of segmented $\mathrm{Ag} \mid \mathrm{ZnO}$ nanowires is outlined, as well as the formation of $\mathrm{TiO}_{2}$ nanotubes and their subsequent filling with $\mathrm{Ag}$ to yield coaxial $\mathrm{TiO}_{2}-\mathrm{Ag}$ nanowires. Furthermore, the photocatalytic activity of the $\mathrm{Ag} \mid \mathrm{ZnO}$ nanowires is demonstrated by converting a methanol/water mixture into $\mathrm{H}_{2}$ and $\mathrm{CO}_{2}$ gas upon irradiation with UV light employing a $\mathrm{Pd}$-based sensor for $\mathrm{H}_{2}$ detection. The emphasis of this protocol is on the preparation and photocatalytic characterization of two differently segmented metal oxide/metal nanowire modules, and a more in-depth treatment and an example of a multifunctional nanowire can be found elsewhere [54]. The water splitting reaction that was employed using the coaxial $\mathrm{TiO}_{2}$ - $\mathrm{Ag}$ nanowires can also be found elsewhere [26].

\subsection{Procedure}

\subsubsection{Segmented $A g \mid Z n O$ nanowire formation in $P C T E$ membranes}

\section{PCTE membrane preparation for templated electrodeposition}

1.1) Take a track-etched polycarbonate membrane with an outer pore diameter of $200 \mathrm{~nm}$ and thickness of $6 \mu \mathrm{m}$ (Figure 2.2a). The diameter of the membrane used here is $25 \mathrm{~mm}$.

1.2) Sputter a gold layer at the backside of the membrane (Figure 2.2b). In this case, a deposition pressure of $2 \cdot 10^{-2}$ mbar was used with $\mathrm{Ar}$ as sputtering gas. Use a slow deposition rate of $\sim 13 \mathrm{~nm} / \mathrm{min}$. NOTE: This Au layer will be used as electrical contact during electrodeposition.

1.3) Use double sided sticky tape to attach a small glass slide $(1.4 \times 2.1 \mathrm{~cm})$ on top of the gold-coated side of the membrane. For this, put four small strips of double sided tape along the edges of the glass slide (Figure 2.2c). NOTE: Make sure the membrane is as smooth as possible, without any folds or wrinkles. This glass slide is used to ensure selective electrodeposition inside the membrane pores. 
1.4) Stick a small piece of copper tape on the part of the membrane that sticks out from the glass slide for mechanical stability. Since copper tape is conducting, the crocodile clip of the working electrode can be attached to the copper tape.

1.5) If necessary, improve the adhesion of the membrane to the glass slide by putting Teflon tape around the edges. NOTE: For depositions at room temperature the adhesion of double sided tape is usually strong enough, but at elevated temperatures it is recommended to use Teflon tape as well.

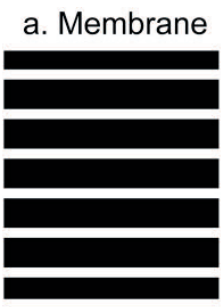

d. Deposition

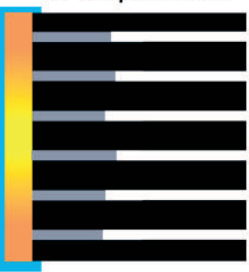

g. Remove

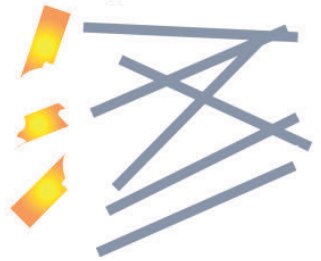

b. + Electrode

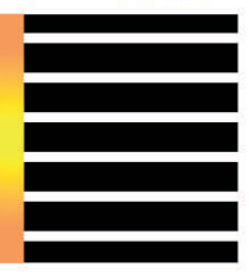

e. Stop

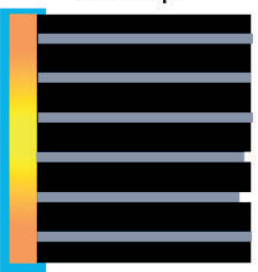

h. Isolation for $A A O$
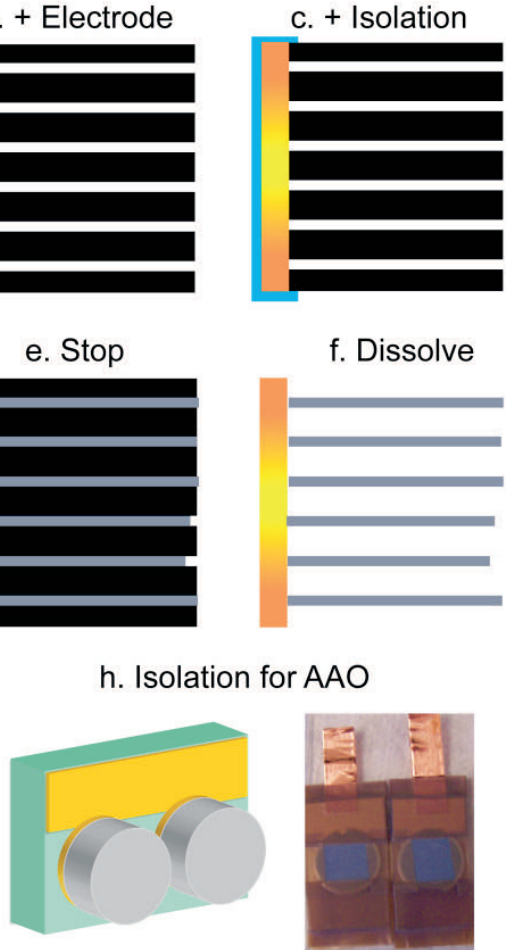

f. Dissolve

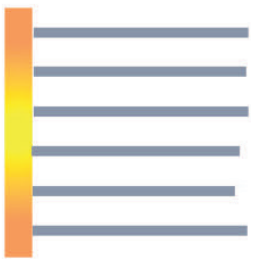

Figure 2.2: Schematic representation of the consecutive steps taken for nanowire synthesis. 


\section{Electrodeposition of $\mathrm{Ag} \mid \mathrm{ZnO}$ nanowires}

2.1) Preparation of the Ag segment

2.1.1) Prepare an aqueous solution containing $0.20 \mathrm{M} \mathrm{AgNO}_{3}$ (1.70 g per $50 \mathrm{~mL}$ ) and $0.10 \mathrm{M} \mathrm{H}_{3} \mathrm{BO}_{3}(0.31 \mathrm{~g}$ per $50 \mathrm{~mL}$ ). Adjust the $\mathrm{pH}$ to 1.5 using $\mathrm{HNO}_{3}$.

2.1.2) Put the prepared membrane together with a Pt counter electrode and an $\mathrm{Ag} / \mathrm{AgCl}(3 \mathrm{M} \mathrm{KCl})$ reference electrode in the as-prepared solution.

2.1.3) Apply a potential of $+0.10 \mathrm{~V}$ vs. the $\mathrm{Ag} / \mathrm{AgCl}$ reference electrode for $30 \mathrm{~s}$ (Figure $2.2 \mathrm{~d}, \mathrm{e})$. NOTE: Although every potentiostat software will be different, all programs should have input lines like "set potential" and "duration", where these values can be filled in. Please refer to the manual of your potentiostat and included software for more details.

2.1.4) Take the electrodes from the solution and rinse them with milli-Q water.

2.2) Preparation of the $\mathrm{ZnO}$ segment

2.2.1) Prepare an aqueous solution containing $0.10 \mathrm{M} \mathrm{Zn}\left(\mathrm{NO}_{3}\right)_{2} \cdot 6 \mathrm{H}_{2} \mathrm{O}$ (1.49 g per $50 \mathrm{~mL}$ ).

2.2.2) Heat the solution to $60{ }^{\circ} \mathrm{C}$ using a water bath, and put the membrane containing the $\mathrm{Ag}$ segment together with a Pt counter electrode and an $\mathrm{Ag} / \mathrm{AgCl}$ reference electrode in the heated solution.

2.2.3) Apply a potential of $-1.00 \mathrm{~V}$ vs. the $\mathrm{Ag} / \mathrm{AgCl}$ reference electrode for $20 \mathrm{~min}$ (Figure $2.2 \mathrm{~d}, \mathrm{e}$ ). NOTE: Although every potentiostat program will be different, all should have input lines like "set potential" and "duration", where these values can be filled in. Please refer to the manual of your potentiostat and included software for more details.

2.2.4) Take the electrodes from the solution and rinse them with milli-Q water.

2.3) Repeat this procedure 4 times to obtain enough nanowires for significant signal from the $\mathrm{H}_{2}$ sensor. 


\section{Extraction of the nanowires and transfer to aqueous solution}

3.1) Cut the membrane containing the nanowires from the glass slide.

3.2) Transfer this part of the membrane to a polypropylene centrifuge tube.

3.3) Add $\sim 2 \mathrm{~mL}$ of $\mathrm{CH}_{2} \mathrm{Cl}_{2}$ to dissolve the PCTE membrane and release the nanowires into the solution. After $\sim 30 \mathrm{~min}$, the membrane should be completely dissolved (Figure 2.2f,g).

3.4) Apply a small droplet of the $\mathrm{CH}_{2} \mathrm{Cl}_{2}$ solution containing nanowires on a small Si wafer for SEM analysis.

3.5) Centrifuge the obtained solution at $\sim 19,000 \times \mathrm{xg}$ for 5 minutes, remove the excess $\mathrm{CH}_{2} \mathrm{Cl}_{2}$, and add fresh $\mathrm{CH}_{2} \mathrm{Cl}_{2}$. Repeat the process at least 3 times to make sure all polycarbonate has been removed.

3.6) After all polycarbonate has been removed, add milli-Q water to the nanowires after removal of the excess $\mathrm{CH}_{2} \mathrm{Cl}_{2}$. Repeat the centrifugation at least 3 times again to completely replace all $\mathrm{CH}_{2} \mathrm{Cl}_{2}$ by milli-Q water.

\subsubsection{Coaxial $\mathrm{TiO}_{2}-\mathrm{Ag}$ nanowire formation in $\mathrm{AAO}$ membranes}

\section{AAO membrane preparation for templated electrodeposition}

4.1) Take an AAO membrane with a pore size of $200 \mathrm{~nm}$ and thickness of $60 \mu \mathrm{m}$ (Figure 2.2a). The diameter of the membrane used here is $13 \mathrm{~mm}$.

4.2) Sputter a gold layer on the backside of the membrane (Figure 2.2b). In this case a deposition pressure of $2 \cdot 10^{-2} \mathrm{mbar}$ was used with $\mathrm{Ar}$ as sputtering gas. Use a slow deposition rate of $\sim 13 \mathrm{~nm} / \mathrm{min}$. NOTE: This Au layer will be used as electrical contact during electrodeposition.

4.3) Attach the AAO membranes to a Au-coated glass slide in a configuration as in Figure $2.2 \mathrm{~h}$ using Teflon tape. NOTE: To ensure selective electrodeposition inside the membrane pores, the AAO membrane needs to be attached to a small glass slide in a different configuration than the PCTE membranes, because the AAO 
membranes are too brittle for connection with a crocodile clip. When a glass slide of $3.0 \times 2.5 \mathrm{~cm}$ is used, two membranes can be used at once.

4.4) Put a small piece of copper tape on the Au coated part of the glass slide for easy handling when connecting the electrodes.

\section{Electrochemical deposition of $\mathrm{TiO}_{2}-\mathrm{Ag}$ nanowires}

5.1) Preparation of a $\mathrm{TiO}_{2}$ gel

5.1.1) Prepare an aqueous solution containing $0.02 \mathrm{M} \mathrm{TiOSO}_{4}(0.16 \mathrm{~g}$ per $50 \mathrm{~mL}$ ), $0.03 \mathrm{M} \mathrm{H}_{2} \mathrm{O}_{2}\left(0.13 \mathrm{~mL}\right.$ per $50 \mathrm{~mL}$ ), $0.05 \mathrm{M} \mathrm{HNO}_{3}$ $\left(0.15 \mathrm{~mL}\right.$ per $50 \mathrm{~mL}$ ) and $0.25 \mathrm{M} \mathrm{KNO}_{3}(1.26 \mathrm{~g}$ per $50 \mathrm{~mL})$.

5.1.2) Put the prepared membrane together with a Pt counter electrode and an $\mathrm{Ag} / \mathrm{AgCl}(3 \mathrm{M} \mathrm{KCl})$ reference electrode in the as-prepared solution.

5.1.3) Apply a potential of $-1.0 \mathrm{~V}$ vs. the $\mathrm{Ag} / \mathrm{AgCl}$ reference electrode for $3.5 \mathrm{~h}$ (Figure $2.2 \mathrm{~d}$,e). NOTE: Although every potentiostat software will be different, all programs should have input lines like "set potential" and "duration", where these values can be filled in. Please refer to the manual of your potentiostat and included software for more details.

5.1.4) Take the electrodes from the solution and DO NOT rinse the membrane with milli-Q water, because the $\mathrm{TiO}_{2}$ gel is still water soluble. The other electrodes can be rinsed with milli-Q water.

5.2) Preparation of coaxial $\mathrm{TiO}_{2}-\mathrm{Ag}$ nanowires

5.2.1) Thermally anneal the membranes with the $\mathrm{TiO}_{2}$ gel in an oven at $650^{\circ} \mathrm{C}$ for $2 \mathrm{~h}$ in air.

5.2.2) Reattach the membranes to a gold coated glass slide.

5.2.3) Prepare an aqueous solution containing $0.20 \mathrm{M} \mathrm{AgNO}_{3}$ (1.70 g per $50 \mathrm{~mL}$ ) and $0.10 \mathrm{M} \mathrm{H}_{3} \mathrm{BO}_{3}(0.31 \mathrm{~g}$ per $50 \mathrm{~mL}$ ). Adjust the $\mathrm{pH}$ to 1.5 using $\mathrm{HNO}_{3}$.

5.2.4) Put the prepared membrane together with a Pt counter electrode and an $\mathrm{Ag} / \mathrm{AgCl}(3 \mathrm{M} \mathrm{KCl})$ reference electrode in the as-prepared solution. 
5.2.5) Apply a potential of $+0.10 \mathrm{~V}$ vs. the $\mathrm{Ag} / \mathrm{AgCl}$ reference electrode for $1.5 \mathrm{~min}$ (Figure 2.2d,e). NOTE: Although every potentiostat software will be different, all programs should have input lines like "set potential" and "duration", where these values can be filled in. Please refer to the manual of your potentiostat and included software for more details.

5.2.6) Take the electrodes from the solution and rinse them with milli-Q water.

5.3) Preparation of $\mathrm{Ag}$ nanoparticles incorporated in $\mathrm{TiO}_{2}$ nanotubes

5.3.1) Heat the membranes with the $\mathrm{TiO}_{2}$ gel overnight at $100{ }^{\circ} \mathrm{C}$.

5.3.2) Prepare an aqueous solution containing $0.20 \mathrm{M} \mathrm{AgNO}_{3}$ (1.70 g per $50 \mathrm{~mL}$ ) and $0.10 \mathrm{M} \mathrm{H}_{3} \mathrm{BO}_{3}(0.31 \mathrm{~g}$ per $50 \mathrm{~mL}$ ). Adjust the $\mathrm{pH}$ to 1.5 using $\mathrm{HNO}_{3}$.

5.3.3) Put the prepared membrane together with a Pt counter electrode and an $\mathrm{Ag} / \mathrm{AgCl}(3 \mathrm{M} \mathrm{KCl})$ reference electrode in the as-prepared solution.

5.3.4) Apply a potential of $+0.10 \mathrm{~V}$ vs. the $\mathrm{Ag} / \mathrm{AgCl}$ reference electrode for $1.5 \mathrm{~min}$ (Figure 2.2d,e). NOTE: Although every potentiostat software will be different, all programs should have input lines like "set potential" and "duration", where these values can be filled in. Please refer to the manual of your potentiostat and included software for more details.

5.3.5) Take the electrodes from the solution and rinse them with milli-Q water.

5.4) Repeat this procedure to obtain at least 10 membranes filled with nanowires/nanotubes to obtain enough material for significant signal from the $\mathrm{H}_{2}$ sensor. 


\section{Extraction of nanotubes and nanowires}

6.1) Cut the membrane containing the nanotubes or nanowires from the glass slide.

6.2) Transfer this part of the membrane into a polypropylene centrifuge tube.

6.3) Add $\sim 2 \mathrm{~mL}$ of an aqueous solution containing 1.0 M NaOH to dissolve the AAO membrane and release the nanotubes or nanowires into the solution. After $\sim 2 \mathrm{~h}$, the membrane should be completely dissolved (Figure 2.2f,g).

6.4) Centrifuge the obtained solution at $\sim 19,000 \mathrm{xg}$ for $5 \mathrm{~min}$, remove the excessive $\mathrm{NaOH}$ solution, and add fresh milli-Q water. Repeat the process at least 3 times to make sure all $\mathrm{NaOH}$ has been removed.

6.5) After all $\mathrm{NaOH}$ has been removed, the aqueous suspension can be used for $\mathrm{H}_{2}$ formation experiments.

6.6) Alternatively, add $\mathrm{CH}_{2} \mathrm{Cl}_{2}$ or another volatile solvent to the nanotubes and nanowires after removal of excess water for visualization of the prepared nanotubes or nanowires with SEM. Repeat the centrifugation at least 3 times to completely replace all water by the volatile solvent. Deposit a small droplet of the solution containing nanotubes or nanowires onto a small Si wafer.

\subsection{3. $\mathrm{H}_{2}$ formation experiments}

\section{Preparation of the hydrogen sensor}

7.1) Take a Pd-based hydrogen sensor.

7.2) Place the sensor inside an NS plug that fits on top of a quartz tube.

7.3) Connect the sensor to a standard Wheatstone bridge as illustrated in Figure 2.3. 

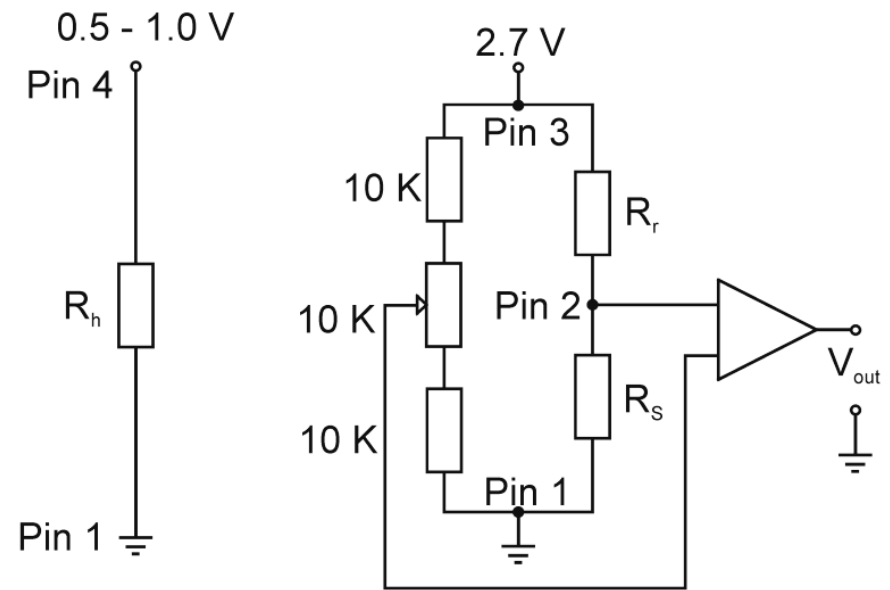

Figure 2.3: Typical operating circuit of the $\mathrm{H}_{2}$ sensor with Wheatstone bridge. In this scheme, Pin 1 to 4 refer to the wiring of the sensor (pin 1 is black, pin 2 is blue, pin 3 is white, pin 4 is brown), $R_{h}$ is the resistance of the heater (150 $\pm 50 \Omega$ ), $R_{r}$ is the resistance of the reference $(1500 \pm 500 \Omega), R_{s}$ is the resistance of the sensor $(1000 \pm 250 \Omega)$. The sensor is connected to a $12 \mathrm{~V}$ power source so that 0.5 to $1.0 \mathrm{~V}$ is applied to the heater and $2.7 \mathrm{~V}$ is applied to the Wheatstone bridge. $V_{\text {out }}$ is connected to the multimeter/potentiostat. The resistance next to Pin $\mathbf{2}$ is variable and can be adjusted in order to obtain an appropriate baseline.

\section{Photocatalytic hydrogen formation}

8.1) Put the aqueous nanowire solution in a $72 \mathrm{~mL}$ quartz tube. Add more water until a total of $10 \mathrm{~mL}$ water is inside the quartz tube. Then add $40 \mathrm{~mL}$ methanol.

8.2) Start recording the signal from the $\mathrm{Pd}$ based $\mathrm{H}_{2}$ sensor before placing it on top of the quartz tube and monitor the variation in signal.

8.3) After $\sim 200 \mathrm{~s}$ of stable signal, put the $\mathrm{H}_{2}$ sensor on top of the quartz tube while simultaneously turning on the UV light source to start the actual measurement. NOTE: In these experiments, the UV source was placed approximately $10-15 \mathrm{~cm}$ away from the sample. 


\subsection{Representative results}

During electrodeposition, the current that is measured between the working and counter electrodes can be visualized in an I- $t$ curve. Since the current is directly related to the amount of deposited material via Faraday's law, the observed current is an important indication of how the deposition proceeds. Typical l-t curves for the deposition of $\mathrm{Ag} \mid \mathrm{ZnO}$ and $\mathrm{TiO}_{2}-\mathrm{Ag}$ nanowires are shown in Figure 2.4. Typical SEM images of $\mathrm{Ag} \mid \mathrm{ZnO}$ nanowires, $\mathrm{TiO}_{2}$ nanotubes, a coaxial $\mathrm{TiO}_{2}-\mathrm{Ag}$ nanowire and $\mathrm{TiO}_{2} / \mathrm{Ag}$ nanotubes can be found in Figure 2.5 and Figure 2.6, respectively.
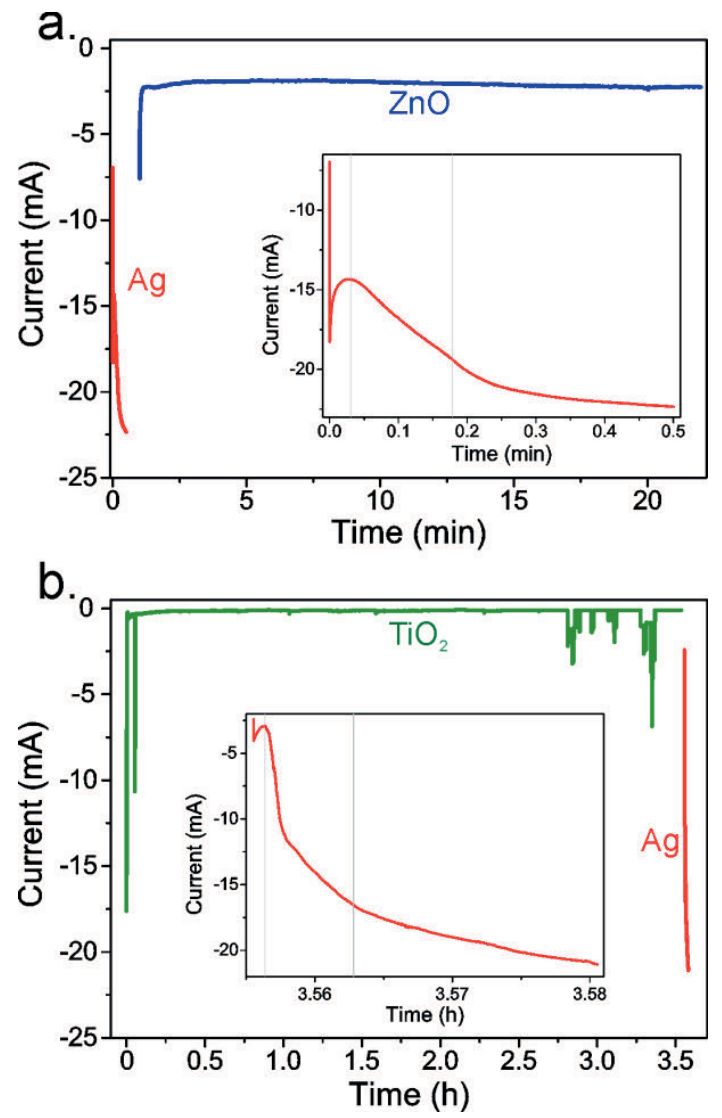

Figure 2.4: Typical l-t curves of (a) $\mathrm{Ag} \mid \mathrm{ZnO}$ nanowire deposition, and (b) $\mathrm{TiO}_{2}-\mathrm{Ag}$ nanowire deposition. The insets show an enlarged curve of the deposition of the Ag segment (a) or core (b). 


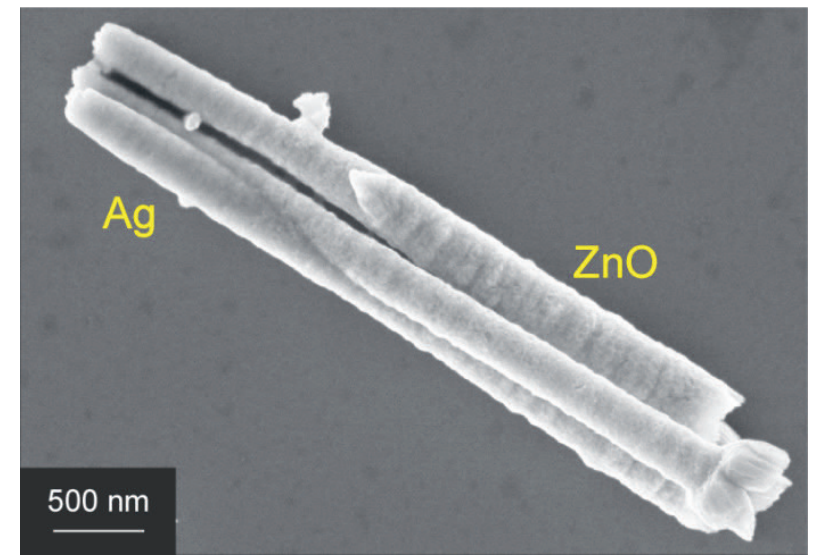

Figure 2.5: Scanning Electron Microscopy (SEM) picture of axially segmented $\mathrm{Ag} \mid \mathrm{ZnO}$ nanowires.
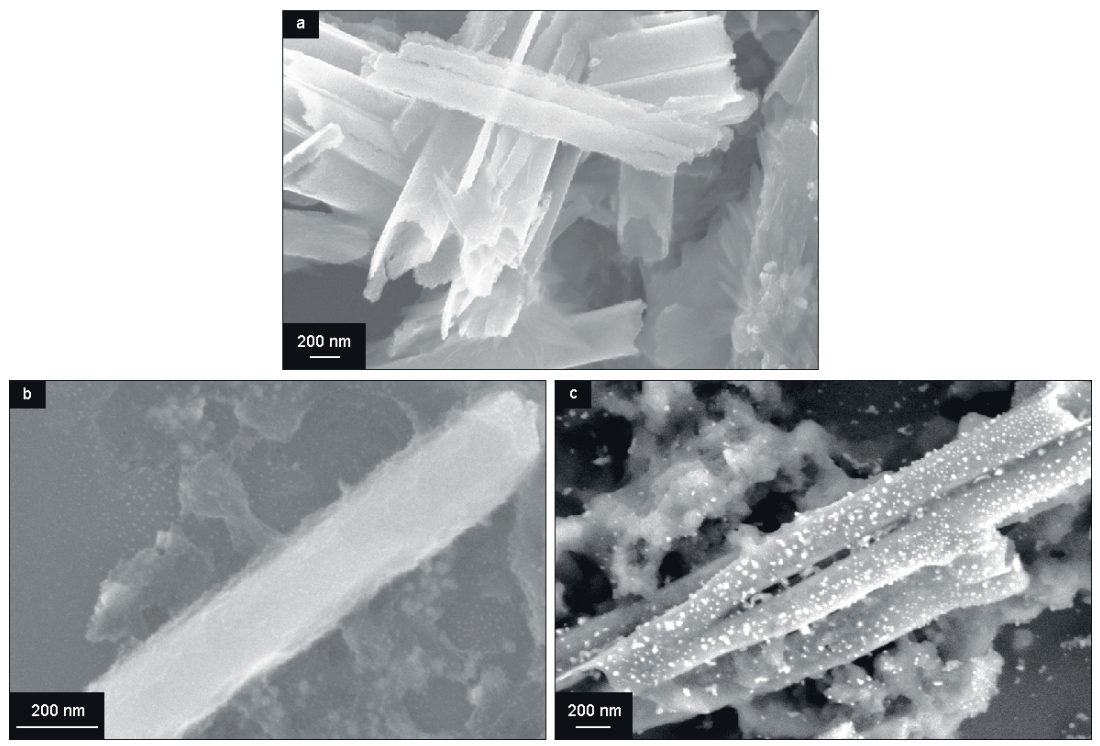

Figure 2.6: $\mathrm{SEM}$ pictures of (a) $\mathrm{TiO}_{2}$ nanotubes, (b) coaxial $\mathrm{TiO}_{2}-\mathrm{Ag}$ nanowire and (c) $\mathrm{TiO}_{2} / \mathrm{Ag}$ nanotubes.

Using the electrochemically induced sol-gel method for deposition of a titania gel inside the template and sequential electrodeposition of $\mathrm{Ag}$ can result in two different structures depending on the temperature used to dry the gel. Drying of the gel overnight at $100{ }^{\circ} \mathrm{C}$ results in condensation of the gel, preventing it to redissolve in water. Since no dense tubular shape has 
yet formed at this temperature, Ag nuclei are deposited inside the titania gel. Subsequent annealing at $650{ }^{\circ} \mathrm{C}$ results in the formation of $\mathrm{Ag}$ nanoparticles incorporated in a $\mathrm{TiO}_{2}$ nanotube (Figure 2.6c), since the collapse of the titania gel causes the Ag nanoparticles to be transported to the pore walls. In contrast, high temperature annealing of the titania gel prior to $\mathrm{Ag}$ electrodeposition leads to the formation of solid $\mathrm{TiO}_{2}$ nanotubes. In this case, $\mathrm{Ag}$ nanowires could be deposited inside these tubes, leading to the formation of $\mathrm{TiO}_{2}-\mathrm{Ag}$ nanowires with a coaxial architecture (Figure 2.6b).

The activity of the segmented $\mathrm{Ag} \mid \mathrm{ZnO}$ nanowires in photocatalytic water splitting can be investigated using a methanol/water solution under UV illumination, where methanol acts as a hole scavenger. A technically simple method to detect gaseous hydrogen evolving from the solution is obtained by placing a $\mathrm{H}_{2}$ sensor directly above the solution (Figure 2.7). This experiment only detects the amount of $\mathrm{H}_{2}$ reaching the sensor, so the actual amount of formed $\mathrm{H}_{2}$ may be higher as some $\mathrm{H}_{2}$ will remain dissolved in the methanol/water phase. The signal as detected by the sensor is shown in Figure 2.8a. Figure 2.8b shows the same signal after transformation to the timeframe of actual $\mathrm{H}_{2}$ formation. When the UV light source was turned on ( $t=17.5 \mathrm{~min}$ in Figure 2.8a), the signal drops substantially due to the light sensitivity of the sensor. Right after this drop in signal, the reaction starts and consequently this moment was defined as $t=0$ min in Figure $2.8 \mathrm{~b}$, and the corresponding signal was defined as $0 \mathrm{~V}$. During UV exposure of the test tube, it was also visible that small gas bubbles were formed. Since the sensor used is slightly cross-sensitive to methanol, the measurement of a reference sample without nanowires was also included. During UV illumination, Figure 2.8 shows that the signal from the sample with nanowires is higher than the signal from the reference sample. 


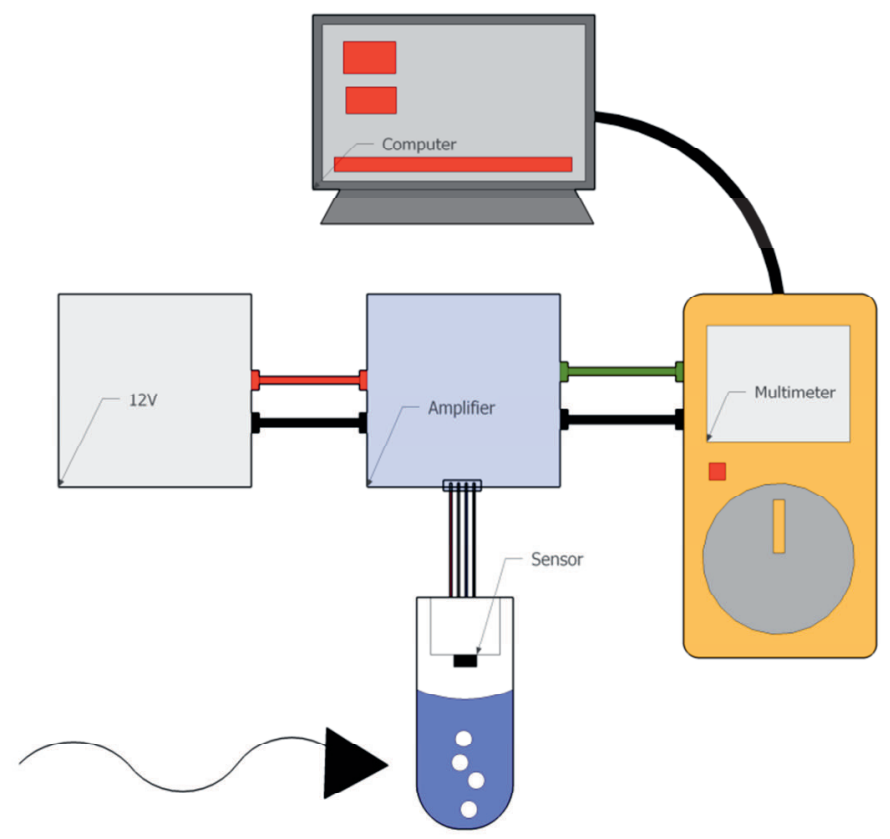

Figure 2.7: Typical setup for the detection of $\mathrm{H}_{2}$ gas evolved from photocatalytic nanowires. The Pd based $\mathrm{H}_{2}$ sensor is placed in the NS plug of a quartz cuvette, and connected to an amplifier (see Figure 2.3). The amplifier is operated by a $12 \mathrm{~V}$ power source and the signal from the sensor is read by a multimeter (or potentiostat) connected to a computer for graphical representation of the obtained signal.
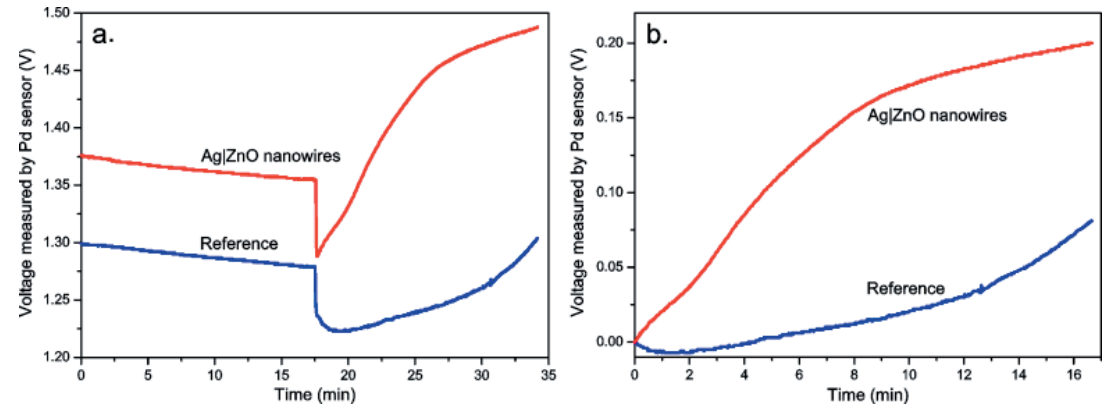

Figure 2.8: Response from the $\mathrm{H}_{2}$ sensor during $\mathrm{UV}$ irradiation of $\mathrm{Ag} \mid \mathrm{ZnO}$ nanowires in a methanol/water solution (red line) and reference experiment without nanowires (blue line). (a) Signal as measured by the sensor; (b) Signal during $\mathrm{H}_{2}$ formation, where the data point at $t=17.5 \mathrm{~min}$ of (a) was defined as the start of the reaction in (b). 
The increase in potential is a relative measure for the amount of gaseous $\mathrm{H}_{2}$ that forms and evolves from the solution. In order to give a quantitative estimate for the amount of evolved $\mathrm{H}_{2}$, the potential response of the sensor from the photocatalytic experiments was compared with its response in a 4 vol\% $\mathrm{H}_{2}$ in $\mathrm{N}_{2}$ gas stream. From the comparison, it was estimated that $17 \mathrm{~min}$ of UV illumination of the $\mathrm{Ag} \mid \mathrm{ZnO}$ nanowires resulted in the formation of approximately $0.2 \mathrm{vol} \% \mathrm{H}_{2}$ in the gas volume above the solution. Since $\sim 0.1 \mathrm{~g}$ of nanowires was used, this equals to a $\mathrm{H}_{2}$ evolution rate of $6.92 \cdot 10^{-6} \mathrm{~mol} / \mathrm{h} \cdot \mathrm{g}$. As reference, experiments with single-phase $\mathrm{ZnO}$ or Ag nanowires were also performed. These experiments, not shown here, did not give any indication of $\mathrm{H}_{2}$ formation; neither from gas bubble formation nor from sensor signal.

\subsection{Discussion}

Very important in the templated electrodeposition of nanowires is isolation of the back side of the gold electrode sputtered on top of the membrane. Without isolation, the material would preferentially deposit on the gold surface at the back side of the membrane instead of inside the pores. This is because the diffusion of ions to a flat electrode is much faster than diffusion into membrane pores. Another disadvantage of deposition on both sides of the gold electrode is that the obtained $l-t$ curve cannot be related to the amount and length of deposited nanowires. In Figure 2.4, several stages can be identified for the deposition of the Ag segment (a) or core (b). The first stage of every electrodeposition experiment is charging of the electrical double layer, which is accompanied by a sudden increase in current that slowly decreases as the electrical double layer reaches its equilibrium. As the PCTE membrane pores from Whatman have a cigarshape, the current increases in the second stage as the surface area of deposition increases, leading to deposition of more material at the same time, and faster supply of reactants since the surface of the nanowire gets closer to the entrance of the membrane pores. In the third stage, the 
change in surface area is minimal, leading to a smaller slope of increasing current since only the effect of faster reactant supply is visible in this stage.

Please note that in the case of depositing segmented nanowires containing both a metal and an oxide segment, the order of electrodeposition inside the pores should be determined by taking the solubility of the deposited phases in each other's solution explicitly into account. In this case, the $\mathrm{Ag}$ segment was deposited before the $\mathrm{ZnO}$ segment as $\mathrm{ZnO}$ would dissolve in the acidic $\mathrm{AgNO}_{3}$ solution. In the case of forming a segmented nanowire containing a noble metal and a less noble one, e.g. Pt and $\mathrm{Ni}$, the galvanic replacement reaction of $\mathrm{Ni}$ by $\mathrm{Pt}$ should be taken into account. This galvanic replacement reaction can be suppressed by using a larger overpotential as discussed in Chapter 3 [55].

The choice for using either PCTE or AAO membranes for nanowire or nanotube synthesis is usually based on whether or not a thermal annealing step is desired for the material of choice. Without the necessity of an annealing step, PCTE membranes are easier to handle and relatively good membranes can be obtained commercially. For high temperature annealing, the use of AAO membranes is required. These membranes are not as flexible as the polycarbonate membranes and are very brittle. Some commercial AAO membranes are available, but the quality of homemade AAO membranes using a 2-step anodization is much better. For this, several recipes are available $[56,57]$.

The Pd-based $\mathrm{H}_{2}$ sensor used in this study is an easy and relatively cheap method for determining whether $\mathrm{H}_{2}$ has formed or not. Unfortunately, it is not suitable for quantitative measurements due to its cross-sensitivity to volatile solvents like methanol, the intrinsic inability to detect dissolved $\mathrm{H}_{2}$ in the methanol/water solution, and its non-linear response as seen in the shape of the curves in Figure 2.8. Quantitative measurements could be performed in a setup with a GC inlet connected to the head space above the methanol/water mixture as demonstrated in Chapters 5 and 6 , but this specialized equipment is not available in every lab. 
$\mathrm{H}_{2}$ formation using $\mathrm{Ag} \mid \mathrm{ZnO}$ nanowires typically ceased after $\sim 48 \mathrm{~h}$ of UV illumination as evidenced by terminated gas bubble formation. The reason for this loss of activity is photocorrosion of $\mathrm{ZnO}$ according to the following reaction [58-61]:

$\mathrm{ZnO}+2 \mathrm{~h}^{+} \rightarrow \mathrm{Zn}^{2+}+1 / 2 \mathrm{O}_{2}$

An SEM image of photocorroded $\mathrm{Ag} \mid \mathrm{ZnO}$ nanowires is shown in Figure 2.9. As can be seen from this figure, the surface of the $\mathrm{ZnO}$ segment became much rougher upon UV illumination as compared to the as-synthesized wires of Figure 2.5. When suspending another batch of $\mathrm{Ag} \mid \mathrm{ZnO}$ nanowires in the same solution in the dark for $48 \mathrm{~h}$, no sign of corrosion was found. This confirmed that the observed corrosion indeed resulted from photocorrosion and not from electrolytic corrosion. In the literature, several methods have been reported for inhibition of $\mathrm{ZnO}$ photocorrosion, including hybridization of $\mathrm{ZnO}$ nanoparticles with a monolayer of polyaniline or $\mathrm{C}_{60}$ and grafting of $\mathrm{ZnO}$ nanorods on $\mathrm{TiO}_{2}$ nanotubes $[60,62,63]$.

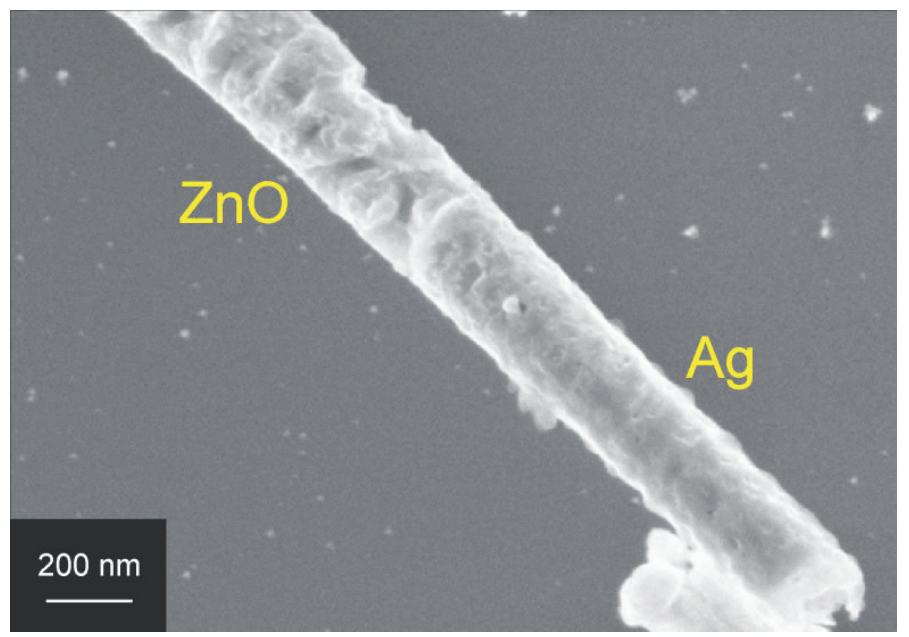

Figure 2.9: SEM image of photocorroded $\mathrm{Ag} \mid \mathrm{ZnO}$ nanowire after $48 \mathrm{~h}$ of UV illumination. 
Templated electrodeposition of axially or radially segmented nanowires is a perfect platform for the deposition of multisegmented nanowires that are able to carry out more than one function at once, in which $\mathrm{Ag} \mid \mathrm{ZnO}$ segments can be applied as photocatalytic elements. In Figure 1.6, an SEM image of a single nanowire containing six segments was introduced: $\mathrm{Pt}|\mathrm{Au}| \mathrm{Pt}|\mathrm{Ni}| \mathrm{Ag} \mid \mathrm{ZnO}$. Such a nanowire could be used for autonomous movement $(\mathrm{Pt}|\mathrm{Au}| \mathrm{Pt})$, magnetic steering $(\mathrm{Ni})$ and photocatalytic $\mathrm{H}_{2}$ formation (Ag|ZnO) [54].

\subsection{Conclusions}

In summary, a simple protocol for the synthesis of segmented $\mathrm{Ag} \mid \mathrm{ZnO}$ nanowires and coaxial $\mathrm{TiO}_{2}$-Ag nanowires by templated electrodeposition is provided. A semi-quantitative method to determine the photocatalytic activity of such nanowires was demonstrated using the photocatalytic conversion of methanol and water into $\mathrm{H}_{2}$ and $\mathrm{CO}_{2}$ under UV illumination. It is envisaged that these metal oxide-metal nanowires can be used in multifunctional nanowires and other nanowire devices.

\subsection{References}

[1] R. J. Kuppler, D. J. Timmons, Q. R. Fang, J. R. Li, T. A. Makal, M. D. Young, D. Yuan, D. Zhao, W. Zhuang, and H. C. Zhou, "Potential applications of metal-organic frameworks", Coordination Chemistry Reviews, 2009, vol. 253, pp. 3042-3066.

[2] C. L. Hsu, S. J. Chang, H. C. Hung, Y. R. Lin, C. J. Huang, Y. K. Tseng, and I. C. Chen, "Well-aligned, vertically Al-doped $\mathrm{ZnO}$ nanowires synthesized on ZnO:Ga/glass templates", Journal of The Electrochemical Society, 2005, vol. 152, pp. G378-G381.

[3] M. G. Maas, E. J. B. Rodijk, W. Maijenburg, J. E. Ten Elshof, and D. H. A. Blank, "Photocatalytic segmented nanowires and single-step iron oxide nanotube synthesis: Templated electrodeposition as all-round tool," Boston, MA, 2010, pp. 1-6. 
[4] T. E. Mallouk and A. Sen, "Powering nanorobots: Catalytic engines enable tiny swimmers to harness fuel from their environment and overcome the weird physics of the microscopic world", Scientific American, 2009, vol. 300, pp. 72-77.

[5] E. Matei, L. Ion, S. Antohe, R. Neumann, and I. Enculescu, "Multisegment CdTe nanowire homojunction photodiode", Nanotechnology, 2010, vol. 21, p. 105202.

[6] E. Matei, N. Preda, M. Enculescu, J. P. Ansermet, M. E. Toimil Molares, and I. Enculescu, "Sequential deposition of multisegment nanowires", Digest Journal of Nanomaterials and Biostructures, 2010, vol. 5, pp. 1067-1076.

[7] M. G. Maas, E. J. B. Rodijk, A. W. Maijenburg, D. H. A. Blank, and J. E. ten Elshof, "Microstructure development in zinc oxide nanowires and iron oxohydroxide nanotubes by cathodic electrodeposition in nanopores", Journal of Materials Research, 2011, vol. 26, pp. 2261-2267.

[8] H. L. Jiang, S. K. Singh, J. M. Yan, X. B. Zhang, and Q. Xu, "Liquid-Phase chemical hydrogen storage: Catalytic hydrogen generation under ambient conditions", ChemSusChem, 2010, vol. 3, pp. 541-549.

[9] G. J. Kubas, "Hydrogen activation on organometallic complexes and $\mathrm{H}_{2}$ production, utilization, and storage for future energy", Journal of Organometallic Chemistry, 2009, vol. 694, pp. 2648-2653.

[10] R. M. Penner and C. R. Martin, "Preparation and electrochemical characterization of ultramicroelectrode ensembles", Analytical, 1987, vol. 59, pp. 2625-2630.

[11] S. J. Hurst, E. K. Payne, L. Qin, and C. A. Mirkin, "Multisegmented one-dimensional nanorods prepared by hard-template synthetic methods", Angewandte Chemie - International Edition, 2006, vol. 45, pp. 2672-2692.

[12] J. B. Cui and U. J. Gibson, "Electrodeposition and room temperature ferromagnetic anisotropy of $\mathrm{Co}$ and $\mathrm{Ni}$-doped $\mathrm{ZnO}$ nanowire arrays", Applied Physics Letters, 2005, vol. 87, pp. 1-3.

[13] M. Lai and D. J. Riley, "Templated electrosynthesis of zinc oxide nanorods", Chemistry of Materials, 2006, vol. 18, pp. 2233-2237.

[14] M. J. Zheng, L. D. Zhang, G. H. Li, and W. Z. Shen, "Fabrication and optical properties of large-scale uniform zinc oxide nanowire arrays by one-step electrochemical deposition technique", Chemical Physics Letters, 2002, vol. 363, pp. 123-128. 
[15] M. Sima, L. Enculescu, M. Enache, E. Vasile, and J. P. Ansermet, "ZnO:Mn:Cu nanowires prepared by template method", Physica Status Solidi (B) Basic Research, 2007, vol. 244, pp. 1522-1527.

[16] Y. Leprince-Wang, G. Y. Wang, X. Z. Zhang, and D. P. Yu, "Study on the microstructure and growth mechanism of electrochemical deposited ZnO nanowires", Journal of Crystal Growth, 2006, vol. 287, pp. 89-93.

[17] Y. Leprince-Wang, A. Yacoubi-Ouslim, and G. Y. Wang, "Structure study of electrodeposited ZnO nanowires", Microelectronics Journal, 2005, vol. 36, pp. 625-628.

[18] D. Ramirez, T. Pauporte, H. Gomez, and D. Lincot, "Electrochemical growth of $\mathrm{ZnO}$ nanowires inside nanoporous alumina templates. A comparison with metallic Zn nanowires growth", Physica Status Solidi (A) Applications and Materials Science, 2008, vol. 205, pp. 2371-2375.

[19] S. Karuppuchamy, K. Nonomura, T. Yoshida, T. Sugiura, and $\mathrm{H}$. Minoura, "Cathodic electrodeposition of oxide semiconductor thin films and their application to dye-sensitized solar cells", Solid State lonics, 2002, vol. 151, pp. 19-27.

[20] Z. Miao, D. Xu, J. Ouyang, G. Guo, X. Zhao, and Y. Tang, "Electrochemically induced sol-gel preparation of single-crystalline $\mathrm{TiO}_{2}$ nanowires", Nano Letters, 2002, vol. 2, pp. 717-720.

[21] S. Otani, J. Katayama, H. Umemoto, and M. Matsuoka, "Effect of bath temperature on the electrodeposition mechanism of zinc oxide film from zinc nitrate solution", Journal of the Electrochemical Society, 2006, vol. 153, pp. C551-C556.

[22] T. Yoshida, D. Komatsu, N. Shimokawa, and H. Minoura, "Mechanism of cathodic electrodeposition of zinc oxide thin films from aqueous zinc nitrate baths", Thin Solid Films, 2004, vol. 451-452, pp. 166-169.

[23] C. Natarajan and G. Nogami, "Cathodic electrodeposition of nanocrystalline titanium dioxide thin films", Journal of the Electrochemical Society, 1996, vol. 143, pp. 1547-1550.

[24] S. Karuppuchamy, D. P. Amalnerkar, K. Yamaguchi, T. Yoshida, $\mathrm{T}$. Sugiura, and $\mathrm{H}$. Minoura, "Cathodic electrodeposition of $\mathrm{TiO}_{2}$ thin films for dye-sensitized photoelectrochemical applications", Chemistry Letters, 2001, pp. 78-79. 
[25] S. A. Kumar, P. H. Lo, and S. M. Chen, "Electrochemical synthesis and characterization of $\mathrm{TiO}_{2}$ nanoparticles and their use as a platform for flavin adenine dinucleotide immobilization and efficient electrocatalysis", Nanotechnology, 2008, vol. 19,

[26] A. W. Maijenburg, J. Veerbeek, R. d. Putter, S. A. Veldhuis, M. G. C. Zoontjes, G. Mul, J. M. Montero, K. Nielsch, H. Schäfer, M. Steinhart, and J. E. t. Elshof, "Electrochemical synthesis of coaxial $\mathrm{TiO}_{2}$-Ag nanowires and their application for photocatalytic water splitting", Accepted in Journal of Materials Chemistry A, 2013,

[27] X. J. Wu, F. Zhu, C. Mu, Y. Liang, L. Xu, Q. Chen, R. Chen, and D. Xu, "Electrochemical synthesis and applications of oriented and hierarchically quasi-1D semiconducting nanostructures", Coordination Chemistry Reviews, 2010, vol. 254, pp. 1135-1150.

[28] A. Fujishima and K. Honda, "Electrochemical photolysis of water at a semiconductor electrode", Nature, 1972, vol. 238, pp. 37-38.

[29] A. Fujishima, K. Kohayakawa, and K. Honda, "Hydrogen production under sunlight with an electrochemical photocell", Journal of The Electrochemical Society, 1975, vol. 122, pp. 1487-1489.

[30] A. Kudo and Y. Miseki, "Heterogeneous photocatalyst materials for water splitting", Chemical Society Reviews, 2009, vol. 38, pp. 253-278.

[31] R. M. Navarro Yerga, M. Consuelo Álvarez Galván, F. del Valle, J. A. Villoria de la Mano, and J. L. Fierro, "Water splitting on semiconductor catalysts under visible-light irradiation", ChemSusChem, 2009, vol. 2, pp. 471-485.

[32] F. E. Osterloh, "Inorganic materials as catalysts for photochemical splitting of water", Chemistry of Materials, 2008, vol. 20, pp. 35-54.

[33] S. U. M. Khan, M. Al-Shahry, and W. B. Ingler Jr, "Efficient photochemical water splitting by a chemically modified n- $\mathrm{TiO}_{2}$ ", Science, 2002, vol. 297, pp. 2243-2245.

[34] W. C. Lin, W. D. Yang, I. L. Huang, T. S. Wu, and Z. J. Chung, "Hydrogen production from methanol/water photocatalytic decomposition using $\mathrm{Pt} / \mathrm{TiO}_{2-x} \mathrm{~N}_{\mathrm{x}}$ catalyst", Energy and Fuels, 2009, vol. 23, pp. 2192-2196.

[35] M. Ni, M. K. H. Leung, D. Y. C. Leung, and K. Sumathy, "A review and recent developments in photocatalytic water-splitting using $\mathrm{TiO}_{2}$ for hydrogen production", Renewable and Sustainable Energy Reviews, 2007, vol. 11, pp. 401-425. 
[36] K. Rajeshwar, "Hydrogen generation at irradiated oxide semiconductor-solution interfaces", Journal of Applied Electrochemistry, 2007, vol. 37, pp. 765-787.

[37] R. F. Service, "Chemistry: Catalyst boosts hopes for hydrogen bonanza", Science, 2002, vol. 297, pp. 2189-2190.

[38] M. Gupta, V. Sharma, J. Shrivastava, A. Solanki, A. Singh, V. Satsangi, S. Dass, and R. Shrivastav, "Preparation and characterization of nanostructured $\mathrm{ZnO}$ thin films for photoelectrochemical splitting of water", Bulletin of Materials Science, 2009, vol. 32, pp. 23-30.

[39] J. H. He, S. T. Ho, T. B. Wu, L. J. Chen, and Z. L. Wang, "Electrical and photoelectrical performances of nano-photodiode based on $\mathrm{ZnO}$ nanowires", Chemical Physics Letters, 2007, vol. 435, pp. 119-122.

[40] K. Maeda and K. Domen, "Solid solution of GaN and ZnO as a stable photocatalyst for overall water splitting under visible light", Chemistry of Materials, 2010, vol. 22, pp. 612-623.

[41] X. Yang, A. Wolcott, G. Wang, A. Sobo, R. C. Fitzmorris, F. Qian, J. Z. Zhang, and Y. Li, "Nitrogen-doped ZnO nanowire arrays for photoelectrochemical water splitting", Nano Letters, 2009, vol. 9, pp. 2331-2336.

[42] S. Ekambaram, "Photoproduction of clean $\mathrm{H}_{2}$ or $\mathrm{O}_{2}$ from water using oxide semiconductors in presence of sacrificial reagent", Journal of Alloys and Compounds, 2008, vol. 448, pp. 238-245.

[43] S. K. Mohapatra, S. E. John, S. Banerjee, and M. Misra, "Water photooxidation by smooth and ultrathin alfa- $\mathrm{Fe}_{2} \mathrm{O}_{3}$ nanotube arrays", Chemistry of Materials, 2009, vol. 21, pp. 3048-3055.

[44] J. P. Best and D. E. Dunstan, "Nanotechnology for photolytic hydrogen production: Colloidal anodic oxidation", International Journal of Hydrogen Energy, 2009, vol. 34, pp. 7562-7578.

[45] A. I. Hochbaum and P. Yang, "Semiconductor nanowires for energy conversion", Chemical Reviews, 2010, vol. 110, pp. 527-546.

[46] A. Kudo, "Recent progress in the development of visible light-driven powdered photocatalysts for water splitting", International Journal of Hydrogen Energy, 2007, vol. 32, pp. 2673-2678.

[47] J. Li and J. Z. Zhang, "Optical properties and applications of hybrid semiconductor nanomaterials", Coordination Chemistry Reviews, 2009, vol. 253, pp. 3015-3041. 
[48] H. Yi, T. Peng, D. Ke, L. Zan, and C. Yan, "Photocatalytic $\mathrm{H}_{2}$ production from methanol aqueous solution over titania nanoparticles with mesostructures", International Journal of Hydrogen Energy, 2008, vol. 33, pp. 672-678.

[49] M. Zäch, C. Hägglund, D. Chakarov, and B. Kasemo, "Nanoscience and nanotechnology for advanced energy systems", Current Opinion in Solid State and Materials Science, 2006, vol. 10, pp. 132-143.

[50] J. Zhu and M. Zäch, "Nanostructured materials for photocatalytic hydrogen production", Current Opinion in Colloid and Interface Science, 2009, vol. 14, pp. 260-269.

[51] C. R. Martin, "Nanomaterials: A membrane-based synthetic approach", Science, 1994, vol. 266, pp. 1961-1966.

[52] A. J. Nozik, "Photochemical diodes", Applied Physics Letters, 1977, vol. 30, pp. 567-569.

[53] D. W. Bahnemann, C. Kormann, and M. R. Hoffmann, "Preparation and characterization of quantum size zinc oxide: A detailed spectroscopic study", Journal of Physical Chemistry, 1987, vol. 91, pp. 3789-3798.

[54] A. W. Maijenburg, E. J. B. Rodijk, M. G. Maas, M. Enculescu, D. H. A. Blank, and J. E. ten Elshof, "Hydrogen generation from photocatalytic silver|zinc oxide nanowires: Towards multifunctional multisegmented nanowire devices", Small, 2011, vol. 7, pp. 2709-2713.

[55] A. W. Maijenburg, A. George, D. Samal, M. Nijland, R. Besselink, B. Kuiper, J. E. Kleibeuker, and J. E. ten Elshof, "Electrodeposition of micropatterned $\mathrm{Ni} \mid \mathrm{Pt}$ multilayers and segmented $\mathrm{Ni}|\mathrm{Pt}| \mathrm{Ni}$ nanowires", Electrochimica Acta, 2012, vol. 81, pp. 123-128.

[56] H. Masuda, K. Yada, and A. Osaka, "Self-ordering of cell configuration of anodic porous alumina with large-size pores in phosphoric acid solution", Japanese Journal of Applied Physics, Part 2: Letters, 1998, vol. 37, pp. L1340-L1342.

[57] K. Nielsch, F. Müller, A. P. Li, and U. Gösele, "Uniform nickel deposition into ordered alumina pores by pulsed electrodeposition", Advanced Materials, 2000, vol. 12, pp. 582-586.

[58] X. Chen, Y. He, Q. Zhang, L. Li, D. Hu, and T. Yin, "Fabrication of sandwich-structured $\mathrm{ZnO} /$ reduced graphite oxide composite and its photocatalytic properties", Journal of Materials Science, 2010, vol. 45, pp. 953-960. 
[59] J. Doménech and A. Prieto, "Stability of $\mathrm{ZnO}$ particles in aqueous suspensions under UV illumination", Journal of Physical Chemistry, 1986, vol. 90, pp. 1123-1126.

[60] H. Fu, T. Xu, S. Zhu, and Y. Zhu, "Photocorrosion inhibition and enhancement of photocatalytic activity for $\mathrm{ZnO}$ via hybridization with $\mathrm{C}_{60} "$, Environmental Science and Technology, 2008, vol. 42, pp. 8064-8069.

[61] N. Kislov, J. Lahiri, H. Verma, D. Y. Goswami, E. Stefanakos, and M. Batzill, "Photocatalytic degradation of methyl orange over single crystalline $\mathrm{ZnO}$ : Orientation dependence of photoactivity and photostability of ZnO", Langmuir, 2009, vol. 25, pp. 3310-3315.

[62] Y. Lei, G. Zhao, M. Liu, Z. Zhang, X. Tong, and T. Cao, "Fabrication, characterization, and photoelectrocatalytic application of $\mathrm{ZnO}$ nanorods grafted on vertically aligned $\mathrm{TiO}_{2}$ nanotubes", Journal of Physical Chemistry C, 2009, vol. 113, pp. 19067-19076.

[63] H. Zhang, R. Zong, and Y. Zhu, "Photocorrosion inhibition and photoactivity enhancement for zinc oxide via hybridization with monolayer polyaniline", Journal of Physical Chemistry C, 2009, vol. 113, pp. 4605-4611. 
Chapter 2

$(62)$ 


\section{Electrodeposition of micropatterned Ni|Pt multilayers and segmented Ni|Pt|Ni nanowires}

This chapter presents a method for the suppression of the galvanic replacement reaction that takes place when a $\mathrm{Ni}$ film is immersed in a solution containing Pt ions. Suppression of the galvanic replacement reaction is needed for electrodeposition of a more noble metal on top of a less noble metal and is therefore of relevance for e.g. templated electrodeposition of segmented nanowires.

This chapter is published as:

A.W. Maijenburg, A. George, D. Samal, M. Nijland, R. Besselink, B. Kuiper, J.E. Kleibeuker, and J.E. ten Elshof, "Electrodeposition of micropatterned $\mathrm{Ni} \mid \mathrm{Pt}$ multilayers and segmented $\mathrm{Ni}|\mathrm{Pt}| \mathrm{Ni}$ nanowires," Electrochimica Acta, 2012, vol. 81, pp. 123-128. 


\subsection{Abstract}

During electrodeposition of a more noble metal on top of a less noble one, the galvanic replacement reaction prevents the formation of pure metal layers. So when depositing Pt on top of $\mathrm{Ni}$ to make $\mathrm{Ni}$ Pt multilayers, or when making segmented metal nanowires containing multiple metal segments, the galvanic replacement reaction needs to be suppressed. As is shown here, at a potential of $-0.6 \mathrm{~V} \mathrm{vs}$. $\mathrm{Ag} / \mathrm{AgCl}(3 \mathrm{M} \mathrm{KCl})$ for the deposition of $\mathrm{Pt}$, no $\mathrm{Ni}$ was replaced and $\mathrm{Ni} / \mathrm{Pt}$ (micropatterned) multilayers and $\mathrm{Ni}|\mathrm{Pt}| \mathrm{Ni}$ segmented nanowires were formed. Magnetization measurements showed the presence of two ferromagnetic phases, which can be of use for switching applications in magnetic devices.

\subsection{Introduction}

Multilayers of $\mathrm{Ni}$ and $\mathrm{Pt}$ exhibit interesting properties for use in catalytic layers in fuel cells and magnetic and magneto-optical properties for magnetic recording media in hard disks [1-6]. Multilayers of $\mathrm{Ni}$ and $\mathrm{Pt}$ are usually deposited by techniques that require a high temperature and/or low pressure, which include atomic layer deposition (ALD) [1], electron-beam evaporation [2] and DC magnetron sputter deposition [3-6].

An alternative low-cost technique that could be used at ambient conditions for both deposition of $\mathrm{Ni}$ and $\mathrm{Pt}$ is electrodeposition. However, the galvanic replacement reaction prevents the formation of $\mathrm{Pt}-\mathrm{on}-\mathrm{Ni}(\mathrm{Ni} \mid \mathrm{Pt})$ multilayers. For instance, Yao et al. yielded a Ni-Pt alloy after electrodeposition of Pt on top of a Ni substrate [7, 8]. Xiang et al. deposited $\mathrm{Pt}$ nanowires using $\mathrm{Ni}$ edges as electrodes $[9,10]$, but they observed a delayed deposition due to the replacement reaction. Kline et al. deposited multisegmented nanowires by templated electrodeposition, but they deposited the Ni segments only after a Pt segment had been deposited first [11]. We also encountered a replacement reaction while trying to form 
segmented nanowires containing both $\mathrm{Ni}$ and Pt segments as shown in Figure 1.6 [12].

Galvanic replacement, or transmetalation, is widely used for the replacement of a metal by a more noble metal. Especially for low-cost catalyst preparation, it is a popular technique because thin layers of noble metal can be prepared by sacrificing a non-noble metal. Since its first introduction by Brankovic et al. [13-15] and Kokkinidis et al. [16, 17], several combinations of less noble metals that can be replaced by more noble metals have been reported. The replacement of $\mathrm{Ni}$ by $\mathrm{Pt}$ is one of these combinations, and it has been used for the deposition of thin Pt films [18-23] and core-shell Ni-Pt nanoparticles [24, 25]. The replacement of $\mathrm{Ni}$ by Pt can take place via two different reactions, depending on the nature of the $\mathrm{Pt}$ ions. When chloroplatinic acid $\left(\mathrm{H}_{2} \mathrm{PtCl}_{6}\right)$ is used, two $\mathrm{Ni}$ atoms are replaced by one $\mathrm{Pt}^{4+}$ ion [18-22]. When potassium tetrachloroplatinate(II) $\left(\mathrm{K}_{2} \mathrm{PtCl}_{4}\right)$ or tetra-amineplatinum(II) nitrate $\left(\mathrm{Pt}\left(\mathrm{NH}_{3}\right)_{4}\left(\mathrm{NO}_{3}\right)_{2}\right)$ are employed, one $\mathrm{Ni}$ atom is replaced by one $\mathrm{Pt}^{2+}$ ion $[23,26]$. Standard redox potentials are $-0.467 \mathrm{~V}$ for $\mathrm{Ni}^{2+}, 0.516 \mathrm{~V}$ for $\mathrm{PtCl}_{6}{ }^{2-}, 0.548 \mathrm{~V}$ for $\mathrm{PtCl}_{4}{ }^{2-}$ and $0.978 \mathrm{~V}$ for $\mathrm{Pt}^{2+}$ (at $25^{\circ} \mathrm{C}$ relative to $\mathrm{Ag} / \mathrm{AgCl}(3 \mathrm{M} \mathrm{KCl}$ ) reference) [27].

In this chapter, electrodeposition at ambient conditions was used to deposit Ni|Pt multilayer thin films and $\mathrm{Ni}|\mathrm{Pt}| \mathrm{Ni}$ segmented nanowires by changing the deposition potential of the Pt layers or Pt segments to $-0.6 \mathrm{~V}$ instead of $-0.3 \mathrm{~V}$ relative to $\mathrm{Ag} / \mathrm{AgCl}(3 \mathrm{M} \mathrm{KCl})$. We also demonstrate that the same strategy can be used to deposit multilayered Ni|Pt micro- and nanopatterns by selective patterning of a self-assembled monolayer (SAM). Magnetic hysteresis loops show the presence of two ferromagnetic phases in the micropatterned $\mathrm{Ni} \mid \mathrm{Pt}$ multilayers, which could be of use for switching applications in magnetic devices $[3,4,6]$. 


\subsection{Experimental details}

All chemicals used were purchased from commercial sources and used without further purification. Nickel sulfate hexahydrate $\left(\mathrm{NiSO}_{4} \cdot 6 \mathrm{H}_{2} \mathrm{O}\right.$, purity $99 \%)$, boric acid $\left(\mathrm{H}_{3} \mathrm{BO}_{3}\right.$, purity $\left.99.99 \%\right)$ and dichloromethane $\left(\mathrm{CH}_{2} \mathrm{Cl}_{2}\right.$, purity 99.9\%) were purchased from Merck, chloroplatinic acid $\left(\mathrm{H}_{2} \mathrm{PtCl}_{6} \cdot 6 \mathrm{H}_{2} \mathrm{O}\right)$ and 1-octadecylthiol (ODT, purity 97\%) were purchased from Sigma-Aldrich, and PDMS and curing agent (Sylgard 184) were purchased from Dow Corning Corporation. Milli-Q water with a resistivity of 18.2 $\mathrm{M} \Omega \cdot \mathrm{cm}$ was used in all experiments.

Electrodeposition in a conventional three-electrode setup was used for the deposition of $\mathrm{Ni}$ and Pt. The working electrode was (1) a Si substrate with thin layers of $\mathrm{Ti}$ and $\mathrm{Au}$ that were both deposited using a Perkin-Elmer sputtering machine operating at $50 \mathrm{~W}$ at a deposition pressure of $2 \times 10^{-2}$ mbar and $\mathrm{Ar}$ as sputtering gas, (2) a polycarbonate track-etched membrane with a thickness of $6 \mu \mathrm{m}$, a pore size of $200 \mathrm{~nm}$ and a pore density of $\sim 3 \times 10^{8}$ pores $/ \mathrm{cm}^{2}$ (Whatman, UK) with a thin layer of $\mathrm{Au}$ sputtered and isolated as described in Chapter 2 [12, 28-31], and (3) a patterned $\mathrm{Au} / \mathrm{Ti} / \mathrm{Si}$ substrate that was prepared by channel diffused plasma etching of an ODT self-assembled monolayer (ODT SAM) as described elsewhere [32]. A Pt sheet (Metrohm Autolab) was used as counter electrode and $\mathrm{Ag} / \mathrm{AgCl}$ in $3 \mathrm{M} \mathrm{KCl}$ (Metrohm Autolab) was used as reference electrode; all reported potentials are with respect to the reference electrode. The electrodes were connected to an Autolab PGSTAT $128 \mathrm{~N}$ potentiostat. $\mathrm{Ni}$ was deposited from an aqueous electrolyte solution containing $0.23 \mathrm{M} \mathrm{NiSO}_{4} \cdot 6 \mathrm{H}_{2} \mathrm{O}$ and $0.15 \mathrm{M} \mathrm{H}_{3} \mathrm{BO}_{3}$. Deposition occurred at $-1.00 \mathrm{~V}$. Pt was deposited using an aqueous electrolyte solution containing $0.01 \mathrm{M} \mathrm{H}_{2} \mathrm{PtCl}_{6} \cdot 6 \mathrm{H}_{2} \mathrm{O}$ using a potential of either $-0.3 \mathrm{~V}$ or $-0.6 \mathrm{~V}$. As-grown nanowires were collected by dissolving the polycarbonate membrane in $\mathrm{CH}_{2} \mathrm{Cl}_{2}$. A droplet of solvent containing nanowires was dried on a $\mathrm{Si}$ substrate for visualization by Scanning Electron Microscopy (SEM) and Energy Dispersive X-ray Spectroscopy (EDX). After deposition, the other 
substrates (1 and 3) were rinsed with water and dried with a stream of $\mathrm{N}_{2}$ gas.

SEM images were taken using a Zeiss HR-LEO 1550 FEG (field emission gun) SEM. EDX mapping was performed using a NORAN EDS spectrometer equipped in the SEM. The samples containing the micropatterned multilayers were cut to a size of $5 \times 5 \mathrm{~mm}$ after which magnetization measurements were conducted on a vibrating sample magnetometer (VSM) (Physical Properties Measurement System, Quantum Design). The magnetic moments were determined as a function of the magnetic field, with the magnetic field applied parallel to the surface of the samples. All magnetization measurements were performed at room temperature.

X-ray photoelectron spectroscopy (XPS) measurements were performed using a vacuum chamber (Omicron Nanotechnology $\mathrm{GmbH}$ ) at a base pressure below $1 \times 10^{-9}$ mbar. The measurements were performed using a monochromatic Al Ka (XM 1000) X-ray source and an EA 125 electron energy analyser. All spectra were acquired in the Constant Analyser Energy (CAE) mode. The escape angle of the electrons was 80 degrees with respect to the analyser normal. The analyser was calibrated with the use of an in situ sputter cleaned Au sample. For analysing the $\mathrm{Ni} 2 p$ and Pt $4 d$ peaks, a Shirley background was subtracted and the spectra were normalised on the total area below the peaks. 


\subsection{Results and discussion}

\subsubsection{Thin film deposition}

We first evaluated the electrodeposition of Pt on Ni thin films. Deposition of a Pt layer on top of a Ni layer at $-0.3 \mathrm{~V}$ from $\mathrm{H}_{2} \mathrm{PtCl}_{6}$ resulted in cracked Pt layers (Figure 3.1a) that did not adhere well to the $\mathrm{Ni}$ layer. On the contrary, Pt electrodeposition at $-0.6 \mathrm{~V}$ resulted in complete coverage of the Ni layer by Pt (Figure 3.1b). The same deposition times were used in both samples for $\mathrm{Ni}$ and $\mathrm{Pt}$ electrodeposition, i.e. $3 \mathrm{~min}$ for $\mathrm{Ni}$ and $7 \mathrm{~min}$ for $\mathrm{Pt}$. Since $\mathrm{H}_{2} \mathrm{PtCl}_{6}$ was used in the Pt electrolyte solution, the driving force for replacement reaction,

$2 \mathrm{Ni}+\mathrm{Pt}^{4+} \rightarrow 2 \mathrm{Ni}^{2+}+\mathrm{Pt}$

under standard conditions without applied bias is $0.98 \mathrm{~V}$. The cracking of the Pt layer at $-0.3 \mathrm{~V}$ was probably caused by replacement of two $\mathrm{Ni}$ atoms by one Pt atom, such that a volume gap developed. The morphology of both Pt layers is also different. At $-0.3 \mathrm{~V}$ for Pt deposition, small crystalline facets developed, while larger flakes developed at $-0.6 \mathrm{~V}$. Another indication for partial replacement of $\mathrm{Ni}$ by $\mathrm{Pt}$ is found in the difference in $\mathrm{Ni}: \mathrm{Pt}$ ratio in the EDX spectra, i.e. 61 at\% $\mathrm{Ni}$ at $-0.3 \mathrm{~V}$, and 90 at\% $\mathrm{Ni}$ at $-0.6 \mathrm{~V}$. EDX is especially sensitive towards atomic concentrations at a few hundred $\mathrm{nm}$ below the surface. The cross sections in Figure 3.1c and d show $\mathrm{Ni}$ layer thicknesses of approximately 325-350 nm, and all Pt layers had a thickness of approximately $250 \mathrm{~nm}$. Comparatively more Pt was observed by EDX in the sample deposited at $-0.3 \mathrm{~V}$, suggesting that galvanic replacement of $\mathrm{Ni}$ was simultaneously operative to Pt electrodeposition. XPS, which is especially sensitive to elemental surface concentrations, showed a reverse trend for the same samples, i.e. 92 at\% $\mathrm{Ni}$ at $-0.3 \mathrm{~V}$, and 19 at\% $\mathrm{Ni}$ at $-0.6 \mathrm{~V}$. This implies that the surface became enriched in Ni due to galvanic replacement at $-0.3 \mathrm{~V}$, while $\mathrm{Ni}$ is covered by $\mathrm{Pt}$ without galvanic replacement at $-0.6 \mathrm{~V}$. 

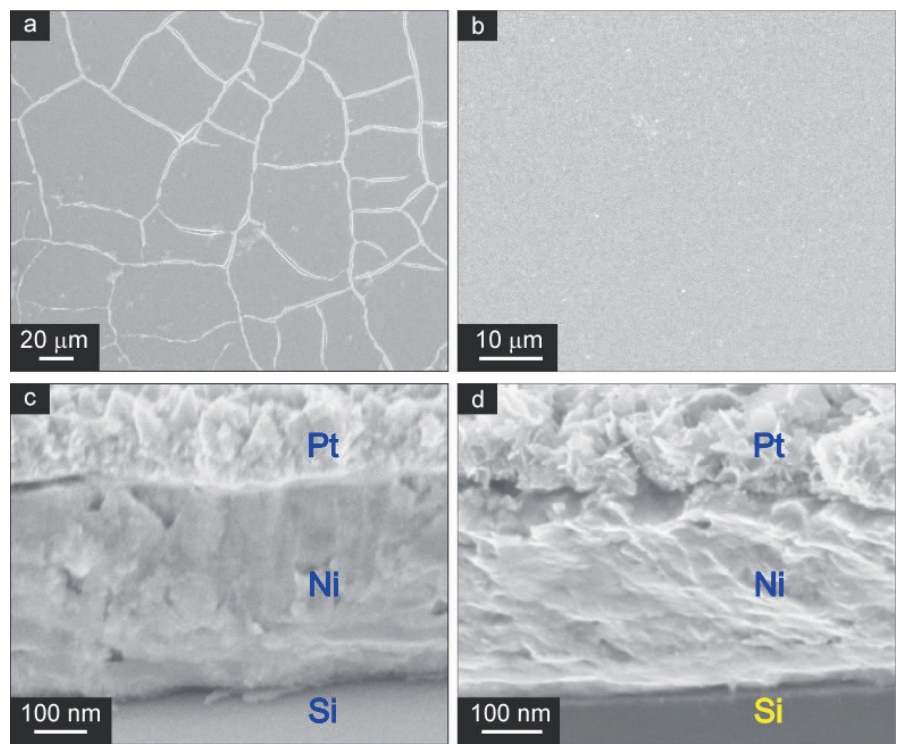

Figure 3.1: Top view $(a, b)$ and cross section (c,d) SEM images of Ni|Pt multilayer thin films grown by electrodeposition on a Si substrate with sputtered layers of $\mathrm{Ti}$ and $\mathrm{Au}$; Left column $(\mathrm{a}, \mathrm{c})$ shows films after Pt electrodeposition at $-0.3 \mathrm{~V}$ and right column (b,d) shows films after Pt electrodeposition at $\mathbf{- 0 . 6} \mathrm{V}$.

The preferred deposition potential of $-0.6 \mathrm{~V}$ for Pt on Ni can be understood by considering the cyclic voltammograms (CV) of $\mathrm{Ni}$ electrodeposition on $\mathrm{Au}$, and $\mathrm{Pt}$ on $\mathrm{Ni} / \mathrm{Au}$ in Figure 3.2. For $\mathrm{Ni}$ the third cycle is shown, because the effect of the underlying Au substrate was absent in that case. For Pt the second cycle is shown, which reveals the effect of the underlying Ni layer. The Pt curve was cut off below $-2 \cdot 2 \cdot 10^{-3} \mathrm{~A}$ for clearer visualization of the $\mathrm{y}$-axis; in reality the curve decreased steadily to $-5.2 \cdot 10^{-3} \mathrm{~A}$ at $-1.0 \mathrm{~V}$. The $\mathrm{CV}$ of Pt on $\mathrm{Ni}$ (Figure 3.2, red curve) shows cathodic mass deposition at potentials below $-0.28 \mathrm{~V}$, which is similar as used in earlier studies [8, 12]. The CV of Ni (Figure 3.2, black curve) shows cathodic mass deposition at potentials below $-0.57 \mathrm{~V}$, so $\mathrm{Ni}$ will be dissolved via direct exchange when Pt is deposited between $-0.28 \mathrm{~V}$ and $-0.57 \mathrm{~V}$. Therefore, a deposition potential of $-0.6 \mathrm{~V}$ for Pt on Ni avoids galvanic replacement, while the overpotential is as small as possible to ensure well-controlled slow growth conditions. 


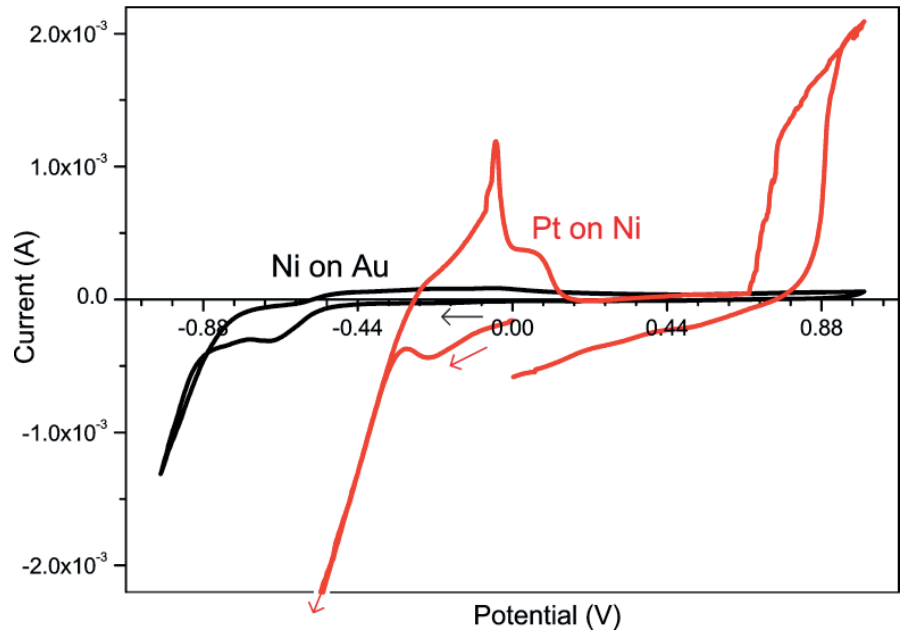

Figure 3.2: Cyclic voltammograms of $\mathrm{Ni}$ on $\mathrm{Au}$ (black curve) and $\mathrm{Pt}$ on $\mathrm{Ni}$ (red curve) electrodeposition. The potential sweep started at $0 \mathrm{~V}$ and proceeded first in negative direction with $-1 \mathrm{~V}$ and $+1 \mathrm{~V}$ as lower and upper boundary, respectively. Scan rate: $10 \mathrm{mV} / \mathrm{s}$, step potential: $2.44 \mathrm{mV}$. The aqueous $\mathrm{Ni}$ electrolyte contained $0.23 \mathrm{M} \mathrm{NiSO}_{4} \cdot 6 \mathrm{H}_{2} \mathrm{O}$ and $0.15 \mathrm{M} \mathrm{H}_{3} \mathrm{BO}_{3}$. The aqueous $\mathrm{Pt}$ electrolyte contained $0.01 \mathrm{M} \mathrm{H}_{2} \mathrm{PtCl}_{6} \cdot 6 \mathrm{H}_{2} \mathrm{O}$.

An alternative method for electrodeposition of $\mathrm{Pt}$ on $\mathrm{Ni}$ is galvanostatic deposition. Francis et al. used a current of -0.1 A for the deposition of Pt on $\mathrm{Ni}$ foam in an experiment in which the Pt ions were dissolved from a Pt counter electrode [33]. During the first stage of the deposition they measured a potential of $-1.0 \mathrm{~V}$, which falls well into the Pt on Ni deposition regime as discussed above. After $30 \mathrm{~min}$ the potential dropped to $-0.4 \mathrm{~V}$, which may lead to galvanic replacement of Ni for Pt. Indeed their Pt $4 f$ XPS spectra exhibited peaks that were attributed to $\mathrm{Ni}(\mathrm{OH})_{2}$ and $\mathrm{NiO}$ [33]. These are thought to originate from a locally very thin or incomplete Pt layer, or galvanic replacement and formation of a Ni-Pt alloy. 


\subsubsection{Nanowires and patterning}

We compared the formation of the Pt segment in $\mathrm{Ni}|\mathrm{Pt}|$ Ni multisegmented nanowires at applied potentials of $-0.3 \mathrm{~V}$ (Figure 3.3a) and $-0.6 \mathrm{~V}$ (Figure 3.3b). The deposition times were the same for both samples, i.e. $3 \mathrm{~min}$ for all $\mathrm{Ni}$ and Pt segments. At $-0.3 \mathrm{~V}$, the first $\mathrm{Ni}$ segment was replaced and only Pt|Ni nanowires remained, as confirmed by EDX spectral imaging (Figure 3.3c,d). At $-0.6 \mathrm{~V}$, both Ni segments stayed intact and three segments could be identified with SEM and EDX (Figure 3.3e,f). The Pt segments deposited at $-0.3 \mathrm{~V}$ had an average length of $390 \mathrm{~nm}$, while the average length of the Pt segments deposited at $-0.6 \mathrm{~V}$ was only $240 \mathrm{~nm}$.
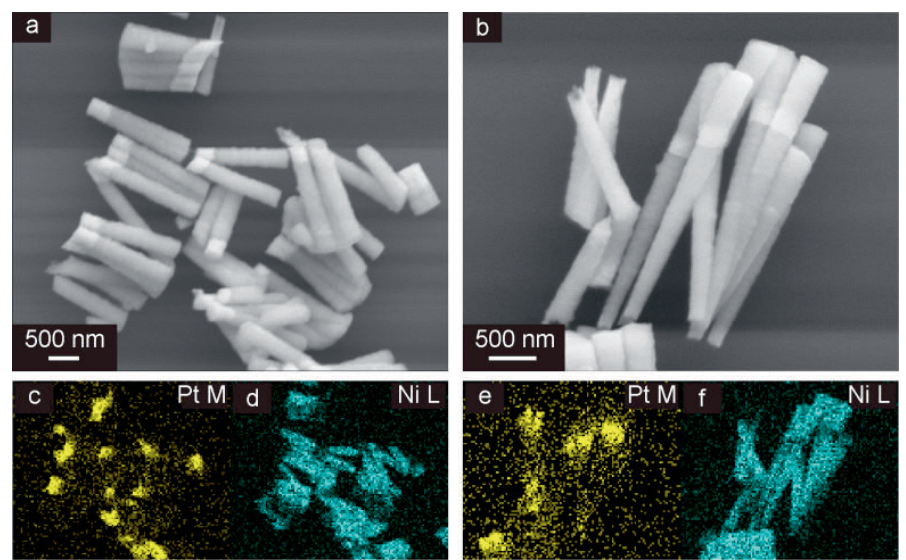

Figure 3.3: SEM images (a,b) and EDX spectral imaging (c,d,e,f) of $\mathrm{Ni}|\mathrm{Pt}| \mathrm{Ni}$ nanowires grown by templated electrodeposition in PCTE membranes. The Pt segments were grown at $-0.3 \mathrm{~V}(\mathrm{a}, \mathrm{c}, \mathrm{d})$ and $-0.6 \mathrm{~V}(\mathrm{~b}, \mathrm{e}, \mathrm{f})$, respectively.

The same strategy was also applied to deposit micro- and nanopatterned structures by selective electrodeposition of a $\mathrm{Ni} \mid \mathrm{Pt}$ dual layer, as shown in Figure 3.4. An ODT SAM micropatterned substrate was made by soft lithographic channel diffused plasma patterning [32]. Ni|Pt multilayers made via soft-lithographic patterning may provide a new route towards cost-effective micro- and nanoscale patterned magnetic memory components. The ODT monolayer prevents electron transport across the Au interface. Hence, electrodeposition can occur only on those locations where 
the ODT was selectively removed by an oxygen plasma. In both examples shown, a dense pattern of $\mathrm{Ni}$ was covered with Pt 'flakes', as the deposition times were kept relatively short to prevent deposition on top of the SAM, i.e. $15 \mathrm{~s}$ for $\mathrm{Ni}$ and $30 \mathrm{~s}$ for Pt.
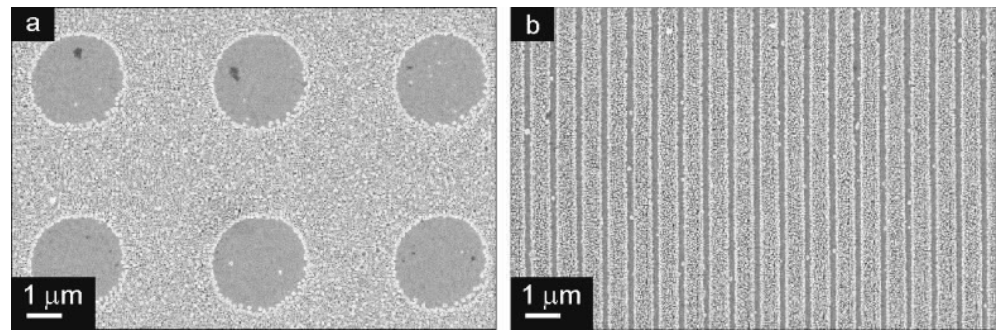

Figure 3.4: SEM images of (a) $\mathrm{Ni} / \mathrm{Pt}$ antidot micropatterns and (b) $\mathrm{Ni}$ | Pt nanopatterns made by electrodeposition on a SAM-patterned template formed by selective plasma etching. The circles in (a) have a diameter of $2.8 \mu \mathrm{m}$ and are separated by a distance of $3 \mu \mathrm{m}$. The Ni|Pt lines in (b) have a width of $500 \mathrm{~nm}$ and they are separated by a distance of $250 \mathrm{~nm}$. The Pt structures were all deposited at $-0.6 \mathrm{~V}$.

The magnetic hysteresis loops of micropatterned Ni|Pt films with an antidot pattern, as shown in Figure 3.4a, are shown in Figure 3.5. The $\mathrm{Ni}$ antidot pattern showed hysteresis behavior proofing the presence of a ferromagnet. Both samples with $\mathrm{Ni}$ and $\mathrm{Pt}$ exhibited typical double loop behavior [34, 35], as can be observed at the top left and bottom right of the hysteresis loops. Double loop behavior implies the presence of two ferromagnetic materials. According to the Ni-Pt phase diagram, several other phases can coexist with the pure $\mathrm{Ni}$ phase, but only the $\mathrm{Ni}_{3} \mathrm{Pt}$ alloy is ferromagnetic at room temperature [36-39]. This suggests that the two ferromagnetic phases that appear in the double hysteresis loops are $\mathrm{Ni}$ and $\mathrm{Ni}_{3} \mathrm{Pt}$ formed at the Ni-Pt interface. The contribution of the small additional loop to the total magnetic moment implies alloy formation up to $5-10 \%$ of the total Ni volume. Since the total $\mathrm{Ni}$ film thickness was $\sim 10 \mathrm{~nm}$, the $\mathrm{Ni}_{3} \mathrm{Pt}$ phase would occupy the equivalent of $\sim 1 \mathrm{~nm}$ thickness or less near the $\mathrm{Ni}$-Pt interface. Mixing of $\mathrm{Ni}$ and $\mathrm{Pt}$ via diffusion over such a short length scale is possible even at room temperature. Double loop behavior was more pronounced in the sample deposited at $-0.3 \mathrm{~V}$, implying more alloy 
formation due to galvanic replacement. Distinct double loop behavior with sharp edges can be of use for switching applications in magnetic devices. Although the double loops in Figure 3.5 did not have sharp edges and only showed a small contribution of the second phase, we believe that a distinct double loop behavior could be obtained by well controlled partial replacement and correlated alloy formation. This can be accomplished by careful optimization of the deposition potential to form a greater portion of $\mathrm{Ni}_{3} \mathrm{Pt}$ alloy.

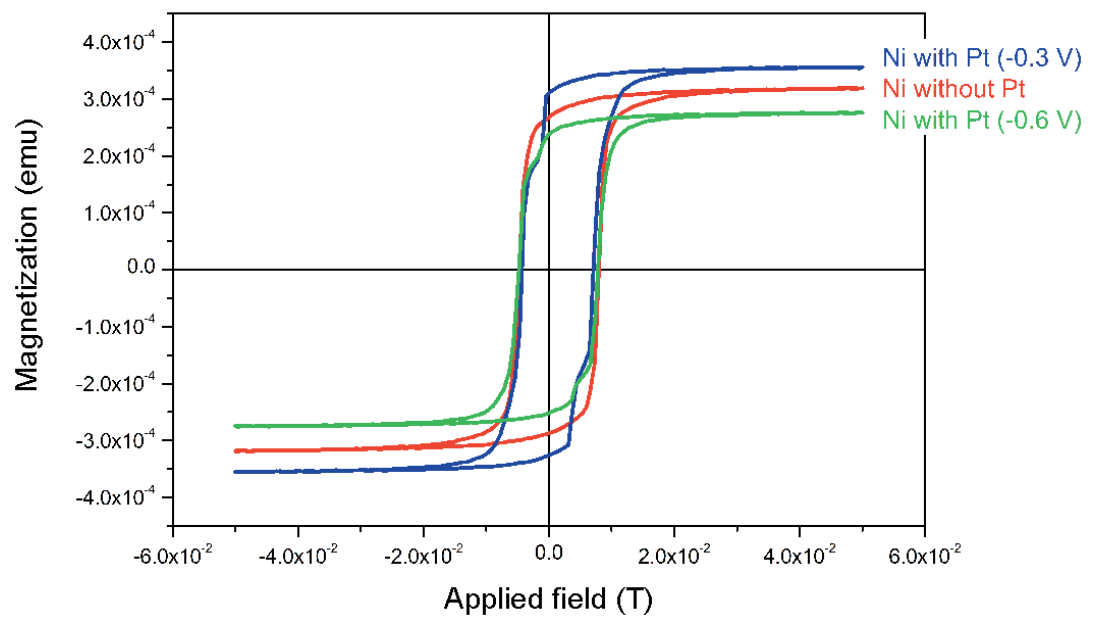

Figure 3.5: Magnetic hysteresis loops of (red) a Ni antidot pattern, (blue) a $\mathrm{Ni}$ antidot pattern with $\mathrm{Pt}$ deposited on top at $-0.3 \mathrm{~V}$, and (green) a $\mathrm{Ni}$ antidot pattern with Pt deposited on top at $-0.6 \mathrm{~V}$.

XPS measurements were performed to validate the presence of the proposed $\mathrm{Ni}_{3} \mathrm{Pt}$ alloy. For this purpose, films were made on $\mathrm{Au} / \mathrm{Ti} / \mathrm{Si}$ substrates. Ni was deposited for $15 \mathrm{~s}$, and if Pt was also deposited, this was done for $5 \mathrm{~s}$. In the Ni $2 p_{3 / 2}$ spectra we could distinguish five different peaks as shown in Figure 3.6a. The $\mathrm{Pt} 4 d$ spectra showed a peak shape representative of a single Pt species as shown in Figure 3.6b. For the Ni $2 p$ spectra of the sample with only $\mathrm{Ni}$, the $\mathrm{Ni}(0)$ peaks are expected to originate from pure $\mathrm{Ni}[40,41]$. The $\mathrm{Ni}(\mathrm{II})$ peaks originate from $\mathrm{NiO}$ and/or surface $\mathrm{Ni}(\mathrm{OH})_{2}[42,43]$, which formed during exposure of the $\mathrm{Ni}$ film to air and/or water. For both $\mathrm{Ni}(\mathrm{O})$ and $\mathrm{Ni}(\mathrm{II})$ we observe peak splitting in the $\mathrm{Ni}$ 
$2 p$ spectra that are of $\underline{c} 3 d^{9} \underline{L} / 3 d^{8}$ (ground state) character for the peaks at lower binding energy and from $\underline{c} d^{10} \underline{L}^{2}$ (screened) / $\underline{c} d^{8}$ (unscreened) at higher binding energy, where $\underline{c}$ and $\underline{\underline{L}}$ refer to a hole in the $2 p$ core level and in the ligand band, respectively $[42,43]$. For the Ni films with Pt deposited on top, the $\mathrm{Ni}(0)$ peaks could be assigned to pure $\mathrm{Ni}$, but they might also partly or completely originate from $\mathrm{Ni}_{3} \mathrm{Pt}$. It is hard to distinguish between $\mathrm{Ni}$ and $\mathrm{Ni}_{3} \mathrm{Pt}$ on the basis of the $\mathrm{Ni}$ and Pt XPS spectra, since only small shifts of $\sim 0.15 \mathrm{eV}$ are expected $[44,45]$. Since the double hysteresis loop was found for both samples containing Pt but not for the sample with only $\mathrm{Ni}$, the samples with Pt should contain an extra $\mathrm{Ni}$ or $\mathrm{Pt}$ species that is ferromagnetic. The only $\mathrm{Ni}$ or Pt species that was found in a larger extend on the samples with $\mathrm{Pt}$ is $\mathrm{Ni}(\mathrm{II})$, however it is unlikely that the observed $\mathrm{Ni}(\mathrm{II})$ species are ferromagnetic. Therefore, it is expected that the $\mathrm{Ni}(0)$ peaks in the samples with $\mathrm{Pt}$ originate from $\mathrm{Ni}_{3} \mathrm{Pt}$.
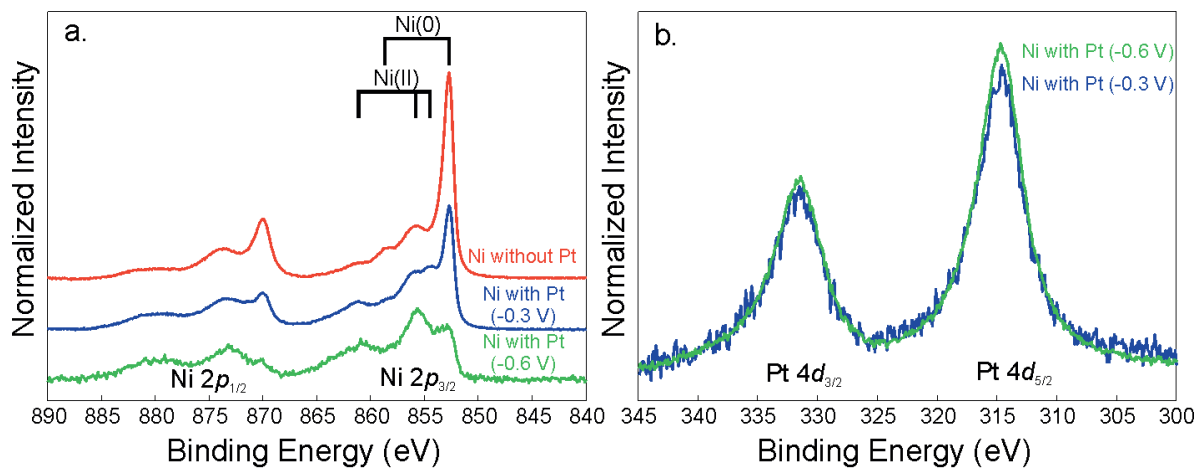

Figure 3.6: XPS (a) Ni $2 p$ spectra and (b) Pt $4 d$ spectra of (red) Ni without Pt, (blue) $\mathrm{Ni}$ with Pt deposited at $-0.3 \mathrm{~V}$ and (green) $\mathrm{Ni}$ with $\mathrm{Pt}$ deposited at $-0.6 \mathrm{~V}$. The $\mathrm{Ni}$ $2 p$ spectrum for the sample with $\mathrm{Pt}$ deposited at $-0.6 \mathrm{~V}$ has a reduced signal-to-noise ratio due to the low amount of Ni present at the surface of this sample. The same holds for the reduced signal-to-noise ratio in the $\mathrm{Pt} 4 d$ spectrum for the sample with Pt deposited at $-0.3 \mathrm{~V}$. 


\subsection{Conclusions}

Electrodeposition of $\mathrm{Pt}$ on $\mathrm{Ni}$ at a potential of $-0.6 \mathrm{~V} \mathrm{vs} . \mathrm{Ag} / \mathrm{AgCl}(3 \mathrm{M} \mathrm{KCl})$ suppressed the galvanic replacement reaction between $\mathrm{Ni}$ and $\mathrm{Pt}$. This allowed formation of $\mathrm{Ni} / \mathrm{Pt}$ multilayers and $\mathrm{Ni} / \mathrm{Pt}$ micro- and nanopatterned surfaces for applications in fuel cells or magnetic memory devices. Magnetic hysteresis loops showed double loop behavior, which indicates the simultaneous presence of $\mathrm{Ni}$ and a second ferromagnetic phase, possibly $\mathrm{Ni}_{3} \mathrm{Pt}$, which can be beneficial in magnetic devices. Multisegmented functional $\mathrm{Ni}|\mathrm{Pt}| \mathrm{Ni}$ nanowires were formed via the same strategy. In principle, the same strategy can be used for electrodeposition of any metal on top of a less noble one and to make nanostructured films and objects which are otherwise impossible to realize.

\subsection{References}

[1] R. R. Hoover and Y. V. Tolmachev, "Electrochemical properties of Pt coatings on Ni prepared by atomic layer deposition", Journal of the Electrochemical Society, 2009, vol. 156, pp. A37-A43.

[2] V. Karoutsos, P. Papasotiriou, P. Poulopoulos, V. Kapaklis, C. Politis, M. Angelakeris, T. Kehagias, N. K. Flevaris, and E. T. Papaioannou, "Growth modes of nanocrystalline Ni/Pt multilayers with deposition temperature", Journal of Applied Physics, 2007, vol. 102,

[3] Y. S. Kim, J. R. Jeong, M. G. Kim, and S. C. Shin, "Observation of magnetic dead layer in Ni/Pt multilayers", IEEE Transactions on Magnetics, 1999, vol. 35, pp. 3073-3075.

[4] Y. S. Kim and S. C. Shin, "Role of magnetoelastic anisotropy in Ni/Pt multilayer films", IEEE Transactions on Magnetics, 1998, vol. 34, pp. 858-860.

[5] V. Ramaswamy, M. A. Phillips, W. D. Nix, and B. M. Clemens, "Observation of the strengthening of Pt layers in Ni/Pt and $\mathrm{Pd} / \mathrm{Pt}$ multilayers by in-situ substrate curvature measurement", Materials Science and Engineering A, 2001, vol. 319-321, pp. 887-892.

[6] G. Srinivas and S. C. Shin, "Magnetic and magneto-optical properties of $\mathrm{Ni} / \mathrm{Pt}$ multilayers with perpendicular magnetic anisotropy at room temperature", Journal of Magnetism and Magnetic Materials, 1999, vol. 198, pp. 341-344. 
[7] K. Yao and Y. F. Cheng, "Electrodeposited Ni-Pt binary alloys as electrocatalysts for oxidation of ammonia", Journal of Power Sources, 2007, vol. 173, pp. 96-101.

[8] K. Yao and Y. F. Cheng, "Fabrication by electrolytic deposition of Pt-Ni electrocatalyst for oxidation of ammonia in alkaline solution", International Journal of Hydrogen Energy, 2008, vol. 33, pp. 6681-6686.

[9] C. Xiang, S. C. Kung, D. K. Taggart, F. Yang, M. A. Thompson, A. G. Güell, Y. Yang, and R. M. Penner, "Lithographically patterned nanowire electrodeposition: A method for patterning electrically continuous metal nanowires on dielectrics", ACS Nano, 2008, vol. 2, pp. 1939-1949.

[10] C. Xiang, M. A. Thompson, F. Yang, E. J. Menke, L. M. C. Yang, and R. M. Penner, "Lithographically patterned nanowire electrodeposition", Physica Status Solidi (C) Current Topics in Solid State Physics, 2008, vol. 5, pp. 3503-3505.

[11] T. R. Kline, W. F. Paxton, T. E. Mallouk, and A. Sen, "Catalytic nanomotors: Remote-controlled autonomous movement of striped metallic nanorods", Angewandte Chemie - International Edition, 2005, vol. 44, pp. 744-746.

[12] A. W. Maijenburg, E. J. B. Rodijk, M. G. Maas, M. Enculescu, D. H. A. Blank, and J. E. ten Elshof, "Hydrogen generation from photocatalytic silver|zinc oxide nanowires: Towards multifunctional multisegmented nanowire devices", Small, 2011, vol. 7, pp. 2709-2713.

[13] S. R. Brankovic, J. McBreen, and R. R. Adžić, "Spontaneous deposition of $\mathrm{Pd}$ on a Ru(0001) surface", Surface Science, 2001, vol. 479, pp. L363-L368.

[14] S. R. Brankovic, J. McBreen, and R. R. Adžić, "Spontaneous deposition of $\mathrm{Pt}$ on the $\mathrm{Ru}(0001)$ surface", Journal of Electroanalytical Chemistry, 2001, vol. 503, pp. 99-104.

[15] S. R. Brankovic, J. X. Wang, and R. R. Adžić, "Metal monolayer deposition by replacement of metal adlayers on electrode surfaces", Surface Science, 2001, vol. 474, pp. L173-L179.

[16] G. Kokkinidis, A. Papoutsis, D. Stoychev, and A. Milchev, "Electroless deposition of Pt on $\mathrm{Ti}$ - catalytic activity for the hydrogen evolution reaction", Journal of Electroanalytical Chemistry, 2000, vol. 486, pp. 48-55. 
[17] G. Kokkinidis, D. Stoychev, V. Lazarov, A. Papoutsis, and A. Milchev, "Electroless deposition of Pt on Ti: Part II. Catalytic activity for oxygen reduction", Journal of Electroanalytical Chemistry, 2001, vol. 511, pp. 20-30.

[18] S. Papadimitriou, S. Armyanov, E. Valova, A. Hubin, O. Steenhaut, E. Pavlidou, G. Kokkinidis, and S. Sotiropoulos, "Methanol oxidation at $\mathrm{Pt}-\mathrm{Cu}, \mathrm{Pt}-\mathrm{Ni}$, and $\mathrm{Pt}-\mathrm{Co}$ electrode coatings prepared by a galvanic replacement process", Journal of Physical Chemistry C, 2010, vol. 114, pp. 5217-5223.

[19] S. Papadimitriou, A. Tegou, E. Pavlidou, S. Armyanov, E. Valova, G. Kokkinidis, and S. Sotiropoulos, "Preparation and characterisation of platinum- and gold-coated copper, iron, cobalt and nickel deposits on glassy carbon substrates", Electrochimica Acta, 2008, vol. 53, pp. 6559-6567.

[20] R. E. Rettew, J. W. Guthrie, and F. M. Alamgir, "Layer-by-layer Pt growth on polycrystalline au: Surface-limited redox replacement of overpotentially deposited $\mathrm{Ni}$ monolayers", Journal of the Electrochemical Society, 2009, vol. 156, pp. D513-D516.

[21] A. Tegou, S. Armyanov, E. Valova, O. Steenhaut, A. Hubin, G. Kokkinidis, and S. Sotiropoulos, "Mixed platinum-gold electrocatalysts for borohydride oxidation prepared by the galvanic replacement of nickel deposits", Journal of Electroanalytical Chemistry, 2009, vol. 634, pp. 104-110.

[22] A. Tegou, S. Papadimitriou, G. Kokkinidis, and S. Sotiropoulos, "A rotating disc electrode study of oxygen reduction at platinised nickel and cobalt coatings", Journal of Solid State Electrochemistry, 2010, vol. 14, pp. 175-184.

[23] S. Wang, J. He, J. Xie, Y. Zhu, Y. Xie, and J. G. Chen, "Synthesis of bimetallic systems using replacement reactions", Applied Surface Science, 2008, vol. 254, pp. 2102-2109.

[24] Y. Ran, S. Rongrong, G. Guanhua, Z. Ning, C. Xuemei, H. Yuehui, and L. Xiaohe, "Hollow metallic microspheres: Fabrication and characterization", Journal of Physical Chemistry C, 2009, vol. 113, pp. 1222-1226.

[25] D. Sun, J. P. He, J. H. Zhou, T. Wang, Z. Y. Di, and X. C. Ding, "Galvanic replacement strategy for a core-shell like $\mathrm{Ni}-\mathrm{Pt}$ electrocatalyst with high Pt utilization", Wuli Huaxue Xuebao/ Acta Physico - Chimica Sinica, 2010, vol. 26, pp. 1219-1224. 
[26] M. Fayette, Y. Liu, D. Bertrand, J. Nutariya, N. Vasiljevic, and N. Dimitrov, "From Au to Pt via surface limited redox replacement of $\mathrm{Pb}$ UPD in one-cell configuration", Langmuir, 2011, vol. 27, pp. 5650-5658.

[27] A. J. Bard and L. R. Faulkner, Electrochemical methods: Fundamentals and applications, 2nd ed.: John Wiley \& Sons, Inc., 2001.

[28] M. G. Maas, E. J. B. Rodijk, W. Maijenburg, J. E. ten Elshof, and D. H. A. Blank, "Photocatalytic segmented nanowires and single-step iron oxide nanotube synthesis: Templated electrodeposition as all-round tool", MRS Online Proceedings Library, 2009, vol. 1206, pp. M01-08.

[29] M. G. Maas, E. J. B. Rodijk, A. Wouter Maijenburg, D. H. A. Blank, and J. E. ten Elshof, "Microstructure development in zinc oxide nanowires and iron oxohydroxide nanotubes by cathodic electrodeposition in nanopores", Journal of Materials Research, 2011, vol. 26, pp. 2261-2267.

[30] A. W. Maijenburg, M. G. Maas, E. J. B. Rodijk, W. Ahmed, E. S. Kooij, E. T. Carlen, D. H. A. Blank, and J. E. ten Elshof, "Dielectrophoretic alignment of metal and metal oxide nanowires and nanotubes: A universal set of parameters for bridging prepatterned microelectrodes", Journal of Colloid and Interface Science, 2011, vol. 355, pp. 486-493.

[31] E. J. B. Rodijk, A. W. Maijenburg, M. G. Maas, D. H. A. Blank, and J. E. ten Elshof, "Templated electrodeposition of $\mathrm{Ag}_{7} \mathrm{NO}_{11}$ nanowires with very high oxidation states of silver", Materials Letters, 2011, vol. 65, pp. 3374-3376.

[32] A. George, A. W. Maijenburg, M. G. Maas, D. H. A. Blank, and J. E. ten Elshof, "Patterning functional materials using channel diffused plasma-etched self-assembled monolayer templates", Langmuir, 2011, vol. 27, pp. 12235-12242.

[33] S. A. Francis and S. H. Bergens, "Low Pt-loading Ni-Pt and Pt deposits on Ni: Preparation, activity and investigation of electronic properties", Journal of Power Sources, 2011, vol. 196, pp. 7470-7480.

[34] A. N. Dobrynin, M. J. Van Bael, K. Temst, and P. Llevens, "Evidence for coexistence of exchange bias and exchange spring effects in oxidized Co nanocluster assembled films", New Journal of Physics, 2007, vol. 9, p. 258. 
[35] E. Y. Tsymbal and D. G. Pettifor, "Perspectives of giant magnetoresistance", Solid State Physics - Advances in Research and Applications, 2001, vol. 56, pp. 113-237.

[36] H. Okamoto, "Ni-Pt (nickel-platinum)", Journal of Phase Equilibria and Diffusion, 2010, vol. 31, pp. 322-322.

[37] U. Kumar, K. G. Padmalekha, P. K. Mukhopadhyay, D. Paudyal, and A. Mookerjee, "Magnetic transition in NiPt alloy systems: experiment and theory", Journal of Magnetism and Magnetic Materials, 2005, vol. 292, pp. 234-240.

[38] S.-L. Shang, Y. Wang, Y. Du, and Z.-K. Liu, "Entropy favored ordering: Phase stability of $\mathrm{Ni}_{3} \mathrm{Pt}$ revisited by first-principles", Intermetallics, 2010, vol. 18, pp. 961-964.

[39] A. Pisanty, C. Amador, Y. Ruiz, and M. de la Vega, "Band structures of $\mathrm{Ni}_{3} \mathrm{Pt}$ and $\mathrm{NiPt}_{3} "$, Zeitschrift für Physik B Condensed Matter, 1990, vol. 80, pp. 237-239.

[40] A. Tanaka, T. Jo, and G. A. Sawatzky, "Configuration interaction in Ni metal and $\mathrm{Ni}$ alloys and high-energy spectroscopy", Journal of the Physical Society of Japan, 1992, vol. 61, pp. 2636-2639.

[41] C. Guillot, Y. Ballu, J. Paigné, J. Lecante, K. P. Jain, P. Thiry, R. Pinchaux, Y. Pétroff, and L. M. Falicov, "Resonant photoemission in nickel metal", Physical Review Letters, 1977, vol. 39, pp. 1632-1635.

[42] D. Alders, F. C. Voogt, T. Hibma, and G. A. Sawatzky, "Nonlocal screening effects in $2 p$ x-ray photoemission spectroscopy of $\mathrm{NiO}$ (100)", Physical Review B - Condensed Matter and Materials Physics, 1996, vol. 54, pp. 7716-7719.

[43] M. A. Van Veenendaal and G. A. Sawatzky, "Nonlocal screening effects in $2 p x$-ray photoemission spectroscopy core-level line shapes of transition metal compounds", Physical Review Letters, 1993, vol. 70, pp. 2459-2462.

[44] T. U. Nahm, H. J. Noh, J. Y. Kim, and S. J. Oh, "Electron spectroscopic evidence of electron correlation in Ni-Pt alloys: Comparison with specific heat measurement", Journal of Physics Condensed Matter, 2003, vol. 15, pp. 3191-3202.

[45] N. J. Shevchik and D. Bloch, "XPS d bands and core levels of Pt-Ni alloys", Journal of Physics F: Metal Physics, 1977, vol. 7, pp. 543-550. 
Chapter 3

$(80)$ 


\section{4. \\ Hydrogen generation from photocatalytic silver|zinc oxide nanowires}

This chapter presents a new approach for the preparation of photocatalytic segmented nanowires comprised of $\mathrm{Ag}$ and $\mathrm{ZnO}$ segments that are able to form $\mathrm{H}_{2}$ from a methanol/water mixture without the need for an external electrical circuit. Since these nanowires are able to autonomously generate $\mathrm{H}_{2}$ gas, they can e.g. be applied for fueling nanorobots or for other applications in which a fuel needs to be created and used at the same location.

This chapter is published as:

A.W. Maijenburg, E.J.B. Rodijk, M.G. Maas, M. Enculescu, D.H.A. Blank, and J.E. ten Elshof, "Hydrogen Generation from Photocatalytic Silver|Zinc Oxide Nanowires: Towards Multifunctional Multisegmented Nanowire Devices," Small, 2011, vol. 7, pp. 2709-2713. 


\subsection{Abstract}

Templated electrodeposition can be used for the formation of segmented nanowires comprised of both a metal and a metal oxide component, as is demonstrated here for the preparation of $\mathrm{Ag} \mid \mathrm{ZnO}$ nanowires. The combination of $\mathrm{ZnO}$ as an $n$-type semiconductor and photocathode, and $\mathrm{Ag}$ as $\mathrm{H}_{2}$ evolution catalyst makes it possible to combine both electrodes of a standard photoelectrochemical cell for photocatalytic $\mathrm{H}_{2}$ formation into a single nanowire. Using this approach, $\sim 0.2$ vol\% $\mathrm{H}_{2}$ had formed after 17 minutes of UV radiation of a methanol/water mixture containing these $\mathrm{Ag} \mid \mathrm{ZnO}$ nanowires. This makes it very promising to use photocatalytic modules within multisegmented and multifunctional nanowires.

\subsection{Introduction}

Nanowires have a high potential for use in a range of biomedical and nanotechnological applications, like sensing, multiplexing, and imaging, and for gene delivery and vaccinations [1]. Many single component nanowires with functional properties have been reported, e.g., optically active $\mathrm{ZnO}$ and $\mathrm{CdTe}$ [2-5], catalysts such as $\mathrm{Au}$ and $\mathrm{Pt}[6]$, and magnetic $\mathrm{Ni}, \mathrm{Fe}_{2} \mathrm{O}_{3}$ and $\mathrm{Fe}_{3} \mathrm{O}_{4}$ phases [7]. But a variety of metals, polymers and metal oxide segments can also be incorporated sequentially into the wires, for instance via infiltration or templated electrodeposition techniques $[8,9]$. Such a modular approach allows the fabrication of multifunctional nanowires that consist of different segments, each with their own specific function. Even functional properties not present in the individual segments may emerge when these are connected into a single nanowire. For instance, segmented $\mathrm{Au} \mid \mathrm{Pt}$ nanowires have been reported that are able to move autonomously when placed in a hydrogen peroxide solution [6]. 
In this chapter, a novel type of segmented nanowire with emergent photocatalytic property is demonstrated. It can be used as such for photochemical conversion of suitable reactants, and/or be combined with other functional materials to realize multiple functions, including photocatalytic, in a single nanowire. The emphasis of this chapter is to demonstrate the photocatalytic function of the metal oxide/metal nanowire module.

Fujishima and Honda showed that water can be split under UV light by a rutile electrode coupled to a platinum electrode [10,11]. Over 130 types of semiconductors have been identified in the meantime as photocatalysts [12-14]. Among the most intensively studied are titanium dioxide [15-19], zinc oxide [20-23], and iron oxide [24, 25]. When these materials are miniaturized into nanoparticles or nanowires, the surface-to-volume ratio is increased drastically, leading to improved photocatalytic efficiencies $[12,13,26-32]$. For the construction of our nanowire, we combined the photoactive $\mathrm{n}$-type semiconducting $\mathrm{ZnO}$ phase with $\mathrm{Ag}$ via sequential electrodeposition in a polycarbonate track-etched (PCTE) membrane with straight-channel pores of 50-200 nm diameter and 6-30 $\mu \mathrm{m}$ length [33]. We used the conversion of methanol and water into hydrogen and carbon dioxide as a model reaction to show that a metal and a metal oxide nanowire component, connected via a Schottky barrier, allow the formation of hydrogen under the influence of UV light.

\subsection{Experimental details}

Commercially available Nuclepore ${ }^{\circledR}$ (Whatman Inc.) polycarbonate track-etched (PCTE) membranes with a thickness of $6 \mu \mathrm{m}$, a pore diameter of $200 \mathrm{~nm}$ and a pore density of $\sim 3 \times 10^{8}$ pores $/ \mathrm{cm}^{2}$ were used as template for the formation of nanowires with lengths up to $6 \mu \mathrm{m}$. 
To obtain templates for the synthesis of multifunctional multisegmented nanowires of more than $6 \mu \mathrm{m}$ length, polycarbonate foils with a thickness of $30 \mu \mathrm{m}$ were irradiated at the GSI in Darmstadt with swift heavy ions with fluences in the range $10^{4}-10^{9}$ ions $/ \mathrm{cm}^{2}$. In order to obtain cylindrical pores, the ion tracks were etched using a solution of $5 \mathrm{M} \mathrm{NaOH}$ containing $10 \%$ methanol at $50{ }^{\circ} \mathrm{C}$. In this way, we prepared membranes containing pores with diameters ranging from $130 \mathrm{~nm}$ to $500 \mathrm{~nm}$. Further details can be found elsewhere [34, 35].

Prior to electrodeposition, a gold layer with a thickness of $50 \mathrm{~nm}$ was sputtered on one side of the membrane. The gold coated side was then attached to a glass slide with double-sided tape and used as working electrode in a 3-electrode setup using a Bank Elektronik POS 73 potentiostat and an Autolab PGSTAT 128N potentiostat from Metrohm. As counter electrode, a small piece of platinum mesh was used. The reference potential was set by a $3 \mathrm{M} \mathrm{KCl} \mathrm{Ag/AgCl}$ reference electrode (REF 321, Radio Analytical) or a $\mathrm{Ag} / \mathrm{AgCl}$ reference electrode (Metrohm). Silver segments were deposited from an electrolyte solution containing $0.20 \mathrm{M} \mathrm{AgNO}_{3}$ (99+\%, Acros) and $0.10 \mathrm{M} \mathrm{H}_{3} \mathrm{BO}_{3}$ (99.99\%, Sigma-Aldrich). The $\mathrm{pH}$ was adjusted to 1.5 with nitric acid. Silver deposition was done potentiostatically at room temperature at $+0.10 \mathrm{~V}$ versus reference. Zinc oxide segments were deposited at $-1.00 \mathrm{~V}$ at $70^{\circ} \mathrm{C}$ from an aqueous electrolyte solution containing $0.10 \mathrm{M} \mathrm{Zn}\left(\mathrm{NO}_{3}\right)_{2} \cdot 6 \mathrm{H}_{2} \mathrm{O}$ (98\%, Sigma-Aldrich). After deposition, the PCTE membranes were dissolved in dichloromethane (Merck).

The isolated nanowires were characterized using a Zeiss HR-LEO 1550 FEG Scanning Electron Microscope (SEM), before and after the photocatalytic experiments. The $I-V$ characteristics were determined using a Karl Suss PM8 low leakage Manual Probe Station and a Keithley 4200 power source. 
For photocatalytic experiments, approximately $0.1 \mathrm{~g}$ of segmented nanowires were suspended in $50 \mathrm{~mL}$ of a $4: 1 \mathrm{vol} / \mathrm{vol}$ methanol/water mixture in a sealed quartz tube with a total volume of $72 \mathrm{~mL}$. A Pd-based Kebaili KHS-100 hydrogen sensor, based on a palladium/nickel alloy which is highly selective for hydrogen, was placed in the plug and properly sealed. The hydrogen sensor was connected to a standard Wheatstone bridge. The voltage response was logged every second with a Peaktech multimeter connected to a computer. A UV-source of $60 \mathrm{~W}$ was used, at a distance of 10-15 cm from the sample. The experiments were performed in ambient atmosphere.

\subsection{Results and discussion}

An SEM picture of a small bundle of three $\mathrm{ZnO} / \mathrm{Ag}$ nanowires is shown in Figure 4.1(a). The ZnO phase acts as photoanode, and Ag as cathode. In contrast to conventional photo-electrochemical cells, no external circuit connecting the electrodes is present. This aids in increasing efficiency by reducing Ohmic losses, and simplifies device architecture and ease of construction considerably in comparison with conventional photoelectrochemical cells. Figure 4.1(b) shows a schematic overview of the envisaged process. The combination of $\mathrm{ZnO}$ and $\mathrm{Ag}$ was selected because the electron affinity of $\mathrm{ZnO}$ is slightly higher $(4.35 \mathrm{eV})$ than the work function of Ag $(4.25 \mathrm{eV})$. This allows the formation of a Schottky barrier between these phases [36], across which excited electrons can flow freely from the conduction band of $\mathrm{ZnO}$ into $\mathrm{Ag}$, without a chance of electron-hole recombination [37]. Moreover, $\mathrm{ZnO}$ can be formed already at $60-90^{\circ} \mathrm{C}$ in the active wurtzite phase, while most other photoactive oxides made via cathodic electrodeposition would require an intermediate high temperature treatment in order to be formed. 

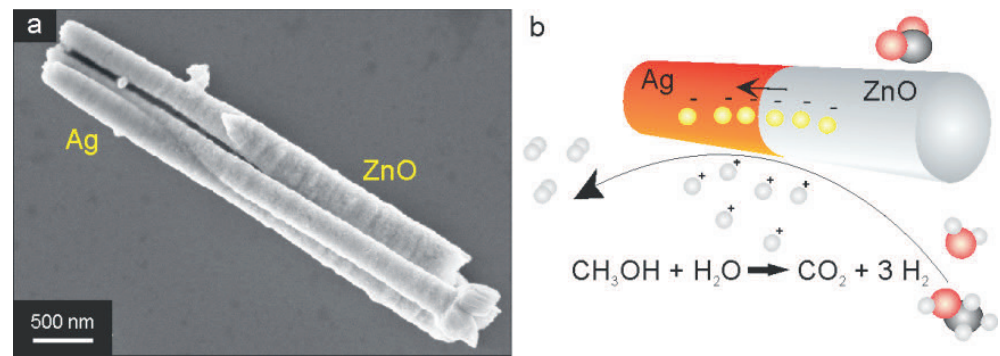

Figure 4.1: (a) Scanning Electron Microscopy (SEM) picture of axially segmented $\mathrm{ZnO}$ |Ag nanowires of $200 \mathrm{~nm}$ diameter and $6 \mu \mathrm{m}$ length; (b) Working principle of photoactive segmented $\mathrm{Ag} \mid \mathrm{ZnO}$ nanowire. UV radiation is absorbed by the $\mathrm{ZnO}$ segment, creating an electron-hole pair. The electrons flow into the $\mathrm{Ag}$ phase and are consumed in an electrochemical reduction process. The hole in the $\mathrm{ZnO}$ segment is consumed in an oxidative half-reaction.

The conversion of methanol-water mixtures into hydrogen and $\mathrm{CO}_{2}$ is a relatively low energy process. Methanol acts as a hole scavenger at the $\mathrm{ZnO}$ anode, and is oxidized into $\mathrm{CO}_{2}$ following the net reaction

$\mathrm{CH}_{3} \mathrm{OH}+\mathrm{H}_{2} \mathrm{O}+6 \mathrm{~h}^{+} \rightarrow \mathrm{CO}_{2}+6 \mathrm{H}^{+}$,

where $\mathrm{h}^{+}$indicates an electron hole. At the silver cathode, protons are reduced to $\mathrm{H}_{2}$ according to

$2 \mathrm{H}^{+}+2 \mathrm{e}^{-} \rightarrow \mathrm{H}_{2}$.

The net energy required for the overall reaction is $0.7 \mathrm{eV}$ [16], much smaller than the band gap of $\mathrm{ZnO}(3.2 \mathrm{eV})$.

In order to verify that a Schottky barrier had formed between the silver and wurtzite phases, the $I-V$ curves of an ensemble of segmented $\mathrm{Ag} \mid \mathrm{ZnO}$ wires was determined by sputtering a small gold electrode on top of a PCTE membrane containing as-grown nanowires, and characterized by 2-point measurements. This method ensures good ohmic contacts between electrodes and nanowires, but the number of wires included in the measurement is not known exactly. Moreover, the PCTE matrix is still present, which might influence the experimental data. So while the 
presence or absence of a Schottky barrier in the wire may be determined from this measurement, the absolute conductivity can not be estimated.

The I- $V$ characteristics of single component $\mathrm{ZnO}$ wires were therefore also determined (Figure 4.2). To this end, a PCTE matrix containing as-grown wires was dissolved in dichloromethane, followed by breaking off the nanowires from the bottom electrode via ultrasonic treatment. The wires in solution were then positioned between gold microelectrodes using a dielectrophoretic alignment technique [38]. This method ensures that the measured current passes through a single wire, but establishing good ohmic contacts between microelectrodes and nanowire is challenging. However, the overall shape of the $I-V$ curve measured from the nanowire ensemble in Figure $4.2 \mathrm{c}$ was exactly the same as for the single $\mathrm{ZnO}$ nanowire [38], and the difference in conductivity may be attributed to the uncertainty in the number of wires that contributed to the conductivity of the ensemble.
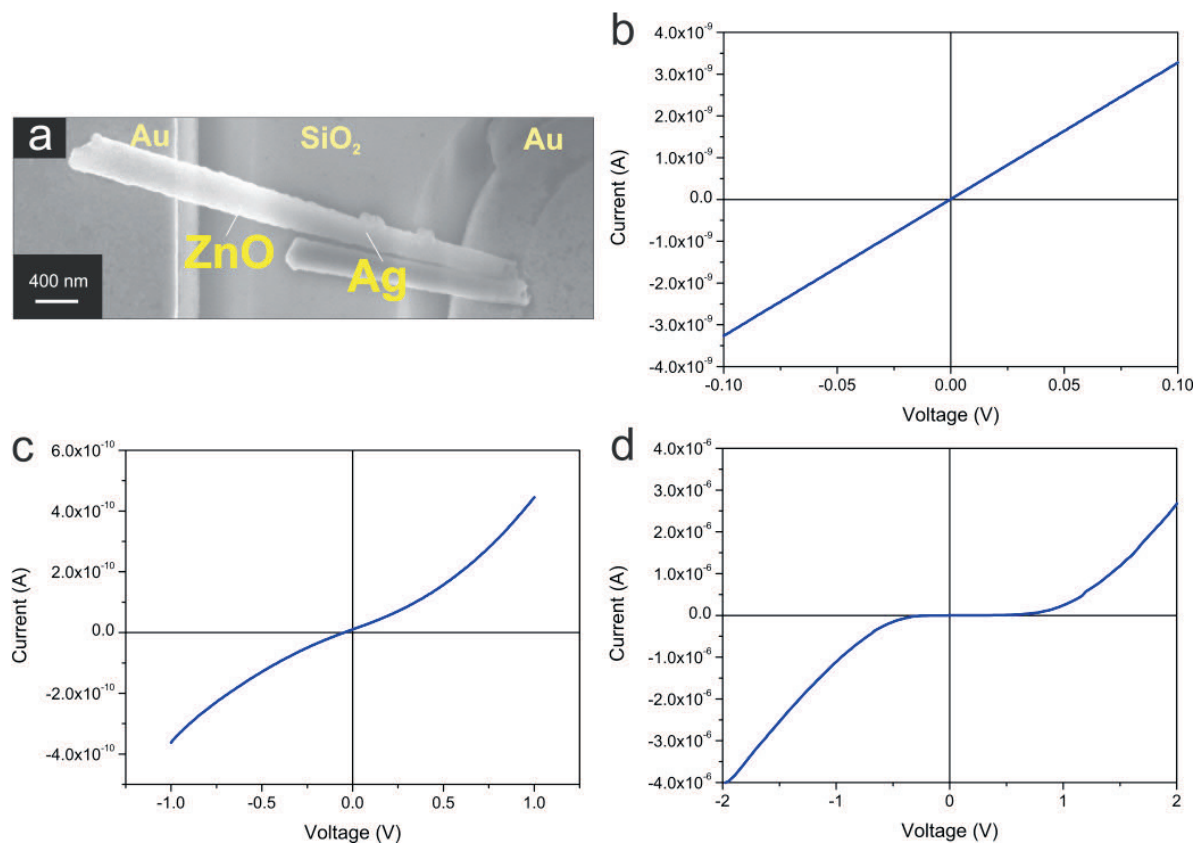

Figure 4.2: (a) Segmented $\mathrm{Ag} \mid \mathrm{ZnO}$ nanowire placed between gold microelectrodes via dielectrophoretic alignment; (b-d) I-V curves of (b) Ag nanowires, (c) $\mathrm{ZnO}$ nanowires, and (d) $\mathrm{Ag} \mid \mathrm{ZnO}$ nanowires. 
An example of an aligned $\mathrm{Ag} \mid \mathrm{ZnO}$ nanowire is shown in Figure 4.2a. The $\mathrm{I}-\mathrm{V}$ characteristics of $\mathrm{Ag}, \mathrm{ZnO}$, and segmented $\mathrm{Ag} \mid \mathrm{ZnO}$ nanowire ensembles are shown in Figure $4.2 \mathrm{~b}-\mathrm{d}$. The current responses of $\mathrm{Ag}$ and $\mathrm{ZnO}$ nanowires showed ohmic and semiconducting behavior, respectively. Their response was symmetrical and did not show rectifying behavior, suggesting ohmic contacts with the gold electrodes. The shape of the $\mathrm{Ag} \mid \mathrm{ZnO}$ curve is also representative of a semiconductor, implying ohmic contacts to the Au electrode and the Ag segment of the nanowire. However, the I- $V$ curve was symmetrical around $\mathrm{V}=+200 \mathrm{mV}$. This indicates a small energy barrier between silver and zinc oxide, in agreement with theoretical expectation. Since it requires more energy to inject electrons into $\mathrm{ZnO}$ via the silver segment, the symmetry point is expected to move to positive values under a forward bias, indicating the presence of a space charge layer. These measurements show that $\mathrm{Ag} \mid \mathrm{ZnO}$ segmented nanowires behave like Schottky barriers, as theory predicts.

The photocatalytic activity of the nanowires was tested in a $4: 1 \mathrm{v} / \mathrm{v}$ methanol/water solution. A Pd-based sensor placed in the atmosphere directly above the solution was used to detect gaseous hydrogen (Figure 4.3). It is noted that this experiment cannot detect hydrogen dissolved in the methanol/water phase. As can be seen in Figure 4.3a, the $\mathrm{Pd}$-based sensor is also slightly cross-sensitive to methanol, so therefore a reference sample without nanowires was also measured. After UV exposure, the signal for the sample with segmented $\mathrm{Ag} \mid \mathrm{ZnO}$ nanowires increased much faster than the signal from the reference sample. 

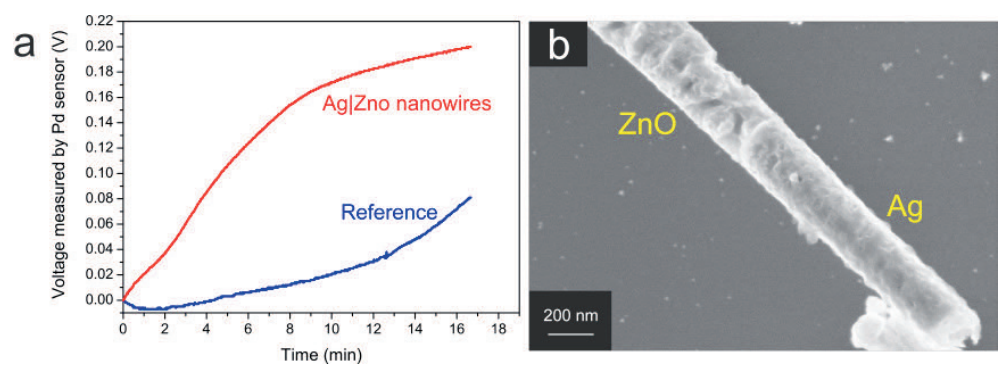

Figure 4.3: (a) Hydrogen sensor response during UV irradiation of a methanol/water solution containing $\mathrm{Ag} \mid \mathrm{ZnO}$ segmented nanowires (red line). Reference experiment without nanowires is indicated by a blue line; (b) SEM picture of $\mathrm{Ag} \mid \mathrm{ZnO}$ nanowire after $48 \mathrm{~h}$ of $\mathrm{UV}$ exposure.

The increase in potential indicates that gaseous hydrogen was forming and evolving from the solution. This was supported by the visual observation of the formation of small gas bubbles in the test tube. By comparing the potential response of the sensor in a 4 vol\% $\mathrm{H}_{2}$ in $\mathrm{N}_{2}$ gas stream, it was estimated that approximately 0.2 vol\% $\mathrm{H}_{2}$ had formed in the gas volume by the $\mathrm{Ag} \mid \mathrm{ZnO}$ nanowires after 17 minutes. It is noted that the presence of methanol vapor may slightly poison the Ni-Pd sensor surface and causes a slight decrease of output potential. However, the effect should be small compared to the change that we measured experimentally in this experiment, and it was observed that the signal returned to its original value in air after the experiment.

When the same experiment was repeated in the absence of nanowires, no gas bubble evolution was observed. In this case the sensor showed a very small increase of potential with time directly after UV exposure. Other reference experiments with single-phase $\mathrm{ZnO}$ or Ag nanowires, not shown here, gave no indication for the formation of hydrogen.

In the UV experiments involving nanowires, the formation of gas bubbles typically ended after $\sim 48 \mathrm{~h}$ of irradiation. The reason for the loss of activity can be ascribed to photocorrosion of $\mathrm{ZnO}$, following the reaction

$$
\mathrm{ZnO}+2 h^{+} \rightarrow \mathrm{Zn}^{2+}+1 / 2 \mathrm{O}_{2}[39-42]
$$


Figure $4.3 \mathrm{~b}$ shows an SEM picture of a $\mathrm{Ag} \mid \mathrm{ZnO}$ segmented nanowire after experiments. The surface of the $\mathrm{ZnO}$ segment is corroded and appears much rougher than the as-synthesized wires of Figure $4.1 \mathrm{~b}$. To verify that the corrosion was in fact the result of photocorrosion and not of electrolytic corrosion, segmented nanowires were suspended in the methanol/water mixture and left in darkness for $48 \mathrm{~h}$, but no indications for corrosion were found in that case. Methods for the inhibition of $\mathrm{ZnO}$ photocorrosion, including grafting of $\mathrm{ZnO}$ nanorods on $\mathrm{TiO}_{2}$ nanotubes, and hybridization of $\mathrm{ZnO}$ nanoparticles with a monolayer of polyaniline or $\mathrm{C}_{60}$ have been developed in the literature $[41,43,44]$.

\subsection{Conclusions}

In summary, we demonstrated that $\mathrm{Ag} \mid \mathrm{ZnO}$ nanowire diodes of 200-300 nm diameter and a length of about $6 \mu \mathrm{m}$ are photocatalytically active in the conversion of methanol to hydrogen under UV illumination. These nanowires could find application in multifunctional nanowires and nanowire devices.

\subsection{References}

[1] R. J. Kuppler, D. J. Timmons, Q. R. Fang, J. R. Li, T. A. Makal, M. D. Young, D. Yuan, D. Zhao, W. Zhuang, and H. C. Zhou, "Potential applications of metal-organic frameworks", Coordination Chemistry Reviews, 2009, vol. 253, pp. 3042-3066.

[2] M. G. Maas, E. J. B. Rodijk, W. Maijenburg, J. E. Ten Elshof, and D. H. A. Blank, "Photocatalytic segmented nanowires and single-step iron oxide nanotube synthesis: Templated electrodeposition as all-round tool," Boston, MA, 2010, pp. 1-6.

[3] C. L. Hsu, S. J. Chang, H. C. Hung, Y. R. Lin, C. J. Huang, Y. K. Tseng, and I. C. Chen, "Well-aligned, vertically Al-doped ZnO nanowires synthesized on $\mathrm{ZnO}: \mathrm{Ga} / \mathrm{glass}$ templates", Journal of The Electrochemical Society, 2005, vol. 152, pp. G378-G381. 
[4] E. Matei, L. Ion, S. Antohe, R. Neumann, and I. Enculescu, "Multisegment CdTe nanowire homojunction photodiode", Nanotechnology, 2010, vol. 21, p. 105202.

[5] E. Matei, N. Preda, M. Enculescu, J. P. Ansermet, M. E. Toimil Molares, and I. Enculescu, "Sequential deposition of multisegment nanowires", Digest Journal of Nanomaterials and Biostructures, 2010, vol. 5, pp. 1067-1076.

[6] T. E. Mallouk and A. Sen, "Powering nanorobots: Catalytic engines enable tiny swimmers to harness fuel from their environment and overcome the weird physics of the microscopic world", Scientific American, 2009, vol. 300, pp. 72-77.

[7] R. M. Penner and C. R. Martin, "Preparation and electrochemical characterization of ultramicroelectrode ensembles", Analytical, 1987, vol. 59, pp. 2625-2630.

[8] H. L. Jiang, S. K. Singh, J. M. Yan, X. B. Zhang, and Q. Xu, "Liquid-Phase chemical hydrogen storage: Catalytic hydrogen generation under ambient conditions", ChemSusChem, 2010, vol. 3, pp. 541-549.

[9] G. J. Kubas, "Hydrogen activation on organometallic complexes and $\mathrm{H}_{2}$ production, utilization, and storage for future energy", Journal of Organometallic Chemistry, 2009, vol. 694, pp. 2648-2653.

[10] A. Fujishima and K. Honda, "Electrochemical photolysis of water at a semiconductor electrode", Nature, 1972, vol. 238, pp. 37-38.

[11] A. Fujishima, K. Kohayakawa, and K. Honda, "Hydrogen production under sunlight with an electrochemical photocell", Journal of The Electrochemical Society, 1975, vol. 122, pp. 1487-1489.

[12] A. Kudo and Y. Miseki, "Heterogeneous photocatalyst materials for water splitting", Chemical Society Reviews, 2009, vol. 38, pp. 253-278.

[13] R. M. Navarro Yerga, M. Consuelo Álvarez Galván, F. del Valle, J. A. Villoria de la Mano, and J. L. Fierro, "Water splitting on semiconductor catalysts under visible-light irradiation", ChemSusChem, 2009, vol. 2, pp. 471-485.

[14] F. E. Osterloh, "Inorganic materials as catalysts for photochemical splitting of water", Chemistry of Materials, 2008, vol. 20, pp. 35-54.

[15] S. U. M. Khan, M. Al-Shahry, and W. B. Ingler Jr, "Efficient photochemical water splitting by a chemically modified n- $\mathrm{TiO}_{2}$ ", Science, 2002, vol. 297, pp. 2243-2245. 
[16] W. C. Lin, W. D. Yang, I. L. Huang, T. S. Wu, and Z. J. Chung, "Hydrogen production from methanol/water photocatalytic decomposition using $\mathrm{Pt} / \mathrm{TiO}_{2-\mathrm{x}} \mathrm{N}_{\mathrm{x}}$ catalyst", Energy and Fuels, 2009, vol. 23, pp. 2192-2196.

[17] M. Ni, M. K. H. Leung, D. Y. C. Leung, and K. Sumathy, "A review and recent developments in photocatalytic water-splitting using $\mathrm{TiO}_{2}$ for hydrogen production", Renewable and Sustainable Energy Reviews, 2007, vol. 11, pp. 401-425.

[18] K. Rajeshwar, "Hydrogen generation at irradiated oxide semiconductor-solution interfaces", Journal of Applied Electrochemistry, 2007, vol. 37, pp. 765-787.

[19] R. F. Service, "Chemistry: Catalyst boosts hopes for hydrogen bonanza", Science, 2002, vol. 297, pp. 2189-2190.

[20] M. Gupta, V. Sharma, J. Shrivastava, A. Solanki, A. Singh, V. Satsangi, S. Dass, and R. Shrivastav, "Preparation and characterization of nanostructured $\mathrm{ZnO}$ thin films for photoelectrochemical splitting of water", Bulletin of Materials Science, 2009, vol. 32, pp. 23-30.

[21] J. H. He, S. T. Ho, T. B. Wu, L. J. Chen, and Z. L. Wang, "Electrical and photoelectrical performances of nano-photodiode based on $\mathrm{ZnO}$ nanowires", Chemical Physics Letters, 2007, vol. 435, pp. 119-122.

[22] K. Maeda and K. Domen, "Solid solution of GaN and ZnO as a stable photocatalyst for overall water splitting under visible light", Chemistry of Materials, 2010, vol. 22, pp. 612-623.

[23] X. Yang, A. Wolcott, G. Wang, A. Sobo, R. C. Fitzmorris, F. Qian, J. Z. Zhang, and Y. Li, "Nitrogen-doped ZnO nanowire arrays for photoelectrochemical water splitting", Nano Letters, 2009, vol. 9, pp. 2331-2336.

[24] S. Ekambaram, "Photoproduction of clean $\mathrm{H}_{2}$ or $\mathrm{O}_{2}$ from water using oxide semiconductors in presence of sacrificial reagent", Journal of Alloys and Compounds, 2008, vol. 448, pp. 238-245.

[25] S. K. Mohapatra, S. E. John, S. Banerjee, and M. Misra, "Water photooxidation by smooth and ultrathin alfa- $\mathrm{Fe}_{2} \mathrm{O}_{3}$ nanotube arrays", Chemistry of Materials, 2009, vol. 21, pp. 3048-3055.

[26] J. P. Best and D. E. Dunstan, "Nanotechnology for photolytic hydrogen production: Colloidal anodic oxidation", International Journal of Hydrogen Energy, 2009, vol. 34, pp. 7562-7578.

[27] A. I. Hochbaum and P. Yang, "Semiconductor nanowires for energy conversion", Chemical Reviews, 2010, vol. 110, pp. 527-546. 
[28] A. Kudo, "Recent progress in the development of visible light-driven powdered photocatalysts for water splitting", International Journal of Hydrogen Energy, 2007, vol. 32, pp. 2673-2678.

[29] J. Li and J. Z. Zhang, "Optical properties and applications of hybrid semiconductor nanomaterials", Coordination Chemistry Reviews, 2009, vol. 253, pp. 3015-3041.

[30] H. Yi, T. Peng, D. Ke, L. Zan, and C. Yan, "Photocatalytic $\mathrm{H}_{2}$ production from methanol aqueous solution over titania nanoparticles with mesostructures", International Journal of Hydrogen Energy, 2008, vol. 33, pp. 672-678.

[31] M. Zäch, C. Hägglund, D. Chakarov, and B. Kasemo, "Nanoscience and nanotechnology for advanced energy systems", Current Opinion in Solid State and Materials Science, 2006, vol. 10, pp. 132-143.

[32] J. Zhu and M. Zäch, "Nanostructured materials for photocatalytic hydrogen production", Current Opinion in Colloid and Interface Science, 2009, vol. 14, pp. 260-269.

[33] C. R. Martin, "Nanomaterials: A membrane-based synthetic approach", Science, 1994, vol. 266, pp. 1961-1966.

[34] I. Enculescu, M. Sima, M. Enculescu, C. Ghica, M. Enache, and R. Neumann, "Preparation of metallic nanowires with magnetic properties using the template method", Journal of Optoelectronics and Advanced Materials, 2007, vol. 9, pp. 1468-1470.

[35] M. Enculescu, "Potassium hydrogen phthalate (KAP) micro- and nanorods prepared by a template approach", Journal of Optoelectronics and Advanced Materials, 2008, vol. 10, pp. 1501-1504.

[36] A. J. Nozik, "Photochemical diodes", Applied Physics Letters, 1977, vol. 30, pp. 567-569.

[37] D. W. Bahnemann, C. Kormann, and M. R. Hoffmann, "Preparation and characterization of quantum size zinc oxide: $A$ detailed spectroscopic study", Journal of Physical Chemistry, 1987, vol. 91, pp. 3789-3798.

[38] A. W. Maijenburg, M. G. Maas, E. J. B. Rodijk, W. Ahmed, E. S. Kooij, E. T. Carlen, D. H. A. Blank, and J. E. ten Elshof, "Dielectrophoretic alignment of metal and metal oxide nanowires and nanotubes: A universal set of parameters for bridging prepatterned microelectrodes", Journal of Colloid and Interface Science, 2011, vol. 355 , pp. 486-493. 
[39] X. Chen, Y. He, Q. Zhang, L. Li, D. Hu, and T. Yin, "Fabrication of sandwich-structured $\mathrm{ZnO} /$ reduced graphite oxide composite and its photocatalytic properties", Journal of Materials Science, 2010, vol. 45, pp. 953-960.

[40] J. Doménech and A. Prieto, "Stability of ZnO particles in aqueous suspensions under UV illumination", Journal of Physical Chemistry, 1986, vol. 90, pp. 1123-1126.

[41] H. Fu, T. Xu, S. Zhu, and Y. Zhu, "Photocorrosion inhibition and enhancement of photocatalytic activity for $\mathrm{ZnO}$ via hybridization with $\mathrm{C}_{60} "$ ", Environmental Science and Technology, 2008, vol. 42, pp. 8064-8069.

[42] N. Kislov, J. Lahiri, H. Verma, D. Y. Goswami, E. Stefanakos, and M. Batzill, "Photocatalytic degradation of methyl orange over single crystalline $\mathrm{ZnO}$ : Orientation dependence of photoactivity and photostability of ZnO", Langmuir, 2009, vol. 25, pp. 3310-3315.

[43] Y. Lei, G. Zhao, M. Liu, Z. Zhang, X. Tong, and T. Cao, "Fabrication, characterization, and photoelectrocatalytic application of $\mathrm{ZnO}$ nanorods grafted on vertically aligned $\mathrm{TiO}_{2}$ nanotubes", Journal of Physical Chemistry C, 2009, vol. 113, pp. 19067-19076.

[44] H. Zhang, R. Zong, and Y. Zhu, "Photocorrosion inhibition and photoactivity enhancement for zinc oxide via hybridization with monolayer polyaniline", Journal of Physical Chemistry C, 2009, vol. 113, pp. 4605-4611. 


\section{Electrochemical synthesis of coaxial $\mathrm{TiO}_{2}-\mathrm{Ag}$ nanowires and their application in photocatalytic water splitting}

This chapter presents an approach for the synthesis of coaxial nanowires composed of a $\mathrm{TiO}_{2}$ shell and Ag core via electrochemical synthesis in AAO templates. These coaxial nanowires were also used for photocatalytic water splitting, making it the second photocatalytic nanowire system in this thesis, and it was found that the coaxial architecture of these nanowires has a positive effect on the $\mathrm{H}_{2}$ formation rate.

This chapter is accepted as:

A.W. Maijenburg, J. Veerbeek, R. de Putter, S.A. Veldhuis, M.G.C. Zoontjes, G. Mul, J.M. Montero-Moreno, K. Nielsch, H. Schäfer, M. Steinhart, and J.E. ten Elshof, "Electrochemical synthesis of coaxial $\mathrm{TiO}_{2}-\mathrm{Ag}$ nanowires and their application in photocatalytic water splitting", Journal of Materials Chemistry A. 


\subsection{Abstract}

A new method for the formation of coaxial $\mathrm{TiO}_{2}-\mathrm{Ag}$ nanowires is presented, in which $\mathrm{TiO}_{2}$ nanotubes were formed by the templated electrochemically induced sol-gel method, followed by thermal annealing. The as-formed $\mathrm{TiO}_{2}$ nanotubes have been successfully filled with a Ag core using a subsequent electrodeposition step. Coaxial nanowires have a very suitable architecture for photocatalysis, solar cells or batteries due to the high contact area between the two different phases, the large outer surface area exposed to the reactant, and short electron diffusion paths. The coaxial nanowires showed a higher efficiency than empty $\mathrm{TiO}_{2}$ nanotubes and $\mathrm{TiO}_{2}$ nanotubes with attached $\mathrm{Ag}$ nanoparticles in photocatalytic water splitting. Coaxial $\mathrm{TiO}_{2}-\mathrm{Ag}$ nanowires formed $\mathrm{H}_{2}$ at a rate of $\sim 1.23 \cdot 10^{-3} \pm 0.3 \cdot 10^{-3} \mathrm{~mol} / \mathrm{g} \cdot \mathrm{h}$ without deactivation for at least $6 \mathrm{~h}$.

\subsection{Introduction}

One-dimensional nanostructures, such as nanowires and nanotubes, have attracted increasing attention in the last years. The unique physical and chemical properties of these nanostructures make them promising building blocks for various kinds of future applications, such as nanosensors [1-3], cell trackers [4-6], and self-propelling nanomotors [7-9]. Because of their very high surface-to-volume ratio, some of the most interesting applications of nanowires and nanotubes are solar cells and photocatalytic water splitting [10-13]. The physical properties of most semiconductors demand the use of one-dimensional nanostructures, since the diffusion length of minority charge carriers in most semiconductors is of the order of $100 \mathrm{~nm}$, while the absorption depth near the band gap is of the order of $10 \mu \mathrm{m}$ [14-17]. In this respect, a maximum of solar light can be absorbed over the nanowire length, while the nanowire diameter is small enough for efficient electron and hole diffusion, thereby leading to high efficiency [18]. 
With a band gap of $3.0 \mathrm{~V}$, high chemical stability and low synthesis costs, $\mathrm{TiO}_{2}$ in the anatase phase is a very interesting material for efficient solar hydrogen formation [18-20]. $\mathrm{TiO}_{2}$ is therefore the most commonly used material for photocatalytic water splitting and solar cells [21-23]. $\mathrm{TiO}_{2}$ nanotubes are also often used for photocatalytic water splitting [24-30], although few authors present actual $\mathrm{H}_{2}$ formation rates [25, 28, 29]. Alternatively, $\mathrm{TiO}_{2}$ nanowires and nanotubes can also be used as micromotors, microfireworks or micropumps upon excitation by UV light [31], as catalyst for methanol (electro)oxidation [32, 33], or as anode material in Li-ion batteries [34-36]. The formation of a core-shell structure based on $\mathrm{TiO}_{2}$ nanotubes may also be advantageous for such applications.

$\mathrm{TiO}_{2}$ nanowires and nanotubes can be formed via several techniques, i.e. hydrothermal treatment [37], anodization of titanium foils [38-40], atomic layer deposition (ALD) [41, 42], modified sol-gel route [10, 43, 44], sol-gel electrophoresis [45, 46], electrochemical deposition [47, 48], and electrochemically induced sol-gel synthesis [49, 50]. As sol-gel electrophoresis and the modified sol-gel route provide nanowires or nanotubes consisting of smaller sol-gel particles, the resulting nanostructures are very brittle with rough surfaces, which decreases the mechanical stability of the formed nanowires. Although a large area of single crystalline $\mathrm{TiO}_{2}$ nanotubes with tuneable dimensions can be made by anodization of $\mathrm{Ti}$ foil, the main disadvantage of this technique is that the formed nanotubes do not contain a conductive back electrode, so that extra steps need to be applied before these nanotubes can be filled with a second material [51]. In contrast, the availability of a back electrode and the synthesis of smooth films or nanostructures makes the electrochemically induced sol-gel method a very promising technique for the synthesis of core-shell nanostructures with a $\mathrm{TiO}_{2}$ shell.

The electrochemically induced sol-gel method for the cathodic electrodeposition of titanium dioxide thin films was first introduced by Natarajan et al. [52] and was further improved by Karuppuchamy et al. $[53,54]$. This method involves dissolving titanium oxysulfate $\left(\mathrm{TiOSO}_{4}\right)$ powder in an aqueous solution of hydrogen peroxide $\left(\mathrm{H}_{2} \mathrm{O}_{2}\right)$, yielding a peroxotitanate complex $\left(\mathrm{Ti}_{(}\left(\mathrm{O}_{2}\right) \mathrm{SO}_{4}\right)$ (equation (5.1)):

$\mathrm{TiOSO}_{4}+\mathrm{H}_{2} \mathrm{O}_{2} \rightarrow \mathrm{Ti}\left(\mathrm{O}_{2}\right) \mathrm{SO}_{4}+\mathrm{H}_{2} \mathrm{O}$. 
At potentials more negative than $-0.9 \mathrm{~V}$ vs. $\mathrm{Ag} / \mathrm{AgCl}$, nitrate is reduced to form hydroxyl ions (equation (5.2)) [54], and consequently the $\mathrm{pH}$ in the vicinity of the electrode surface is increased [49]:

$\mathrm{NO}_{3}^{-}+\mathrm{H}_{2} \mathrm{O}+2 \mathrm{e}^{-} \rightarrow \mathrm{NO}_{2}^{-}+2 \mathrm{OH}^{-}$

This local increase in $\mathrm{pH}$ is necessary for the formation of a titanium hydroxide gel as shown in equation (5.3) [54]:

$\mathrm{Ti}\left(\mathrm{O}_{2}\right) \mathrm{SO}_{4}+2 \mathrm{OH}^{-}+(\mathrm{x}+1) \mathrm{H}_{2} \mathrm{O} \rightarrow \mathrm{TiO}(\mathrm{OH})_{2} \cdot x \mathrm{H}_{2} \mathrm{O}+\mathrm{H}_{2} \mathrm{O}_{2}+\mathrm{SO}_{4}^{2-}$.

According to differential thermal analysis data of Natarajan et al., water is removed from the gel during thermal annealing around $283{ }^{\circ} \mathrm{C}$ (equation (5.4)), resulting in an amorphous $\mathrm{TiO}_{2}$ phase [52]. When the temperature is increased above $365{ }^{\circ} \mathrm{C}$, crystallization into the anatase phase occurs $[52,55]$.

$\mathrm{TiO}(\mathrm{OH})_{2} \cdot x \mathrm{H}_{2} \mathrm{O} \rightarrow \mathrm{TiO}_{2}+(x+1) \mathrm{H}_{2} \mathrm{O}$.

By employing the electrochemically induced sol-gel method within the pores of an anodic aluminium oxide (AAO) template, nanowires and nanotubes can be formed. Nanowires were previously made using templates with pores of $50 \mathrm{~nm}$ diameter and smaller $[49,50]$. In the present study, AAO templates with a diameter of $200 \mathrm{~nm}$ were used, which resulted in nanotube formation. The mechanism of nanotube formation was previously described by Maas et al., and occurs by removal of water from the titanium hydroxide gel [56]. The first 6 steps in Figure 5.1 provide a schematic representation of $\mathrm{TiO}_{2}$ nanotube formation according to the above reactions. 


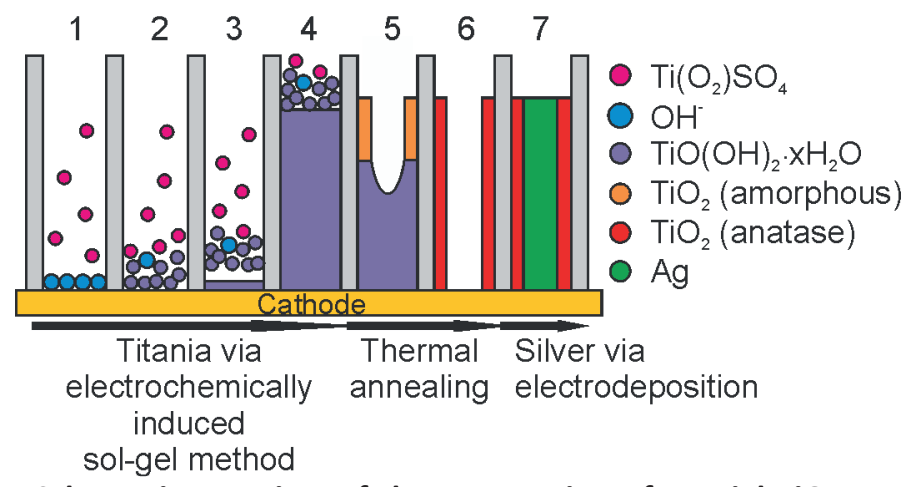

Figure 5.1: Schematic overview of the preparation of coaxial $\mathrm{TiO}_{2}-\mathrm{Ag}$ nanowires using the electrochemically induced sol-gel method: formation of $\mathrm{OH}^{-}$at the electrode (step 1, reaction (5.2)), reaction of $\mathrm{Ti}\left(\mathrm{O}_{2}\right) \mathrm{SO}_{4}$ with $\mathrm{OH}^{-}$to $\mathrm{TiO}(\mathrm{OH})_{2} \cdot \mathrm{xH}_{2} \mathrm{O}$ and filling of the template (step 2-4, reaction (5.3)), drying and thermal annealing of the titanium hydroxide gel to $\mathrm{TiO}_{2}$ (step 5-6, reaction (5.4)), and filling of the $\mathrm{TiO}_{2}$ nanotubes with $\mathrm{Ag}$ (step 7).

As mentioned above, an advantage of the electrochemically induced sol-gel method for $\mathrm{TiO}_{2}$ nanotube formation is the availability of a cathode at one end of the AAO membrane or template. This allows for the formation of coaxial nanowires by filling the $\mathrm{TiO}_{2}$ nanotubes in a subsequent deposition step with a second phase like silver (step 7 in Figure 5.1). By combining an $n$-type semiconductor like $\mathrm{TiO}_{2}$ with a noble metal, a Schottky barrier is formed when the work function of the metal is smaller than that of the $n$-type semiconductor, which diminishes electron-hole recombination [18]. This is schematically depicted in Figure 5.2. Upon illumination, electrons and holes are formed in the $\mathrm{TiO}_{2}$ shell layer (step 1). As the electrons are transferred to the silver core of the wires, the holes go to the surface of the $\mathrm{TiO}_{2}$ phase (steps 2), where they are known to react with water to form $\mathrm{H}^{+}$ions and $\mathrm{O}_{2}$ (steps 3 ). In the Ag phase, at the outer ends of the coaxial nanowire, electrons and protons can combine to form $\mathrm{H}_{2}$ (step 4) [18-20]. 
a.

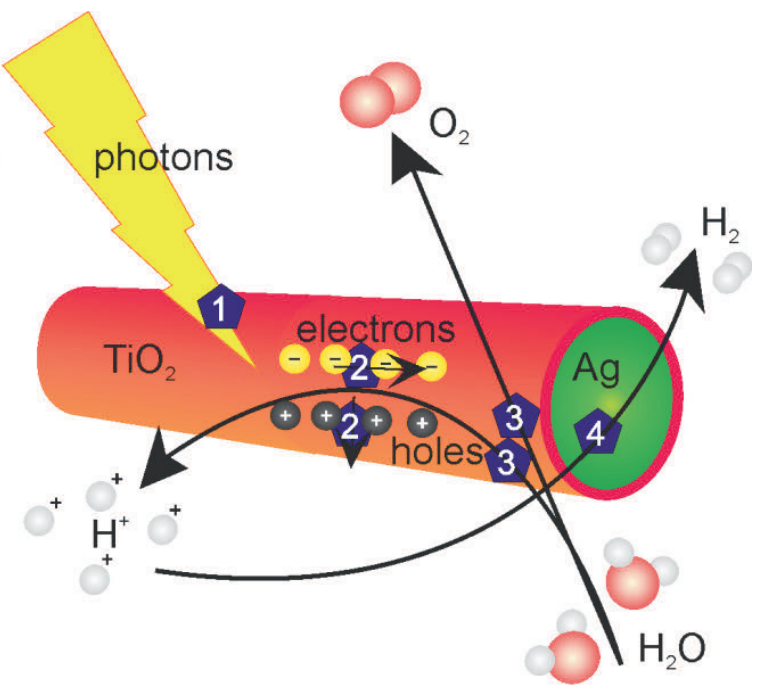

b.

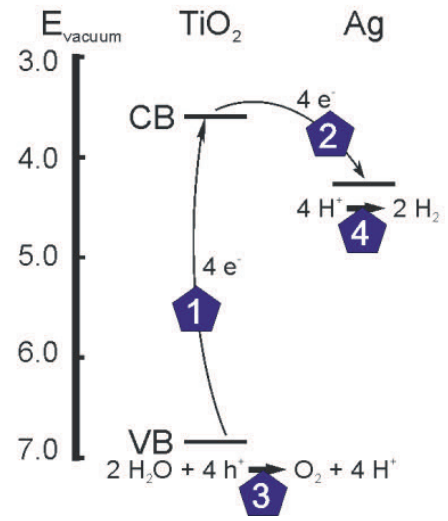

Figure 5.2: (a) Schematic representation and (b) band energy diagram of water splitting by coaxial $\mathrm{TiO}_{2}-\mathrm{Ag}$ nanowires in an alkaline solution: Formation of electrons and holes in the $\mathrm{TiO}_{2}$ phase (step 1), electron-hole separation at the $\mathrm{TiO}_{2}$ - $\mathrm{Ag}$ interface (steps 2 ), water oxidation at the $\mathrm{TiO}_{2}$ surface (steps 3 ) and $\mathrm{H}_{2}$ formation at the $\mathrm{Ag}$ surface (step 4).

In this study, we employed the electrochemically induced sol-gel method for the formation of $\mathrm{TiO}_{2}$ nanotubes and filled these nanotubes with a silver phase using electrodeposition. The photocatalytic activity of the coaxial $\mathrm{TiO}_{2}-\mathrm{Ag}$ nanowires in splitting water was investigated in an alkaline solution. Furthermore, the photocatalytic activity of the coaxial $\mathrm{TiO}_{2}-\mathrm{Ag}$ nanowires was compared with similar $\mathrm{TiO}_{2}$ nanostructures with/without $\mathrm{Ag}$ that were also prepared in this study, and with values reported in other studies. 


\subsection{Experimental details}

All chemicals were purchased from commercial sources and used without further purification. Titanium oxysulfate $\left(\mathrm{TiOSO}_{4}\right.$, synthesis grade), hydrogen peroxide $\left(\mathrm{H}_{2} \mathrm{O}_{2}, 35 \mathrm{wt} \%\right)$, boric acid $\left(\mathrm{H}_{3} \mathrm{BO}_{3}\right.$, purity $\left.99.97 \%\right)$, sodium hydroxide $(\mathrm{NaOH}$, purity $>98 \%$ ) and titanium(IV)isopropoxide $(99 \%)$ were purchased from Sigma-Aldrich. Silver nitrate $\left(\mathrm{AgNO}_{3}\right.$, purity $\left.>99 \%\right)$, nitric acid $\left(\mathrm{HNO}_{3}, 65 \%\right)$, potassium nitrate $\left(\mathrm{KNO}_{3}\right.$, purity $\left.>99 \%\right)$, chromium( $\mathrm{VI})$ oxide $\left(\mathrm{CrO}_{3}\right.$, purity $\left.99.5 \%\right)$ and phosphoric acid $\left(\mathrm{H}_{3} \mathrm{PO}_{4},>85 \%\right)$ were purchased from Acros Organics. Oxalic acid $\left(\mathrm{C}_{2} \mathrm{H}_{2} \mathrm{O}_{4}\right.$, p.a. grade) was purchased from Merck Millipore. Silver sulfate $\left(\mathrm{Ag}_{2} \mathrm{SO}_{4}\right.$, purity $\left.99.999 \%\right)$, diammoniumcitrate (purity $>99 \%$ ) and potassium thiocyanide (KSCN, purity $98 \%$ ) were purchased from Alfa Aesar. Milli-Q water with a resistivity of $18.2 \mathrm{M} \Omega \cdot \mathrm{cm}$ was used in all experiments.

Anodized aluminium oxide (AAO) membranes and templates with a pore diameter of $200 \mathrm{~nm}$ were either purchased commercially (Anopore ${ }^{\circledR}$, Whatman Inc.), or custom-made. The commercial AAO membranes contained open pores on both sides and are therefore referred to as "membrane" in the text. A back electrode of AuPd was sputtered on one side of the commercial membranes as cathode using a tabletop sputterer (SC7640, Quorum Technologies). Prior to deposition, the backside of the AuPd electrode was isolated to ensure exclusive deposition inside the pores of the membrane and avoid deposition on the external surface of the back electrode.

The custom-made AAO templates (referred to as "template") contained self-ordered arrays of aligned cylindrical pores with narrow diameter distribution and is closed on one side. Self-ordered AAO was prepared by two-step anodization following procedures introduced by Masuda et al. [57]. In the first step, an Al chip (Goodfellow, purity > $99.999 \%$ ) was anodized at $195 \mathrm{~V}$ for $10 \mathrm{~h}$ using $1 \mathrm{wt} \% \mathrm{H}_{3} \mathrm{PO}_{3}$ cooled to $0-1{ }^{\circ} \mathrm{C}$ as electrolyte solution. The resulting porous alumina layer was selectively removed by etching with an aqueous solution of $0.18 \mathrm{M} \mathrm{CrO}_{3}$ and $0.72 \mathrm{M} \mathrm{H}_{3} \mathrm{PO}_{4}$. As a result, patterned $\mathrm{Al}$ substrates with hexagonal arrays of indentations were obtained. In the second step, hierarchical pores consisting of macroporous segments branching into dendritic mesopores were obtained by adapting a method introduced by Nielsch et al. [58]. Using 1 wt\% $\mathrm{H}_{3} \mathrm{PO}_{4}$ at $0-1{ }^{\circ} \mathrm{C}$ as 
electrolyte solution, the anodization voltage $U(t)$ was directly reduced from $195 \mathrm{~V}$ to $80 \mathrm{~V}$ according to

$\mathrm{U}(t)=U_{0} e^{-t / \tau}$,

where $U_{0}$ is the start voltage of $195 \mathrm{~V}, \tau$ is a constant, i.e. $191.7 \mathrm{~min}$ in this case, and $t$ is the anodization time (171 min to reach a voltage of $80 \mathrm{~V}$ ). Then, the electrolyte was replaced by an aqueous solution of $0.3 \mathrm{M} \mathrm{C}_{2} \mathrm{H}_{2} \mathrm{O}_{4}$, and the temperature was adjusted to $10{ }^{\circ} \mathrm{C}$. Following the profile of equation (5.5) with $U_{0}=80 \mathrm{~V}$ and $\tau=14.0 \mathrm{~min}$, the anodization voltage was further reduced to a target value of $0.01 \mathrm{~V}$, which was reached after 125 min. Subsequently, the AAO layer was rinsed with deionized water. Prior to electrodeposition, the aluminium disks were isolated with nail varnish to ensure exclusive deposition inside the pores of these AAO templates.

The AAO membranes and templates were used as working electrode in a three electrode setup, with a Pt sheet (Metrohm Autolab) as counter electrode and $\mathrm{Ag} / \mathrm{AgCl}$ in $3 \mathrm{M} \mathrm{KCl}$ (Metrohm Autolab) as reference electrode. All potentials are given with respect to the reference electrode. These electrodes were connected to an Autolab PGSTAT 128N potentiostat. $\mathrm{TiO}_{2}$ nanotubes were formed from an electrolyte containing $0.02 \mathrm{M} \mathrm{TiOSO}_{4}$, $0.03 \mathrm{M} \mathrm{H}_{2} \mathrm{O}_{2}, 0.05 \mathrm{M} \mathrm{HNO}_{3}$ and $0.25 \mathrm{M} \mathrm{KNO}_{3}$ with a $\mathrm{pH}$ of 1.4. Deposition occurred at $-1.00 \mathrm{~V}$ for $6 \mathrm{~h}$. After deposition, the gel was either dried overnight at $100{ }^{\circ} \mathrm{C}$ or annealed for $2 \mathrm{~h}$ at $650^{\circ} \mathrm{C}$ in a tube furnace. $\mathrm{Ag}$ was electrodeposited for $15 \mathrm{~min}$ at $+0.10 \mathrm{~V}$ in an aqueous electrolyte containing $0.20 \mathrm{M} \mathrm{AgNO}_{3}$ and $0.10 \mathrm{M} \mathrm{H}_{3} \mathrm{BO}_{3}$ with $\mathrm{pH}$ adjusted to 1.5 using $\mathrm{HNO}_{3}$. In the final steps, the nanowires or nanotubes were collected by dissolving the AAO membranes or templates in an aqueous solution of $1 \mathrm{M} \mathrm{NaOH}$ or in an aqueous solution of $0.18 \mathrm{M} \mathrm{CrO}_{3}$ and $0.72 \mathrm{M} \mathrm{H}_{3} \mathrm{PO}_{4}$, respectively, followed by detachment from the back electrode by gentle swirling. In order to get rid of the $\mathrm{NaOH}$ or $\mathrm{CrO}_{3}$ in the nanowire/nanotube solution, the solution was washed at least 5 times with water using a Hermle Z36HK centrifuge at 10,000 rpm for $5 \mathrm{~min}$. 
The $\mathrm{TiO}_{2}$ nanotubes made by Atomic Layer Deposition (ALD) were also prepared inside custom-made AAO membranes with the same dimensions as the templates used for $\mathrm{TiO}_{2}$ nanotube formation by the electrochemically induced sol-gel method. Amorphous $\mathrm{TiO}_{2}$ was deposited at $120{ }^{\circ} \mathrm{C}$ using titanium(IV)isopropoxide preheated at $70{ }^{\circ} \mathrm{C}$ as metal containing reactant and water vapor as oxygen source. The porous membranes were coated using the exposure-mode sequence due to the high aspect ratio of these nanostructures, where a full ALD cycle consisted of $2 \mathrm{~s}$ pulse, $40 \mathrm{~s}$ exposure and $60 \mathrm{~s}$ purging for the titanium precursor, followed by $0.5 \mathrm{~s}$ pulse, $40 \mathrm{~s}$ exposure, and $60 \mathrm{~s}$ purging for the water vapor. Dried Ar was used as carrier and purging gas and the process was carried out in a commercial ALD reactor SAVANNAH 100 (Cambridge NanoTech Inc., USA). After thermal annealing for $3 \mathrm{~h}$ at $400{ }^{\circ} \mathrm{C}$ and Au sputtering, $\mathrm{Ag}$ was electrodeposited at $-1.2 \mathrm{~V}$ in a two-electrode setup using $\mathrm{Pt}$ as the counter electrode from an aqueous electrolyte containing $0.027 \mathrm{M} \mathrm{Ag}_{2} \mathrm{SO}_{4}, 0.88 \mathrm{M}$ diammoniumcitrate and $1.08 \mathrm{M} \mathrm{KSCN}$ at $\mathrm{pH}$ 4.5. The procedures used for dissolution of the AAO membrane and washing were the same as above.

Samples were measured with X-ray powder diffraction (XRD) to confirm the formation of crystalline $\mathrm{TiO}_{2}$ phases in the membranes using a PANalytical $X^{\prime}$ Pert Pro (PANalytical B.V., Almelo, The Netherlands) instrument. Samples were measured from $2 \theta=20-50^{\circ}$, with step sizes of $0.026^{\circ}$ and $600 \mathrm{~s}$ per step using a PIXcel 1D scanning line detector. The spectra were further analyzed using the X'Pert Highscore Plus software package (version 3.0e). Scanning Electron Microscopy (SEM) images were taken using a Zeiss HR-LEO 1550 FEG SEM or a Zeiss Merlin HRSEM. Transmission Electron Microscopy (TEM) images and Electron Energy Loss Spectroscopy (EELS) maps were taken with an Analytical TEM from FEl Instruments.

The photocatalytic activity of $\mathrm{TiO}_{2}$ nanotubes with and without $\mathrm{Ag}$ core was investigated by water splitting experiments in a custom-made setup consisting of 8 top-illuminated reactors with a volume of $36.4 \mathrm{~mL}$ each, connected to a Compact gas chromatograph (GC) (Interscience BV) equipped with a thermal conductivity detector (TCD). 5-14 mg of nanotubes/wires (1 completely filled AAO template with a diameter of $\sim 3.5 \mathrm{~cm}$ ) was dispersed in $15 \mathrm{~mL}$ of a $1 \mathrm{M} \mathrm{NaOH}$ stock solution $(\mathrm{pH} 13)$ that was bubbled with Ar gas for at least $30 \mathrm{~min}$ to remove a large part of the $\mathrm{O}_{2}$ from the solution. Then the reactors were evacuated to $3 \mathrm{mbar}$ and subsequently filled with Ar to remove all air from the head space in the reactors. After three evacuations, a 120 Watt high pressure Mercury lamp 
(Dr. Gröbel UV-Elektronic GmbG) was turned on, of which the emission was divided over 12 optical fibers. During illumination, the formed $\mathrm{H}_{2}$ was measured subsequently in each reactor. In a standard procedure, the composition in each reactor was measured every 15 min for 13 times. In a long-term measurement, the formed $\mathrm{H}_{2}$ gas was measured 5 times using a measurement interval of $1.5 \mathrm{~h}$.

\subsection{Results and discussion}

Since it was found that annealing within a template resulted in crystallization at a higher temperature than in films, we investigated the crystallinity of different samples annealed at variable temperatures (Figure 5.3). The figure shows that $\mathrm{TiO}_{2}$ within an AAO template crystallized into a mixture of anatase, rutile and brookite between $525{ }^{\circ} \mathrm{C}$ and $550{ }^{\circ} \mathrm{C}$, while unconstrained $\mathrm{TiO}_{2}$ gel made via the same procedure crystallized below $400{ }^{\circ} \mathrm{C}$ (data not shown, see e.g. Natarajan et al.) [52]. Also for $\mathrm{TiO}_{2}$ powder made via a different sol-gel process, it is known that $\mathrm{TiO}_{2}$ crystallizes below $400{ }^{\circ} \mathrm{C}$ [59]. A possible explanation for the large difference found in crystallization temperatures between $\mathrm{TiO}_{2}$ powder and the nanotubes formed in this study may be clamping of the $\mathrm{TiO}_{2}$ phase on the sidewalls of the AAO template. Clamping was also previously found to retard the crystallization of $\mathrm{BaTiO}_{3}$ and $\mathrm{SrRuO}_{3}$ films [60]. 


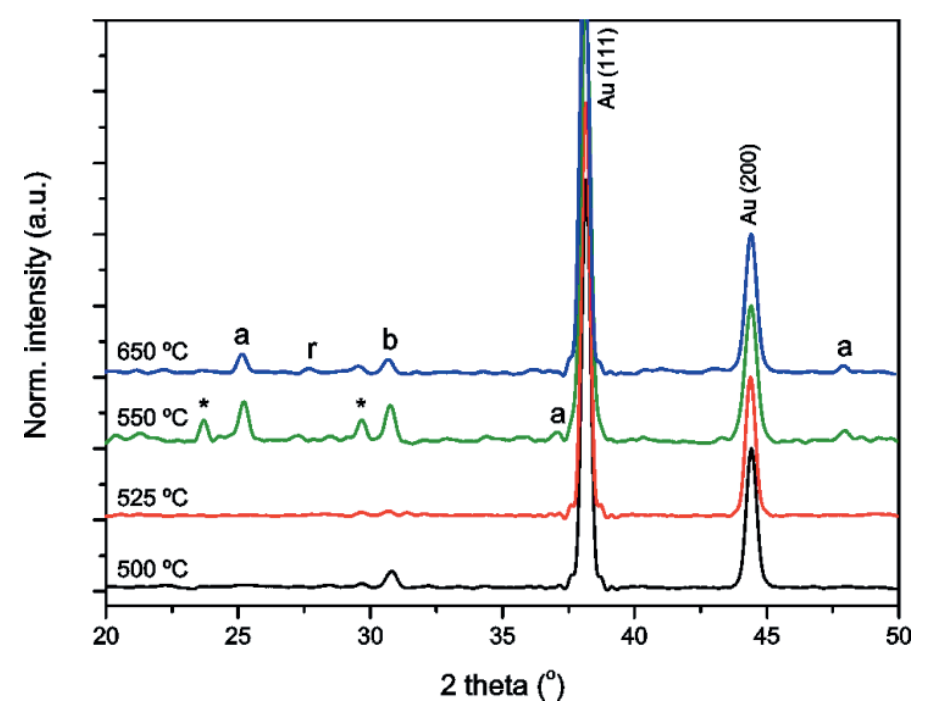

Figure 5.3: XRD patterns of $\mathrm{TiO}_{2}$ nanotubes annealed for $2 \mathrm{~h}$ at $500{ }^{\circ} \mathrm{C}$ (black line), $525^{\circ} \mathrm{C}$ (red line), $550{ }^{\circ} \mathrm{C}$ (green line), and $650{ }^{\circ} \mathrm{C}$ (blue line), with the tubes still inside an AAO membrane; Diffraction peaks were assigned to Au (PDF \# 00-004-0784), anatase $\mathrm{TiO}_{2}$ (a, PDF \# 00-021-1272), rutile $\mathrm{TiO}_{2}$ (r, PDF \# 00-021-1276) and brookite $\mathrm{TiO}_{2}$ (b, PDF \# 00-029-1360); An unknown impurity phase is denoted with an asterisk (*).

After annealing the titania gel inside an AAO membrane for $2 \mathrm{~h}$ at $650{ }^{\circ} \mathrm{C}$, the $\mathrm{TiO}_{2}$ gel was crystallized into a polycrystalline mixture of the anatase, rutile and brookite polymorphs of $\mathrm{TiO}_{2}$, with no preferred orientation. It is noted that the presence of all three polymorphs of $\mathrm{TiO}_{2}$ is known to have a positive influence on the photocatalytic activity as previously discussed in several other studies $[61,62]$. After annealing at $550^{\circ} \mathrm{C}$, the formation of an unidentified impurity phase was observed, which is denoted with an asterisk. For the $\mathrm{TiO}_{2}$ nanotubes, crystallite sizes of approximately 42 and $45 \mathrm{~nm}$ were found when annealed at 550 and $650{ }^{\circ} \mathrm{C}$, respectively, showing negligible crystallite growth. For $\mathrm{TiO}_{2}$ films made via the same method we observed exponential crystallite growth with sizes of 19 and $28 \mathrm{~nm}$ when annealed at 550 and $650{ }^{\circ} \mathrm{C}$, respectively. 
The cross section of a membrane containing $\mathrm{TiO}_{2}$ nanotubes after annealing at $650{ }^{\circ} \mathrm{C}$ shows a gradual decrease in thickness of the $\mathrm{TiO}_{2}$ coating on the AAO pore walls from $\sim 55 \mathrm{~nm}$ at the bottom of the membrane (Figure 5.4b), which is the cathode side, to $10 \mathrm{~nm}$ at the top of the membrane (Figure 5.4a). The thickness gradient can be explained by the formation of a thicker gel near the electrode as $\mathrm{OH}^{-}$is formed here. To put the thickness of the $\mathrm{TiO}_{2}$ phase into perspective of the proposed application in solar water splitting, a wall thickness less than $20 \mathrm{~nm}$ would provide efficient charge carrier separation as the minority carrier diffusion length in $\mathrm{TiO}_{2}$ is approximately $20 \mathrm{~nm}$ [63]. This means that the most efficient charge carrier separation takes place only in the upper part of these nanotubes. On the other hand, the chance that a photon is absorbed by the material is higher when the titania wall is thicker. It is expected that a lower concentration of $\mathrm{KNO}_{3}$ in the electrolyte solution can provide $\mathrm{TiO}_{2}$ nanotubes with thinner walls, but a trade-off has to be made between carrier diffusion length, mechanical stability of the nanotubes and degree of photon absorption. After dissolving the membrane, a droplet of nanotube solution was placed on a silicon wafer for visualization with SEM. These nanotubes appear to be smooth at first sight, but a closer look reveals that they are composed of very small grains (Figure 5.4c). 

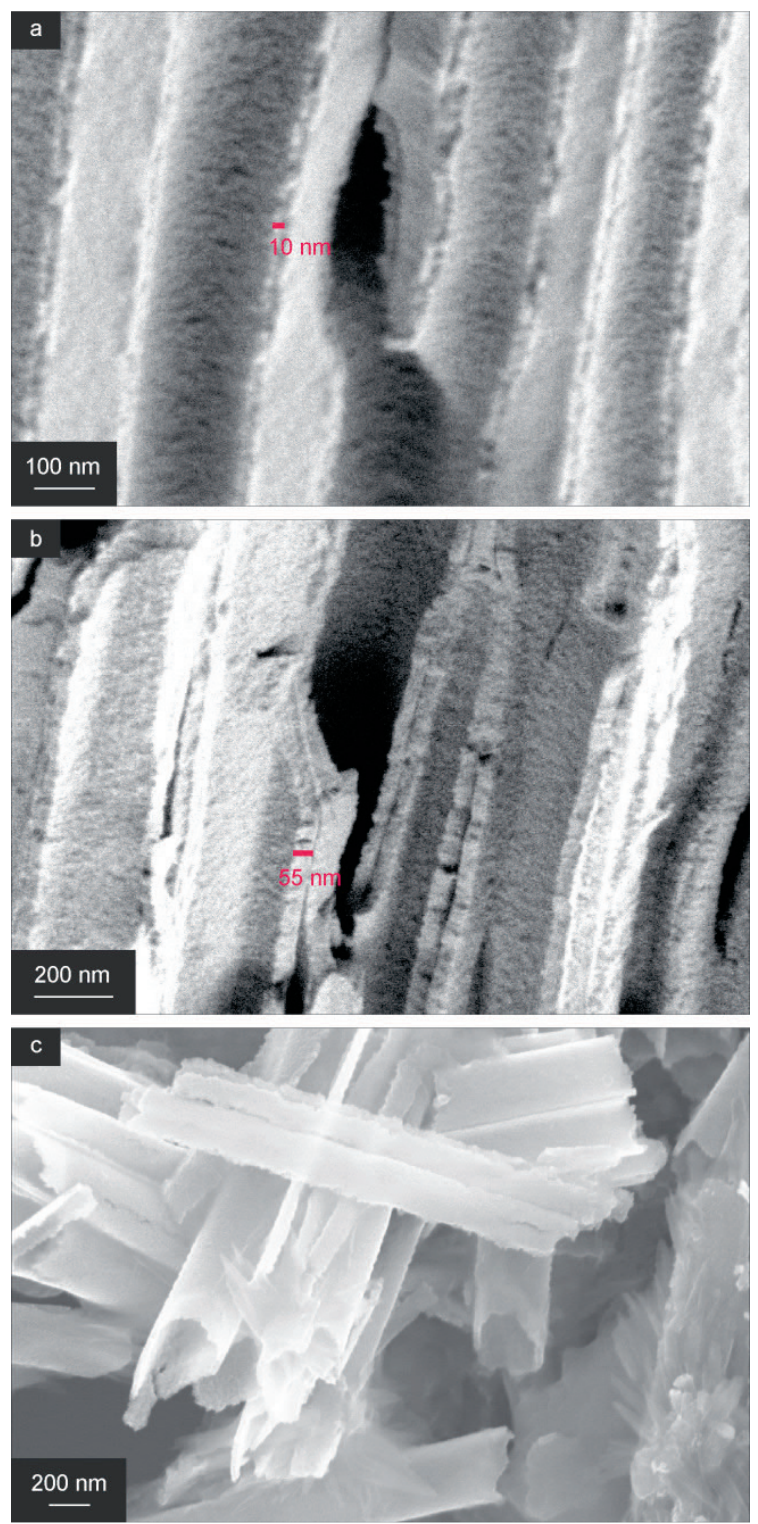

Figure 5.4: Cross section SEM images of $\mathrm{TiO}_{2}$ nanotubes inside the membrane (a) at the top of the membrane, (b) at the bottom of the membrane, and (c) $\mathrm{TiO}_{2}$ nanotubes after dissolving the membrane.

After formation of a titania gel inside the AAO membrane, a fraction of the samples was dried overnight at $100{ }^{\circ} \mathrm{C}$ to remove water, while the other fraction was annealed for $2 \mathrm{~h}$ at $650{ }^{\circ} \mathrm{C}$ to form crystalline nanotubes. When 
silver was deposited inside a membrane after drying at $100{ }^{\circ} \mathrm{C}$, $\mathrm{TiO}_{2}$ nanotubes containing isolated $\mathrm{Ag}$ nanoparticles $\left(\mathrm{TiO}_{2} / \mathrm{Ag}\right.$ nanotubes) were formed after $\mathrm{Ag}$ electrodeposition and subsequent annealing (Figure 5.5a). The reason for this is that the $\mathrm{Ag}^{+}$ions could penetrate the gel, because the titania phase was not completely dense after exposure to $100{ }^{\circ} \mathrm{C}$. As a result, Ag nuclei formed where such ions combined with an electron. During subsequent heat treatment at $650{ }^{\circ} \mathrm{C}$, these $\mathrm{Ag}$ nanoparticles were transported to the pore walls along with the collapse of the titania gel. However, when $\mathrm{Ag}$ was electrodeposited after high temperature annealing of the $\mathrm{TiO}_{2}$ gel at $650{ }^{\circ} \mathrm{C}$, solid $\mathrm{TiO}_{2}$ nanotubes formed first, and dense silver nanowires were deposited inside these tubes. This resulted in the formation of coaxial $\mathrm{TiO}_{2}-\mathrm{Ag}$ nanowires (Figure $5.5 \mathrm{~b}$ and Figure 5.6).
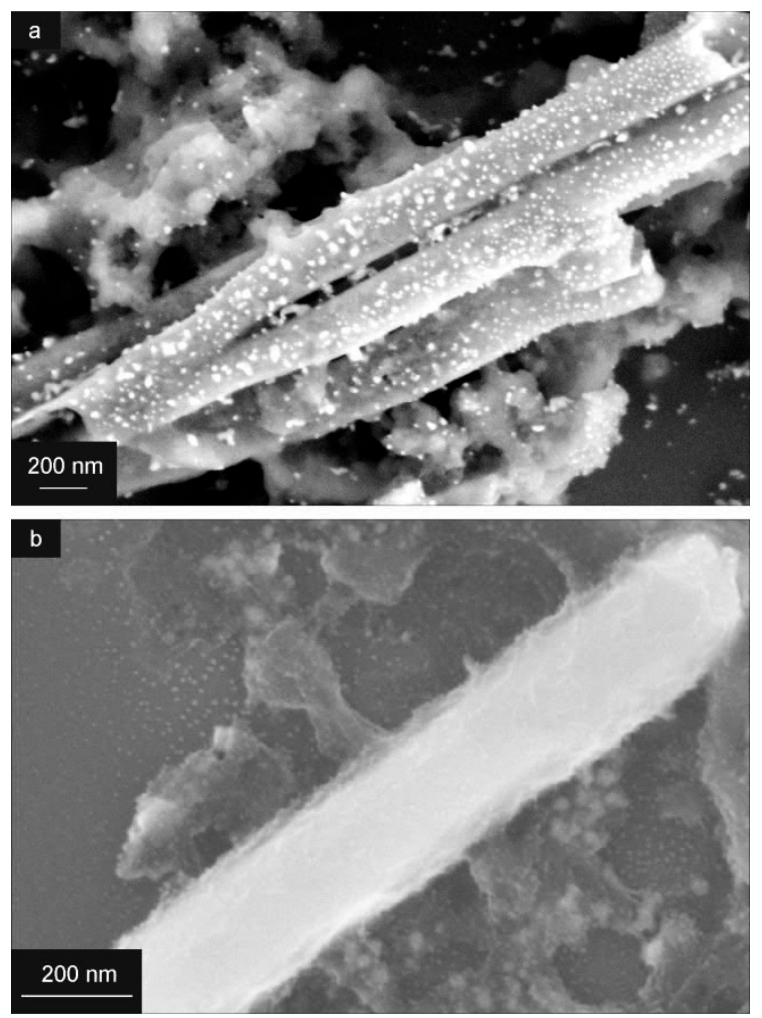

Figure 5.5: SEM images of (a) $\mathrm{TiO}_{2} / \mathrm{Ag}$ nanotubes from two step electrodeposition process with intermediate $\mathrm{TiO}_{2}$ gel drying at $100{ }^{\circ} \mathrm{C}$, and (b) a coaxial $\mathrm{TiO}_{2}-\mathrm{Ag}$ nanowire from two step electrodeposition process with intermediate $\mathrm{TiO}_{2}$ tube solidification at $650^{\circ} \mathrm{C}$. See main text for details. 

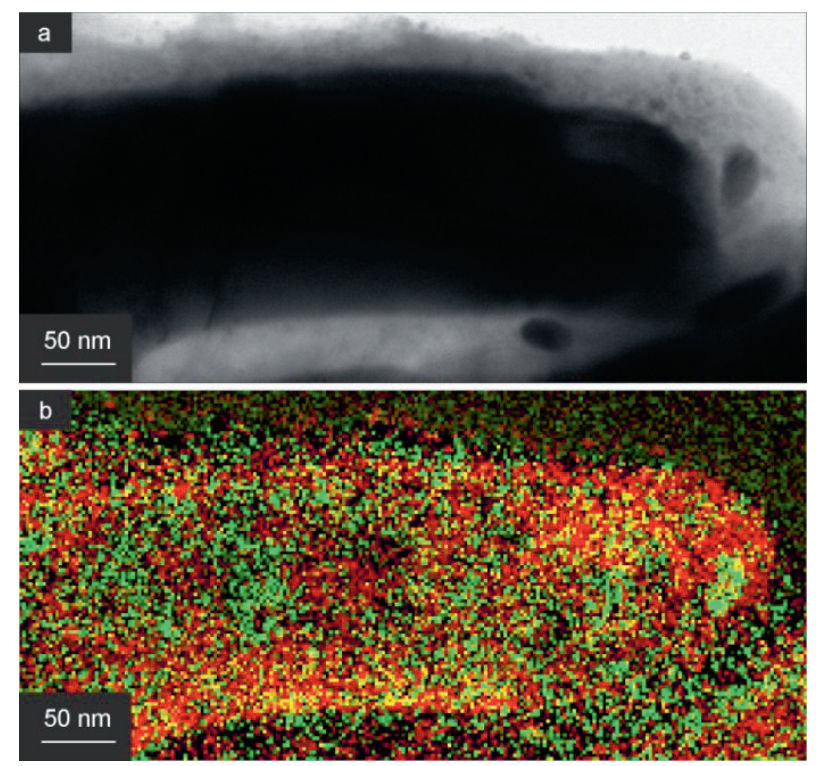

Figure 5.6: (a) TEM image and (b) EELS TEM map of a $\mathrm{TiO}_{2}$ nanotube (red) filled with Ag (green).

A TEM image of a $\mathrm{TiO}_{2}$ nanotube with $\mathrm{Ag}$ core is shown in Figure 5.6a. Especially the Electron Energy Loss Spectroscopy (EELS) TEM map in Figure $5.6 \mathrm{~b}$ clearly shows the architecture of the core-shell structure, with a higher concentration of $\mathrm{Ti}(\mathrm{red})$ at the outside of the coaxial nanowire, and a higher concentration of $\mathrm{Ag}$ (green) at the interior of the tube.

The photocatalytic activities in photocatalytic water splitting of coaxial $\mathrm{TiO}_{2}-\mathrm{Ag}$ nanowires, empty $\mathrm{TiO}_{2}$ nanotubes and $\mathrm{TiO}_{2} / \mathrm{Ag}$ nanotubes with isolated $\mathrm{Ag}$ nanoparticles were compared in Figure $5.7 \mathrm{a}$ after $3.5 \mathrm{~h}$ of irradiation. The coaxial $\mathrm{TiO}_{2}-\mathrm{Ag}$ nanowires formed significantly more $\mathrm{H}_{2}$ than the $\mathrm{TiO}_{2}$ nanotubes and the $\mathrm{TiO}_{2} / \mathrm{Ag}$ nanotubes. $\mathrm{H}_{2}$ formation was absent in the reference reactor containing aqueous $1 \mathrm{M} \mathrm{NaOH}$ solution. Only the intensity of the $\mathrm{H}_{2}$ signals from the coaxial $\mathrm{TiO}_{2}-\mathrm{Ag}$ nanowires was sufficient for automatic integration, so for this system a long-term measurement was performed (Figure 5.7b). Continuous $\mathrm{H}_{2}$ formation was observed for a period of $6 \mathrm{~h}$ at a rate of $6.2 \pm 1.5 \cdot 10^{-6} \mathrm{~mol} / \mathrm{h}$, after which the reaction was terminated. 

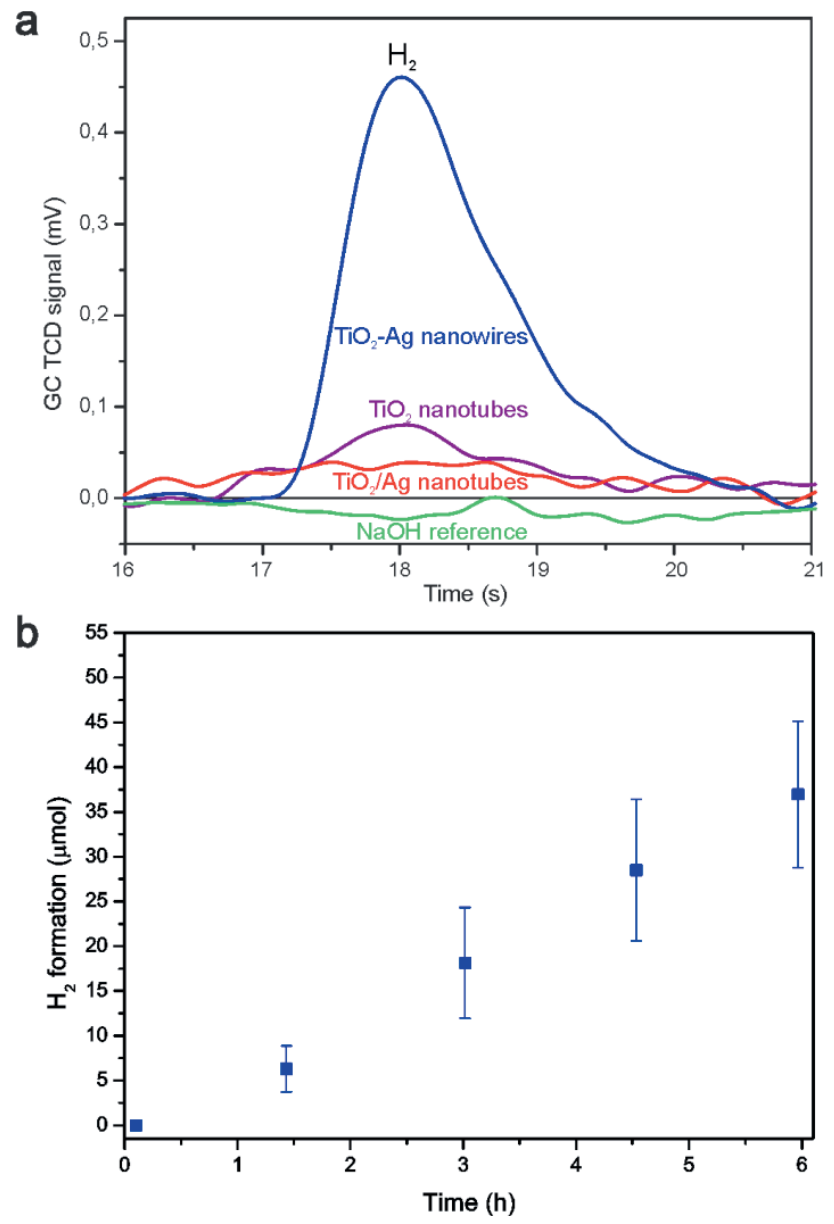

Figure 5.7: (a) GC TCD peaks showing $\mathrm{H}_{2}$ formation from $\mathrm{TiO}_{2}$ nanotubes (purple line), $\mathrm{TiO}_{2} / \mathrm{Ag}$ nanotubes (red line), $\mathrm{TiO}_{2}-\mathrm{Ag}$ nanowires (blue line) and $\mathrm{NaOH}$ baseline (green line). (b) Moles of $\mathrm{H}_{2}$ formed from coaxial $\mathrm{TiO}_{2}-\mathrm{Ag}$ nanowires during $6 \mathrm{~h}$ measurement in $1 \mathrm{M} \mathrm{NaOH}$.

Several possible explanations can be given for the higher $\mathrm{H}_{2}$ formation rate by the coaxial $\mathrm{TiO}_{2}-\mathrm{Ag}$ nanowires compared to the $\mathrm{TiO}_{2}$ nanotubes: (1) The availability of an $\mathrm{H}_{2}$ evolution catalyst such as $\mathrm{Ag}$, which decreases the chance for electron-hole recombination, (2) the use of the metallic Ag core as a mirror to reflect photons back into the $\mathrm{TiO}_{2}$ shell, which could approximately double the number of photons captured by the photocatalyst, and/or (3) the use of the Ag core for enhancement of the light absorption due to localized surface plasmon resonance of the $\mathrm{Ag}$ nanowire. 
Comparing the $\mathrm{TiO}_{2} / \mathrm{Ag}$ nanotubes with the coaxial nanowires, several possible explanations can be given for the higher $\mathrm{H}_{2}$ formation rate of the latter: (1) The availability of a larger amount of $\mathrm{Ag}$ catalyst with an increased interface between the photocatalyst and $\mathrm{H}_{2}$ evolution catalyst, which shortens the electron diffusion length and decreases the chance for electron-hole recombination in the coaxial nanowires, and/or (2) since most of the $\mathrm{Ag}$ particles are located at the outside of the $\mathrm{TiO}_{2}$ nanotubes, these particles may prevent some of the photons from reaching the $\mathrm{TiO}_{2}$ phase which decreases the efficiency of this system. It is however unlikely that the second possibility alone can explain the large difference.

For comparison with other data from literature, the observed $\mathrm{H}_{2}$ formation rate was corrected for either the weight of nanowires that was put in solution or the initial surface area of the template, resulting in an $\mathrm{H}_{2}$ formation rate of $1.2 \cdot 10^{-3} \pm 0.3 \cdot 10^{-3} \mathrm{~mol} / \mathrm{g} \cdot \mathrm{h}$ and $0.18 \cdot 10^{-6} \pm 0.04 \cdot 10^{-6}$ $\mathrm{mol} / \mathrm{cm}^{2} \cdot \mathrm{h}$, respectively. As can be seen from Table 5.1, this was higher than what we measured previously using segmented $\mathrm{ZnO} / \mathrm{Ag}$ nanowires, where $\mathrm{H}_{2}$ formation at a rate of $6.9 \cdot 10^{-6} \mathrm{~mol} / \mathrm{g} \cdot \mathrm{h}$ was observed [13]. Especially the increased surface area between the photocatalytic oxide phase and the $\mathrm{H}_{2}$ evolution catalyst, and the shorter diffusion length for electrons to cross the oxide/metal junction are likely explanations for the difference of $\sim 3$ orders of magnitude. Obviously, the use of different photocatalytic materials and the fact that methanol was used as hole scavenger by the $\mathrm{ZnO} \mathrm{Ag}$ nanowires also influence the efficiency. 
Table 5.1: Comparison of $\mathrm{H}_{2}$ formation from different nanowire and nanotube systems.

\begin{tabular}{|c|c|c|c|c|c|c|}
\hline $\begin{array}{l}\text { Nanowire/ } \\
\text { tube system }\end{array}$ & Reference & $\begin{array}{l}\mathrm{H}_{2} \\
\text { formation } \\
\mathrm{mol} / \mathrm{g} \cdot \mathrm{h}\end{array}$ & $\begin{array}{l}\mathrm{H}_{2} \\
\text { formation } \\
\mathrm{mol} / \mathrm{cm}^{2} \cdot \mathrm{h}\end{array}$ & $\begin{array}{l}\text { Dimensions } \\
\text { diameter } \\
\text { (TiO }_{2} \\
\text { thickness) } \\
\text { x length }\end{array}$ & Electrolyte & $\begin{array}{l}\text { Light } \\
\text { source }\end{array}$ \\
\hline $\begin{array}{l}\text { Coaxial } \mathrm{TiO}_{2}-\mathrm{Ag} \\
\text { nanowires }\end{array}$ & This work & $1.2 \cdot 10^{-3}$ & $0.18 \cdot 10^{-6}$ & $\begin{array}{l}200 \mathrm{~nm} \\
(10-50 \mathrm{~nm}) \\
\times 40 \mu \mathrm{m}\end{array}$ & $\begin{array}{l}1.0 \mathrm{M} \\
\mathrm{NaOH}\end{array}$ & $\begin{array}{l}10 \mathrm{~W} \mathrm{Hg} \\
\text { lamp }\end{array}$ \\
\hline $\begin{array}{l}\text { Coaxial } \mathrm{TiO}_{2}-\mathrm{Ag} \\
\text { nanowires by } \\
\text { ALD }\end{array}$ & This work & $0.26 \cdot 10^{-3}$ & & $\begin{array}{l}175 \mathrm{~nm} \\
(20 \mathrm{~nm}) \\
\times 8 \mu \mathrm{m}\end{array}$ & $\begin{array}{l}1.0 \mathrm{M} \\
\mathrm{NaOH}\end{array}$ & $\begin{array}{l}10 \text { W Hg } \\
\text { lamp }\end{array}$ \\
\hline $\begin{array}{l}\text { Segmented } \\
\mathrm{Ag} \mid \mathrm{ZnO} \\
\text { nanowires }\end{array}$ & {$[13]$} & $6.9 \cdot 10^{-6}$ & & $\begin{array}{l}200 \mathrm{~nm} \\
\times 6 \mu \mathrm{m}\end{array}$ & $\begin{array}{l}4: 1 \mathrm{v} / \mathrm{v} \\
\mathrm{MeOH} / \mathrm{H}_{2} \mathrm{O}\end{array}$ & $\begin{array}{l}60 \mathrm{~W} \mathrm{Hg} \\
\text { lamp }\end{array}$ \\
\hline $\begin{array}{l}\text { Anodized } \mathrm{TiO}_{2} \\
\text { with Pt mesh } \\
\text { counter } \\
\text { electrode }\end{array}$ & {$[25]$} & $2.83 \cdot 10^{-3}$ & & $\begin{array}{l}60 \mathrm{~nm} \\
(10 \mathrm{~nm}) \\
\times 1.5 \mu \mathrm{m}\end{array}$ & $\begin{array}{l}0.01 \mathrm{M} \\
\mathrm{KOH} \\
1.0 \mathrm{mM} \mathrm{KI}\end{array}$ & $\begin{array}{l}400 \mathrm{~W} \mathrm{Hg} \\
\text { lamp }\end{array}$ \\
\hline $\begin{array}{l}\text { Anodized } \mathrm{TiO}_{2} \\
\text { with Pt counter } \\
\text { electrode in } \\
\text { second } \\
\text { compartment }\end{array}$ & [29] & & $97 \cdot 10^{-6}$ & $\begin{array}{l}75 \mathrm{~nm} \\
(20-70 \mathrm{~nm}) \\
\times 6 \mu \mathrm{m}\end{array}$ & $1.0 \mathrm{M} \mathrm{KOH}$ & $\begin{array}{l}350 \mathrm{~W} \text { Xe } \\
\text { lamp }\end{array}$ \\
\hline $\begin{array}{l}\text { Anodized } \mathrm{TiO}_{2} \\
\text { containing } \\
\text { evaporated } \mathrm{Pt}\end{array}$ & {$[28]$} & & $14 \cdot 10^{-6}$ & $\begin{array}{l}150 \mathrm{~nm} \\
(30 \mathrm{~nm}) \\
\times 650 \mathrm{~nm}\end{array}$ & $\begin{array}{l}0.01 \mathrm{M} \\
\mathrm{KOH} \\
1.0 \mathrm{mM} \mathrm{KI}\end{array}$ & $\begin{array}{l}400 \text { W } \\
\text { metal } \\
\text { hydride } \\
\text { lamp }\end{array}$ \\
\hline
\end{tabular}

We also compared the $\mathrm{H}_{2}$ formation rate from the coaxial $\mathrm{TiO}_{2}-\mathrm{Ag}$ nanowires with an alternative coaxial $\mathrm{TiO}_{2}-\mathrm{Ag}$ nanowire system in which the $\mathrm{TiO}_{2}$ phase was prepared by Atomic Layer Deposition (ALD), and the Ag phase by electrodeposition. An SEM image of $\mathrm{TiO}_{2}$ nanotubes made by ALD is shown in Figure 5.8. Compared to the SEM image in Figure 5.4c, the nanotubes made by both techniques have approximately the same dimensions, but the nanotubes made by ALD appear much smoother. It was confirmed by XRD that the $\mathrm{TiO}_{2}$ nanotubes made by ALD are also polycrystalline without preferred orientation, the difference being that they are composed of large anatase crystallites with a size of $250-300 \mathrm{~nm}$ as shown in ref. [64]. Using the same setup for photocatalytic water splitting, we found $\mathrm{a} \mathrm{H}_{2}$ formation rate of $0.26 \cdot 10^{-3} \mathrm{~mol} / \mathrm{g} \cdot \mathrm{h}$ for the ALD-based system, which is $\sim 4.7$ times lower than the rate found for the 
electrochemically deposited $\mathrm{TiO}_{2}-\mathrm{Ag}$ system and also lower than the $\mathrm{TiO}_{2}$ nanotubes without $\mathrm{Ag}$. Since the $\mathrm{TiO}_{2}$ nanotubes deposited by ALD were polycrystalline anatase with a larger crystallite size, it was expected $a$ priori that the photocatalytic activity of these nanowires would be higher, since the concentration of grain boundaries that can induce electron-hole recombination is lower. On the other hand, it is known that photocatalytic water splitting is more efficient on specific facets, so when these facets are not exposed to the solution this will lead to a lower $\mathrm{H}_{2}$ evolution rate. Of course, the different $\mathrm{TiO}_{2}$ polymorphs that were observed in both systems, purely anatase for the ALD-based system vs. a mixture of anatase, rutile and brookite for the system prepared via the electrochemically induced sol-gel method, might also influence the photocatalytic activity. Also other effects like impurities or secondary phases can have a positive effect on the photocatalytic properties of the electrochemically synthesized system. As listed in Table 5.1, there are also some other minor differences between the two systems in nanowire length, diameter and $\mathrm{TiO}_{2}$ shell thickness, but it is not expected that these differences alone can explain the large difference in photocatalytic activity.

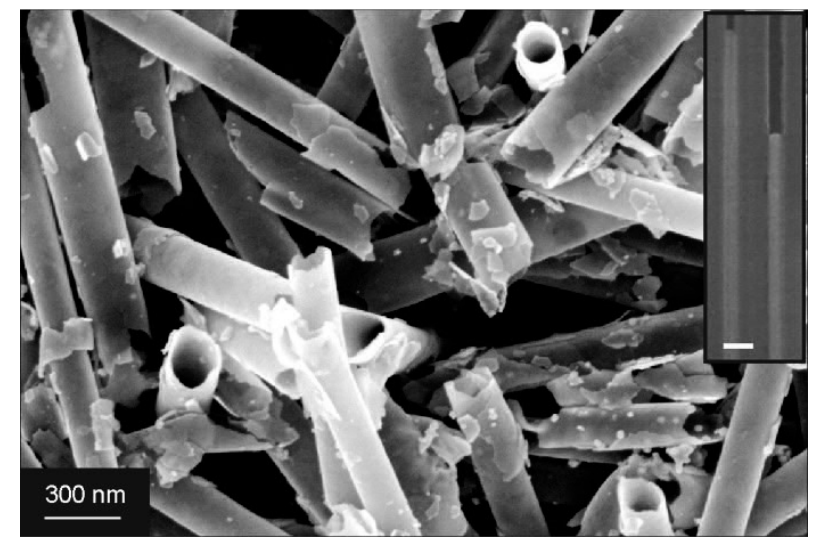

Figure 5.8: SEM image of $\mathrm{TiO}_{2}$ nanotubes made by ALD before Ag filling, after release from the template. The inset shows coaxial $\mathrm{TiO}_{2}-\mathrm{Ag}$ nanowires inside the membrane, where the $\mathrm{TiO}_{2}$ phase is visible as a bright white phase covering the pore walls at the top of the figure, and the Ag phase is visible as a solid nanowire at the bottom of the figure. 
Only a few other publications report $\mathrm{H}_{2}$ evolution from $\mathrm{TiO}_{2}$ nanotubes, and these are listed in Table 5.1. The geometries and process conditions vary widely between these studies, so that direct comparison of these data should be done with care. Besides one other publication on hydrogen evolution by autonomous nanowires in methanol [13], all other studies involve photoelectrochemical cells with compositionally distinct, and in some cases spatially separated, hydrogen and oxygen evolution catalysts. Only one publication reports the $\mathrm{H}_{2}$ evolution rate per weight of used material for $\mathrm{TiO}_{2}$ nanotubes, resulting in an evolution rate of $2.83 \cdot 10^{-3} \mathrm{~mol} / \mathrm{g} \cdot \mathrm{h} \mathrm{H}_{2}$ [25]. This is a factor of 2.3 higher than our current result, and it might be explained by the difference in crystallinity of $\mathrm{TiO}_{2}$, as anodization can result in the formation of single crystalline $\mathrm{TiO}_{2}$ nanotubes, while polycrystalline $\mathrm{TiO}_{2}$ nanotubes were made in the current research. Two other main differences are that a light source with higher energy was used in ref. [25], and that an $\mathrm{IO}_{3}{ }^{-} / \mathrm{I}^{-}$redox couple was used as a redox mediator to prevent recombination of $\mathrm{H}_{2}$ and $\mathrm{O}_{2}$ into $\mathrm{H}_{2} \mathrm{O}$. Both these differences also drastically influence the $\mathrm{H}_{2}$ evolution rate.

Others calculated the $\mathrm{H}_{2}$ formation rate per unit surface area of the anodized Ti foil, resulting in $\mathrm{H}_{2}$ formation rates of $97 \cdot 10^{-6} \mathrm{~mol} / \mathrm{cm}^{2} \cdot \mathrm{h}$ [29], and $14 \cdot 10^{-6} \mathrm{~mol} / \mathrm{cm}^{2} \cdot \mathrm{h}[28]$, which are both much higher than our current result using coaxial $\mathrm{TiO}_{2}-\mathrm{Ag}$ nanowires made via the electrochemically induced sol-gel method. Part of this difference may be explained by the different methods used to measure the surface area: the surface area of the AAO template before dissolution vs. the anodized surface area of the Ti foil. Both authors used Pt as counter electrode [29], or as thin layer on top of the nanotubes for enhanced photocatalytic activity [28]. Also here a light source with higher energy was used in both studies and an $\mathrm{IO}_{3}^{-} / \mathrm{I}^{-}$couple was used as redox mediator in one of the two studies to prevent recombination of $\mathrm{H}_{2}$ and $\mathrm{O}_{2}$ into $\mathrm{H}_{2} \mathrm{O}$ [28]. Another method to prevent recombination of $\mathrm{H}_{2}$ and $\mathrm{O}_{2}$ is to split the electrodes in a two-compartment setup [29]. On the other hand, even though efficiencies could be increased by preventing $\mathrm{H}_{2}$ and $\mathrm{O}_{2}$ recombination, we have shown that coaxial $\mathrm{TiO}_{2}$-Ag nanowires are able to split water autonomously without addition of sacrificial agents, redox mediators or external power supply. This can be of advantage for self-fuelling nanodevices in aqueous environments, or to generate $\mathrm{H}_{2}$ at a specific location. 
Next to the possible explanation of different crystallinity, use of redox mediators and two-compartment setups, it is still difficult to directly compare these results, because every author uses different light sources and electrolytes that both have a large impact on the efficiency for $\mathrm{H}_{2}$ formation. In that respect, a better way for comparison would be to keep the nanowires attached to the substrate for photocurrent measurements. Also the applied potential should be compensated for the reference electrode and $\mathrm{pH}$ of the solution, as illustrated by Seabold et al. [65]. Unfortunately, with the AAO templates available for this study, it was not possible to keep the nanotubes or nanowires standing on the substrate after dissolving the template because the nanowire/nanotube connection to the bottom was mechanically too weak. Additionally, standardized simulated AM1.5 solar illumination with an energy of $100 \mathrm{~mW} / \mathrm{cm}^{2}$ should be used in all measurements, but unfortunately these solar simulators are expensive and not available in every lab.

Several strategies can be pursued to further improve the activity and $\mathrm{H}_{2}$ formation rate. One of these strategies includes changing the alkaline electrolyte for water splitting to either an acidic or neutral electrolyte [30]. The second method includes the use of a sacrificial agent, e.g. methanol, or redox mediator, e.g. $\mathrm{KI}$, to increase the $\mathrm{H}_{2}$ formation rate [24, 66-68]. As a third option, the activity for water splitting can be improved by adding an oxidation catalyst, e.g. $\mathrm{Mn}_{3} \mathrm{O}_{4}$, for more efficient $\mathrm{O}_{2}$ formation. In the fourth method, the dimensions of the coaxial $\mathrm{TiO}_{2}-\mathrm{Ag}$ nanowires could be changed in order to find an optimum in total diameter, $\mathrm{TiO}_{2}$ shell thickness and nanowire length. These methods should be systematically investigated in future research.

\subsection{Conclusions}

The electrochemically induced sol-gel method was used to prepare anatase $\mathrm{TiO}_{2}$ nanotubes in AAO membranes and templates with a diameter of $200 \mathrm{~nm}$. By varying the intermediate thermal annealing process of the titania gel phase, the location where Ag deposited during the subsequent electrodeposition step in the same template could be tuned. Intermediate heating at $100{ }^{\circ} \mathrm{C}$ resulted in the formation of $\mathrm{Ag}$ nanoparticles incorporated in the shell of the $\mathrm{TiO}_{2}$ nanotubes, while thermal annealing at $650{ }^{\circ} \mathrm{C}$ led to $\mathrm{TiO}_{2}$ nanotubes filled with a continuous $\mathrm{Ag}$ phase, thus 
forming coaxial $\mathrm{TiO}_{2}-\mathrm{Ag}$ nanowires. These coaxial $\mathrm{TiO}_{2}-\mathrm{Ag}$ nanowires showed improved photocatalytic activity for direct water splitting due to the favorable geometry of core/shell systems, which is favorable due to a large contact area between the photoactive material $\left(\mathrm{TiO}_{2}\right)$ and the $\mathrm{H}_{2}$ evolution catalyst $(\mathrm{Ag})$, photon reflection by the $\mathrm{Ag}$ core to capture the maximum number of photons in the titania phase, and short diffusion paths from the $\mathrm{TiO}_{2}$ phase to the $\mathrm{Ag}$ phase in order to separate the exciton efficiently. During a long-term experiment, $\mathrm{H}_{2}$ was formed at a rate of $1.2 \cdot 10^{-3} \mathrm{~mol} / \mathrm{g} \cdot \mathrm{h}$ for at least $6 \mathrm{~h}$.

This technique is not only limited to the formation of $\mathrm{TiO}_{2}-\mathrm{Ag}$ nanowires, but basically any combination of core-shell materials can be envisaged as long as electrodeposition or a related technique results in the formation of a nanotube for the shell material and a nanowire for the core material. Just as the choice of materials is not limited to what is described in this paper, also the possible applications are not limited to photocatalysis, but they can be extended to other areas, e.g. solar cells and batteries.

\subsection{References}

[1] Y. W. Heo, D. P. Norton, L. C. Tien, Y. Kwon, B. S. Kang, F. Ren, S. J. Pearton, and J. R. Laroche, "ZnO nanowire growth and devices", Materials Science and Engineering R: Reports, 2004, vol. 47, pp. 1-47.

[2] R. Fan, R. Karnik, M. Yue, D. Li, A. Majumdar, and P. Yang, "DMA translocation in inorganic nanotubes", Nano Letters, 2005, vol. 5, pp. 1633-1637.

[3] F. Patolsky, G. Zheng, and C. M. Lieber, "Nanowire-based biosensors", Analytical Chemistry, 2006, vol. 78, pp. 4260-4269.

[4] C. D. Keating and M. J. Natan, "Striped metal nanowires as building blocks and optical tags", Advanced Materials, 2003, vol. 15, pp. 451-454.

[5] L. A. Bauer, D. H. Reich, and G. J. Meyer, "Selective functionalization of two-component magnetic nanowires", Langmuir, 2003, vol. 19, pp. 7043-7048.

[6] J. Wang, "Barcoded metal nanowires", Journal of Materials Chemistry, 2008, vol. 18, pp. 4017-4020. 
[7] W. F. Paxton, S. Sundararajan, T. E. Mallouk, and A. Sen, "Chemical locomotion", Angewandte Chemie - International Edition, 2006, vol. 45, pp. 5420-5429.

[8] Y. Wang, R. M. Hernandez, D. J. Bartlett Jr, J. M. Bingham, T. R. Kline, A. Sen, and T. E. Mallouk, "Bipolar electrochemical mechanism for the propulsion of catalytic nanomotors in hydrogen peroxide solutions", Langmuir, 2006, vol. 22, pp. 10451-10456.

[9] J. Wang, "Can man-made nanomachines compete with nature biomotors?", ACS Nano, 2009, vol. 3, pp. 4-9.

[10] T. S. Kang, A. P. Smith, B. E. Taylor, and M. F. Durstock, "Fabrication of highly-ordered $\mathrm{TiO}_{2}$ nanotube arrays and their use in dye-sensitized solar cells", Nano Letters, 2009, vol. 9, pp. 601-606.

[11] M. Z. Hu, P. Lai, M. S. Bhuiyan, C. Tsouris, B. Gu, M. Parans Paranthaman, J. Gabitto, and L. Harrison, "Synthesis and characterization of anodized titanium-oxide nanotube arrays", Journal of Materials Science, 2009, vol. 44, pp. 2820-2827.

[12] J. Jitputti, Y. Suzuki, and S. Yoshikawa, "Synthesis of $\mathrm{TiO}_{2}$ nanowires and their photocatalytic activity for hydrogen evolution", Catalysis Communications, 2008, vol. 9, pp. 1265-1271.

[13] A. W. Maijenburg, E. J. B. Rodijk, M. G. Maas, M. Enculescu, D. H. A. Blank, and J. E. ten Elshof, "Hydrogen generation from photocatalytic silver|zinc oxide nanowires: Towards multifunctional multisegmented nanowire devices", Small, 2011, vol. 7, pp. 2709-2713.

[14] P. E. De Jongh, D. Vanmaekelbergh, and J. J. Kelly, "Photoelectrochemistry of electrodeposited $\mathrm{Cu}_{2} \mathrm{O}$ ", Journal of the Electrochemical Society, 2000, vol. 147, pp. 486-489.

[15] C. J. Engel, T. A. Polson, J. R. Spado, J. M. Bell, and A. Fillinger, "Photoelectrochemistry of porous $\mathrm{p}-\mathrm{Cu}_{2} \mathrm{O}$ films", Journal of the Electrochemical Society, 2008, vol. 155, pp. F37-F42.

[16] S. Sunkara, V. K. Vendra, J. H. Kim, T. Druffel, and M. K. Sunkara, "Scalable synthesis and photoelectrochemical properties of copper oxide nanowire arrays and films", Catalysis Today, 2013, vol. 199, pp. 27-35.

[17] Z. Zhang, R. Dua, L. Zhang, H. Zhu, H. Zhang, and P. Wang, "Carbon-layer-protected cuprous oxide nanowire arrays for efficient water reduction", ACS Nano, 2013, vol. 7, pp. 1709-1717.

[18] R. Van De Krol, Y. Liang, and J. Schoonman, "Solar hydrogen production with nanostructured metal oxides", Journal of Materials Chemistry, 2008, vol. 18, pp. 2311-2320. 
[19] A. Kudo and Y. Miseki, "Heterogeneous photocatalyst materials for water splitting", Chemical Society Reviews, 2009, vol. 38, pp. 253-278.

[20] T. Bak, J. Nowotny, M. Rekas, and C. C. Sorrell, "Photo-electrochemical hydrogen generation from water using solar energy. Materials-related aspects", International Journal of Hydrogen Energy, 2002, vol. 27, pp. 991-1022.

[21] A. Fujishima and K. Honda, "Electrochemical photolysis of water at a semiconductor electrode", Nature, 1972, vol. 238, pp. 37-38.

[22] R. Abe, "Recent progress on photocatalytic and photoelectrochemical water splitting under visible light irradiation", Journal of Photochemistry and Photobiology C: Photochemistry Reviews, 2010, vol. 11, pp. 179-209.

[23] P. Roy, D. Kim, K. Lee, E. Spiecker, and P. Schmuki, "TiO ${ }_{2}$ nanotubes and their application in dye-sensitized solar cells", Nanoscale, 2010, vol. 2, pp. 45-59.

[24] D. Eder, M. Motta, and A. H. Windle, "Iron-doped Pt-TiO nanotubes for photo-catalytic water splitting", Nanotechnology, 2009, vol. 20,

[25] E. Y. Kim, J. H. Park, and G. Y. Han, "Design of $\mathrm{TiO}_{2}$ nanotube array-based water-splitting reactor for hydrogen generation", Journal of Power Sources, 2008, vol. 184, pp. 284-287.

[26] C. J. Lin, Y. T. Lu, C. H. Hsieh, and S. H. Chien, "Surface modification of highly ordered $\mathrm{TiO}_{2}$ nanotube arrays for efficient photoelectrocatalytic water splitting", Applied Physics Letters, 2009, vol. 94,

[27] Y. Lin, S. Zhou, X. Liu, S. Sheehan, and D. Wang, " $\mathrm{TiO}_{2} / \mathrm{TiSi}_{2}$ heterostructures for high-efficiency photoelectrochemical $\mathrm{H}_{2} \mathrm{O}$ splitting", Journal of the American Chemical Society, 2009, vol. 131, pp. 2772-2773.

[28] W. Nam and G. Y. Han, "Preparation and characterization of anodized $\mathrm{Pt}_{-} \mathrm{TiO}_{2}$ nanotube arrays for water splitting", Journal of Chemical Engineering of Japan, 2007, vol. 40, pp. 266-269.

[29] Y. Sun, G. Wang, and K. Yan, " $\mathrm{TiO}_{2}$ nanotubes for hydrogen generation by photocatalytic water splitting in a two-compartment photoelectrochemical cell", International Journal of Hydrogen Energy, 2011, vol. 36, pp. 15502-15508.

[30] A. Wolcott, W. A. Smith, T. R. Kuykendall, Y. Zhao, and J. Z. Zhang, "Photoelectrochemical water splitting using dense and aligned $\mathrm{TiO}_{2}$ nanorod arrays", Small, 2009, vol. 5, pp. 104-111. 
[31] Y. Hong, M. Diaz, U. M. Córdova-Fteueroa, and A. Sen, "Light-driven titanium-dioxide-based reversible microfireworks and micromotor/micropump systems", Advanced Functional Materials, 2010, vol. 20, pp. 1568-1576.

[32] M. G. Hosseini, M. M. Momeni, and M. Faraji, "Highly active nickel nanoparticles supported on $\mathrm{TiO}_{2}$ nanotube electrodes for methanol electrooxidation", Electroanalysis, 2010, vol. 22, pp. 2620-2625.

[33] L. Xing, J. Jia, Y. Wang, B. Zhang, and S. Dong, "Pt modified $\mathrm{TiO}_{2}$ nanotubes electrode: Preparation and electrocatalytic application for methanol oxidation", International Journal of Hydrogen Energy, 2010, vol. 35, pp. 12169-12173.

[34] A. R. Armstrong, G. Armstrong, J. Canales, and P. G. Bruce, " $\mathrm{TiO}_{2}-\mathrm{B}$ nanowires as negative electrodes for rechargeable lithium batteries", Journal of Power Sources, 2005, vol. 146, pp. 501-506.

[35] B. L. He, B. Dong, and H. L. Li, "Preparation and electrochemical properties of $\mathrm{Ag}$-modified $\mathrm{TiO}_{2}$ nanotube anode material for lithium-ion battery", Electrochemistry Communications, 2007, vol. 9, pp. 425-430.

[36] C. M. Park, W. S. Chang, H. Jung, J. H. Kim, and H. J. Sohn, "Nanostructured $\mathrm{Sn} / \mathrm{TiO}_{2} / \mathrm{C}$ composite as a high-performance anode for Li-ion batteries", Electrochemistry Communications, 2009, vol. 11, pp. 2165-2168.

[37] R. Yoshida, Y. Suzuki, and S. Yoshikawa, "Syntheses of $\mathrm{TiO}_{2}$ (B) nanowires and $\mathrm{TiO}_{2}$ anatase nanowires by hydrothermal and postheat treatments", Journal of Solid State Chemistry, 2005, vol. 178, pp. 2179-2185.

[38] S. P. Albu, A. Ghicov, S. Berger, H. Jha, and P. Schmuki, "TiO nanotube layers: Flexible and electrically active flow-through membranes", Electrochemistry Communications, 2010, vol. 12, pp. 1352-1355.

[39] W. Jun and L. Zhiqun, "Anodic formation of ordered $\mathrm{TiO}_{2}$ nanotube arrays: Effects of electrolyte temperature and anodization potential", Journal of Physical Chemistry C, 2009, vol. 113, pp. 4026-4030.

[40] S. Li, G. Zhang, D. Guo, L. Yu, and W. Zhang, "Anodization fabrication of highly ordered $\mathrm{TiO}_{2}$ nanotubes", Journal of Physical Chemistry C, 2009, vol. 113, pp. 12759-12765. 
[41] M. S. Sander, M. J. Côté, W. Gu, B. M. Kile, and C. P. Tripp, "Template-assisted fabrication of dense, aligned arrays of titania nanotubes with well-controlled dimensions on substrates", Advanced Materials, 2004, vol. 16, pp. 2052-2057.

[42] C. Bae, Y. Yoon, H. Yoo, D. Han, J. Cho, B. H. Lee, M. M. Sung, M. Lee, J. Kim, and $\mathrm{H}$. Shin, "Controlled fabrication of multiwall anatase $\mathrm{TiO}_{2}$ nanotubular architectures", Chemistry of Materials, 2009, vol. 21, pp. 2574-2576.

[43] S. Inoue, S. Z. Chu, K. Wada, D. Li, and H. Haneda, "New roots to formation of nanostructures on glass surface through anodic oxidation of sputtered aluminum", Science and Technology of Advanced Materials, 2003, vol. 4, pp. 269-276.

[44] Z. Ye, H. Liu, I. Schultz, W. Wu, D. G. Naugle, and I. Lyuksyutov, "Template-based fabrication of nanowire-nanotube hybrid arrays", Nanotechnology, 2008, vol. 19,

[45] S. J. Limmer, S. Seraji, Y. Wu, T. P. Chou, C. Nguyen, and G. Z. Cao, "Template-based growth of various oxide nanorods by sol-gel electrophoresis", Advanced Functional Materials, 2002, vol. 12, pp. 59-64.

[46] Y. Lin, G. S. Wu, X. Y. Yuan, T. Xie, and L. D. Zhang, "Fabrication and optical properties of $\mathrm{TiO}_{2}$ nanowire arrays made by sol-gel electrophoresis deposition into anodic alumina membranes", Journal of Physics Condensed Matter, 2003, vol. 15, pp. 2917-2922.

[47] S. Liu and K. Huang, "Straightforward fabrication of highly ordered $\mathrm{TiO}_{2}$ nanowire arrays in AAM on aluminum substrate", Solar Energy Materials and Solar Cells, 2005, vol. 85, pp. 125-131.

[48] X. Y. Zhang, L. D. Zhang, W. Chen, G. W. Meng, M. J. Zheng, L. X. Zhao, and F. Phillipp, "Electrochemical fabrication of highly ordered semiconductor and metallic nanowire arrays", Chemistry of Materials, 2001, vol. 13, pp. 2511-2515.

[49] Z. Miao, D. Xu, J. Ouyang, G. Guo, X. Zhao, and Y. Tang, "Electrochemically Induced Sol-Gel Preparation of Single-Crystalline $\mathrm{TiO}_{2}$ Nanowires", Nano Letters, 2002, vol. 2, pp. 717-720.

[50] X. J. Wu, F. Zhu, C. Mu, Y. Liang, L. Xu, Q. Chen, R. Chen, and D. Xu, "Electrochemical synthesis and applications of oriented and hierarchically quasi-1D semiconducting nanostructures", Coordination Chemistry Reviews, 2010, vol. 254, pp. 1135-1150.

[51] J. M. Macak, B. G. Gong, M. Hueppe, and P. Schmuki, "Filling of $\mathrm{TiO}_{2}$ nanotubes by self-doping and electrodeposition", Advanced Materials, 2007, vol. 19, pp. 3027-3031. 
[52] C. Natarajan and G. Nogami, "Cathodic electrodeposition of nanocrystalline titanium dioxide thin films", Journal of the Electrochemical Society, 1996, vol. 143, pp. 1547-1550.

[53] S. Karuppuchamy, D. P. Amalnerkar, K. Yamaguchi, T. Yoshida, $\mathrm{T}$. Sugiura, and $\mathrm{H}$. Minoura, "Cathodic electrodeposition of $\mathrm{TiO}_{2}$ thin films for dye-sensitized photoelectrochemical applications", Chemistry Letters, 2001, pp. 78-79.

[54] S. Karuppuchamy, K. Nonomura, T. Yoshida, T. Sugiura, and $\mathrm{H}$. Minoura, "Cathodic electrodeposition of oxide semiconductor thin films and their application to dye-sensitized solar cells", Solid State lonics, 2002, vol. 151, pp. 19-27.

[55] S. A. Kumar, P. H. Lo, and S. M. Chen, "Electrochemical synthesis and characterization of $\mathrm{TiO}_{2}$ nanoparticles and their use as a platform for flavin adenine dinucleotide immobilization and efficient electrocatalysis", Nanotechnology, 2008, vol. 19,

[56] M. G. Maas, E. J. B. Rodijk, W. Maijenburg, J. E. ten Elshof, and D. H. A. Blank, "Photocatalytic segmented nanowires and single-step iron oxide nanotube synthesis: Templated electrodeposition as all-round tool," in Multifunction at the Nanoscale through Nanowires, Pittsburg, 2010, pp. M01-08.

[57] H. Masuda, K. Yada, and A. Osaka, "Self-ordering of cell configuration of anodic porous alumina with large-size pores in phosphoric acid solution", Japanese Journal of Applied Physics, Part 2: Letters, 1998, vol. 37, pp. L1340-L1342.

[58] K. Nielsch, F. Müller, A. P. Li, and U. Gösele, "Uniform nickel deposition into ordered alumina pores by pulsed electrodeposition", Advanced Materials, 2000, vol. 12, pp. 582-586.

[59] J. Sekulić, J. E. ten Elshof, and D. H. A. Blank, "A microporous titania membrane for nanofiltration and pervaporation", Advanced Materials, 2004, vol. 16, pp. 1546-1550.

[60] V. Lyahovitskaya, Y. Feldman, I. Zon, A. Yoffe, and A. I. Frenkel, "Strain-arranged structure in amorphous films", Journal of Materials Research, 2012, vol. 27, pp. 2819-2828.

[61] A. Di Paola, G. Cufalo, M. Addamo, M. Bellardita, R. Campostrini, M. Ischia, R. Ceccato, and L. Palmisano, "Photocatalytic activity of nanocrystalline $\mathrm{TiO}_{2}$ (brookite, rutile and brookite-based) powders prepared by thermohydrolysis of $\mathrm{TiCl}_{4}$ in aqueous chloride solutions", Colloids and Surfaces A: Physicochemical and Engineering Aspects, 2008, vol. 317, pp. 366-376. 
[62] A. M. Luís, M. C. Neves, M. H. Mendonça, and O. C. Monteiro, "Influence of calcination parameters on the $\mathrm{TiO}_{2}$ photocatalytic properties", Materials Chemistry and Physics, 2011, vol. 125, pp. 20-25.

[63] C. A. Grimes and G. K. Mor, "Chapter 4: $\mathrm{TiO}_{2}$ nanotube arrays: Application to photoelectrochemical water splitting," in $\mathrm{TiO}_{2}$ nanotube arrays: Synthesis, properties and applications, ed Dordrecht Heidelberg London New York: Springer, 2009, pp. 149-216.

[64] M. Kim, C. Bae, H. Kim, H. Yoo, J. M. Montero Moreno, H. S. Jung, J. Bachmann, K. Nielsch, and H. Shin, "Confined crystallization of anatase $\mathrm{TiO}_{2}$ nanotubes and their implications on transport properties", Journal of Materials Chemistry A, 2013, vol. 1, pp. 14080-14088.

[65] J. A. Seabold and K. S. Choi, "Efficient and stable photo-oxidation of water by a bismuth vanadate photoanode coupled with an iron oxyhydroxide oxygen evolution catalyst", Journal of the American Chemical Society, 2012, vol. 134, pp. 2186-2192.

[66] R. Abe, K. Sayama, and H. Arakawa, "Significant effect of iodide addition on water splitting into $\mathrm{H}_{2}$ and $\mathrm{O}_{2}$ over Pt-loaded $\mathrm{TiO}_{2}$ photocatalyst: Suppression of backward reaction", Chemical Physics Letters, 2003, vol. 371, pp. 360-364.

[67] R. Abe, K. Sayama, K. Domen, and H. Arakawa, "A new type of water splitting system composed of two different $\mathrm{TiO}_{2}$ photocatalysts (anatase, rutile) and a $\mathrm{IO}_{3}{ }^{-} / \mathrm{I}^{-}$shuttle redox mediator", Chemical Physics Letters, 2001, vol. 344, pp. 339-344.

[68] K. Lee, W. S. Nam, and G. Y. Han, "Photocatalytic water-splitting in alkaline solution using redox mediator. 1: Parameter study", International Journal of Hydrogen Energy, 2004, vol. 29, pp. 1343-1347. 


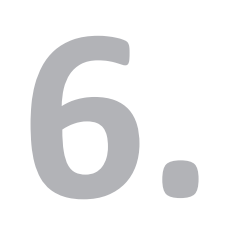

Photoelectrochemical diodes consisting of axially segmented

$\mathrm{Cu}_{2} \mathrm{O}$ nanowires with $\mathrm{p}$ - and $\mathrm{n}$-type

segments for autonomous

$\underline{\mathrm{H}}_{2}$ formation

This chapter presents the third and final nanowire system for autonomous water splitting. Instead of a Schottky barrier for efficient electron-hole separation, the nanowires in this chapter are made of $p$ - and n-type $\mathrm{Cu}_{2} \mathrm{O}$, leading to the spontaneous formation of an Ohmic interface layer. Due to this Ohmic interface layer, a photoelectrochemical diode was formed. This system has several advantages over the nanowires presented in Chapters 4 and 5: (1) $\mathrm{Cu}_{2} \mathrm{O}$ has a lower bandgap leading to enhanced photon absorption, (2) a photoelectrochemical diode is also capable of driving electrochemical reactions that are uphill in energy, and (3) both phases have a comparable chemical composition resulting in an interface with enhanced chemical and mechanical stability, which allows the formation of nanowires with more than 2 segments. 


\subsection{Abstract}

A photoelectrochemical diode was shaped into a nanowire composed of p- and n-type $\mathrm{Cu}_{2} \mathrm{O}$ segments in which an Ohmic contact was spontaneously created at the interface between the segments. These photoelectrochemical diodes enable solar $\mathrm{H}_{2}$ formation without the application of an external bias. It was found that the addition of $\mathrm{PO}_{4}{ }^{3-}$ ions to the electrolyte as a hole scavenger enhanced the $\mathrm{H}_{2}$ formation rate significantly. The effect of adding more $p$ - and n-type segments within one nanowire was investigated, resulting in the highest $\mathrm{H}_{2}$ formation rate for $\mathrm{Cu}_{2} \mathrm{O}$ nanowires comprising $2 \mathrm{p}-$ and $2 \quad \mathrm{n}-\mathrm{Cu}_{2} \mathrm{O}$ segments $(2.2 \pm 0.5 \mathrm{mmol} / \mathrm{g} \cdot \mathrm{h})$.

\subsection{Introduction}

Photocatalytic and photoelectrochemical water splitting is emerging as a promising technique for the synthesis of $\mathrm{H}_{2}$ gas, which can be used as a clean and renewable energy source. $\mathrm{Cu}_{2} \mathrm{O}$ is a very promising material for use in photocatalytic and photoelectrochemical water splitting because it is abundant, cheap and environmentally benign, and its band gap of 1.9-2.2 $\mathrm{eV}$ is suitable for solar energy conversion in the visible light region [1-3]. There are three main reasons why $\mathrm{Cu}_{2} \mathrm{O}$ is not widely used yet in photocatalytic or photoelectrochemical water splitting: (1) its limited chemical stability in aqueous solutions, (2) the large mismatch between the minority charge carrier diffusion length $(20-100 \mathrm{~nm})$ and absorption depth near the band gap $(10 \mu \mathrm{m})$, and (3) the band edge positions of most semiconductors, including $\mathrm{Cu}_{2} \mathrm{O}$, are insufficient for both the reduction and oxidation reactions involved in water splitting [3-7]. (1) The poor chemical stability in water can be resolved by coating $\mathrm{Cu}_{2} \mathrm{O}$ with thin layers of $\mathrm{Al}: \mathrm{ZnO}$ and $\mathrm{TiO}_{2}$ or a thin layer of carbon, which simultaneously increases the overall performance of the electrodes [3, 7]. (2) The mismatch between the charge carrier diffusion length and absorption depth can be obviated by using an array of one-dimensional nanostructures, so that a maximum of solar light can be absorbed along the nanowire length, while the nanowire diameter is small enough for efficient electron and hole diffusion to the electrolyte [6-8]. Another advantage of nanosized photocatalysts is their 
high surface-to-volume ratio, which increases the semiconductorelectrolyte interface area allowing more efficient charge injection to the solution species. (3) With the use of a photoelectrochemical diode consisting of a p-type and an n-type semiconductor that are electrically connected with a metallic interface layer, it becomes possible to select a p-type material with a sufficiently high conduction band for the reduction reaction and an n-type material with a sufficiently low valence band for the oxidation reaction. When irradiated with photons, a photocurrent is generated within the photoelectrochemical diode, making it possible to drive electrochemical reactions that are uphill in energy [9].

In the present study, axially segmented $\mathrm{Cu}_{2} \mathrm{O}$ nanowires with one or more $\mathrm{p}$ - and $\mathrm{n}$-type segments were made. At the interface between the $\mathrm{p}$ - and n-type segments, a layer with Ohmic properties was formed spontaneously, resulting in the formation of a photoelectrochemical diode. Similar to the previous chapters on axially segmented $\mathrm{Ag} \mid \mathrm{ZnO}$ and coaxial $\mathrm{TiO}_{2}-\mathrm{Ag}$ nanowires $[10,11]$, no external power supply connecting the different $\mathrm{Cu}_{2} \mathrm{O}$ conduction types was needed, enabling autonomous solar $\mathrm{H}_{2}$ formation with reduced device costs and dimensions. In addition, the spontaneous formation of an Ohmic interface layer in this study has the unique advantage that it is not needed to insert additional metallic nanowire segments that would add mechanically less stable metal-metal oxide interfaces. We used $\mathrm{p}$ - and n-type $\mathrm{Cu}_{2} \mathrm{O}$ segments for increased chemical and mechanical stability due to their comparable chemical composition, allowing us to study the effect of adding more $\mathrm{p}$ - and $\mathrm{n}$-type segments on the photocatalytic activity. A schematic representation of the envisaged process for photocatalytic water splitting from $\mathrm{p} \mid \mathrm{n}-\mathrm{Cu}_{2} \mathrm{O}$ nanowires is shown in Figure 6.1 together with an energy diagram showing the positions of the conduction and valence bands of both $\mathrm{Cu}_{2} \mathrm{O}$ segments. 
a.
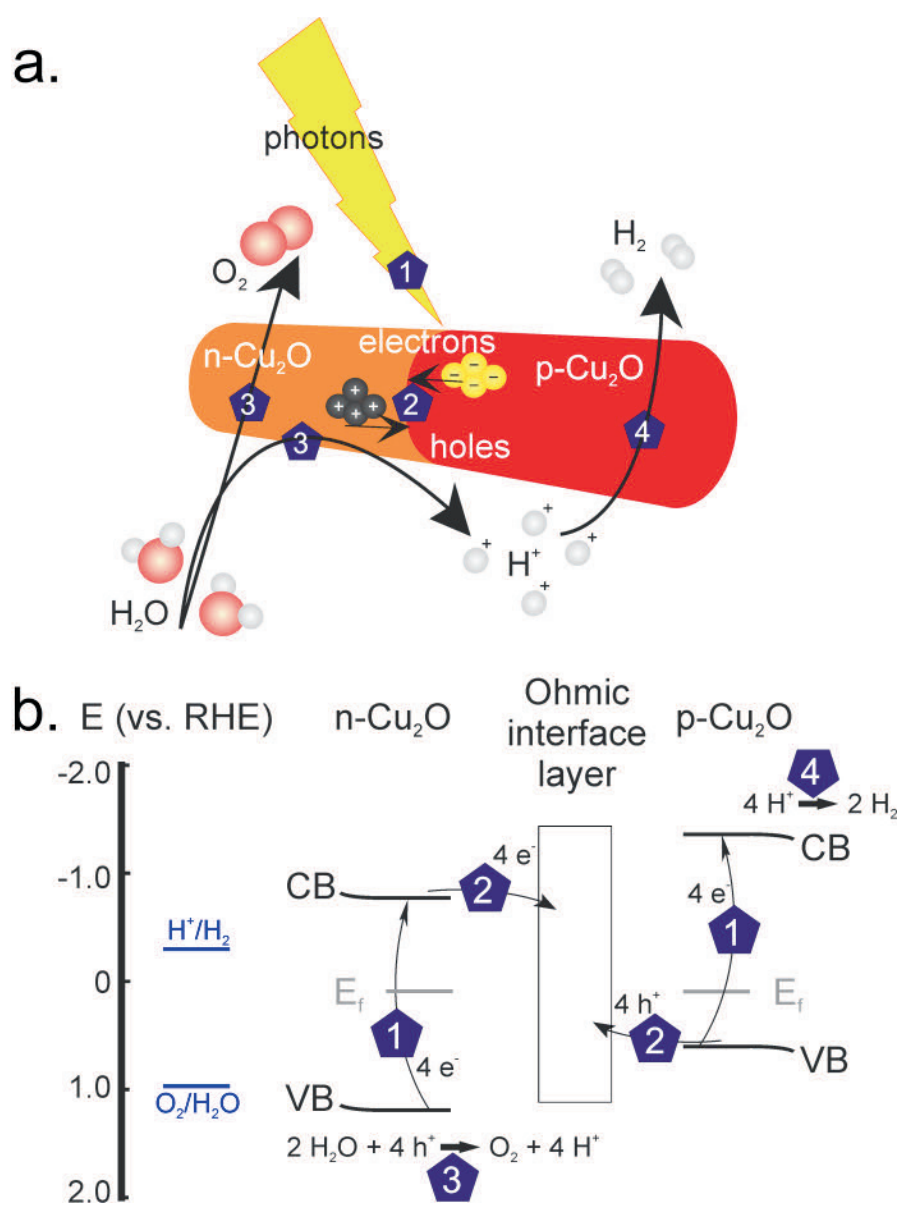

Figure 6.1: Working principle of a photoelectrochemical diode consisting of a segmented $\mathrm{p} \mid \mathrm{n}-\mathrm{Cu}_{2} \mathrm{O}$ nanowire: (a) schematic representation, and (b) energy diagram. Light is absorbed by both segments, creating electron-hole pairs (step 1). The holes of the p-type segment and the electrons of the n-type segment flow towards the Ohmic interface layer where they recombine (step 2). The remaining holes in the $n$-type segment are consumed in an oxidative half-reaction to form $\mathrm{O}_{2}$ and $\mathrm{H}^{+}$(step 3), and the remaining electrons in the p-type segment are consumed in a reductive half-reaction to form $\mathrm{H}_{2}$ (step 4). In (b), for the location of the conduction bands (CB), valence bands (VB) and Fermi level energy $\left(E_{f}\right)$ of $\mathrm{Cu}_{2} \mathrm{O}$, the values from ref. [1] were used after conversion to the Reversible Hydrogen Electrode (RHE) and correction to pH 4.9. Slight band bending was introduced at the semiconductor-electrolyte interface for understanding of the direction of electron and hole flow. The bands of $\mathrm{p}-\mathrm{Cu}_{2} \mathrm{O}$ were shifted to reach equilibrium. The standard reduction potentials for the reduction and oxidation reactions involved in water splitting were also corrected to $\mathrm{pH} 4.9$ and are added in blue. 
Using electrodeposition, it is possible to make both $\mathrm{p}$ - and n-type conducting $\mathrm{Cu}_{2} \mathrm{O}$ by changing the $\mathrm{pH}$ of the solution and the deposition potential $[1,8,12-14]$. These procedures incorporate small quantities of $\mathrm{Cu}^{+}$vacancies in the lattice of $\mathrm{p}-\mathrm{Cu}_{2} \mathrm{O}$, which can lead to the formation of $\mathrm{Cu}^{2+}$ ions to balance the charge, and $\mathrm{Cu}^{0}$ donors in the lattice of $\mathrm{n}-\mathrm{Cu}_{2} \mathrm{O}$ $[1,15]$. A few groups report a $\mathrm{p}-\mathrm{n} \mathrm{Cu}_{2} \mathrm{O}$ homojunction for solar cell applications made by electrodeposition $[1,8,12,13]$. Of these, the solar cell with the highest performance to date has an efficiency of $1.06 \%$, which is expected to further increase by optimization of the Fermi level, the conductivity of both $\mathrm{p}$ - and $\mathrm{n}-\mathrm{Cu}_{2} \mathrm{O}$, and identification of optimum contact materials to the $\mathrm{Cu}_{2} \mathrm{O}$ layers [1]. Incorporation of one-dimensional nanostructures is also expected to improve the performance of $p-n \mathrm{Cu}_{2} \mathrm{O}$ solar cells. Only one publication reported on the photocurrent response measured for a $\mathrm{p}-\mathrm{n} \mathrm{Cu}_{2} \mathrm{O}$ homojunction in which the $\mathrm{n}-\mathrm{Cu}_{2} \mathrm{O}$ layer was deposited on top of the $\mathrm{p}-\mathrm{Cu}_{2} \mathrm{O}$ layer [8]. After deposition of the second layer, they observed a change of the photocurrent response from cathodic to anodic, showing the availability of an n-type material as the top layer.

\subsection{Experimental details}

All chemicals used were purchased from commercial sources and used without further purification. Copper sulfate pentahydrate $\left(\mathrm{CuSO}_{4} \cdot 5 \mathrm{H}_{2} \mathrm{O}\right.$, p.a. quality) and sodium sulfate $\left(\mathrm{Na}_{2} \mathrm{SO}_{4}\right.$, p.a. quality) were purchased from Boom Chemie; lactic acid (extra pure), copper acetate $\left(\mathrm{Cu}\left(\mathrm{CH}_{3} \mathrm{COO}\right)_{2}\right.$, purity $99 \%)$, acetic acid $\left(\mathrm{CH}_{3} \mathrm{COOH}\right.$, purity $\left.99.5 \%\right)$, sodium hydroxide $(\mathrm{NaOH}$, purity $98.3 y 5 \%)$, sulfuric acid $\left(\mathrm{H}_{2} \mathrm{SO}_{4}, 96 \%\right.$ in water) and dipotassium phosphate trihydrate $\left(\mathrm{K}_{2} \mathrm{HPO}_{4} \cdot 3 \mathrm{H}_{2} \mathrm{O}\right.$, purity $\left.>99 \%\right)$ were purchased from Acros Organics; dichloromethane $\left(\mathrm{CH}_{2} \mathrm{Cl}_{2}\right.$, purity $\left.99.9 \%\right)$ was purchased from Merck. Milli-Q water with a resistivity of $18.2 \mathrm{M} \Omega \cdot \mathrm{cm}$ was used in all experiments.

$\mathrm{p} \mid \mathrm{n}-\mathrm{Cu}_{2} \mathrm{O}$ nanowires were made by templated electrodeposition in a conventional three-electrode setup. As the working electrode, a polycarbonate track-etched (PCTE) membrane with a thickness of $10 \mu \mathrm{m}$, a pore size of $200 \mathrm{~nm}$ and a pore density of $\sim 3 \cdot 10^{8}$ pores $/ \mathrm{cm}^{2}$ (Whatman, UK) was covered with a $200 \mathrm{~nm}$ thick Au layer using a Perkin-Elmer 2400 sputtering system operating at $50 \mathrm{~W}$, a deposition pressure of $2 \cdot 10^{-2} \mathrm{mbar}$ and $\mathrm{Ar}$ as sputtering gas. Prior to deposition, the 
backside of the Au layer was isolated to ensure exclusive deposition inside the pores of the membrane and avoid deposition on the external surface of the Au layer. A Pt sheet (Metrohm Autolab) was used as counter electrode and $\mathrm{Ag} / \mathrm{AgCl}$ in $3 \mathrm{M} \mathrm{KCl}$ (Metrohm Autolab) was used as reference electrode. The electrodes were connected to an Autolab PGSTAT 128N potentiostat.

$\mathrm{p}-\mathrm{Cu}_{2} \mathrm{O}$ was deposited at $-0.4 \mathrm{~V}$ vs. $\mathrm{Ag} / \mathrm{AgCl}$ from an aqueous electrolyte containing $0.02 \mathrm{M} \mathrm{CuSO}_{4}$ and $0.4 \mathrm{M}$ lactic acid. Before deposition, the solution was adjusted to $\mathrm{pH} 11$ using $\mathrm{NaOH}$ and $\mathrm{H}_{2} \mathrm{SO}_{4}$, and heated to a temperature of $60{ }^{\circ} \mathrm{C} . \mathrm{n}-\mathrm{Cu}_{2} \mathrm{O}$ was deposited at $0.02 \mathrm{~V} \mathrm{vs}$. $\mathrm{Ag} / \mathrm{AgCl}$ from an aqueous solution containing $0.02 \mathrm{M} \mathrm{Cu}\left(\mathrm{CH}_{3} \mathrm{COO}\right)_{2}$ and $0.08 \mathrm{M}$ acetic acid. Before deposition, this solution was adjusted to $\mathrm{pH} 4.9$ and heated to a temperature of $70{ }^{\circ} \mathrm{C}$. Multisegmented nanowires containing both $\mathrm{p}$ - and n-type $\mathrm{Cu}_{2} \mathrm{O}$ were made by sequential electrodeposition of these phases in the same template. Table 6.1 gives an overview of the different nanowires made and characterized for photocatalytic $\mathrm{H}_{2}$ formation in this study.

Table 6.1: Overview of the different nanowires made in this study showing their composition, number of $p-n$ interfaces, deposition time, approximate nanowire length and approximate length of the individual segments.

\begin{tabular}{llllll}
\hline $\begin{array}{l}\text { Sample } \\
\text { name }\end{array}$ & Composition & $\begin{array}{l}\# p-n \\
\text { interfaces }\end{array}$ & $\begin{array}{l}\text { Deposition } \\
\text { time }(\mathrm{s})\end{array}$ & $\begin{array}{l}\text { Nanowire } \\
\text { length }(\mu \mathrm{m})\end{array}$ & $\begin{array}{l}\text { Segment } \\
\text { length }(\mathrm{nm})\end{array}$ \\
\hline $\mathrm{p}-\mathrm{Cu}_{2} \mathrm{O}$ & $\mathrm{p}-\mathrm{Cu}_{2} \mathrm{O}$ & 0 & $1 \times 2400$ & 3.3 & 3,300 \\
$1 \mathrm{xp} \mid \mathrm{n}$ & $\mathrm{p} \mid \mathrm{n}-\mathrm{Cu}_{2} \mathrm{O}$ & 1 & $2 \times 1200$ & 3.5 & 1,750 \\
$2 \mathrm{x} \mid \mathrm{n}$ & $\mathrm{p}|\mathrm{n}| \mathrm{p} \mid \mathrm{n}-\mathrm{Cu}_{2} \mathrm{O}$ & 3 & $4 \times 600$ & 3.8 & 950 \\
$3 x \mathrm{p} \mid \mathrm{n}$ & $\mathrm{p}|\mathrm{n}| \mathrm{p}|\mathrm{n}| \mathrm{p} \mid \mathrm{n}-\mathrm{Cu}_{2} \mathrm{O}$ & 5 & $6 \times 400$ & 4.1 & 680 \\
$4 \mathrm{x} \mid \mathrm{n}$ & $\mathrm{p}|\mathrm{n}| \mathrm{p}|\mathrm{n}| \mathrm{p}|\mathrm{n}| \mathrm{p} \mid \mathrm{n}-\mathrm{Cu}_{2} \mathrm{O}$ & 7 & $8 \times 300$ & 4.3 & 540 \\
$1 \mathrm{x}$ short & $\mathrm{p} \mid \mathrm{n}-\mathrm{Cu}_{2} \mathrm{O}$ & 1 & $2 \times 400$ & 1.6 & 800 \\
\hline
\end{tabular}

After deposition, the PCTE membranes were dissolved in $\mathrm{CH}_{2} \mathrm{Cl}_{2}$ to release the nanowires into solution. Subsequently, the solution was washed at least 3 times with fresh $\mathrm{CH}_{2} \mathrm{Cl}_{2}$ using a Hermle $\mathrm{Z36HK}$ centrifuge to remove dissolved polymeric residues. For visualization of the nanowires by SEM and measurement of the $I-V$ curves, a droplet of solvent containing nanowires was dried on a Si substrate. Scanning Electron Microscopy (SEM) images were taken using a Zeiss Merlin HRSEM. Samples were measured by $X$-ray powder diffraction (XRD) with the nanowires still in the membranes using a PANalytical X'Pert Pro (PANalytical B.V., Almelo, The Netherlands) instrument from $2 \theta=20-85^{\circ}$, with step sizes of $0.013^{\circ}$ and $29 \mathrm{~s}$ per step using a PIXcel 1D scanning line detector. The spectra were further analyzed using the X'Pert Highscore Plus software package (version 3.0e). 
I-V curves were measured with an Omicron LT Nanoprobe 4-probe system at room temperature connected to a Keithley 2601 Sourcemeter and HP $3488 \mathrm{~A}$ multiplexing unit. DC-etched $\mathrm{W}$ tips were prepared using a heating contact with a Ta foil through which $8 \mathrm{~A}$ of current was sent, and the tips were positioned by a Matrix SPM Control System. A Zeiss Gemini (Omicron UHV version) SEM operated at 5kV/1nA and a working distance of $19 \mathrm{~mm}$ was used for visualization of the tip positions on the sample. The working pressure of the system was of the order of $10^{-10}$ mbar. The tips were landed softly on the sample in the auto approach mode for STM. The tips were indented 10-20 nm nominally for electrical contacting the wires. During I-V measurements, the SEM beam was blanked. 2-point measurements were used to check the contact of each tip to the nanowire surface before the 4-point measurements were performed. If necessary, the tips were cleaned by putting them into electrical contact with each other while applying a current of $1 \mathrm{~mA}$. Degassing of the sample was done at $\sim 200{ }^{\circ} \mathrm{C}$ on a radiative heater for five minutes, which removed residual water.

The photocatalytic activity of the $\mathrm{p} \mid \mathrm{n}-\mathrm{Cu}_{2} \mathrm{O}$ nanowires with different numbers of $p$ - and $n$-type segments was investigated by $\mathrm{H}_{2}$ evolution experiments in a custom-made setup consisting of 8 top-illuminated reactors with a volume of $36.4 \mathrm{~mL}$ each. These reactors were connected to a Compact gas chromatograph (GC) (Interscience BV) equipped with a thermal conductivity detector (TCD). 4 $\mathrm{mg}$ of nanowires was dispersed in $15 \mathrm{~mL}$ of an aqueous solution containing $1.0 \mathrm{M} \mathrm{Na}_{2} \mathrm{SO}_{4}$ and $0.1 \mathrm{M} \mathrm{K}_{2} \mathrm{HPO}_{4}$ at $\mathrm{pH} 4.9$ that was bubbled with $\mathrm{Ar}$ gas for at least 30 min to remove a large part of $\mathrm{O}_{2}$ from the solution. Then the reactors were evacuated to $3 \mathrm{mbar}$ and subsequently filled with Ar to remove a large part of the air from the head space in the reactors. After three evacuations, a $120 \mathrm{~W}$ high pressure Mercury lamp (Dr. Gröbel UV-Elektronic GmbG) was turned on, of which the emission was divided over 12 optical fibers. During illumination, the amount of formed $\mathrm{H}_{2}$ was measured subsequently in each reactor using a standard procedure consisting of 5 measurements with an interval of $1.5 \mathrm{~h}$. 


\subsection{Results and discussion}

Figure 6.2a shows a SEM image of a $\mathrm{p} \mid \mathrm{n}-\mathrm{Cu}_{2} \mathrm{O}$ nanowire in which the $\mathrm{p}$-type segment was deposited for $840 \mathrm{~s}$ and the $\mathrm{n}$-type segment was deposited for $2100 \mathrm{~s}$. The diameter of the nanowires used for this study is $200-300 \mathrm{~nm}$, which is optimized for efficient minority electron and hole diffusion over the nanowire radius. Since both segments were made from the same material with low doping levels, it is very difficult to make a visible distinction between both segments. Only in this specific nanowire, we observed that the n-type segment had a slightly rougher surface so that a visual distinction could be made.

Figure $6.2 \mathrm{~b}$ shows the XRD pattern of $1 \times \mathrm{p} \mid \mathrm{n}-\mathrm{Cu}_{2} \mathrm{O}$ nanowires that were still embedded inside the PCTE membrane. $\mathrm{SiO}_{2}$ and $\mathrm{Au}$ peaks were observed that originated from the glass slide used for isolation of the backside of the membrane and from the $\mathrm{Au}$ back electrode, respectively. Polycrystalline $\mathrm{Cu}_{2} \mathrm{O}$ nanowires were deposited with a strong preference for the (111) direction. Even though two small peaks of an unknown impurity phase were observed, the XRD pattern did not provide any indication of unwanted deposition of $\mathrm{CuO}$ or $\mathrm{Cu}$. We also measured an XRD pattern for $\mathrm{p}-\mathrm{Cu}_{2} \mathrm{O}$ nanowires (not shown), which showed no difference with the pattern of the $\mathrm{p} \mid \mathrm{n}-\mathrm{Cu}_{2} \mathrm{O}$ nanowires, indicating that $\mathrm{n}-\mathrm{Cu}_{2} \mathrm{O}$ grew in a similar (111) oriented fashion on top of $\mathrm{p}-\mathrm{Cu}_{2} \mathrm{O}$.

We also investigated the electrical characteristics of a $1 \mathrm{x} p \mid \mathrm{n}-\mathrm{Cu}_{2} \mathrm{O}$ nanowire and a representative curve is shown in Figure 6.2c. Concerning the shape of the $I-V$ curve, we observed almost Ohmic behavior with a small semiconducting effect. After degassing the sample at elevated temperature to get rid of adsorbed water and other organic contaminants, we observed a resistivity of $1.3 \pm 0.2 \cdot 10^{2} \Omega \cdot \mathrm{cm}$ which is comparatively low for $\mathrm{Cu}_{2} \mathrm{O}$ $[13,16,17]$. This indicates that without the addition of metallic segments in between the $\mathrm{p}$ - and $\mathrm{n}$-type $\mathrm{Cu}_{2} \mathrm{O}$ segments, an Ohmic interface between the segments was spontaneously created. We expect that the small dimensions of these nanowires and the comparable nature of the $p$ - and n-type segments may have caused $\mathrm{Cu}^{2+}$ interstitials and $\mathrm{Cu}^{0}$ donors to diffuse to the interface region, where they mixed and yielded a heavily doped layer with Ohmic properties. The advantage of spontaneous formation of an Ohmic interface between the $p$ - and n-type nanowire segments is that there is no need to incorporate metallic segments in between the $p$ - and 
n-type segments, which would have induced additional metal-metal oxide interfaces that are mechanically not as strong as an interface of the same material.
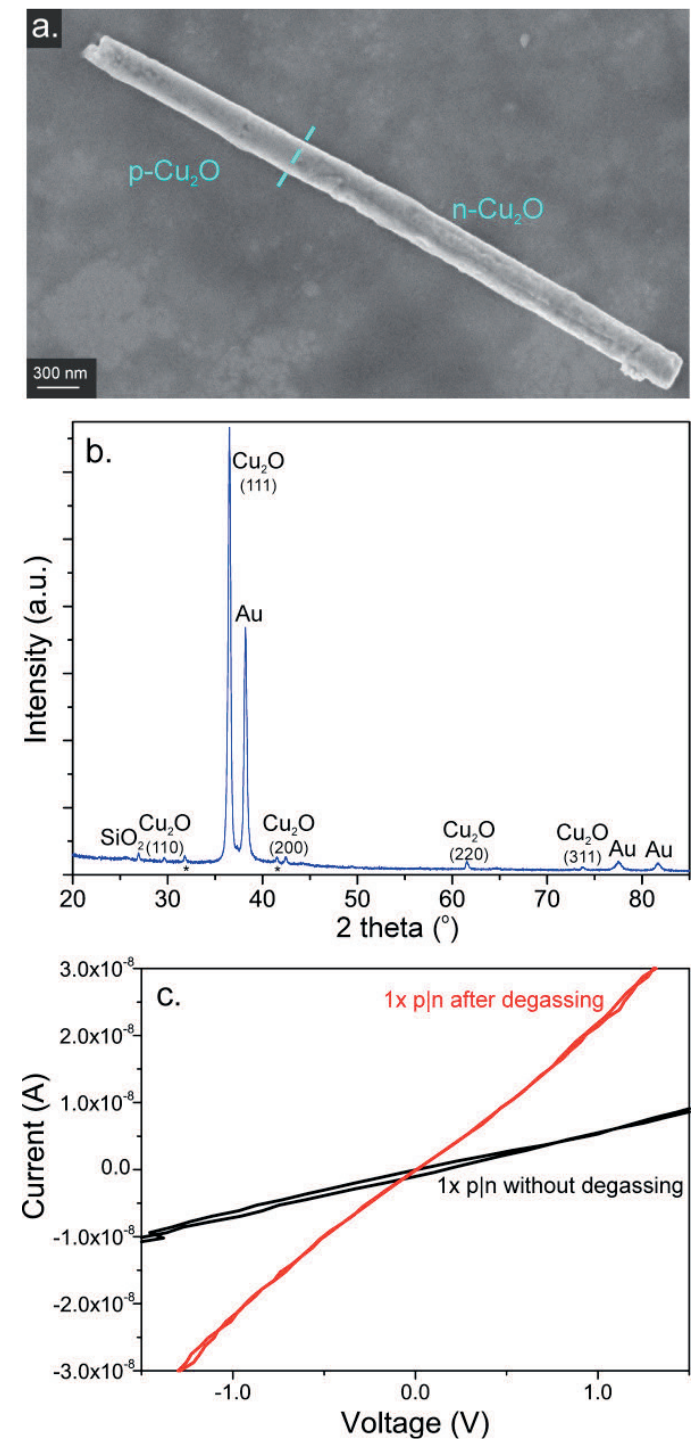

Figure 6.2: (a) SEM image of a $p \mid n-\mathrm{Cu}_{2} \mathrm{O}$ nanowire, (b) XRD pattern of $p \mid n-\mathrm{Cu}_{2} \mathrm{O}$ nanowires embedded inside a PCTE membrane: Diffraction peaks were assigned to $\mathrm{Au}$ (PDF \# 00-004-0784), $\mathrm{Cu}_{2} \mathrm{O}$ (PDF \# 00-005-0667) and $\mathrm{SiO}_{2}$ (PDF \# 00-046-1045); An unknown impurity phase is denoted with an asterisk (*), and (c) I-V curves measured on a single $\mathrm{p} \mid \mathrm{n}-\mathrm{Cu}_{2} \mathrm{O}$ nanowire before (black curve) and after (red curve) degassing of adsorbed water vapour. 
The photocatalytic activity of $\mathrm{p} \mid \mathrm{n}-\mathrm{Cu}_{2} \mathrm{O}$ nanowires was measured by detection of the amount of $\mathrm{H}_{2}$ formed during water splitting experiments for which the nanowires were suspended in an aqueous solution. In Figure 6.3, the amount of $\mathrm{H}_{2}$ that was formed during photocatalytic experiments is compared for three different systems: p-type $\mathrm{Cu}_{2} \mathrm{O}$ nanowires with the addition of phosphate to the electrolyte, $1 x p \mid n-\mathrm{Cu}_{2} \mathrm{O}$ nanowires with the addition of phosphate to the electrolyte, and $1 \mathrm{x} \mathrm{p} \mid \mathrm{n}-\mathrm{Cu}_{2} \mathrm{O}$ nanowires without the addition of phosphate to the electrolyte. This figure shows that the addition of $n$-type segments to make a $p$-n photoelectrochemical diode within the same nanowire enhances the amount of $\mathrm{H}_{2}$ formed with a factor 15 , because the valence band of $\mathrm{Cu}_{2} \mathrm{O}$ is insufficient for water oxidation when not coupled to another material (Figure 6.1b).

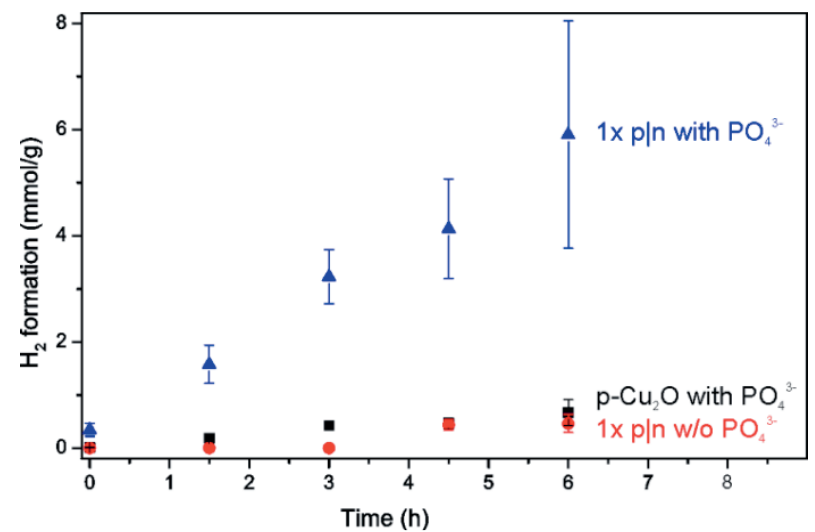

Figure 6.3: $\mathrm{H}_{2}$ formation from $\mathrm{p} \mid \mathrm{n}-\mathrm{Cu}_{2} \mathrm{O}$ nanowires dispersed in an aqueous solution containing 1.0 $\mathrm{M} \mathrm{Na}_{2} \mathrm{SO}_{4}$ with and without $0.1 \mathrm{M} \mathrm{K}_{2} \mathrm{HPO}_{4}$ at $\mathrm{pH}$ 4.9: p-type $\mathrm{Cu}_{2} \mathrm{O}$ nanowires with $\mathrm{PO}_{4}{ }^{3-}$ (black), $1 \mathrm{x}$ p/n- $\mathrm{Cu}_{2} \mathrm{O}$ nanowires with $\mathrm{PO}_{4}{ }^{3-}$ (blue), and $1 \times \mathrm{p} \mid \mathrm{n}-\mathrm{Cu}_{2} \mathrm{O}$ nanowires without $\mathrm{PO}_{4}{ }^{3-}$ (red).

Figure 6.3 also shows the difference in photocatalytic activity of $1 \times \mathrm{p} \mid \mathrm{n}-\mathrm{Cu}_{2} \mathrm{O}$ with or without the addition of phosphate to the electrolyte. It was observed that the availability of phosphate in the electrolyte was essential for $\mathrm{H}_{2}$ evolution using $\mathrm{p} \mid \mathrm{n}-\mathrm{Cu}_{2} \mathrm{O}$ nanowires, suggesting that phosphate acts as a hole scavenger on the $\mathrm{n}-\mathrm{Cu}_{2} \mathrm{O}$ surface. With our setup, we could not monitor the formation of $\mathrm{O}_{2}$ during water splitting due to the incomplete removal of dissolved $\mathrm{O}_{2}$ from the solution, so therefore it is unknown whether this difference in activity is due to a thermodynamically or kinetically unfavorable oxidation of water. 
Although the same total deposition time was used for all nanowires, the average nanowire length increased from 3.5 to $4.3 \mu \mathrm{m}$ when the number of $p$ - and n-type segments was increased from 1 to 4 (Figure 6.4). The increase can be explained by an increased deposition rate at the beginning of each segment: the ion concentration inside the membrane pores has a chance to reach high values similar to the bulk of the solution when the membrane is immersed in a solution for deposition of a new segment. As a result, the nanowire growth rate is higher in the beginning of a new section than in later stages, when the ion concentration in the pore has lower values.

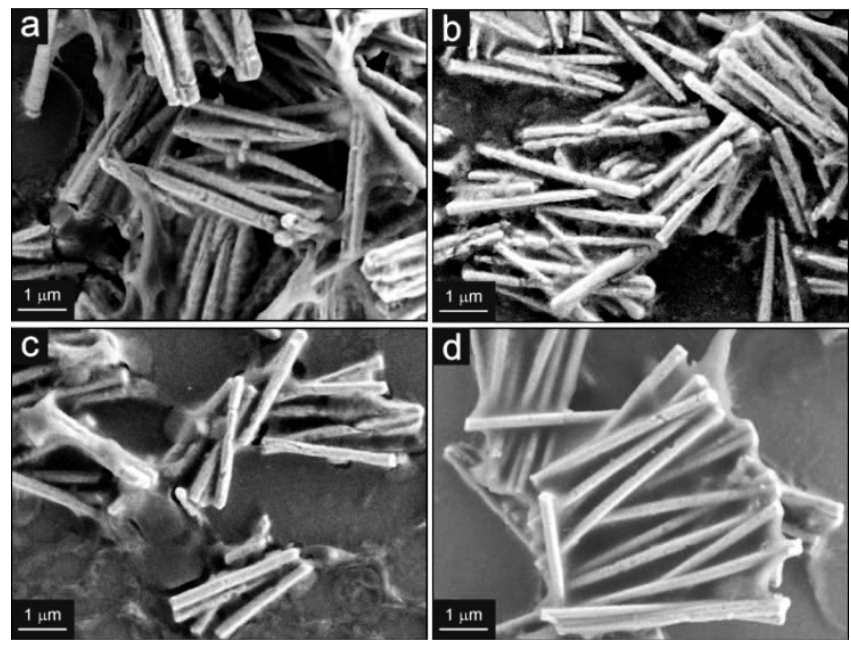

Figure 6.4: SEM images of $\mathrm{p} \mid \mathrm{n}-\mathrm{Cu}_{2} \mathrm{O}$ nanowires containing different numbers of p- and n-type segments: (a) $1 x \mathrm{p} \mid \mathrm{n}-\mathrm{Cu}_{2} \mathrm{O}$ nanowires, (b) $2 \mathrm{x} / \mathrm{n}-\mathrm{Cu}_{2} \mathrm{O}$ nanowires, (c) $3 \times \mathrm{p} \mid \mathrm{n}-\mathrm{Cu}_{2} \mathrm{O}$ nanowires, and (d) $4 \times \mathrm{p} \mid \mathrm{n}-\mathrm{Cu}_{2} \mathrm{O}$ nanowires.

Figure 6.5 shows the amount of $\mathrm{H}_{2}$ that was formed using $\mathrm{p} \mid \mathrm{n}-\mathrm{Cu}_{2} \mathrm{O}$ nanowires with different numbers of $p$ - and $n$-type doped segments. By increasing the number of $\mathrm{p}$ - and n-type segments within one nanowire, the $\mathrm{H}_{2}$ formation rate initially increased, but it was lower for nanowires with $3 \mathrm{x}$ and $4 \mathrm{xp} \mid \mathrm{n}-\mathrm{Cu}_{2} \mathrm{O}$ segments. Since $\mathrm{Cu}_{2} \mathrm{O}$, like most semiconductors, has a very poor conductivity, it was expected a priori that the $\mathrm{H}_{2}$ formation rate would increase even further with further addition of $p$ - and n-type segments. However, this was not the case in our experiments. A possible explanation for the difference between experiments and expectations can be an increased chance of breaking of the nanowires at the $p$-n interface, releasing a number of singly doped $p$ - or $n$-type nanowires that are less 
capable of $\mathrm{H}_{2}$ formation, as illustrated in Figure 6.3. In order to validate this hypothesis, also shorter $1 \mathrm{x} p \mid \mathrm{n} \mathrm{Cu}_{2} \mathrm{O}$ nanowires with a deposition time similar to $3 \mathrm{x} \mathrm{p} / \mathrm{n} \mathrm{Cu}_{2} \mathrm{O}$ nanowires were prepared and characterized. Although the length of the individual segments of these nanowires was in between those of $2 x$ and $3 x p \mid n-\mathrm{Cu}_{2} \mathrm{O}$ nanowires, the $\mathrm{H}_{2}$ formation rate of these shorter nanowires fell in between that of $1 \mathrm{x}$ and $3 \mathrm{x} p \mid \mathrm{n} \mathrm{Cu}_{2} \mathrm{O}$ nanowires. This suggests that breaking of the nanowires at a $p$-n interface could indeed be the reason for decreased activity, since the smaller number of $p-n$ interfaces had a positive effect on the $\mathrm{H}_{2}$ formation rate as the chance of breaking decreased.

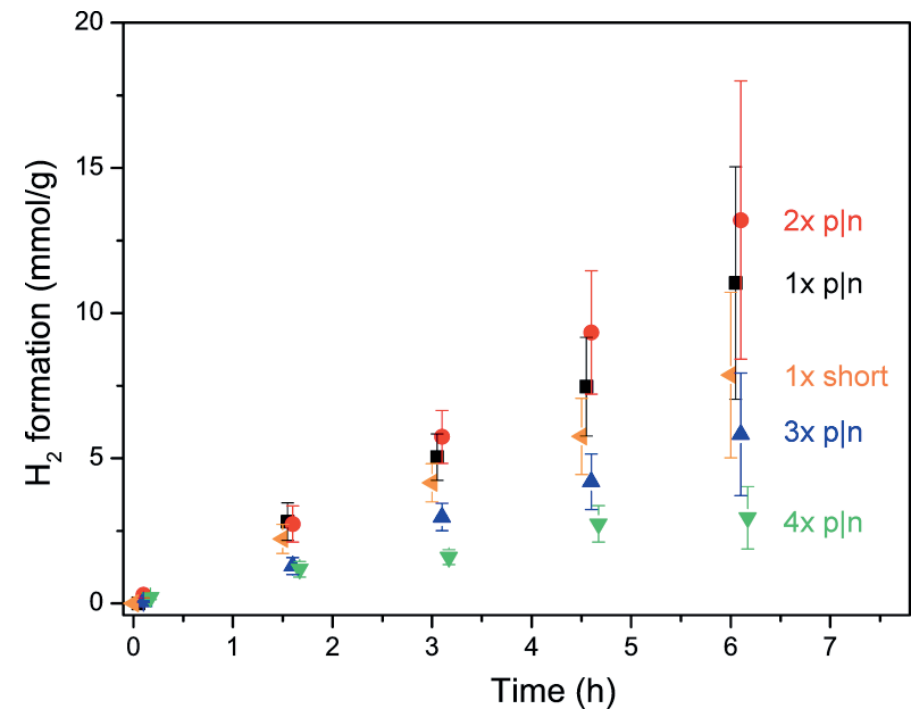

Figure 6.5: $\mathrm{H}_{2}$ formation from $\mathrm{p} \mid \mathrm{n}-\mathrm{Cu}_{2} \mathrm{O}$ nanowires dispersed in an aqueous solution containing $1.0 \mathrm{M} \mathrm{Na}_{2} \mathrm{SO}_{4}$ and $0.1 \mathrm{M} \mathrm{K}_{2} \mathrm{HPO}_{4}$ at $\mathrm{pH}$ 4.9: $1 \mathrm{x} \mathrm{p} \mid \mathrm{n}-\mathrm{Cu}_{2} \mathrm{O}$ nanowires (black), $2 \times \mathrm{p} \mid \mathrm{n}-\mathrm{Cu}_{2} \mathrm{O}$ nanowires (red), $3 \times \mathrm{p} \mid \mathrm{n}-\mathrm{Cu}_{2} \mathrm{O}$ nanowires (blue), $4 \times \mathrm{p} \mid \mathrm{n}-\mathrm{Cu}_{2} \mathrm{O}$ nanowires (green), and $1 \times$ short $\mathrm{p} \mid \mathrm{n}-\mathrm{Cu}_{2} \mathrm{O}$ nanowires (orange).

As can be observed in Figure 6.5, the $\mathrm{H}_{2}$ formation rate of the $2 x \mathrm{p} \mid \mathrm{n}-\mathrm{Cu}_{2} \mathrm{O}$ nanowires is $2.2 \pm 0.5 \mathrm{mmol} / \mathrm{g} \cdot \mathrm{h}$, which is almost two times higher than the $\mathrm{H}_{2}$ formation rate of coaxial $\mathrm{TiO}_{2}-\mathrm{Ag}$ nanowires consisting of $\mathrm{TiO}_{2}$ nanotubes filled with $\mathrm{Ag}(1.2 \pm 0.3 \mathrm{mmol} / \mathrm{g} \cdot \mathrm{h})$, which we previously measured using the same setup [11]. Since $\mathrm{Cu}_{2} \mathrm{O}$ has a smaller band gap than $\mathrm{TiO}_{2}$, this is probably the main reason for the improved $\mathrm{H}_{2}$ formation rate as a larger section of the solar spectrum can be captured by these $\mathrm{Cu}_{2} \mathrm{O}$ nanowires. Although the $\mathrm{TiO}_{2}-\mathrm{Ag}$ system has a coaxial nanowire structure that has a much larger junction area than the axially segmented $\mathrm{p} \mid \mathrm{n}-\mathrm{Cu}_{2} \mathrm{O}$ nanowires, 
the gain from more efficient electron-hole separation due to a larger junction area appears to be less significant than the gain obtained by enhanced photon absorption in $\mathrm{Cu}_{2} \mathrm{O}$.

Several studies showed $\mathrm{H}_{2}$ evolution from $\mathrm{Cu}_{2} \mathrm{O}$ photocathodes [18-22], but to the best of our knowledge only one of those studies is comparable to ours in that a powder was dispersed in an aqueous solution so that no external circuit was needed. Hu et al. dispersed $\mathrm{p}-\mathrm{Cu}_{2} \mathrm{O}$ powder coupled with commercial n- $\mathrm{WO}_{3}$ powder, which resulted in a $\mathrm{H}_{2}$ formation rate of $\sim 2.5 \mu \mathrm{mol} / \mathrm{g} \cdot \mathrm{h}$ [20]. This value is three orders of magnitude lower than that of the $\mathrm{H}_{2}$ formation rate observed in this study, which underlines the advantage of using nanowires with a higher surface area. Other important differences between both studies are the use of phosphate as hole scavenger in this study, and the use of a light source with higher intensity by Hu et al.

$\mathrm{Cu}_{2} \mathrm{O}$ is known for its photodegradation in aqueous solutions, so therefore we investigated the stability of the $\mathrm{Cu}_{2} \mathrm{O}$ nanowires during and after $\mathrm{H}_{2}$ formation experiments. In Figure 6.5, the samples $1 \mathrm{x} p \mid n-\mathrm{Cu}_{2} \mathrm{O}$ and $2 \times \mathrm{p} \mid \mathrm{n}-\mathrm{Cu}_{2} \mathrm{O}$ did not show a decrease in photoactivity for at least $6 \mathrm{~h}$ of illumination, but in the other samples a slight decrease of photoactivity was observed. Figure 6.6 is a SEM image of $1 x \mathrm{p} \mid \mathrm{n}-\mathrm{Cu}_{2} \mathrm{O}$ nanowires after photocatalytic $\mathrm{H}_{2}$ formation experiments, showing a change in morphology from nanowires into smaller nanospheres with a wire-like arrangement. This indicates that, even though the effect on the $\mathrm{H}_{2}$ formation rate was minimal, the $\mathrm{Cu}_{2} \mathrm{O}$ nanowires used for photocatalytic $\mathrm{H}_{2}$ formation were indeed subjected to photocorrosion during the experiments. Even though photocorrosion seemed to have no influence on the outcome of the results in this study, the photocorrosion reaction needs to be suppressed before practical application of $\mathrm{Cu}_{2} \mathrm{O}$ nanowires in photocatalytic water splitting can become feasible. Methods for this are e.g. coating $\mathrm{Cu}_{2} \mathrm{O}$ with thin layers of $\mathrm{Al}: \mathrm{ZnO}$ and $\mathrm{TiO}_{2}$ or a thin layer of carbon $[3,7]$. 


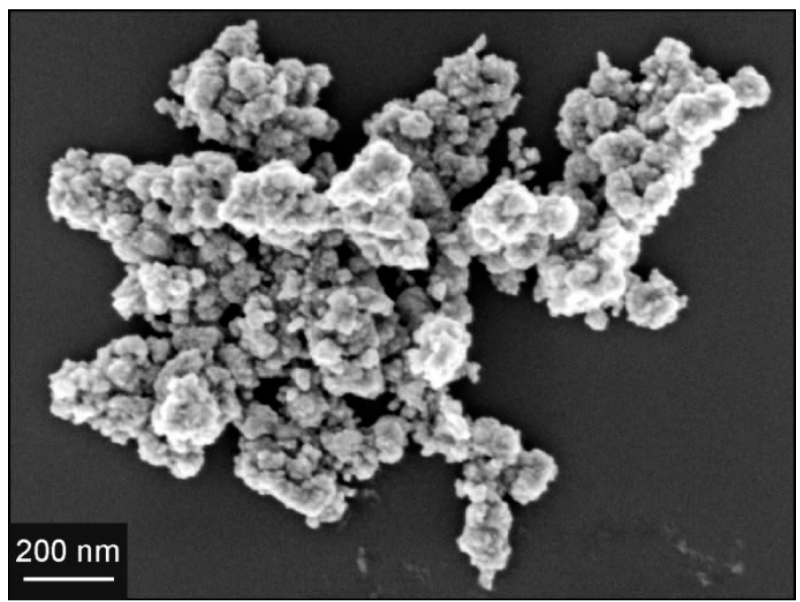

Figure 6.6: SEM image of $1 \times \mathrm{p} \mid \mathrm{n}-\mathrm{Cu}_{2} \mathrm{O}$ nanowires after $6 \mathrm{~h}$ of illumination during photocatalytic $\mathrm{H}_{2}$ formation experiments.

\subsection{Conclusions}

$\mathrm{p} \mid \mathrm{n}-\mathrm{Cu}_{2} \mathrm{O}$ nanowires showed Ohmic behavior with a relatively low resistivity of $1.3 \pm 0.2 \cdot 10^{2} \Omega \cdot \mathrm{cm}$. Diffusion and mixing of $\mathrm{Cu}^{2+}$ interstitials and $\mathrm{Cu}^{0}$ donors at the interface between the $\mathrm{p}$ - and $\mathrm{n}$-type segments resulted in the spontaneous formation of a highly conductive $\mathrm{Cu}_{2} \mathrm{O}$ layer, which spontaneously transformed the undesired $p-n$ junction in a photoelectrochemical diode with Ohmic interface layer. As a photoelectrochemical diode, these nanowires showed enhanced photocatalytic $\mathrm{H}_{2}$ formation compared to other structures. The presence of $\mathrm{PO}_{4}{ }^{3-}$ ions in the electrolyte was beneficial for photocatalytic $\mathrm{H}_{2}$ formation since these $\mathrm{PO}_{4}{ }^{3-}$ ions acted as hole scavenger. The tendency that a nanowire breaks at the $p-n$ interface increases for nanowires containing more $\mathrm{p}$ - and n-type segments, which leads to a lower photocatalytic activity. 


\subsection{References}

[1] C. M. McShane and K. S. Choi, "Junction studies on electrochemically fabricated $\mathrm{p}-\mathrm{n} \mathrm{Cu}_{2} \mathrm{O}$ homojunction solar cells for efficiency enhancement", Physical Chemistry Chemical Physics, 2012, vol. 14, pp. 6112-6118.

[2] L.-k. Tsui, L. Wu, N. Swami, and G. Zangari, "Photoelectrochemical performance of electrodeposited $\mathrm{Cu}_{2} \mathrm{O}$ on $\mathrm{TiO}_{2}$ nanotubes", ECS Electrochemistry Letters, 2012, vol. 1, pp. D15-D19.

[3] A. Paracchino, V. Laporte, K. Sivula, M. Grätzel, and E. Thimsen, "Highly active oxide photocathode for photoelectrochemical water reduction", Nature Materials, 2011, vol. 10, pp. 456-461.

[4] P. E. De Jongh, D. Vanmaekelbergh, and J. J. Kelly, "Photoelectrochemistry of electrodeposited $\mathrm{Cu}_{2} \mathrm{O}$ ", Journal of the Electrochemical Society, 2000, vol. 147, pp. 486-489.

[5] C. J. Engel, T. A. Polson, J. R. Spado, J. M. Bell, and A. Fillinger, "Photoelectrochemistry of porous $\mathrm{p}-\mathrm{Cu}_{2} \mathrm{O}$ films", Journal of the Electrochemical Society, 2008, vol. 155, pp. F37-F42.

[6] S. Sunkara, V. K. Vendra, J. H. Kim, T. Druffel, and M. K. Sunkara, "Scalable synthesis and photoelectrochemical properties of copper oxide nanowire arrays and films", Catalysis Today, 2013, vol. 199, pp. 27-35.

[7] Z. Zhang, R. Dua, L. Zhang, H. Zhu, H. Zhang, and P. Wang, "Carbon-layer-protected cuprous oxide nanowire arrays for efficient water reduction", ACS Nano, 2013, vol. 7, pp. 1709-1717.

[8] Y. Tan, X. Xue, Q. Peng, H. Zhao, T. Wang, and Y. Li, "Controllable fabrication and electrical performance of single crystalline $\mathrm{Cu}_{2} \mathrm{O}$ nanowires with high aspect ratios", Nano Letters, 2007, vol. 7, pp. 3723-3728.

[9] A. J. Nozik, "Photochemical diodes", Applied Physics Letters, 1977, vol. 30, pp. 567-569.

[10] A. W. Maijenburg, E. J. B. Rodijk, M. G. Maas, M. Enculescu, D. H. A. Blank, and J. E. ten Elshof, "Hydrogen generation from photocatalytic silver|zinc oxide nanowires: Towards multifunctional multisegmented nanowire devices", Small, 2011, vol. 7, pp. 2709-2713. 
[11] A. W. Maijenburg, J. Veerbeek, R. d. Putter, S. A. Veldhuis, M. G. C. Zoontjes, G. Mul, J. M. Montero, K. Nielsch, H. Schäfer, M. Steinhart, and J. E. t. Elshof, "Electrochemical synthesis of coaxial $\mathrm{TiO}_{2}$-Ag nanowires and their application for photocatalytic water splitting", Accepted in Journal of Materials Chemistry A.

[12] K. Han and M. Tao, "Electrochemically deposited p-n homojunction cuprous oxide solar cells", Solar Energy Materials and Solar Cells, 2009, vol. 93, pp. 153-157.

[13] C. M. McShane, W. P. Siripala, and K. S. Choi, "Effect of junction morphology on the performance of polycrystalline $\mathrm{Cu}_{2} \mathrm{O}$ homojunction solar cells", Journal of Physical Chemistry Letters, 2010, vol. 1, pp. 2666-2670.

[14] L. Xiong, S. Huang, X. Yang, M. Qiu, Z. Chen, and Y. Yu, "p-Type and n-type $\mathrm{Cu}_{2} \mathrm{O}$ semiconductor thin films: Controllable preparation by simple solvothermal method and photoelectrochemical properties", Electrochimica Acta, 2011, vol. 56, pp. 2735-2739.

[15] D. O. Scanlon and G. W. Watson, "Undoped n-type $\mathrm{Cu}_{2} \mathrm{O}$ : Fact or fiction?", Journal of Physical Chemistry Letters, 2010, vol. 1, pp. 2582-2585.

[16] S. Cheng Siah, Y. Seog Lee, Y. Segal, and T. Buonassisi, "Low contact resistivity of metals on nitrogen-doped cuprous oxide $\left(\mathrm{Cu}_{2} \mathrm{O}\right)$ thin-films", Journal of Applied Physics, 2012, vol. 112, pp. 1-5.

[17] A. A. Ogwu, T. H. Darma, and E. Bouquerel, "Electrical resistivity of copper oxide thin films prepared by reactive magnetron sputtering", Journal of Achievements in Materials and Manufacturing Engineering, 2007, vol. 24, pp. 172-177.

[18] D. Barreca, P. Fornasiero, A. Gasparotto, V. Gombac, C. Maccato, T. Montini, and $\mathrm{E}$. Tondello, "The potential of supported $\mathrm{Cu}_{2} \mathrm{O}$ and $\mathrm{CuO}$ nanosystems in photocatalytic $\mathrm{H}_{2}$ production", ChemSusChem, 2009, vol. 2, pp. 230-233.

[19] A. D. Handoko and J. Tang, "Controllable proton and $\mathrm{CO}_{2}$ photoreduction over $\mathrm{Cu}_{2} \mathrm{O}$ with various morphologies", International Journal of Hydrogen Energy, 2013,

[20] C. C. Hu, J. N. Nian, and H. Teng, "Electrodeposited p-type $\mathrm{Cu}_{2} \mathrm{O}$ as photocatalyst for $\mathrm{H}_{2}$ evolution from water reduction in the presence of $\mathrm{WO}_{3} "$, Solar Energy Materials and Solar Cells, 2008, vol. 92, pp. 1071-1076. 
[21] J. N. Nian, C. C. Hu, and H. Teng, "Electrodeposited p-type $\mathrm{Cu}_{2} \mathrm{O}$ for $\mathrm{H}_{2}$ evolution from photoelectrolysis of water under visible light illumination", International Journal of Hydrogen Energy, 2008, vol. 33, pp. 2897-2903.

[22] M. K. I. Senevirathna, P. K. D. D. P. Pitigala, and K. Tennakone, "Water photoreduction with $\mathrm{Cu}_{2} \mathrm{O}$ quantum dots on $\mathrm{TiO}_{2}$ nano-particles", Journal of Photochemistry and Photobiology A: Chemistry, 2005, vol. 171, pp. 257-259. 


\section{Ni and $\mathrm{p}-\mathrm{Cu}_{2} \mathrm{O}$ nanocubes with a small size distribution by templated electrodeposition, and their characterization by photocurrent measurement}

This chapter presents an new approach for the synthesis of nanocubes by templated electrodeposition in a PMMA photoresist containing a cubic hole pattern. In this chapter, $\mathrm{Ni}$ and $\mathrm{p}-\mathrm{Cu}_{2} \mathrm{O}$ nanocubes were successfully made inside these templates. It is also shown that the photocurrent measured for $\mathrm{p}-\mathrm{Cu}_{2} \mathrm{O}$ nanocube samples was twice that of planar films made using the same electrodeposition conditions.

This chapter is published as:

A. W. Maijenburg, A. N. Hattori, M. De Respinis, C. M. McShane, K.-S. Choi, B. Dam, $\mathrm{H}$. Tanaka, and J. E. ten Elshof, "Ni and $\mathrm{p}-\mathrm{Cu}_{2} \mathrm{O}$ nanocubes with a small size distribution by templated electrodeposition and their characterization by photocurrent measurement", ACS Applied Materials \& Interfaces, 2013, vol. 5, pp. 10938-10945. 


\subsection{Abstract}

A method for reproducible formation of $\mathrm{Ni}$ and $\mathrm{Cu}_{2} \mathrm{O}$ nanocubes with dimensions of 200-500 $\mathrm{nm}$ and a small size distribution is introduced. For this, the well-known templated electrodeposition technique was extended to cubic PMMA templates made by nanoimprint lithography. When cubic templates would be made in larger quantities, this method has the potential to become simple and cost-effective. This method was successfully used for the formation of $\mathrm{Ni}$ and $\mathrm{p}-\mathrm{Cu}_{2} \mathrm{O}$ nanocubes, and for the formation of segmented nanobars containing both phases. The lateral dimensions of the nanocubes exactly resembled the dimensions of the template, and the height could be varied by adjustment of deposition time. Nanocubes formed via this method can either remain attached to the substrate or can be dispersed in solution. $\mathrm{p}-\mathrm{Cu}_{2} \mathrm{O}$ is considered to be one of the most promising photocathode materials for solar water splitting. It is demonstrated that the activity of the $\mathrm{p}-\mathrm{Cu}_{2} \mathrm{O}$ nanocubes for photocatalytic water splitting can be measured, and it was found that the nanocube morphology enhances the photocatalytic activity compared to thin films.

\subsection{Introduction}

The synthesis of nanoparticles of well-defined shape and size has attracted large interest over the past decades as material properties and functionality can be tuned by changing the shape and size of the particles. Particularly, the synthesis of nanocubes has attracted large interest. For self-assembly purposes it is advantageous to have an object of cubic symmetry with well-defined facets. Park et al. showed that assembly and disassembly of nanoparticles by DNA linkers strongly depends on the curvature of the exposed facets [1], and other authors showed the high potential of nanocubes for self-assembly processes as well [2-7]. Nanocubes can also show catalytic performance. The catalytic activity depends on the crystal facet that is exposed, and differs between polycrystalline and single-crystalline facets. For instance, $X u$ et al. investigated the electrocatalytic activity of $\mathrm{Pt}-\mathrm{Cu}$ nanocubes for the oxidation of methanol and formic acid $[8,9]$, and Jalem et al. used Pt nanocube-mosaics for the electro-oxidation of methanol [10]. Nanocubes are also considered for other applications, e.g. in photocatalysis [11-14], fuel cells $[15,16]$, 
batteries [17-19], biomedical applications [20-23], and surface-enhanced Raman scattering [24-29].

The most commonly used technique for making nanocubes in solution is the polyol process for $\mathrm{Ag}[30-32], \mathrm{Cu}_{2} \mathrm{O}[17,33]$, and $\alpha-\mathrm{NaYF}_{4}$ nanocubes [34]. Au nanocubes are typically prepared by electrochemical synthesis $[35,36]$ or surfactant-mediated growth [37-39]. Other innovative techniques for nanocube synthesis include particle replication in non-wetting templates (PRINT) [40], biological synthesis [41], and electrodeposition on graphene paper [15]. Unfortunately, none of these techniques allow for the synthesis of nanocubes of various materials having a small size distribution. Another disadvantage of these techniques is that the window of experimental conditions to make nanocubes is usually very small, i.e. a small deviation from the required conditions results in the formation of a heterogeneous distribution of nanoparticles with various sizes and shapes.

Templated electrodeposition is a widely used technique for the formation of nanowires and nanotubes of desired composition having a small size distribution [42-45]. The only requirement for templated electrodeposition is the availability of a template with the desired dimensions and shape, and a conductive layer for electron transport. In the case of nanowires and nanotubes, typically track-etched polycarbonate (PCTE) and anodized aluminum oxide (AAO) membranes have been used as templates, either commercially available or custom made. In both cases, billions of cylindrical pores are created within a few processing steps. While templates containing cylindrical pores are readily available, templates containing cubic pores for templated electrodeposition of nanocubes have not been reported.

In this chapter, an approach is presented to synthesize metal and metal oxide nanocubes by templated electrodeposition in cubic templates formed by nanoimprint lithography (NIL). NIL is a promising technique to create templates with innovative shapes for templated electrodeposition as it can form patterns with a resolution as small as $10 \mathrm{~nm}$ over a large area at high throughput and low cost [46-50]. Once a mold is made, e.g. by e-beam lithography (EBL) or focused ion beam (FIB), the mold can be reused as often as needed and the NIL pattern will perfectly replicate the inverse of the mold. The most commonly used photoresist for NIL is polymethylmethacrylate (PMMA). Previously, Ross et al. used similar 
lithographically patterned resist layers containing cylindrical holes for the electrodeposition of magnetic nanostructures [51, 52].

The electrodeposition of $\mathrm{Ni}$ nanocubes is used as an example to show the feasibility of PMMA photoresist templates for templated electrodeposition of new types of nanostructures, which can either stay attached to the substrate or be dispersed in solution. We also deposited single component $\mathrm{p}-\mathrm{Cu}_{2} \mathrm{O}$ nanocubes, which showed a higher photocatalytic activity towards $\mathrm{H}_{2}$ evolution than $\mathrm{p}-\mathrm{Cu}_{2} \mathrm{O}$ films, and multicomponent nanobars of $\mathrm{Ni}$ and $\mathrm{p}-\mathrm{Cu}_{2} \mathrm{O}$. It is envisaged that nanocubes and other nanostructures of desired composition, as well as layered nanocubes containing multiple different materials, can be made using this technique.

\subsection{Experimental details}

All chemicals used were purchased from commercial sources and used without further purification. Polymethylmethacrylate (PMMA) was purchased from Tokyo Ohka Kogyo Co., LTD; nickel sulfate hexahydrate ( $\mathrm{NiSO}_{4} \cdot 6 \mathrm{H}_{2} \mathrm{O}$, purity $99 \%$ ), boric acid $\left(\mathrm{H}_{3} \mathrm{BO}_{3}\right.$, purity $\left.99.99 \%\right)$ and dichloromethane $\left(\mathrm{CH}_{2} \mathrm{Cl}_{2}\right.$, purity $\left.99.9 \%\right)$ were purchased from Merck; copper sulfate pentahydrate $\left(\mathrm{CuSO}_{4} \cdot 5 \mathrm{H}_{2} \mathrm{O}\right.$, p.a. quality) and sodium sulphate $\left(\mathrm{Na}_{2} \mathrm{SO}_{4}\right.$, p.a. quality) were purchased from Boom Chemie; lactic acid (extra pure), sodium hydroxide $(\mathrm{NaOH}$, purity $98.5 \%)$, sulfuric acid $\left(\mathrm{H}_{2} \mathrm{SO}_{4}, 96 \%\right.$ in water) and dipotassium phosphate trihydrate $\left(\mathrm{K}_{2} \mathrm{HPO}_{4} .3 \mathrm{H}_{2} \mathrm{O}\right.$, purity $\left.99+\%\right)$ were purchased from Acros Organics; tetrahydrofuran (THF, purity 99\%) and gold etchant were purchased from Sigma-Aldrich; and acetone was purchased from Assink Chemie. Milli-Q water with a resistivity of $18.2 \mathrm{M} \Omega \cdot \mathrm{cm}$ was used in all experiments.

The technique for making nanopatterns is reported elsewhere [49], the difference being that in the present study Au-coated Si wafers were used as substrate for templated electrodeposition. Essentially, 4-inch Si(100) wafers were coated with a $\sim 15 \mathrm{~nm} \mathrm{Ti}$ and $\sim 75 \mathrm{~nm}$ Au layer using a Perkin-Elmer sputtering machine operating at $50 \mathrm{~W}$ at a deposition pressure of $2 \cdot 10^{-2} \mathrm{mbar}$ and $\mathrm{Ar}$ as sputtering gas. After spincoating a layer of PMMA on top of these substrates, various quartz molds containing cubic pillar patterns with a height of $200 \mathrm{~nm}$ (NTT-AT Nanofabrication Co., Japan) were used for UV-NIL at room temperature using a force of $600 \mathrm{~N}$ for 2 min of UV 
exposure by a nanoimprinter (Eitre 3, Obducat). The residual layers were removed by a $\mathrm{CF}_{4}$ and $\mathrm{O}_{2}$ plasma process using a reactive ion etching system ((RIE-10NR), Samco, Japan).

Templated electrodeposition was carried out by connecting the Au substrate containing the patterns to the working electrode in a conventional 3-electrode setup using a Pt sheet (Metrohm Autolab) as counter electrode and $\mathrm{Ag} / \mathrm{AgCl}$ in $3 \mathrm{M} \mathrm{KCl}$ (Metrohm Autolab) as reference electrode. All reported potentials are given with respect to the reference electrode unless otherwise stated. The electrodes were connected to an Autolab PGSTAT $128 \mathrm{~N}$ potentiostat. $\mathrm{Ni}$ was deposited at $-1.00 \mathrm{~V}$ from an aqueous electrolyte solution containing $0.23 \mathrm{M} \mathrm{NiSO}{ }_{4} \cdot 6 \mathrm{H}_{2} \mathrm{O}$ and $0.15 \mathrm{M} \mathrm{H}_{3} \mathrm{BO}_{3}$. $\mathrm{p}-\mathrm{Cu}_{2} \mathrm{O}$ was deposited at $-0.4 \mathrm{~V}$ from an aqueous electrolyte containing $0.02 \mathrm{M} \mathrm{CuSO}_{4}$ and $0.4 \mathrm{M}$ lactic acid. Before deposition, the solution was adjusted to $\mathrm{pH} 11$ using $\mathrm{NaOH}$ and $\mathrm{H}_{2} \mathrm{SO}_{4}$, and heated to a temperature of $60{ }^{\circ} \mathrm{C}$. During deposition, the current was monitored as a function of time using NOVA 1.9 software (Metrohm Autolab).

After deposition, the PMMA patterns were dissolved by immersing the substrates in either acetone or THF. The Au layer could be removed by immersing the substrates in a commercial gold etchant containing $\mathrm{KI} / \mathrm{I}_{2}$. For SEM imaging of the dispersed nanocubes, the gold etchant solution was first replaced at least 5 times with water by centrifugation at 10,000 rpm for 15 min using a Hermle Z36HK centrifuge. Subsequently, water was replaced with acetone by centrifugation for 3 times. The complete process of template formation and nanocube electrodeposition is schematically shown in Figure 7.1. 


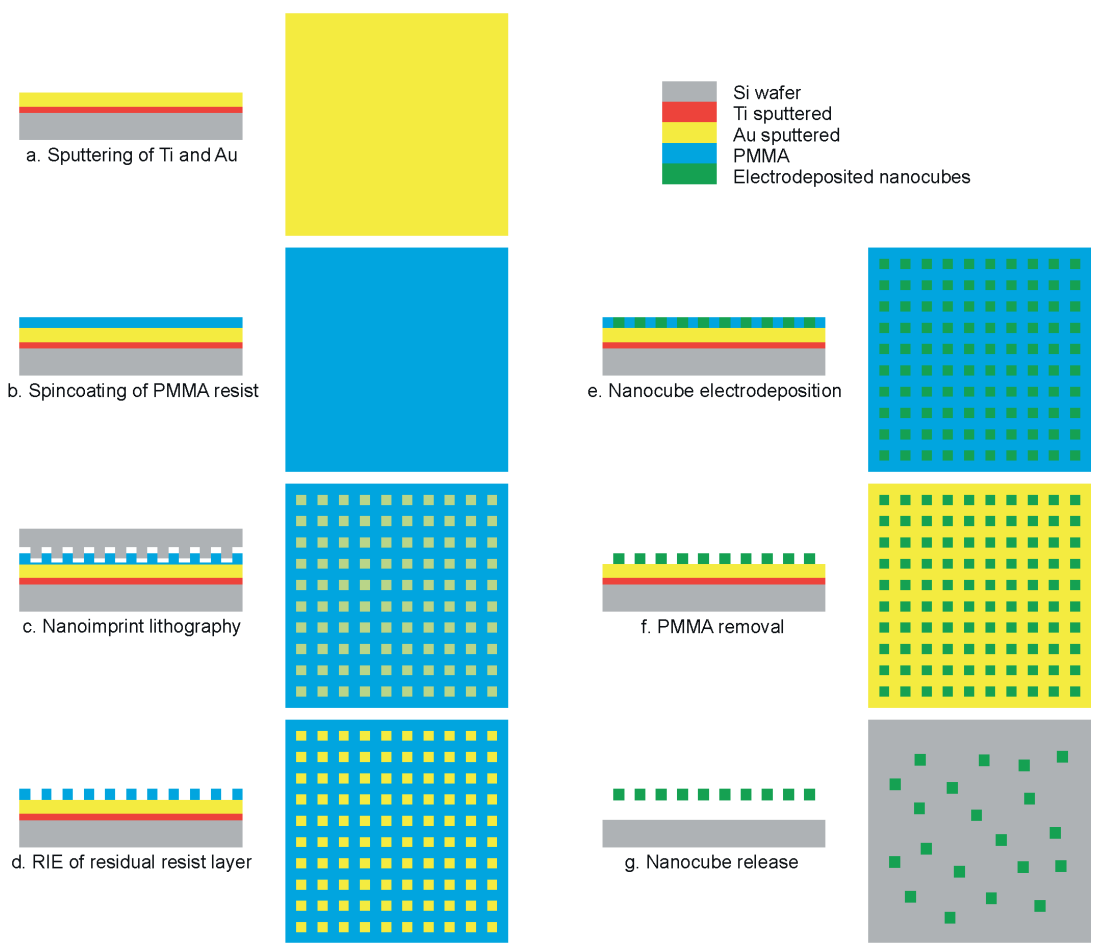

Figure 7.1. Schematic representation of template formation and nanocube electrodeposition: (a) Sputtering of Ti and Au on clean Si wafer, (b) spincoating of PMMA, (c) nanoimprint lithography with desired mask, (d) reactive ion etching (RIE) of residual resist layer, (e) electrodeposition of nanocubes inside template, (f) removal of the PMMA template, and (g) release of nanocubes using Au etchant.

Tapping-mode atomic force microscopy (AFM) images were taken using a Veeco Dimension Icon. SEM images were taken using a Zeiss HR-LEO 1550 FEG (field emission gun) SEM and a Zeiss Merlin HRSEM. X-ray diffraction (XRD) on nanocubes was performed with a Bruker D2 Phaser with a Cu K $\alpha$ X-ray source and a wavelength of $1.54 \AA$.

Photoelectrochemical characterization was carried out in an aqueous solution containing $1 \mathrm{M} \mathrm{Na}_{2} \mathrm{SO}_{4}$ and $0.1 \mathrm{M} \mathrm{K}_{2} \mathrm{HPO}_{4}$, which was adjusted to pH 4.9 using $\mathrm{H}_{2} \mathrm{SO}_{4}$ and $\mathrm{NaOH}$. The solution was purged with nitrogen prior to and during the measurements to remove any dissolved oxygen. Potential control was provided by an EG\&G PAR 283 potentiostat in a three-electrode cell with a fused silica window. An XR300 Radiometer Analytical $\mathrm{Ag} / \mathrm{AgCl}$ electrode and a coiled Pt wire were used as reference 
and counter electrodes, respectively. White-light photocurrent densities were measured under simulated AM1.5 solar illumination $\left(100 \mathrm{~mW} / \mathrm{cm}^{2}\right)$ with a Newport Sol3A Class AAA solar simulator (type 94023A-SR3). For the nanocube samples, the measured current was multiplied by 2.5 as correction factor so that only the top surface area of the nanocubes was taken into account, which was $40 \%$ of the total surface area. The potential of the photocurrent measurements was converted to the NHE reference electrode by

$E($ vs. NHE $)=E($ vs. Ag/AgCl $)+E_{\mathrm{Ag} / \mathrm{AgCl}}($ ref $)+0.0591 \mathrm{~V} \cdot \mathrm{pH}$,

$E_{\mathrm{Ag} / \mathrm{AgCl}}(\mathrm{ref})=0.1976 \mathrm{~V}$ vs. $\mathrm{NHE}$ at $25^{\circ} \mathrm{C}$.

\subsection{Results and discussion}

Figure 7.2 shows an AFM image of one of the cubic templates that were used for the experiments shown in Figure 7.3. The cubic hole patterns in this template have lateral dimensions of $200 \mathrm{~nm} \times 200 \mathrm{~nm}$ and a depth of $100 \mathrm{~nm}$. For the results shown in Figure 7.4 and Figure 7.6, templates with a depth of at least $300 \mathrm{~nm}$ were used. The major drawback of all lithography techniques for the formation of templates for nanocubes is that it is currently impossible to create perfectly sharp edges. But for the proposed applications in self-assembly and photocurrent measurements, this does not significantly influence the performance.
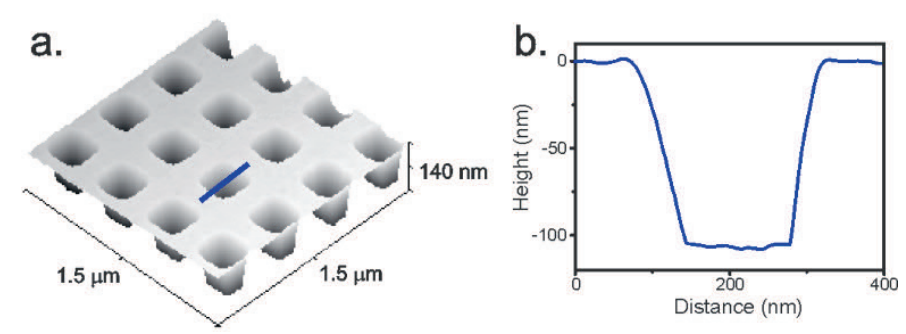

Figure 7.2. (a) AFM topography image and (b) height profile of a cubic PMMA template formed by UV-NIL. 
$\mathrm{Ni}$ was electrodeposited inside these cubic templates following a recipe that resulted in well-controlled growth and smooth films. $\mathrm{Ni}$ electrodeposition was carried out for 40-105 $\mathrm{s}$ in templates like the one presented in Figure 7.2. A chronoamperogram (I-t curve) was recorded during deposition to monitor the deposition rate of $\mathrm{Ni}$ in these templates, see Figure 7.3(a,b). As indicated by the arrow in Figure 7.3(a), the current slightly increased after $50 \mathrm{~s}$ of deposition, indicating a gradually increasing growth rate due to "mushrooming" on top of the template [45]. After $70 \mathrm{~s}$, the deposition rate became constant as the mushrooming stage was completed and a relatively flat surface covering the whole sample was formed. Because the deposition consisted of two consecutive electrodeposition steps, the $l-t$ curve shows the charging of the electrical double layer around $45 \mathrm{~s}$ when the second deposition step of $60 \mathrm{~s}$ initiated. The mushrooming effect was also observed by AFM and SEM, see Figure $7.3(c, e, g, i)$. On the other hand, when deposition was terminated before the $\mathrm{Ni}$ phase reached the top of the template, as indicated by the absence of a change in current in Figure $7.3(\mathrm{~b})$, a relatively flat nanocube top surface was observed, see Figure $7.3(\mathrm{~d}, \mathrm{f}, \mathrm{h}, \mathrm{j})$. The roughness of the top surface of these nanocubes was estimated with the root mean square (rms) method and was found to be $5 \pm 1 \mathrm{~nm}$, which is in the same range as the rms value of a $\mathrm{Ni}$ film made by electrodeposition ( $6 \mathrm{~nm}$ ). From the observation that mushrooming started after $50 \mathrm{~s}$ in a template with a depth of $100 \mathrm{~nm}$, that a mushroom with a $20 \mathrm{~nm}$ thick top was deposited after $60 \mathrm{~s}$, and that deposition was terminated $20 \mathrm{~nm}$ underneath the template surface after $40 \mathrm{~s}$ of deposition, a growth rate for Ni nanocubes of $\sim 2 \mathrm{~nm} / \mathrm{s}$ can be derived. 

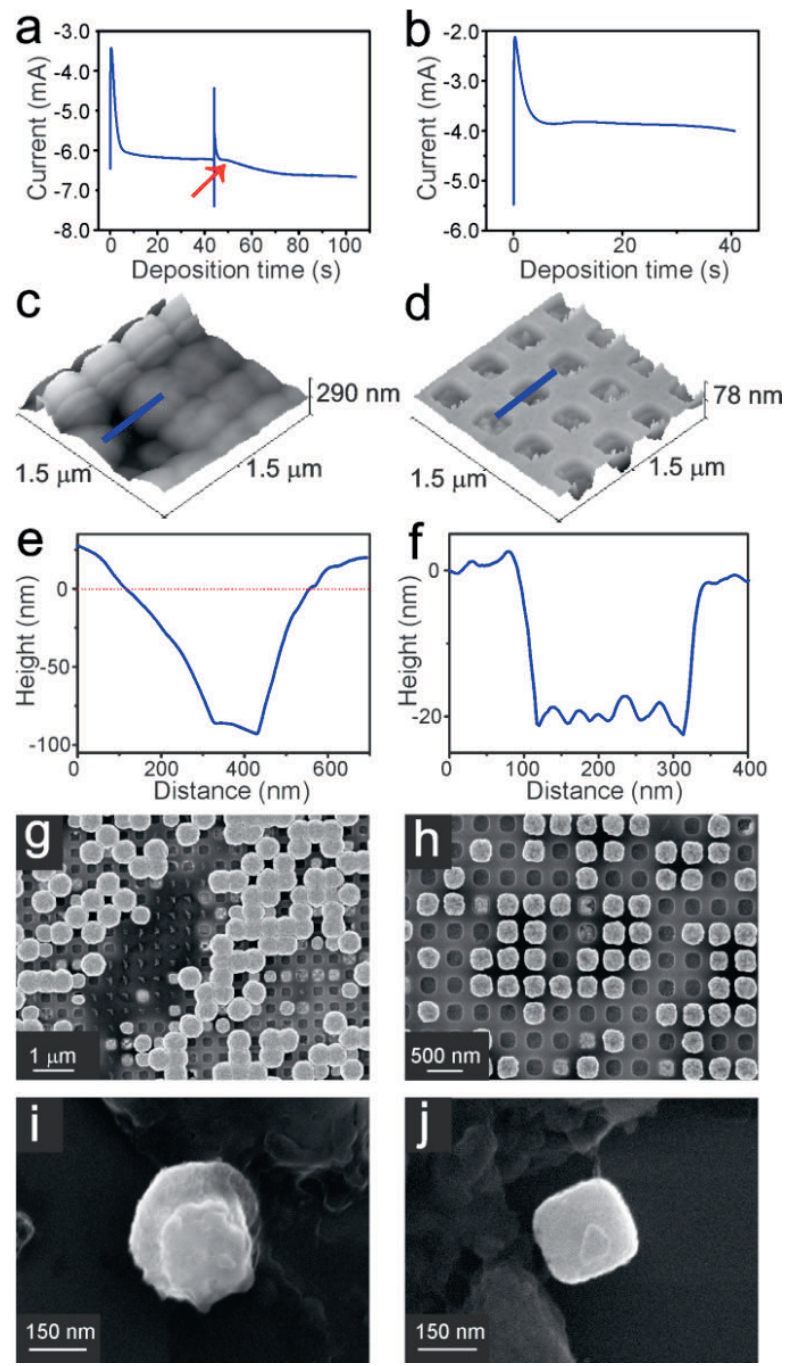

Figure 7.3. Ni electrodeposited inside PMMA templates with squared holes on $\mathrm{Au}$; (a) Chronoamperogram of $105 \mathrm{~s}$ deposition, (b) chronoamperogram of $40 \mathrm{~s}$ deposition, (c) AFM topography image of nanocubes inside the template after $60 \mathrm{~s}$ deposition, (d) AFM topography image of nanocubes inside the template after $40 \mathrm{~s}$ deposition, (e) AFM height profile taken at the blue line in (c) where the dotted red line indicates the location of the top surface of the pattern, (f) AFM height profile taken at the blue line in (d), (g) SEM image of nanocubes deposited for $60 \mathrm{~s}$ after dissolving the PMMA template, (h) SEM image of nanocubes deposited for $40 \mathrm{~s}$ after dissolving the PMMA template, (i) SEM image of nanocubes deposited for $60 \mathrm{~s}$ after dissolving the Au substrate, (j) SEM image of nanocubes deposited for $\mathbf{4 0} \mathrm{s}$ after dissolving the Au substrate. 
After the PMMA resist was dissolved in acetone, stable mushrooms or nanocubes remained on the Au substrate, see Figure 7.3(g,h). Templated electrodeposition perfectly replicates the shape of the pattern including the rounded edges of the template as seen in the formed nanocubes, see Figure $7.3(\mathrm{~h})$. The open spaces in these figures represent hole patterns where no deposition took place, probably because of the presence of a small residual resist layer that electrically shielded the conductive $\mathrm{Au}$ substrate from the liquid phase by preventing electron transfer. When the residual resist layer was completely removed by a plasma etching process before electrodeposition, all holes were filled as illustrated in Figure 7.4. Figure $7.3(\mathrm{i}, \mathrm{j})$ illustrates the possibility to disperse the deposited nanocubes in a solvent and drop cast them onto another substrate. For this, the Au substrate was dissolved in $\mathrm{Au}$ etchant in order to release the nanocubes from the substrate. After subsequent centrifugation, the $\mathrm{Au}$ etchant solution was first replaced by distilled water and then by acetone for fast drying and SEM imaging. As can be seen from the SEM images in Figure $7.3(i, j)$, the process to dissolve the Au substrate and immerse the $\mathrm{Ni}$ nanocubes did not damage the dispersed nanocubes. It is noted that this specific $\mathrm{Au}$ etchant is compatible with $\mathrm{Ni}$, so care should be taken when dispersing nanocubes of a different composition.

Metal oxides were also deposited in these cubic templates. Figure 7.4(a-e) show p-type doped $\mathrm{Cu}_{2} \mathrm{O}$ nanocubes of different sizes. Interesting to note for these nanocubes is that their surface is rougher than that of the $\mathrm{Ni}$ nanocubes since each $\mathrm{Cu}_{2} \mathrm{O}$ cube is composed of multiple very small crystallites. When the same $\mathrm{p}-\mathrm{Cu}_{2} \mathrm{O}$ electrodeposition process was carried out on an ITO or Au substrate without the use of a template, the formation of larger crystallites with a lateral dimension of $\sim 1 \mu \mathrm{m}$ or more and cubic morphology was observed $[53,54]$. The $\mathrm{p}-\mathrm{Cu}_{2} \mathrm{O}$ nanocubes deposited in the nano-sized cubic templates are composed of smaller crystallites, which suggests that the nucleation of $\mathrm{Cu}_{2} \mathrm{O}$ in the nano-sized template takes place more easily than without template. The deposition of $\mathrm{Cu}_{2} \mathrm{O}$ is a two-step process in which $\mathrm{Cu}^{+}$ions are formed by electrochemical reduction of $\mathrm{Cu}^{2+}$, and $\mathrm{Cu}^{+}$ions are subsequently precipitated to form $\mathrm{Cu}_{2} \mathrm{O}$ due to the limited solubility of $\mathrm{Cu}^{+}$in water. Therefore, the nucleation of $\mathrm{Cu}_{2} \mathrm{O}$ requires the build-up of $\mathrm{Cu}^{+}$ions exceeding its solubility limit $\left(\log \left[\mathrm{Cu}^{+}\right]=-0.84-\mathrm{pH}\right)[55]$. When $\mathrm{Cu}^{+}$ions are generated within the nanopores of a template, diffusion of $\mathrm{Cu}^{+}$ions away from the electrode should be much more difficult compared to the diffusion of $\mathrm{Cu}^{+}$ions along the planar electrode surface at which they were generated. As a result, severe supersaturation of $\mathrm{Cu}^{+}$ions 
can be easily achieved in the nanopores, facilitating the nucleation process. The formation of multiple smaller crystallites compared to the formation of fewer larger crystals is a good indication that the nucleation process is more favored than the growth process.

When we compare the nucleation densities of $\mathrm{p}-\mathrm{Cu}_{2} \mathrm{O}$ within the different dimensions of nanocube templates used, we observed a largest nucleation density for the templates with lateral dimensions of $400 \mathrm{~nm}$ and $500 \mathrm{~nm}$ depth, followed by the templates with lateral dimensions of $200 \mathrm{~nm}$ and $350 \mathrm{~nm}$ depth, and then the templates with lateral dimensions of $500 \mathrm{~nm}$ and $600 \mathrm{~nm}$ depth. This indicates that with the current samples, no correlation between nucleation density and lateral and vertical dimensions was found. Detailed inspection of the SEM images of the nanocubes grown within the smaller $(200 \mathrm{~nm})$ templates showed the intergrowth of only one to three crystallites within a single pore (Figure 7.4(a)). Due to the preferred growth direction of these crystallites, they were only attached to the substrate by a few nucleation points, and, therefore, had poor adhesion to the substrate and easily washed off during template removal. This can be seen in the top left part of Figure 7.4(a) where the PMMA has been dissolved and the crystals inadvertently washed away. The bottom right part of this figure shows that the crystals that are still surrounded by undissolved PMMA are still present. Using a template with lateral dimensions of $400 \mathrm{~nm}$ (Figure 7.4(c-e)) or $500 \mathrm{~nm}$ (Figure 7.4(b)) resulted in the intergrowth of more crystallites within one hole, which enhanced the stability of the respective nanocubes. A closer look at the tilted SEM image in Figure 7.4(e) shows that these nanocubes display pillar-like growth with a diameter of $\sim 50-100 \mathrm{~nm}$ and roughly shaped sides and top surfaces. 

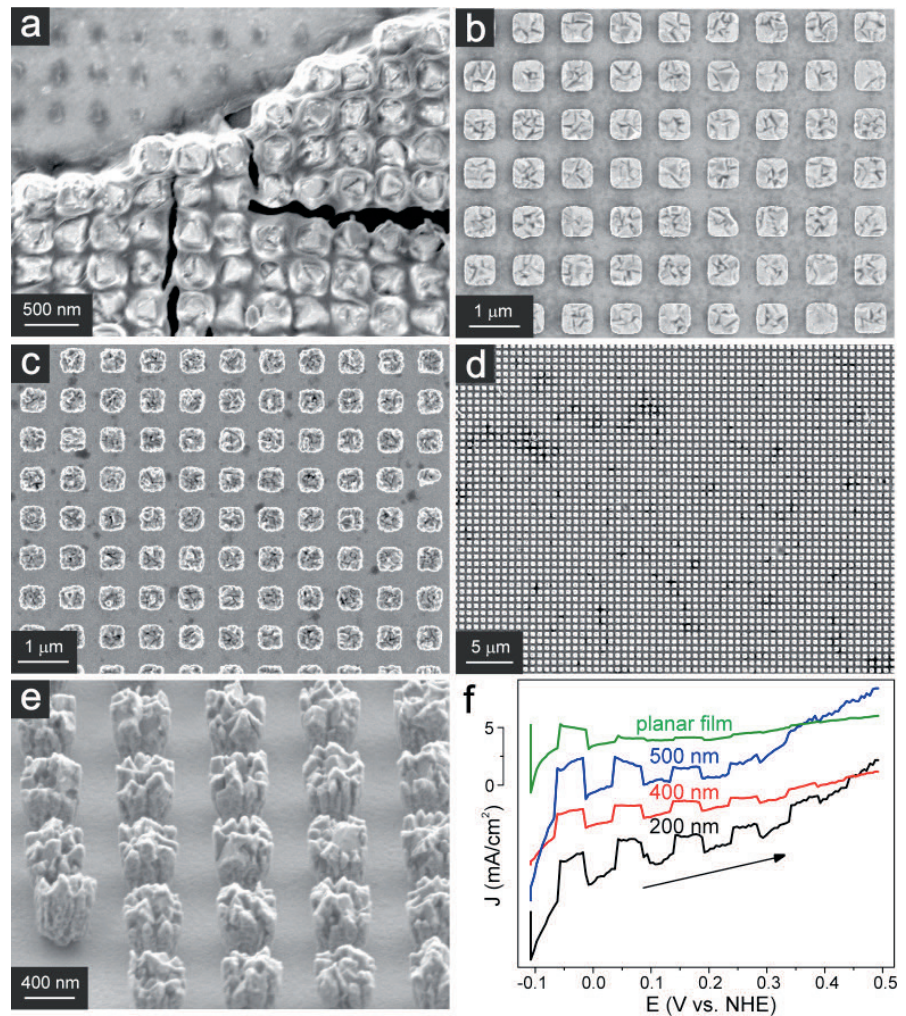

Figure 7.4. (a-d) Top view SEM images of $p-\mathrm{Cu}_{2} \mathrm{O}$ nanocubes made by templated electrodeposition for $4 \mathrm{~min}$ in a cubic template with dimensions of (a) $200 \mathrm{~nm}$ lateral and $350 \mathrm{~nm}$ depth, (b) $500 \mathrm{~nm}$ lateral and $600 \mathrm{~nm}$ depth, (c, d) $400 \mathrm{~nm}$ lateral and $500 \mathrm{~nm}$ depth, and (e) $45^{\circ}$ tilted SEM image of $\mathrm{p}-\mathrm{Cu}_{2} \mathrm{O}$ nanocubes with lateral dimensions of $400 \mathrm{~nm}$ and $500 \mathrm{~nm}$ depth after template removal. (f) Photocurrent $\mathrm{LSV}$ curves of $\mathrm{p}-\mathrm{Cu}_{2} \mathrm{O}$ nanocubes and $\mathrm{p}-\mathrm{Cu}_{2} \mathrm{O}$ films in $1 \mathrm{M} \mathrm{Na}_{2} \mathrm{SO}_{4}$ and $0.1 \mathrm{M} \mathrm{K}_{2} \mathrm{HPO}_{4}$ at pH 4.9 continuously bubbled with $\mathrm{N}_{2}$; the scan rate was $10 \mathrm{mV} / \mathrm{s}$ in the positive direction and the light was chopped with intervals of $5 \mathrm{~s}$. For the sake of comparison, the electrolyte used by Grätzel and coworkers [56] was employed in this study. For the sake of clarity, the LSV curves were offset.

$\mathrm{Cu}_{2} \mathrm{O}$ is an interesting material for application in solar cells and as photocathode in photoelectrochemical water splitting, because it is a cheap and abundant material with a direct bandgap of $2.0 \mathrm{eV}$. With the $\mathrm{p}-\mathrm{Cu}_{2} \mathrm{O}$ nanocubes still attached to the substrate after PMMA removal, the photocurrent was measured and the results are shown in Figure 7.4(f) for $\mathrm{p}-\mathrm{Cu}_{2} \mathrm{O}$ nanocube samples with different lateral dimensions. The photocurrent of a planar $\mathrm{p}-\mathrm{Cu}_{2} \mathrm{O}$ film is also shown for comparison. 
All samples were electrodeposited for $4 \mathrm{~min}$ from the previously mentioned $\mathrm{p}-\mathrm{Cu}_{2} \mathrm{O}$ plating solution. A few differences in efficiency between the nanocubes and the film are apparent from this graph: the nanocubes show (1) a higher photocurrent at $0 \mathrm{~V}$ vs. NHE, (2) noticeable photocurrent at more positive potentials, e.g. higher than $0.3 \mathrm{~V}$ vs. NHE, and (3) a higher dark current. (1) The higher photocurrent (up to $\sim 3 \mathrm{~mA} / \mathrm{cm}^{2}$ at $0 \mathrm{~V}$ vs. NHE for the nanocube samples vs. $\sim 1.5 \mathrm{~mA} / \mathrm{cm}^{2}$ for the films) may be explained by the larger true surface area of a nanostructure. It is noteworthy that the photocurrent of the nanocubes was slightly higher than the bare $\mathrm{p}-\mathrm{Cu}_{2} \mathrm{O}$ films measured by Grätzel and coworkers in the same electrolyte [56], while the photocurrent of our films was slightly lower. To the best of our knowledge, the only difference between the two measurements was that we did not use Pt nanoparticles, which is a well-known catalyst for $\mathrm{H}_{2}$ formation, and thereby increased photostability of $\mathrm{p}-\mathrm{Cu}_{2} \mathrm{O}$. However, the increase in photocurrent achieved by the nanocube electrodes was not as high as the ca. fivefold increase achieved in surface area by nanocube formation over the planar film electrode. This suggests that the nanocube formation may also have caused an adverse effect such as an increase in surface states which would result in decreased photocurrent. (2) In addition to the explanation in (1) for the higher photocurrent at $0 \mathrm{~V}$ vs. NHE, the noticeable photocurrent at more positive potentials for the nanocube samples compared to a negligible photocurrent for the planar film electrode may be due to an earlier photocurrent onset potential at more positive potentials and/or an enhanced photostability of the nanocubes. The first explanation, an earlier photocurrent onset potential, often results when a nanostructure is incorporated into the photoelectrode because the presence of a nanostructure generally helps electron-hole separation by increasing the relative volume of the depletion layer and/or reducing the distance that the minority carriers need to travel to reach the electrode/electrolyte interface $[57,58]$. Since $\mathrm{Cu}_{2} \mathrm{O}$ is known to photodegrade easily during photocurrent measurements [56], the linear sweep voltammetry (LSV) curves in Figure 7.4(f) were measured in the positive direction so that the photodegradation effect on the photocurrent measured at $0 \mathrm{~V}$ vs. NHE was minimized. Figure 7.5 shows LSV curves of two different films in which the scan direction were opposite. Regardless of scan direction, for both samples the photocurrent decreased as the measurement continued. Therefore, these LSV curves show the dependence of the current density not only on the potential, but also on the degradation with time. For this reason, the second explanation for the increased photocurrent at more positive potentials could be an increased 
photostability of the nanocubes. The photostability of $p-\mathrm{Cu}_{2} \mathrm{O}$ for photoelectrochemical water reduction can be further increased by passivation with a coating of Al-doped $\mathrm{ZnO}$ and $\mathrm{TiO}_{2}$, as demonstrated by Grätzel and coworkers [56]. However, further investigation into the origin of the enhanced photocurrent at more positive potentials observed in this study is necessary, which is outside the scope of this study. (3) The higher cathodic dark current observed for the nanocube electrodes was represented by deviation from perfectly horizontal dark current lines for especially the 200 and $500 \mathrm{~nm}$ nanocube electrodes. This can be explained by a secondary reaction taking place, in which the photodegradation product, $\mathrm{CuO}$, was reduced back to $\mathrm{Cu}_{2} \mathrm{O}$, which again could be explained by the larger true surface area of the nanocube samples.

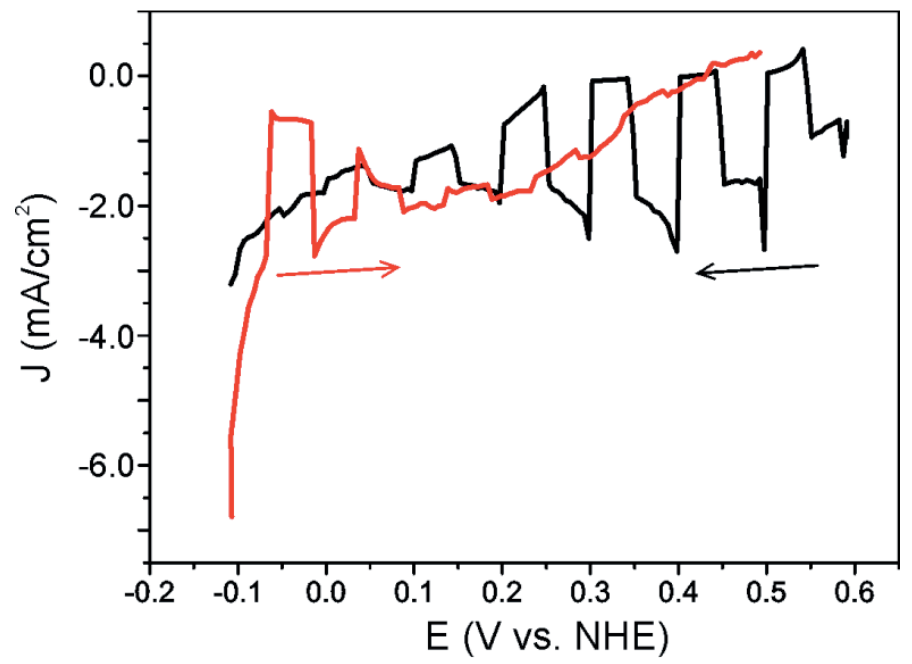

Figure 7.5. Photocurrent LSV curves of two different $\mathrm{p}-\mathrm{Cu}_{2} \mathrm{O}$ films in $1 \mathrm{M} \mathrm{Na}_{2} \mathrm{SO}_{4}$ and $0.1 \mathrm{M} \mathrm{K}_{2} \mathrm{HPO}_{4}$ at $\mathrm{pH} 4.9$ continuously bubbled with $\mathrm{N}_{2}$. The scan rate was $10 \mathrm{mV} / \mathrm{s}$ in the negative direction (black curve) or in the positive direction (red curve), and the light was chopped with intervals of $5 \mathrm{~s}$.

The same technique was also applied to form nanocubes with both $\mathrm{Ni}$ and $\mathrm{p}-\mathrm{Cu}_{2} \mathrm{O}$ segments within the same template, yielding segmented nanocubes composed of both phases. It is noted that the combination of $\mathrm{Ni}$ and $\mathrm{p}-\mathrm{Cu}_{2} \mathrm{O}$ is merely a model system for which no clear application yet exists, but that illustrates the possibility to form nanocubes consisting of two or more different phases, which is unique for this technique. Figure 7.6 shows examples of nanobars composed of $\mathrm{Ni}$ at the bottom and $\mathrm{p}-\mathrm{Cu}_{2} \mathrm{O}$ at the top. It is interesting to note that the $\mathrm{p}-\mathrm{Cu}_{2} \mathrm{O}$ grown inside these type of 
templates when $\mathrm{Ni}$ was deposited first appear much smoother. A closer look at the top of these nanocubes, where the top of the template used to be and mushrooming was expected for templated electrodeposition of polycrystalline materials, reveals that the $\mathrm{p}-\mathrm{Cu}_{2} \mathrm{O}$ phase grew as a large crystal on top of the Ni phase. Apparently, the Ni phase acted as a perfect seed layer for the growth of large $\mathrm{p}-\mathrm{Cu}_{2} \mathrm{O}$ crystals. The porous appearance of the $\mathrm{p}-\mathrm{Cu}_{2} \mathrm{O}$ phase, which is also visible in these SEM images, is probably induced by etching during template removal. Although harsh cleaning conditions were used to ensure the dissolution of all PMMA before SEM imaging, $\sim 50 \%$ of the nanobars still appeared intact and contained both $\mathrm{Ni}$ and $\mathrm{Cu}_{2} \mathrm{O}$. These harsh conditions included immersion in acetone and THF for several days and ultrasonication in these solvents for several hours. The EDX spectra in Figure 7.6(d,e) confirmed the deposition of both a $\mathrm{Ni}$ and a $\mathrm{Cu}$ containing phase within the nanobar of Figure 7.6(c). The Si peaks in Figure $7.6(\mathrm{~d}, \mathrm{e})$ originate from the Si substrate, and both $\mathrm{C}$ peaks and the $\mathrm{O}$ peak in Figure $7.6(\mathrm{e})$ originate from undissolved organic template residues.
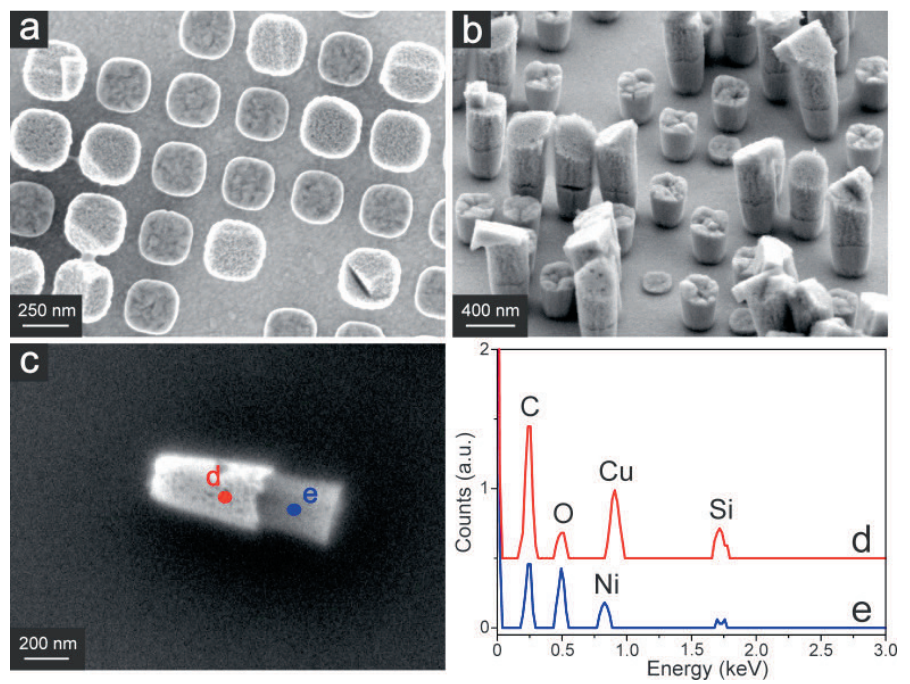

Figure 7.6. (a) Top view and (b) $45^{\circ}$ tilted SEM images of bifunctional $\mathrm{Ni} \mid \mathrm{p}-\mathrm{Cu}_{2} \mathrm{O}$ nanobars made by sequential templated electrodeposition in a cubic template with dimensions $200 \times 200 \mathrm{~nm}$ after template removal, (c) SEM image after release from the substrate of the same nanobars, and EDX spectra of (d) the $\mathrm{p}-\mathrm{Cu}_{2} \mathrm{O}$ segment and (e) the $\mathrm{Ni}$ segment of the horizontally placed nanobar in (c). 
The phases of the nanocubes made in this study were investigated with $\mathrm{X}$-ray diffraction (XRD). As shown in Figure 7.7, the main phases of the respective nanocubes are $\mathrm{Ni}$ and $\mathrm{Cu}_{2} \mathrm{O}$. It is likely that the minor peaks for $\mathrm{CuO}$ and $\mathrm{NiO}$ originate from oxidized surface layers and are not formed during deposition. The observed Au peaks originate from the substrate used for nanocube growth. An unidentified impurity phase, denoted with an asterisk, probably originates from the substrate as it is present in all samples, but reference patterns for $\mathrm{Si}, \mathrm{SiO}_{2}, \mathrm{Ti}$ and $\mathrm{Au}$ did not overlap.

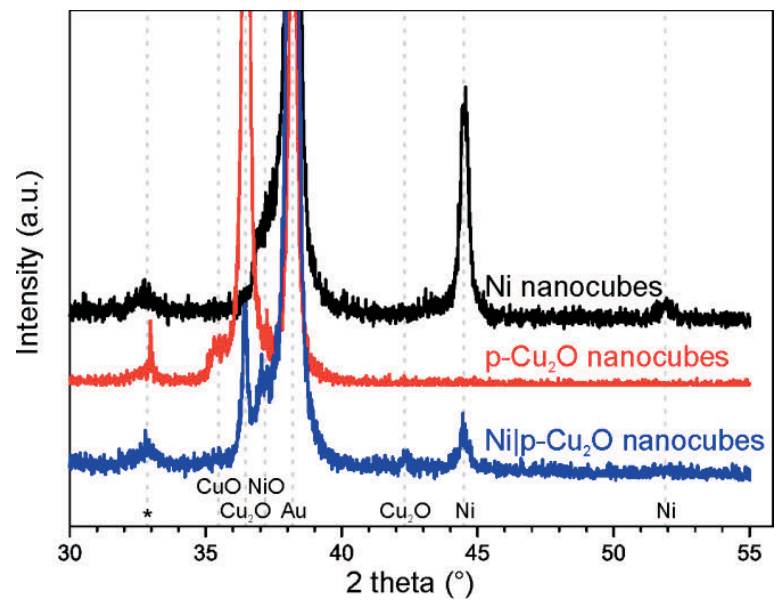

Figure 7.7. XRD patterns of Ni nanocubes (black line), $p-\mathrm{Cu}_{2} \mathrm{O}$ nanocubes (red line) and segmented $\mathrm{Ni} / \mathrm{p}-\mathrm{Cu}_{2} \mathrm{O}$ nanocubes with lateral dimensions of $200 \mathrm{~nm}$. Diffraction peaks were assigned to $\mathrm{Au}$ (PDF \# 00-004-0784), $\mathrm{Ni}$ (PDF \# 00-004-0850), $\mathrm{Cu}_{2} \mathrm{O}$ (PDF \# 00-005-0667), NiO (PDF \# 00-047-1049) and CuO (PDF \# 00-048-1548); An unknown impurity phase is denoted with an asterisk (*).

The ability of this method to yield nanocubes on a substrate and the possibility to detach them from the substrate opens up prospects for their use in many different types of applications. However, it should be noted that, although this method worked perfectly for the formation of $\mathrm{Ni}$ and $\mathrm{p}-\mathrm{Cu}_{2} \mathrm{O}$ nanocubes, more effort is needed to realize the formation of nanocubes of other compositions. These efforts include optimization of the electrodeposition conditions, e.g. $\mathrm{pH}$ of the electrolyte and pulsed electrodeposition. It is expected that with these improvements, nanocubes can also be made from many more materials via the same procedure. With the possibility of making multicomponent nanocubes within the same template, it is also possible to make different types of functional segmented nanocubes, as demonstrated here for the case of $\mathrm{Ni} \mid \mathrm{p}-\mathrm{Cu}_{2} \mathrm{O}$. 


\subsection{Conclusions}

A new type of template was introduced which extends the method of templated electrodeposition to the formation of nanocubes, as was demonstrated by the formation of $\mathrm{Ni}$ and $\mathrm{p}-\mathrm{Cu}_{2} \mathrm{O}$ nanocubes, and segmented nanobars containing both phases. The lateral dimensions of the formed nanocubes can be controlled by the pattern on the master used for $\mathrm{NIL}$, and the height can be controlled by the deposition time. After deposition, the nanocubes can either remain attached to the substrate or the nanocubes can be removed from the substrate by dissolving the Au layer. The Ni nanocubes were very smooth and the rms roughness value of the top layer was found to be comparable to the rms value of $\mathrm{Ni}$ films made by electrodeposition without template. The roughness of $\mathrm{p}-\mathrm{Cu}_{2} \mathrm{O}$ nanocubes was much higher as a high concentration of small crystallites were nucleated within the templates. Photocurrent measurements of $\mathrm{p}-\mathrm{Cu}_{2} \mathrm{O}$ nanocubes were compared to photocurrent measurements of $\mathrm{p}-\mathrm{Cu}_{2} \mathrm{O}$ films, and it was shown that the nanocubes show a higher photocurrent at $0 \mathrm{~V}$ vs. NHE, an increased photocurrent at more positive potentials, e.g. $0.3 \mathrm{~V}$ vs. NHE, and a higher dark current. These observed differences can be explained by the higher surface area of the nanocube electrodes and an earlier photocurrent onset potential and/or increased photostability of the nanocubes.

\subsection{References}

[1] H. G. Park, J. H. Joo, H. G. Kim, and J. S. Lee, "Shape-dependent reversible assembly properties of polyvalent DNA-silver nanocube conjugates", Journal of Physical Chemistry C, 2012, vol. 116, pp. 2278-2284.

[2] B. Gao, G. Arya, and A. R. Tao, "Self-orienting nanocubes for the assembly of plasmonic nanojunctions", Nature Nanotechnology, 2012, vol. 7, pp. 433-437.

[3] K. I. Mimura, F. Dang, K. Kato, H. Imai, S. Wada, H. Haneda, and M. Kuwabara, "Characterization of dielectric nanocubes ordered structures fabricated by solution self-assembly process", Japanese Journal of Applied Physics, 2011, vol. 50, 
[4] O. Rabin, "Self-assembly: Judging a nanocube by its cover", Nature Nanotechnology, 2012, vol. 7, pp. 419-420.

[5] H. Chen, Z. Sun, W. Ni, K. C. Woo, H. Q. Lin, L. Sun, C. Yan, and J. Wang, "Plasmon coupling in clusters composed of two-dimensionally ordered gold nanocubes", Small, 2009, vol. 5, pp. 2111-2119.

[6] M. A. Mahmoud and M. A. El-Sayed, "Comparative study of the assemblies and the resulting plasmon fields of Langmuir-Blodgett assembled monolayers of silver nanocubes and gold nanocages", Journal of Physical Chemistry C, 2008, vol. 112, pp. 14618-14625.

[7] J. M. Meijer, F. Hagemans, L. Rossi, D. V. Byelov, S. I. R. Castillo, A. Snigirev, I. Snigireva, A. P. Philipse, and A. V. Petukhov, "Self-assembly of colloidal cubes via vertical deposition", Langmuir, 2012, vol. 28, pp. 7631-7638.

[8] D. Xu, Z. Liu, H. Yang, Q. Liu, J. Zhang, J. Fang, S. Zou, and K. Sun, "Solution-based evolution and enhanced methanol oxidation activity of monodisperse platinum-copper nanocubes", Angewandte Chemie, 2009, vol. 121, pp. 4281-4285.

[9] D. Xu, S. Bliznakov, Z. Liu, J. Fang, and N. Dimitrov, "Composition-dependent electrocatalytic activity of Pt-Cu nanocube catalysts for formic acid oxidation", Angewandte Chemie - International Edition, 2010, vol. 49, pp. 1282-1285.

[10] R. Jalem, R. Koike, Y. Yang, M. Nakayama, and M. Nogami, "Electrochemical characterization of a porous $\mathrm{Pt}$ nanoparticle "Nanocube-Mosaic" prepared by a modified polyol method with $\mathrm{HCl}$ addition", Nano Research, 2011, vol. 4, pp. 746-758.

[11] S. I. In, D. D. Vaughn li, and R. E. Schaak, "Hybrid CuO-TiO ${ }_{2-x} \mathrm{~N}_{x}$ hollow nanocubes for photocatalytic conversion of $\mathrm{CO}_{2}$ into methane under solar irradiation", Angewandte Chemie - International Edition, 2012, vol. 51, pp. 3915-3918.

[12] D. Chen, S. H. Yoo, Q. Huang, G. Ali, and S. O. Cho, "Sonochemical synthesis of $\mathrm{Ag} / \mathrm{AgCl}$ nanocubes and their efficient visible-lightdriven photocatalytic performance", Chemistry - A European Journal, 2012, vol. 18, pp. 5192-5200.

[13] J. Tang, G. Cheng, H. Zhou, H. Yang, Z. Lu, and R. Chen, "Shape-dependent photocatalytic activities of bismuth subcarbonate nanostructures", Journal of Nanoscience and Nanotechnology, 2012, vol. 12, pp. 4028-4034. 
[14] Z. Zheng, B. Huang, X. Qin, X. Zhang, and Y. Dai, "Facile synthesis of $\mathrm{SrTiO}_{3}$ hollow microspheres built as assembly of nanocubes and their associated photocatalytic activity", Journal of Colloid and Interface Science, 2011, vol. 358, pp. 68-72.

[15] H. Gao, Y. Wang, F. Xiao, C. B. Ching, and H. Duan, "Growth of copper nanocubes on graphene paper as free-standing electrodes for direct hydrazine fuel cells", Journal of Physical Chemistry C, 2012, vol. 116, pp. 7719-7725.

[16] H. Wu and W. Chen, "Copper nitride nanocubes: Size-controlled synthesis and application as cathode catalyst in alkaline fuel cells", Journal of the American Chemical Society, 2011, vol. 133, pp. 15236-15239.

[17] J. C. Park, J. Kim, H. Kwon, and H. Song, "Gram-scale synthesis of $\mathrm{Cu}_{2} \mathrm{O}$ nanocubes and subsequent oxidation to $\mathrm{CuO}$ hollow nanostructures for lithium-ion battery anode materials", Advanced Materials, 2009, vol. 21, pp. 803-807.

[18] L. Chen, L. Shen, P. Nie, X. Zhang, and H. Li, "Facile hydrothermal synthesis of single crystalline $\mathrm{TiOF}_{2}$ nanocubes and their phase transitions to $\mathrm{TiO}_{2}$ hollow nanocages as anode materials for lithiumion battery", Electrochimica Acta, 2012, vol. 62, pp. 408-415.

[19] R. Liu, S. Yang, F. Wang, X. Lu, Z. Yang, and B. Ding, "Sodium chloride template synthesis of cubic tin dioxide hollow particles for lithium ion battery applications", ACS Applied Materials and Interfaces, 2012, vol. 4, pp. 1537-1542.

[20] S. Tokonami, Y. Yamamoto, H. Shiigi, and T. Nagaoka, "Synthesis and bioanalytical applications of specific-shaped metallic nanostructures: A review", Analytica Chimica Acta, 2012, vol. 716, pp. 76-91.

[21] J. Chen, B. Wiley, Z. Y. Li, D. Campbell, F. Saeki, H. Cang, L. Au, J. Lee, $X$. Li, and Y. Xia, "Gold nanocages: Engineering their structure for biomedical applications", Advanced Materials, 2005, vol. 17, pp. 2255-2261.

[22] P. Guardia, R. Di Corato, L. Lartigue, C. Wilhelm, A. Espinosa, M. Garcia-Hernandez, F. Gazeau, L. Manna, and T. Pellegrino, "Water-soluble iron oxide nanocubes with high values of specific absorption rate for cancer cell hyperthermia treatment", ACS Nano, 2012, vol. 6, pp. 3080-3091.

[23] S. E. Skrabalak, J. Chen, L. Au, X. Lu, X. Li, and Y. Xia, "Gold nanocages for biomedical applications", Advanced Materials, 2007, vol. 19, pp. 3177-3184. 
[24] P. N. Sisco and C. J. Murphy, "Surface-coverage dependence of surface-enhanced raman scattering from gold nanocubes on self-asssembled monolayers of analyte", Journal of Physical Chemistry A, 2009, vol. 113, pp. 3973-3978.

[25] P. H. C. Camargo, L. Au, M. Rycenga, W. Li, and Y. Xia, "Measuring the SERS enhancement factors of dimers with different structures constructed from silver nanocubes", Chemical Physics Letters, 2010, vol. 484, pp. 304-308.

[26] P. H. C. Camargo, M. Rycenga, L. Au, and Y. Xia, "Isolating and probing the hot spot formed between two silver nanocubes", Angewandte Chemie - International Edition, 2009, vol. 48, pp. 2180-2184.

[27] J. M. McLellan, A. Siekkinen, J. Chen, and Y. Xia, "Comparison of the surface-enhanced Raman scattering on sharp and truncated silver nanocubes", Chemical Physics Letters, 2006, vol. 427, pp. 122-126.

[28] M. Rycenga, M. H. Kim, P. H. C. Camargo, C. Cobley, Z. Y. Li, and $Y$ Y. Xia, "Surface-enhanced raman scattering: comparison of three different molecules on single-crystal nanocubes and nanospheres of silver", Journal of Physical Chemistry A, 2009, vol. 113, pp. 3932-3939.

[29] J. C. Santos Costa, R. A. Ando, A. C. Sant'ana, L. M. Rossi, P. S. Santos, M. L. A. Temperini, and P. Corio, "High performance gold nanorods and silver nanocubes in surface-enhanced Raman spectroscopy of pesticides", Physical Chemistry Chemical Physics, 2009, vol. 11, pp. 7491-7498.

[30] T. Darmanin, P. Nativo, D. Gilliland, G. Ceccone, C. Pascual, B. De Berardis, F. Guittard, and F. Rossi, "Microwave-assisted synthesis of silver nanoprisms/nanoplates using a "modified polyol process"', Colloids and Surfaces A: Physicochemical and Engineering Aspects, 2012, vol. 395, pp. 145-151.

[31] Y. Sun and Y. Xia, "Polymer-mediated synthesis of metal nanostructures", 2003, vol. 5224, pp. 43-52.

[32] J. Zhu, C. Kan, X. Zhu, J. G. Wan, M. Han, Y. Zhao, B. Wang, and G. Wang, "Synthesis of perfect silver nanocubes by a simple polyol process", Journal of Materials Research, 2007, vol. 22, pp. 1479-1485.

[33] L. Huang, F. Peng, H. Yu, and H. Wang, "Synthesis of $\mathrm{Cu}_{2} \mathrm{O}$ nanoboxes, nanocubes and nanospheres by polyol process and their adsorption characteristic", Materials Research Bulletin, 2008, vol. 43, pp. 3047-3053. 
[34] R. Qin, H. Song, G. Pan, H. Zhao, X. Ren, L. Liu, X. Bai, Q. Dai, and $X$. $\mathrm{Qu}$, "Polyol-mediated synthesis of well-dispersed $\alpha-\mathrm{NaYF}_{4}$ nanocubes", Journal of Crystal Growth, 2009, vol. 311, pp. 1559-1564.

[35] C. J. Huang, P. H. Chiu, Y. H. Wang, W. R. Chen, and T. H. Meen, "Synthesis of the gold nanocubes by electrochemical technique", Journal of the Electrochemical Society, 2006, vol. 153, pp. D129-D133.

[36] C. J. Huang, Y. H. Wang, P. H. Chiu, M. C. Shih, and T. H. Meen, "Electrochemical synthesis of gold nanocubes", Materials Letters, 2006, vol. 60, pp. 1896-1900.

[37] X. Kou, Z. Sun, Z. Yang, H. Chen, and J. Wang, "Curvature-directed assembly of gold nanocubes, nanobranches, and nanospheres", Langmuir, 2009, vol. 25, pp. 1692-1698.

[38] S. Kundu, S. Panigrahi, S. Praharaj, S. Basu, S. K. Ghosh, A. Pal, and T. Pal, "Anisotropic growth of gold clusters to gold nanocubes under UV irradiation", Nanotechnology, 2007, vol. 18,

[39] T. K. Sau and C. J. Murphy, "Room temperature, high-yield synthesis of multiple shapes of gold nanoparticles in aqueous solution", Journal of the American Chemical Society, 2004, vol. 126, pp. 8648-8649.

[40] T. J. Merkel, K. P. Herlihy, J. Nunes, R. M. Orgel, J. P. Rolland, and J. M. Desimone, "Scalable, shape-specific, top-down fabrication methods for the synthesis of engineered colloidal particles", Langmuir, 2010, vol. 26, pp. 13086-13096.

[41] K. Kalishwaralal, V. Deepak, S. Ram Kumar Pandian, and S. Gurunathan, "Biological synthesis of gold nanocubes from Bacillus licheniformis", Bioresource Technology, 2009, vol. 100, pp. 5356-5358.

[42] P. Aranda and J. M. García, "Porous membranes for the preparation of magnetic nanostructures", Journal of Magnetism and Magnetic Materials, 2002, vol. 249, pp. 214-219.

[43] M. G. Maas, E. J. B. Rodijk, W. Maijenburg, J. E. ten Elshof, and D. H. A. Blank, "Photocatalytic segmented nanowires and single-step iron oxide nanotube synthesis: Templated electrodeposition as all-round tool", 2010, vol. 1206, pp. 1-6.

[44] G. She, L. Mu, and W. Shi, "Electrodeposition of one-dimensional nanostructures", Recent Patents on Nanotechnology, 2009, vol. 3, pp. 182-191. 
[45] M. E. Toimil Molares, V. Buschmann, D. Dobrev, R. Neumann, R. Scholz, I. U. Schuchert, and J. Vetter, "Single-crystalline copper nanowires produced by electrochemical deposition in polymeric ion track membranes", Advanced Materials, 2001, vol. 13, pp. 62-65.

[46] S. Y. Chou, P. R. Krauss, W. Zhang, L. Guo, and L. Zhuang, "Sub-10 nm imprint lithography and applications", Journal of Vacuum Science and Technology B: Microelectronics and Nanometer Structures, 1997, vol. 15, pp. 2897-2904.

[47] M. D. Austin, H. Ge, W. Wu, M. Li, Z. Yu, D. Wasserman, S. A. Lyon, and S. Y. Chou, "Fabrication of $5 \mathrm{~nm}$ linewidth and $14 \mathrm{~nm}$ pitch features by nanoimprint lithography", Applied Physics Letters, 2004, vol. 84, pp. 5299-5301.

[48] N. G. Cha, T. Kanki, and H. Tanaka, "Direct fabrication of integrated 3D epitaxial functional transition metal oxide nanostructures using extremely small hollow nanopillar nano-imprint metal masks", Nanotechnology, 2011, vol. 22,

[49] N. G. Cha, B. K. Lee, T. Kanki, H. Y. Lee, T. Kawai, and H. Tanaka, "Direct fabrication of integrated 3D Au nanobox arrays by sidewall deposition with controllable heights and thicknesses", Nanotechnology, 2009, vol. 20,

[50] A. N. Hattori, A. Ono, and H. Tanaka, "Position-, size-, and shape-controlled highly crystalline ZnO nanostructures", Nanotechnology, 2011, vol. 22,

[51] C. A. Ross, S. Haratani, F. J. Castaño, Y. Hao, M. Hwang, M. Shima, J. Y. Cheng, B. Vögeli, M. Farhoud, M. Walsh, and H. I. Smith, "Magnetic behavior of lithographically patterned particle arrays (invited)", Journal of Applied Physics, 2002, vol. 91, pp. 6848-6853.

[52] C. A. Ross, H. I. Smith, T. Savas, M. Schattenburg, M. Farhoud, M. Hwang, M. Walsh, M. C. Abraham, and R. J. Ram, "Fabrication of patterned media for high density magnetic storage", Journal of Vacuum Science and Technology B: Microelectronics and Nanometer Structures, 1999, vol. 17, pp. 3168-3176.

[53] C. M. McShane and K. S. Choi, "Junction studies on electrochemically fabricated $\mathrm{p}-\mathrm{n} \mathrm{Cu}_{2} \mathrm{O}$ homojunction solar cells for efficiency enhancement", Physical Chemistry Chemical Physics, 2012, vol. 14, pp. 6112-6118.

[54] C. M. McShane, W. P. Siripala, and K. S. Choi, "Effect of junction morphology on the performance of polycrystalline $\mathrm{Cu}_{2} \mathrm{O}$ homojunction solar cells", Journal of Physical Chemistry Letters, 2010, vol. 1, pp. 2666-2670. 
[55] H. S. Jang, S. J. Kim, and K. S. Choi, "Construction of cuprous oxide electrodes composed of 2D single-crystalline dendritic nanosheets", Small, 2010, vol. 6, pp. 2183-2190.

[56] A. Paracchino, V. Laporte, K. Sivula, M. Grätzel, and E. Thimsen, "Highly active oxide photocathode for photoelectrochemical water reduction", Nature Materials, 2011, vol. 10, pp. 456-461.

[57] K. J. McDonald and K. S. Choi, "A new electrochemical synthesis route for a $\mathrm{BiOl}$ electrode and its conversion to a highly efficient porous $\mathrm{BiVO}_{4}$ photoanode for solar water oxidation", Energy and Environmental Science, 2012, vol. 5, pp. 8553-8557.

[58] A. Kay, I. Cesar, and M. Grätzel, "New benchmark for water photooxidation by nanostructured $\alpha-\mathrm{Fe}_{2} \mathrm{O}_{3}$ films", Journal of the American Chemical Society, 2006, vol. 128, pp. 15714-15721. 
Chapter 7

$(164)$ 


\section{8.}

\section{$\underline{M o S}_{2}$ nanocube structures}

as catalysts for electrochemical $\underline{\mathrm{H}}_{2}$ evolution from acidic aqueous solutions

Where the previous chapter presented a technique for templated electrodeposition of nanocubes using a negative template, this chapter presents a technique for making nanocube structures using a positive template. As example, $\mathrm{MoS}_{2}$ nanocube structures were made that showed an increased activity in electrocatalytic $\mathrm{H}_{2}$ evolution. Furthermore, also $\mathrm{Pt}$ nanocube structures and $\mathrm{Ni}$-Au nanoboxes were prepared.

This chapter is submitted as:

A.W. Maijenburg, M. Regis, A.N. Hattori, H. Tanaka, K.-S. Choi, and J.E. ten Elshof, "MoS 2 nanocube structures as catalysts for electrochemical $\mathrm{H}_{2}$ evolution from acidic aqueous solutions". 


\subsection{Abstract}

Core-shell PMMA-Au nanocube structures made by a combination of nano-imprint lithography and sidewall deposition were used as template for electrodeposition of $\mathrm{MoS}_{2}, \mathrm{Ni}$ and Pt. Linear sweep voltammetry experiments obtained in an aqueous solution containing $0.29 \mathrm{M} \mathrm{H}_{2} \mathrm{SO}_{4}$ (pH 0.24) showed that the onset potential of the core-shell-shell PMMA-Au- $\mathrm{MoS}_{2}$ nanocube electrode for the hydrogen evolution reaction (HER) was shifted to the positive direction (i.e. requiring a lower overpotential) by 20-40 mV compared to planar $\mathrm{MoS}_{2}$ films. This indicates that the nanocube electrodes have a significantly increased HER activity, which is probably because of a higher density of catalytically active edge sites available at the nanocube surface. It was also found that the HER activity initially increased with increasing $\mathrm{MoS}_{2}$ deposition time, but decreased after deposition for 60 min because the edges of the nanocubes became rounded, thereby decreasing the number of active edge sites. By depositing $\mathrm{Ni}$ and Pt on top of PMMA-Au nanocubes, it was shown that this method can also be used for the synthesis of nanocube structures with varying compositions.

\subsection{Introduction}

Photocatalytic or photoelectrochemical water splitting is emerging as a promising clean technique for the synthesis of $\mathrm{H}_{2}$ gas, which could be used as a clean and renewable energy source. The main active component of most photocatalysts and photoelectrodes is an inorganic semiconductor with appropriate band edge positions for water splitting and a suitable band gap (ca. $2 \mathrm{eV}$ ) to utilize visible light. One of the major sources for efficiency loss in these systems is surface recombination of charge carriers caused by a poorly active catalytic surface of the semiconductor for the $\mathrm{H}_{2}$ or $\mathrm{O}_{2}$ evolution reactions (HER and OER, respectively). Efficiency loss can be significantly reduced by addition of a catalyst for the HER or OER [1-3]. For the HER, Pt is the most efficient co-catalyst, but large-scale application of Pt or Pt-based composites or alloys is impossible due to its high cost and low abundance. Therefore, it is advantageous to investigate other types of materials that can mimic the performance of Pt for the HER [4-6]. 
An interesting material to use as a HER catalyst is $\mathrm{MoS}_{2}$, because of its high chemical stability in e.g. strong acids [7]. In industry, $\mathrm{MoS}_{2}$ is a well-known catalyst for hydrodesulfurization of petroleum [8-10]. Furthermore, $\mathrm{MoS}_{2}$ is used as a solid lubricant [11-13] and in photo-oxidation of organics [14]. $\mathrm{MoS}_{2}$ is a layered chalcogenide with sheets of S-Mo-S layers, thus exposing Mo (1010) edges, S (1010) edges and basal planes $[15,16]$. Since the first report of $\mathrm{MoS}_{2}$ as HER catalyst by Sobczynski [7], several studies have shown that the edge sites of $\mathrm{MoS}_{2}$ are catalytically the most active sites for $\mathrm{H}_{2}$ evolution [6, 15, 17, 18]. Most research is therefore focused on nanostructuring $\mathrm{MoS}_{2}$ in order to increase its efficiency for the HER by creating a higher concentration of active edge sites and thereby decreasing the required overpotential $[4,7,17-21]$. To date, several $\mathrm{MoS}_{2}$ nanostructures were published that showed an excellent HER performance compared to planar films. Among these are crystalline, single-layered $\mathrm{MoS}_{2}$ polygons [17], amorphous $\mathrm{MoS}_{3}$ films made by electrodeposition [5, 22], double-gyroid porous $\mathrm{MoS}_{2}$ nanostructures [19] and core-shell $\mathrm{MoO}_{3}-\mathrm{MoS}_{2}$ nanowires [4].

The most common method for $\mathrm{MoS}_{2}$ deposition is a thermal deposition process employing high temperature, high pressure and the use of toxic $\mathrm{H}_{2} \mathrm{~S}$ gas as one of the precursors $[7,17,18]$. Although these processes are widely used in industry, safer and less expensive processes are preferred. One of these processes is electrochemical deposition of amorphous $\mathrm{MoS}_{3}$ films, which are thought to be reduced to $\mathrm{MoS}_{2}$ under the experimental conditions of $\mathrm{H}_{2}$ evolution [5, 22]. Another low-cost and scalable process is in situ photo-assisted deposition of $\mathrm{MoS}_{2}$ on top of a semiconductor with proper band edge positions, e.g. $\mathrm{Zn}_{x} \mathrm{Cd}_{1-x} \mathrm{~S}$, for improved $\mathrm{H}_{2}$ evolution rates [23].

In this study, core-shell-shell PMMA-Au-MoS 2 nanocube structures (abbreviated to $\mathrm{MoS}_{2}$ nanocube structures) were prepared by electrodeposition of $\mathrm{MoS}_{2}$ on PMMA-Au nanocube structures. These PMMA-Au nanocube structures were made by a combination of nano-imprint lithography (NIL) and sidewall deposition as schematically shown in Figure 8.1. NIL is a promising technique to create structures with innovative shapes, since NIL can reproducibly create patterns with resolutions down to $10 \mathrm{~nm}$ over a large substrate area at high throughput and low cost [24-28]. Subsequent sidewall deposition of e.g. Au, ZnO or Mo on the sides and top of the resist used for NIL has proven its feasibility for making 3D hollow nanobox structures with dimensions below the 
dimensions of the mold, and these structures were also used in optoelectronic devices [26-28]. PMMA-Au nanocube structures also provide a perfect and reproducible substrate for making nanocube structures containing any desired material by electrodeposition. In this study, $\mathrm{MoS}_{2}$ nanocube structures were prepared by electrodeposition using patterned PMMA-Au nanocube arrays as the substrates. Nanocube arrays with cubes having lateral dimensions of 200 or $500 \mathrm{~nm}$ were prepared. The resulting $\mathrm{MoS}_{2}$ nanostructures were expected to contain an increased density of catalytically active edge sites for the HER. Their electrocatalytic activities were therefore compared with the activity of planar $\mathrm{MoS}_{2}$ films prepared under the same electrodeposition conditions. Here, we report the synthesis and HER properties of these $\mathrm{MoS}_{2}$ nanocube electrodes.

\section{$\begin{array}{ll}\text { 1. Spin Coating } & \text { 2. UV-NIL }\end{array}$}

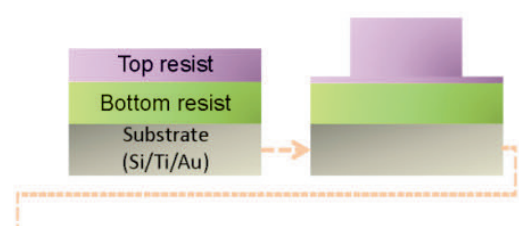

3. RIE 4. Au sputtering
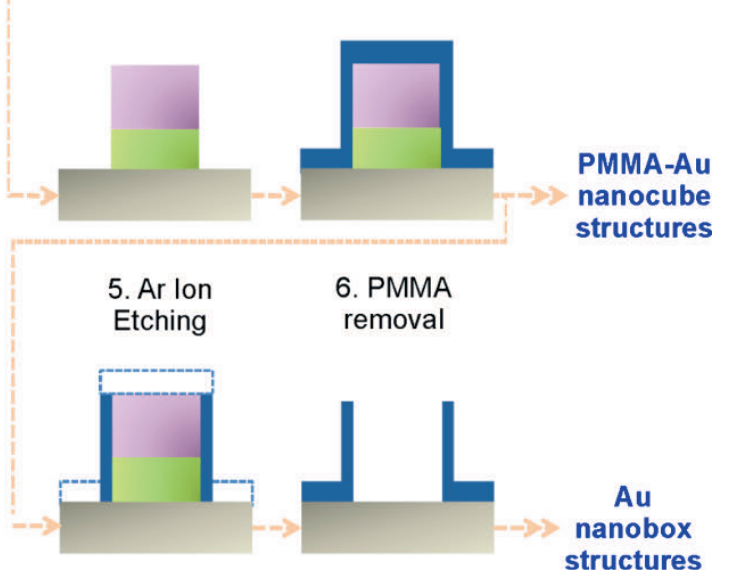

Figure 8.1: Schematic representation of UV-NIL process used for the preparation of PMMA-Au nanocubes and Au nanoboxes: Spincoating of resist layers (step 1), ultraviolet nanoimprint lithography (UV-NIL) (step 2), reactive ion etching (RIE) of residual resist layers (step 3), Au sputtering for the formation of PMMA-Au nanocube structures (step 4), Ar ion etching of unwanted Au layer (step 5) and PMMA removal using acetone for the formation of Au nanobox structures (step 6). 


\subsection{Experimental details}

Resist polymers NX-2030 and NX-3032 were purchased from Nanonex (USA), ammonium tetrathiomolybdate $\left(\left(\mathrm{NH}_{4}\right)_{2} \mathrm{MoS}_{4}\right.$, purity $\left.99.98 \%\right)$, potassium chloride $(\mathrm{KCl}$, purity $99.999 \%)$, ammonium chloride $\left(\mathrm{NH}_{4} \mathrm{Cl}\right.$, purity $99.5 \%)$ and sulfuric acid $\left(\mathrm{H}_{2} \mathrm{SO}_{4}, 96 \%\right.$ in water) were purchased from Acros Organics, formamide (purity 99.5+\%) and chloroplatinic acid hexahydrate $\left(\mathrm{H}_{2} \mathrm{PtCl}_{6} \cdot 6 \mathrm{H}_{2} \mathrm{O}\right.$, powder and chunks) were purchased from Sigma-Aldrich, and nickel sulfate hexahydrate $\left(\mathrm{NiSO}_{4} \cdot 6 \mathrm{H}_{2} \mathrm{O}\right.$, purity $\left.99 \%\right)$ and boric acid $\left(\mathrm{H}_{3} \mathrm{BO}_{3}\right.$, purity $\left.99.99 \%\right)$ were purchased from Merck. Milli-Q water with a resistivity of $18.2 \mathrm{M} \Omega \cdot \mathrm{cm}$ was used in all experiments.

The UV (ultraviolet)-NIL process used for the formation of the nanocube structures was slightly modified with respect to the previously published procedure [27]. In short, a bilayer organic resist system, consisting of a bottom layer of thermally curable resin (NX-2030) and a top layer of UV-curable resin (NX-3032) was employed. The UV-NIL process was performed by a nanoimprinter (Eitre 3, Obducat) at a pressure of $30 \mathrm{mbar}$ at room temperature with $1 \mathrm{~min}$ of UV exposure. Using a reactive ion etching (RIE) system (RIE-10NR, Samco), the top and bottom residual layers were removed by a $\mathrm{CF}_{4}$ and $\mathrm{O}_{2}$ plasma process, respectively. A 10-20 nm thick Au layer was deposited at room temperature for $120 \mathrm{~s}$ at $8 \mathrm{~mL}$ of $\mathrm{Ar}$ flow (STP) using an RF sputter system (SC701HMC, Sanyu, Japan), which was operated at $500 \mathrm{~W}$ input power. For the formation of nanobox structures, an additional ion etching process (EIS-200ER, Elionix, Japan) with Ar was applied as an anisotropic etching process after deposition, which etched away the top Au layer from the nanocube structures. Figure 8.1 gives a schematic representation of this process.

$\mathrm{MoS}_{2}$, Pt and Ni were deposited on Au nanocube or nanobox structures and flat $\mathrm{Au}$ films by electrodeposition in a three-electrode setup. Here, the substrate was the working electrode, and a Pt sheet and $\mathrm{Ag} / \mathrm{AgCl}$ in $3 \mathrm{M} \mathrm{KCl}$ (Metrohm Autolab) were used as counter and reference electrode, respectively. These electrodes were connected to an Autolab PGSTAT 128N potentiostat. $\mathrm{MoS}_{2}$ was electrodeposited from a formamide solution containing $0.002 \mathrm{M}\left(\mathrm{NH}_{4}\right)_{2} \mathrm{MoS}_{4}, 0.04 \mathrm{M} \mathrm{KCl}$ and $0.2 \mathrm{M} \mathrm{NH}_{4} \mathrm{Cl}$ at a potential of $-0.6 \mathrm{~V} \mathrm{vs}$. $\mathrm{Ag} / \mathrm{AgCl}$. After deposition, $\mathrm{MoS}_{2}$ was annealed under a constant flow of $\mathrm{Ar}$ gas for $1 \mathrm{~h}$ at $400{ }^{\circ} \mathrm{C}$. Ni was deposited from an aqueous electrolyte solution containing $0.23 \mathrm{M} \mathrm{NiSO}_{4} \cdot 6 \mathrm{H}_{2} \mathrm{O}$ and $0.15 \mathrm{M} \mathrm{H}_{3} \mathrm{BO}_{3}$ at a 
potential of $-1.0 \mathrm{~V}$ vs. $\mathrm{Ag} / \mathrm{AgCl}$. Pt was deposited using an aqueous electrolyte solution containing $0.01 \mathrm{M} \mathrm{H}_{2} \mathrm{PtCl}_{6} \cdot 6 \mathrm{H}_{2} \mathrm{O}$ at a potential of $-0.3 \mathrm{~V}$ vs. $\mathrm{Ag} / \mathrm{AgCl}$.

Scanning Electron Microscopy (SEM) images were taken with a Zeiss Merlin HRSEM. Transmission Electron Microscopy (TEM) images were taken with an Analytical TEM from FEI Instruments. Electrochemical characterization was performed by linear sweep voltammetry (LSV) using the same three-electrode setup as used for electrodeposition, but using a glassy carbon rod $(7 \mathrm{~mm}$ diameter, $50 \mathrm{~mm}$ length, Alfa Aesar) as counter electrode. The electrolyte was an aqueous solution containing $0.29 \mathrm{M} \mathrm{H}_{2} \mathrm{SO}_{4}$ (pH 0.24), which was purged with $\mathrm{N}_{2}$ gas for at least 30 min prior to the LSV measurements in order to remove any dissolved $\mathrm{O}_{2}$. LSV curves were measured twice for every sample in the negative direction from $0.07 \mathrm{~V}$ to $-0.8 \mathrm{~V}$ vs. $\mathrm{Ag} / \mathrm{AgCl}$ using a step potential of $-0.3 \mathrm{mV}$ and a scan rate of $5 \mathrm{mV} / \mathrm{s}$. Prior and after the LSV measurements, a constant potential of $-0.4 \mathrm{~V}$ vs. $\mathrm{Ag} / \mathrm{AgCl}$ was applied for $10 \mathrm{~min}$ to reduce any oxidized material and verification of the system's chemical stability. The solution was stirred during all measurements. The potential was converted to the RHE reference electrode by

$$
\begin{aligned}
& E(\text { vs. RHE })=E(\text { vs. } \mathrm{Ag} / \mathrm{AgCl})+E_{\mathrm{Ag} / \mathrm{AgCl}}(\mathrm{ref})+0.0591 \mathrm{~V} \cdot \mathrm{pH}, \\
& E_{\mathrm{Ag} / \mathrm{AgCl}}(\mathrm{ref})=0.1976 \mathrm{~V} \text { vs. } \mathrm{RHE} \text { at } 25^{\circ} \mathrm{C} .
\end{aligned}
$$




\subsection{Results and discussion}

Figure 8.2 shows SEM images of $\mathrm{MoS}_{2}$ films and PMMA-Au-MoS 2 nanocube structures after electrodeposition and annealing. From the SEM images in the left column, it can be concluded that the $\mathrm{MoS}_{2}$ films were not completely smooth, since wrinkles were observed of similar dimensions as the nanocube structures. More interestingly, no wrinkles were observed on or in between the nanocube structures and the PMMA-Au nanocube structures were smoothly covered with $\mathrm{MoS}_{2}$. Comparison with a $\mathrm{MoS}_{2}$ film before annealing (Figure 8.3) showed that these wrinkles were formed during thermal annealing by compressive stress. As shown by Hendricks and Lee, this stress can be released by incorporation of a nanostructure or nanoparticles in a polyelectrolyte multilayer coating on PDMS, thereby preventing wrinkle formation [29]. Since the wrinkles observed on the $\mathrm{MoS}_{2}$ films have similar dimensions as the nanocubes used in this study, it is expected that the deposition of $\mathrm{MoS}_{2}$ on discrete nanocube structures prevented the build-up of compressive stress and therefore the formation of wrinkles on the nanocubes. 


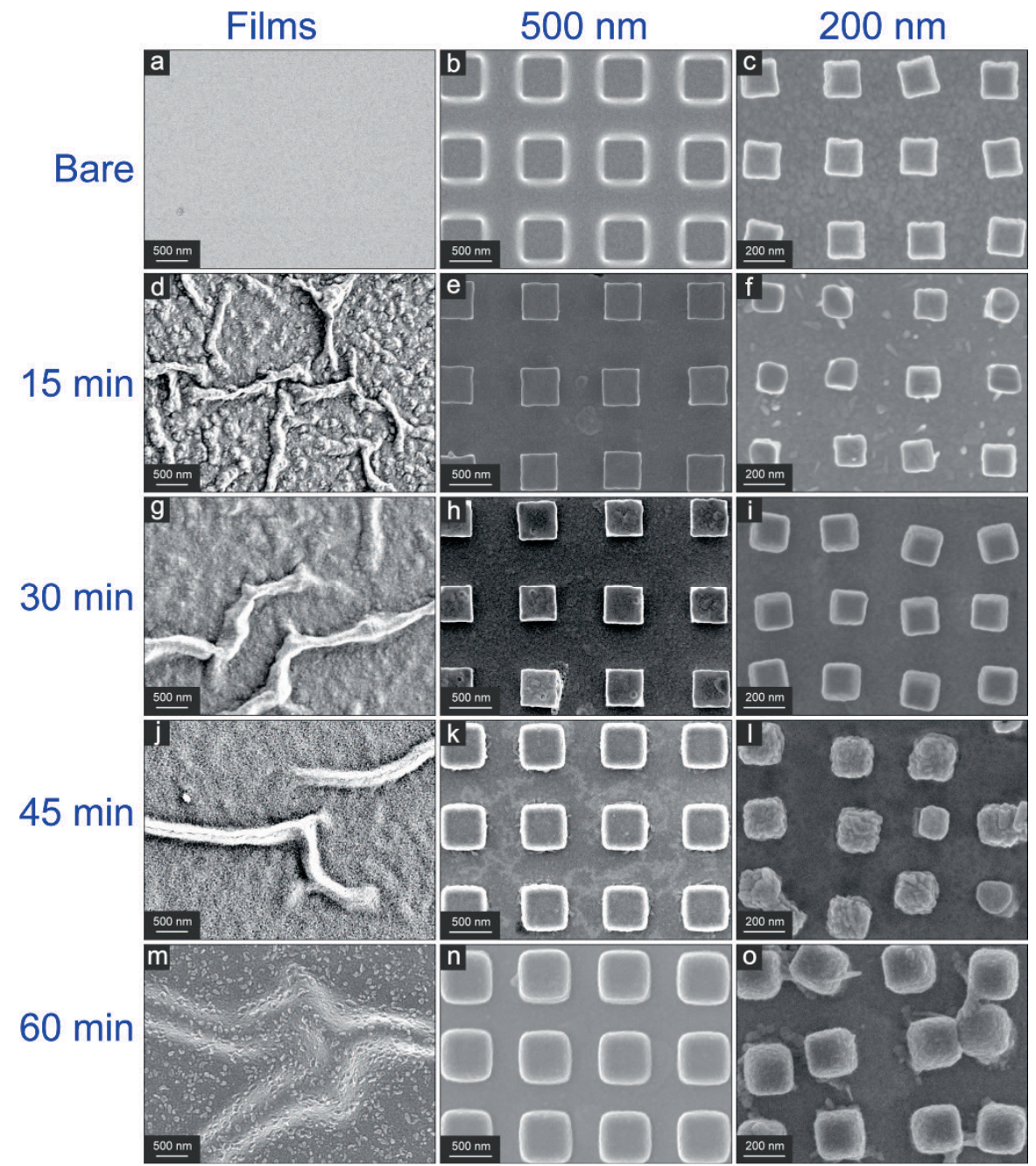

Figure 8.2: SEM images of electrodeposited $\mathrm{MoS}_{2}$ films and nanocube structures: (a) bare Au substrate, (b) Au nanocube structures, lateral size $\sim 500 \mathrm{~nm}$, (c) Au nanocube structures, lateral size $200 \mathrm{~nm}$, (d) $\mathrm{MoS}_{2}$ film after $15 \mathrm{~min} \mathrm{MoS}_{2}$ deposition, (e) $\mathrm{MoS}_{2}$ nanocube structures, lateral size $\sim 500 \mathrm{~nm}, 15 \mathrm{~min} \mathrm{MoS}_{2}$ deposition, (f) $\mathrm{MoS}_{2}$ nanocube structures, lateral size $200 \mathrm{~nm}, 15 \mathrm{~min} \mathrm{MoS}_{2}$ deposition, (g) $\mathrm{MoS}_{2}$ film, $30 \mathrm{~min} \mathrm{MoS}_{2}$ deposition, (h) MoS $\mathrm{S}_{2}$ nanocube structures, lateral size $\sim 500 \mathrm{~nm}, 30 \mathrm{~min} \mathrm{MoS}_{2}$ deposition, (i) $\mathrm{MoS}_{2}$ nanocube structures, lateral size $200 \mathrm{~nm}, 30 \mathrm{~min} \mathrm{MoS}_{2}$ deposition, (j) $\mathrm{MoS}_{2}$ film, $45 \mathrm{~min} \mathrm{MoS}_{2}$ deposition, (k) $\mathrm{MoS}_{2}$ nanocube structures, lateral size $\sim 500 \mathrm{~nm}, 45 \mathrm{~min} \mathrm{MoS}_{2}$ deposition, (I) $\mathrm{MoS}_{2}$ nanocube structures, lateral size $\sim 200 \mathrm{~nm}, 45 \mathrm{~min} \mathrm{MoS}_{2}$ deposition, (m) $\mathrm{MoS}_{2}$ film, $60 \mathrm{~min} \mathrm{MoS}_{2}$ deposition, (n) $\mathrm{MoS}_{2}$ nanocube structures, lateral size $\sim 500 \mathrm{~nm}, 60 \mathrm{~min} \mathrm{MoS}_{2}$ deposition, (o) $\mathrm{MoS}_{2}$ nanocube structures, lateral size $\sim 200 \mathrm{~nm}, 60 \mathrm{~min} \mathrm{MoS}_{2}$ deposition. 


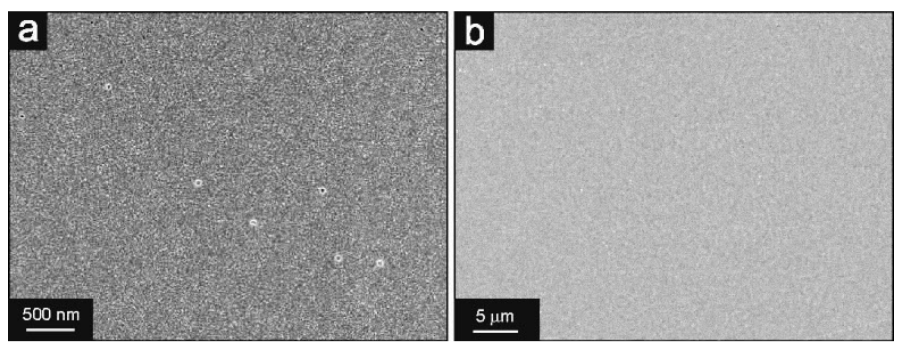

Figure 8.3: (a) HR-SEM and (b) SEM images of as-deposited $\mathrm{MoS}_{2}$ film after 45 min $\mathrm{MoS}_{2}$ deposition.

For the nanocube structures, a small decrease in nanocube size was observed for short deposition times (Figure 8.2e,f), but, upon prolonged deposition, the thickness of the $\mathrm{MoS}_{2}$ layer gradually increased with deposition time at an average deposition rate of $\sim 40 \mathrm{~nm} / \mathrm{h}$. The reason for the initial decrease in nanocube size is that formamide, which is the solvent used for $\mathrm{MoS}_{2}$ deposition, was able to penetrate the Au layer on top of the PMMA nanocube structures and dissolved part of the polymeric resist underneath this Au layer. The flexibility of the Au layer caused the core-shell nanocube structure to partly collapse. Since smaller nanocubes with a larger relative surface area have a higher surface energy per unit volume, the shape of the nanocube structures with lateral dimensions of $200 \mathrm{~nm}$ may be more susceptible to deformation by formamide etching.

Another interesting observation was that after 30 min of $\mathrm{MoS}_{2}$ deposition, the sharp edges of the nanocube structures were still clearly visible (Figure $8.2 \mathrm{~h}, \mathrm{i}$ and Figure $8.4 \mathrm{a}, \mathrm{b}$ ), but after $45 \mathrm{~min}$ they became more rounded (Figure $8.2 \mathrm{k}, \mathrm{I}$ and Figure $8.4 \mathrm{c}, \mathrm{d}$ ). The reason can be found in the layered structure of $\mathrm{MoS}_{2}$, in which it is energetically more favorable to expose fewer edge sites and form a continuous blanket on top of the nanocube structures. Since smaller nanocubes with a larger relative surface area have a higher surface energy per unit volume, the smaller structures with lateral dimensions of $200 \mathrm{~nm}$ obtained a more rounded shape than the larger nanocube structures with lateral dimensions of $500 \mathrm{~nm}$. 


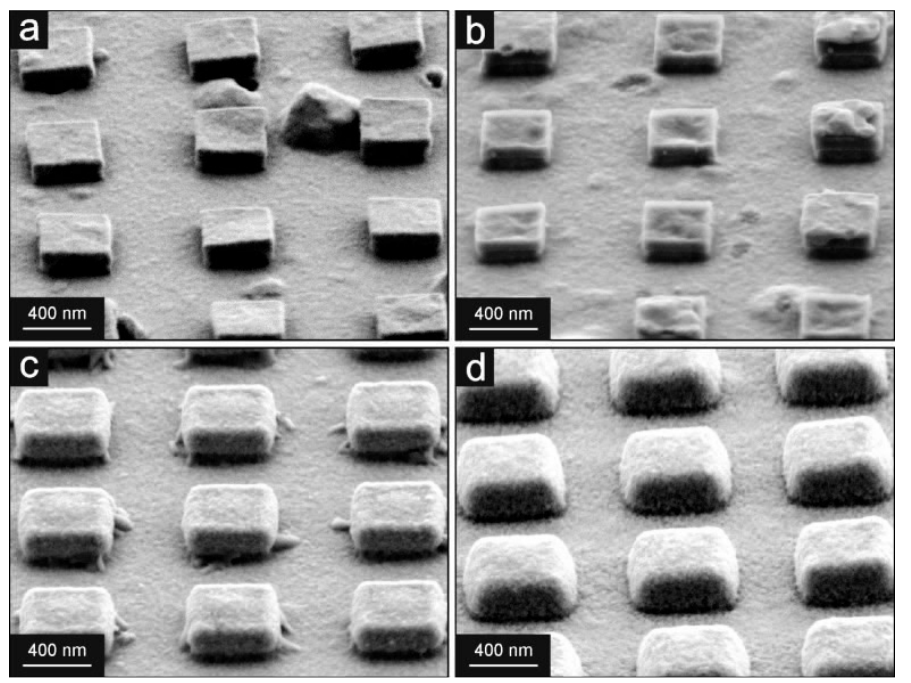

Figure 8.4: Side-view SEM images of $\mathrm{MoS}_{2}$ nanocube structures with a lateral size of approximately $500 \mathrm{~nm}$ after electrodeposition for (a) $15 \mathrm{~min}$, (b) $30 \mathrm{~min}$, (c) $45 \mathrm{~min}$ and (d) $60 \mathrm{~min}$.

In Figure 8.5, a Transmission Electron Microscopy (TEM) image of a cross-section of a $\mathrm{MoS}_{2}$ nanocube structure with a lateral size of $\sim 500 \mathrm{~nm}$ after electrodeposition for $60 \mathrm{~min}$ is shown. Figure 8.5a shows the different phases present in a single nanocube on a Au substrate, where the PMMA core was partly dissolved during sample preparation for TEM imaging. On top of the PMMA core, a 10-20 nm thick Au layer and a $\sim 40 \mathrm{~nm}$ thick $\mathrm{MoS}_{2}$ layer were visible. Figure $8.5 \mathrm{~b}$ is a high resolution TEM image at the top left corner of a $\mathrm{MoS}_{2}$ nanocube structure showing the arrangement of individual $\mathrm{MoS}_{2}$ layers at the atomic level. It was found that $\mathrm{MoS}_{2}$ layers are composed of numerous nanoscale $\mathrm{MoS}_{2}$ domains which are randomly oriented to each other, but with a strong preferential orientation of (002) planes parallel to the underlying Au substrate as confirmed by fast Fourier transform (FFT) analysis (Figure $8.5 \mathrm{c}-\mathrm{j}$ ). The diffuse ring in the FFT patterns represents the reciprocal distance between two adjacent $\mathrm{MoS}_{2}$ planes in the [002] direction. Also displayed in the FFT patterns is a numerical value $r$ for the degree of orientational (an)isotropy within the ring. It is defined as $r=I_{\min } / I_{\max }$, where $I_{\max }$ is the intensity at its maximum value along the (002) ring, i.e. the direction in which the $\mathrm{MoS}_{2}$ planes show the highest degree of organization, and the intensity $I_{\min }$ is measured in the direction perpendicular to that. At the sidewall and on top of a nanocube structure, $\mathrm{MoS}_{2}$ growth was able to proceed parallel to the underlying $\mathrm{Au}$ interface. This is illustrated by the identical FFT patterns in 
Figure $8.5 \mathrm{c}$ and $\mathrm{d}$, and Figure 8.5e and $\mathrm{f}$, respectively, in which the $r$ value shows that the $\mathrm{MoS}_{2}$ planes are oriented parallel to the underlying Au layer. The only difference between bottom and top of the $\mathrm{MoS}_{2}$ layer in these areas is a slight increase in $r$ value, ranging from $r \sim 0.83 \pm 0.02$ near the Au interface to $r \sim 0.87 \pm 0.02$ at the top surface. Many other areas were also analyzed, and they provided average $r$ values of $0.83 \pm 0.01$ and $0.88 \pm 0.04$ near the Au surface and top of the $\mathrm{MoS}_{2}$ layer, respectively. On the other hand, the $\mathrm{MoS}_{2}$ layers from the top surface and side walls meet at the corner of a nanocube structure, so that organization is expected to become more irregular in that area. This process is visible when looking at the FFT patterns made from bottom to top of the $\mathrm{MoS}_{2}$ layer at the edge of a nanocube (Figure $8.5 \mathrm{~g}-\mathrm{j}$ ). At the bottom of the $\mathrm{MoS}_{2}$ layer, a sharp transition from $\mathrm{MoS}_{2}$ planes arranged parallel to the side wall of the nanocube (Figure $8.5 \mathrm{~g}$ ) to $\mathrm{MoS}_{2}$ planes arranged parallel to the top surface of the nanocube (Figure 8.5h) can be observed. When analyzing the FFT patterns of areas closer to the top of the $\mathrm{MoS}_{2}$ layer (Figure 8.5i,j), it can be observed that the alignment of the $\mathrm{MoS}_{2}$ planes decreased accordingly, with a maximum $r$ value of $0.93 \pm 0.02$ at the top corner of the $\mathrm{MoS}_{2}$ nanocube. The decrease in degree of order can be explained by curvature of the $\mathrm{MoS}_{2}$ layers by the blanketing effect, as can be observed in Figure 8.2 and Figure 8.4. Since several studies showed that the edge sites of $\mathrm{MoS}_{2}$ planes are catalytically the most active sites for $\mathrm{H}_{2}$ evolution $[6,15,17,18]$, it is expected a priori that the region near the corners of a $\mathrm{MoS}_{2}$ nanocube before the blanketing effect are catalytically more active for hydrogen evolution than the planar regions. 


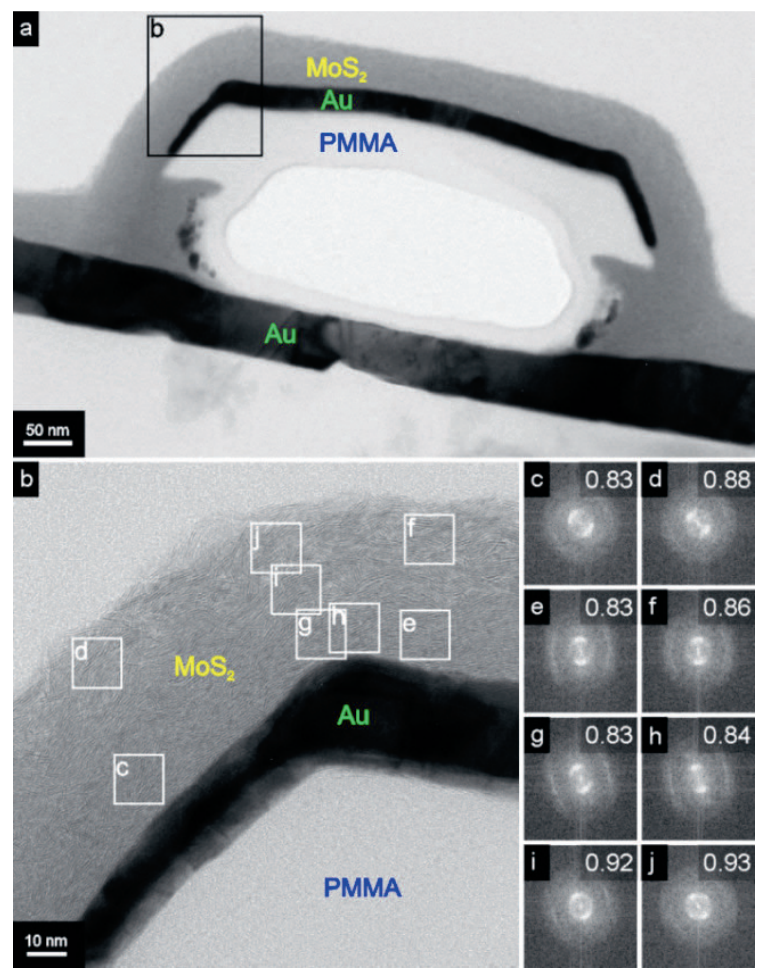

Figure 8.5: (a) TEM image of a $\mathrm{MoS}_{2}$ nanocube structure with a lateral size of approximately $500 \mathrm{~nm}$ after electrodeposition for $60 \mathrm{~min}$, (b) HR-TEM image of the area indicated in (a), and (c-j) fast Fourier transform (FFT) images of the respective areas as indicated in (b). The numbers in the upper right corners of (c-j) are the $r$ values, which express the degree of organizational anisotropy in the respective areas.

Figure 8.6 shows LSV curves and the corresponding Tafel plots measured on different $\mathrm{MoS}_{2}$ samples. In Figure 8.6a-c, $\mathrm{MoS}_{2}$ was deposited on a Au film, $500 \mathrm{~nm}$ nanocube structures and $200 \mathrm{~nm}$ nanocube structures, respectively. On all $\mathrm{MoS}_{2}$ (nano)structures, the onset potential for $\mathrm{H}_{2}$ evolution shifted to more positive potentials (i.e. less overpotential) when the deposition time increased from 15 to $45 \mathrm{~min}$, which is an indication for increasing activity towards $\mathrm{H}_{2}$ formation, but it shifted back to more negative potentials when the deposition time was increased to $60 \mathrm{~min}$. This may be related to a decreased conductivity of thicker $\mathrm{MoS}_{2}$ layers, but for the nanocube structures this may also be explained by the formation of rounded edges after 45-60 min deposition, in which the number of catalytically active edge sites of the disordered $\mathrm{MoS}_{2}$ layers decreased by the 'blanket' formed over the nanocube structures, as shown 
in Figure $8.2 \mathrm{k}, \mathrm{l}, \mathrm{n}, \mathrm{O}$ and Figure $8.4 \mathrm{c}, \mathrm{d}$. The high activity of the $\mathrm{MoS}_{2}$ film deposited for $45 \mathrm{~min}$ can be explained by cracking of the wrinkles (Figure 8.2j), which exposed the edge sites within these wrinkles. As such cracks were smoothly covered with $\mathrm{MoS}_{2}$ after deposition for 60 min (Figure $8.2 \mathrm{~m}$ ), apparently the HER activity decreased upon prolonged deposition.
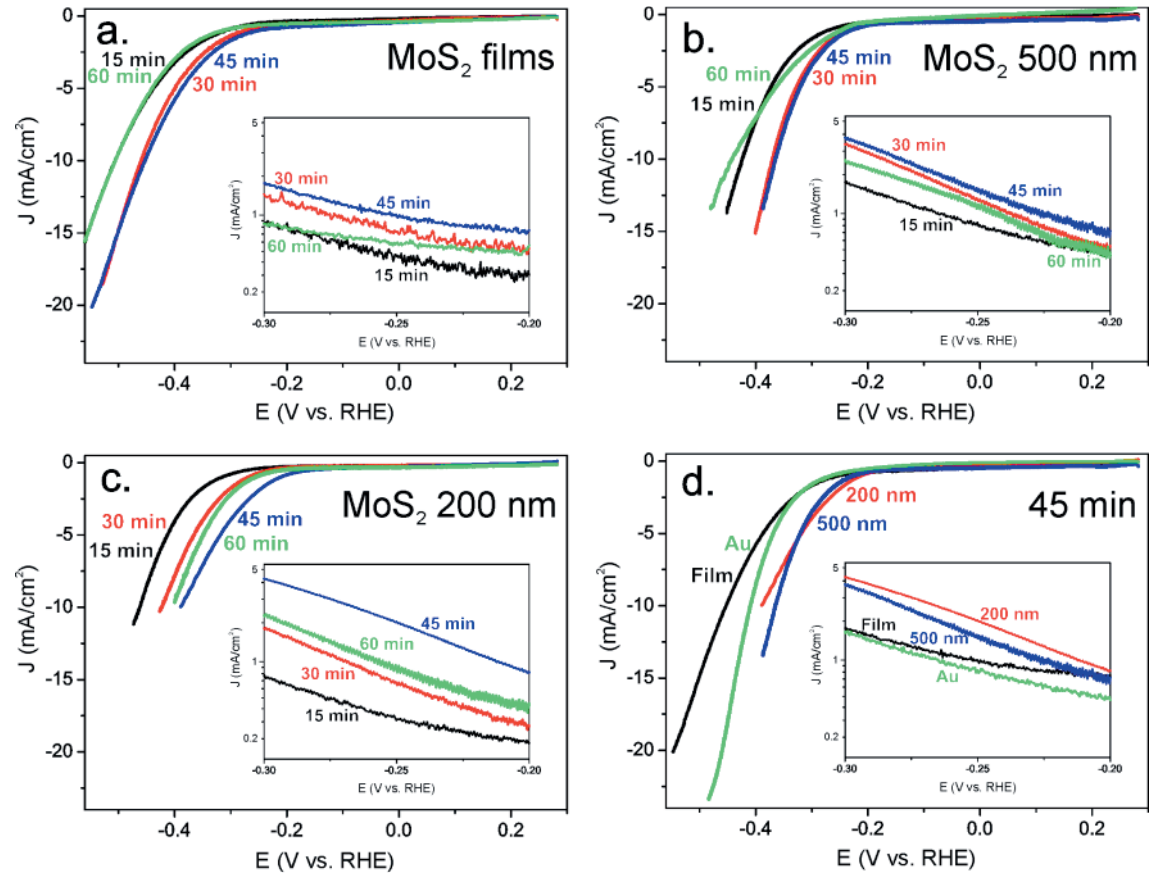

Figure 8.6: LSV measurements and corresponding Tafel plots (insets) of (a) $\mathrm{MoS}_{2}$ films after $\mathrm{MoS}_{2}$ deposition for $15 \mathrm{~min}$ (black line), $30 \mathrm{~min}$ (red line), $45 \mathrm{~min}$ (blue line) and $60 \mathrm{~min}$ (green line), (b) $500 \mathrm{~nm} \mathrm{MoS}$ nanocube structures after $\mathrm{MoS}_{2}$ deposition for $15 \mathrm{~min}$ (black line), $30 \mathrm{~min}$ (red line), $45 \mathrm{~min}$ (blue line) and $60 \mathrm{~min}$ (green line), (c) $200 \mathrm{~nm} \mathrm{MoS}_{2}$ nanocube structures after $\mathrm{MoS}_{2}$ deposition for $15 \mathrm{~min}$ (black line), $30 \mathrm{~min}$ (red line), $45 \mathrm{~min}$ (blue line) and $60 \mathrm{~min}$ (green line); (d) comparison between Au film (green line) and several $\mathrm{MoS}_{2}$ architectures after $45 \mathrm{~min}$ of $\mathrm{MoS}_{2}$ deposition on a film (black line), on $500 \mathrm{~nm}$ nanocubes (blue line), and on $200 \mathrm{~nm}$ nanocubes (red line). All LSV curves were measured in negative direction from $0.28 \mathrm{~V}$ to $-0.59 \mathrm{~V}$ vs. RHE using a step potential of $-0.3 \mathrm{mV}$ and a scan rate of $5 \mathrm{mV} / \mathrm{s}$ in an electrolyte containing $\mathrm{H}_{2} \mathrm{SO}_{4}$ at $\mathrm{pH}$ 0.24, which was stirred during LSV measurements and had been purged with $\mathbf{N}_{2}$ prior to the measurements. The presented current densities were calculated for the real surface area. Because the current was found to be limited by the counter electrode for high overpotentials, the shown curves were cut off before a plateau was observed. 
In Figure 8.6d, all $\mathrm{MoS}_{2}$ structures after deposition for 45 min were compared with each other, and with a Au film without $\mathrm{MoS}_{2}$. It can be seen that the onset potential for $\mathrm{H}_{2}$ formation is more positive for both $\mathrm{MoS}_{2}$ nanocube structures than for the $\mathrm{MoS}_{2}$ film, which implies a higher $\mathrm{H}_{2}$ evolution activity. The presented current densities are calculated based on the real surface area, therefore surface area differences between flat and structured films are not the cause for the observed differences in the onset potential or Tafel slope. Even though the observed wrinkles on the $\mathrm{MoS}_{2}$ films have similar dimensions as the nanocube structures, these wrinkles do not expose a higher concentration of edge sites compared to the nanocube structures, which probably explains the observed later onset potential of the $\mathrm{MoS}_{2}$ films. The smaller nanocube structures show a slightly earlier onset potential than the larger nanostructures, which is in agreement with the larger number of edge sites per unit surface area.

Table 8.1 gives an overview of all relevant data that were extracted from the LSV measurements and Tafel plots in Figure 8.6. The Tafel slope of a given material can be used to distinguish between different mechanistic pathways involving the three reactions generally involved in $\mathrm{H}_{2}$ evolution, i.e. Volmer, Tafel and Heyrovsky steps:

Volmer: $\mathrm{H}^{+}+\mathrm{e}^{-} \rightarrow \mathrm{H}_{\mathrm{ads}}$,

Tafel: $\mathrm{H}_{\mathrm{ads}}+\mathrm{H}_{\mathrm{ads}} \rightarrow \mathrm{H}_{2}$,

Heyrovsky: $\mathrm{H}_{\mathrm{ads}}+\mathrm{H}^{+}+\mathrm{e}^{-} \rightarrow \mathrm{H}_{2}$,

If the first reaction step (Volmer or discharge reaction) is rate-determining, a Tafel slope of $118 \mathrm{mV} / \mathrm{dec}(2 \times 2.303 R T / F)$ or higher is generally observed [22]. Similarly, a Tafel slope of $\sim 29 \mathrm{mV} / \mathrm{dec}(2.303 R T / 2 F)$ is an indication of a rate-determining Tafel reaction, and a Tafel slope of $\sim 39 \mathrm{mV} / \mathrm{dec}(2 \times 2.303 R T / 3 \mathrm{~F})$ is an indication of a rate-determining Heyrovsky reaction [22]. Since all Tafel slopes observed for the $\mathrm{MoS}_{2}$ films and nanocube structures were higher than $118 \mathrm{mV} / \mathrm{dec}$, this means that the formation of atomic $\mathrm{H}$ is most likely the rate-determining reaction step. The large deviation from the theoretical value may be due to the Au substrate having a low conductivity, or to a too high uncompensated resistance in our setup [4]. Unfortunately, a large variation in iR drop (25-75 $\Omega$ ) was observed when we used impedance or I-interrupt techniques for measurement of the 
uncompensated resistance. Consequently, attempts for iR-correction failed, because similar iR drops were expected for different samples. Since false iR-correction may add inappropriate distortions to the original data, it was decided to present the data without iR-correction. As the nanocubes show a smaller average Tafel slope than the planar films, the nature of the active sites may be distinctively different, which can be explained by the availability of more catalytically active edge sites on the nanocube samples. As expected from the LSV curves, $J_{0}$ is the highest after a deposition time of 45 min for all $\mathrm{MoS}_{2}$ structures compared in this study.

Table 8.1: Overview of overpotentials needed to reach a current density of $-1 \mathrm{~mA} / \mathrm{cm}^{2}$ and $-5 \mathrm{~mA} / \mathrm{cm}^{2}$, Tafel slopes and exchange current densities for different samples used in this study, including a comparison with literature data.

\begin{tabular}{|c|c|c|c|c|}
\hline Sample & $\begin{array}{l}\text { Overpotential } \\
\text { needed for } \\
-1 \mathrm{~mA} / \mathrm{cm}^{2}(\mathrm{mV})\end{array}$ & $\begin{array}{l}\text { Overpotential } \\
\text { needed for } \\
-5 \mathrm{~mA} / \mathrm{cm}^{2}(\mathrm{mV})\end{array}$ & $\begin{array}{l}\text { Tafel } \\
\text { slope } \\
\text { (mV/dec) }\end{array}$ & $\begin{array}{l}\text { Exchange } \\
\text { current density } \\
J_{0}\left(\mathrm{~mA} / \mathrm{cm}^{2}\right)\end{array}$ \\
\hline Film $30 \mathrm{~min}$ & 270 & 400 & 179 & $2.9 \times 10^{-2}$ \\
\hline Film $45 \mathrm{~min}$ & 250 & 387 & 189 & $4.4 \times 10^{-2}$ \\
\hline $500 \mathrm{~nm} 15 \mathrm{~min}$ & 260 & 373 & 154 & $1.9 \times 10^{-2}$ \\
\hline $500 \mathrm{~nm} 30 \mathrm{~min}$ & 240 & 328 & 131 & $1.6 \times 10^{-2}$ \\
\hline $500 \mathrm{~nm} 45 \mathrm{~min}$ & 230 & 321 & 134 & $2.0 \times 10^{-2}$ \\
\hline $500 \mathrm{~nm} 60 \mathrm{~min}$ & 240 & 365 & 141 & $1.9 \times 10^{-2}$ \\
\hline $200 \mathrm{~nm} 15 \mathrm{~min}$ & 320 & 414 & 142 & $6.1 \times 10^{-3}$ \\
\hline Au film & 260 & 370 & 135 & $9.4 \times 10^{-3}$ \\
\hline $\mathrm{MoS}_{2}$ nanopolygons [17] & 100 (onset) & n.a. & $55-60$ & $1.3-3.1 \times 10^{-4}$ \\
\hline Amorphous Co- $\mathrm{MoS}_{3}$ [22] & 140 & 175 & 40 & $1.3 \times 10^{-4}$ \\
\hline Amorphous $\mathrm{MoS}_{3}[5]$ & 170 & n.a. & 43 & $5.0 \times 10^{-4}$ \\
\hline $\mathrm{MoO}_{3}-\mathrm{MoS}_{2}$ nanowires [4] & 207 & 264 & $50-60$ & n.a. \\
\hline Double-gyroid $\mathrm{MoS}_{2}$ [19] & 300 & n.a. & n.a. & n.a. \\
\hline Vertically aligned $\mathrm{MoS}_{2}[18]$ & 330 & 370 & $105-120$ & $2.2 \times 10^{-3}$ \\
\hline
\end{tabular}

The bottom part of Table 8.1 provides an overview of the characteristics of a few of the best $\mathrm{MoS}_{2}$ systems reported in literature [4, 5, 17-19, 22]. It is noted that all measurements (this study and the comparison with literature) were performed in acidic solutions with $\mathrm{pH}$ between 0.0 and 0.5 . Considering the overpotential needed to reach a current density of $-1 \mathrm{~mA} / \mathrm{cm}^{2}$, the $\mathrm{MoS}_{2}$ nanocube structures as presented in this study are comparable to the performances of the literature systems, having an early onset potential and therefore a relatively low overpotential at a current density of $-1.0 \mathrm{~mA} / \mathrm{cm}^{2}$. Only $\mathrm{MoS}_{2}$ nanopolygons with a very high concentration of edge sites and amorphous $\mathrm{MoS}_{3}$ films with or without $\mathrm{Co}$ 
promotion show an earlier onset potential $[5,17,22]$, and the required overpotential for our system is approximately the same as that for $\mathrm{MoO}_{3}-\mathrm{MoS}_{2}$ nanowires [4]. Since the amorphous $\mathrm{MoS}_{3}$ films were also prepared by electrodeposition, it is expected that applying the exact same synthesis procedure using Co promotion on top of the nanocube structures from this study might improve the $\mathrm{H}_{2}$ evolution activity even further. It is noted that we obtained very high Tafel slopes compared to the values as reported in most literature, which also resulted in a relatively larger overpotential needed to reach a current density of $-5 \mathrm{~mA} / \mathrm{cm}^{2}$. The Tafel slopes reported in literature $(40-60 \mathrm{mV} / \mathrm{dec})$ indicate a rate-determining desorption step via an ion+atom reaction (Heyrovsky step) [4, 5, 17, 22], whereas the nanocubes in our study showed a rate-determining $\mathrm{H}$ formation reaction (Volmer step). A possible explanation for the shift in reaction mechanism may be the fact that our $\mathrm{MoS}_{2}$ samples are composed of many nano-sized domains. Consequently, a high concentration of defect sites, as observed from the TEM image in Figure 8.5, may have led to different predominant mechanisms than the regular catalytic centers at the edge sites.

It is envisaged that $\mathrm{MoS}_{2}$ could be employed as a segment in photocatalytic nanowires or nanocubes made via templated electrodeposition for improved $\mathrm{H}_{2}$ formation [30]. Since electrodeposition yields $\mathrm{MoS}_{2}$ with a preferred orientation of the $\mathrm{MoS}_{2}$ layers parallel to the substrate as observed here, it is expected that a high density of edge sites would be located at the template wall. In this way, a high density of edge sites would be exposed at the nanowire surface upon template removal, which would increase the $\mathrm{H}_{2}$ evolution rate.

To illustrate the versatility of the presented technique for the synthesis of nanocube structures of arbitrary composition, also Pt was deposited on top of PMMA-Au nanocube structures. As shown in Figure 8.7a,b, these Pt nanocube structures have the same polycrystalline morphology as observed elsewhere [31]. As shown in Figure 8.1, the same procedure for NIL and sidewall deposition can also be applied for the synthesis of Au nanobox structures instead of PMMA-Au nanocube structures. These nanobox structures can also be coated with an arbitrary second material via electrodeposition as shown in Figure 8.7c for the case of Ni. In this figure, the false color difference between the $\mathrm{Au}$ template (grey) and electrodeposited $\mathrm{Ni}$ (white) indicates the location of the two phases, and EDX mapping (not shown) also confirmed deposited $\mathrm{Ni}$ at the outside of the 
Au nanoboxes. Incomplete PMMA removal may be the reason that no $\mathrm{Ni}$ deposition was observed at the inside of the Au nanoboxes. A closer look at the Au-Ni nanobox structures shows that the corners of the Au phase are sharper than that of the $\mathrm{Ni}$ phase due to the previously described 'blanketing' effect.
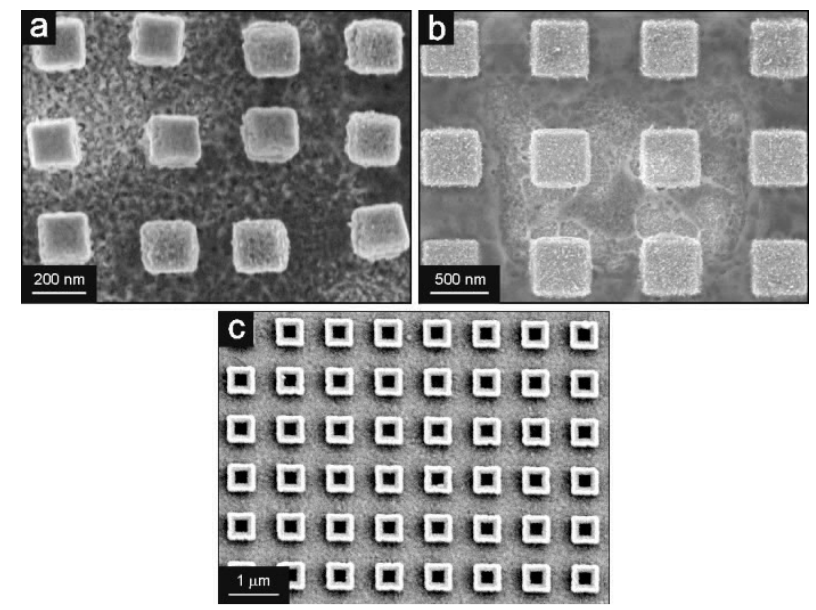

Figure 8.7. (a) Pt nanocube structures with a lateral size of $\sim 200 \mathrm{~nm}$, (b) Pt nanocube structures with a lateral size of $\sim 500 \mathrm{~nm}$, and (c) open $\mathrm{Ni}$ nanobox structures with a lateral size of $\sim 500 \mathrm{~nm}$.

\subsection{Conclusions}

$\mathrm{Au}$ nanocube structures made by a combination of nano-imprint lithography (NIL) and sidewall deposition were conformally covered with a desired second material using electrodeposition. After deposition of $\mathrm{MoS}_{2}$ on top of these $A u$ nanocube structures, the activity towards the $\mathrm{H}_{2}$ evolution reaction (HER) was significantly increased compared to $\mathrm{MoS}_{2}$ films, because a higher relative density of catalytically active $\mathrm{MoS}_{2}$ edge sites was available on these nanocubes. Rounding of the corners of $\mathrm{MoS}_{2}$ nanocube structures is probably responsible for a decrease in HER activity after longer deposition times, since it is energetically more favorable for the system to minimize its total surface area, thereby exposing fewer edge sites. Therefore, $\mathrm{MoS}_{2}$ nanocube structures with a $\sim 30 \mathrm{~nm}$ thick $\mathrm{MoS}_{2}$ layer were found to be most favorable for efficient $\mathrm{H}_{2}$ evolution. These $\mathrm{Au}$ nanocube structures can also be used for the synthesis of nanocubes comprised of other materials like Pt and $\mathrm{Ni}$. 


\subsection{References}

[1] T. Bak, J. Nowotny, M. Rekas, and C. C. Sorrell, "Photo-electrochemical hydrogen generation from water using solar energy. Materials-related aspects", International Journal of Hydrogen Energy, 2002, vol. 27, pp. 991-1022.

[2] A. Kudo and Y. Miseki, "Heterogeneous photocatalyst materials for water splitting", Chemical Society Reviews, 2009, vol. 38, pp. 253-278.

[3] K. Maeda, "Photocatalytic water splitting using semiconductor particles: History and recent developments", Journal of Photochemistry and Photobiology C: Photochemistry Reviews, 2011, vol. 12, pp. 237-268.

[4] Z. Chen, D. Cummins, B. N. Reinecke, E. Clark, M. K. Sunkara, and T. F. Jaramillo, "Core-shell $\mathrm{MoO}_{3}-\mathrm{MoS}_{2}$ nanowires for hydrogen evolution: A functional design for electrocatalytic materials", Nano Letters, 2011, vol. 11, pp. 4168-4175.

[5] D. Merki, S. Fierro, H. Vrubel, and X. Hu, "Amorphous molybdenum sulfide films as catalysts for electrochemical hydrogen production in water", Chemical Science, 2011, vol. 2, pp. 1262-1267.

[6] S. Min and G. Lu, "Sites for high efficient photocatalytic hydrogen evolution on a limited-layered $\mathrm{MoS}_{2}$ cocatalyst confined on graphene sheets-the role of graphene", Journal of Physical Chemistry C, 2012, vol. 116, pp. 25415-25424.

[7] A. Sobczynski, "Molybdenum disulfide as a hydrogen evolution catalyst for water photodecomposition on semiconductors", Journal of Catalysis, 1991, vol. 131, pp. 156-166.

[8] V. H. J. de Beer, J. G. J. Dahlmans, and J. G. M. Smeets, "Hydrodesulfurization and hydrogenation properties of promoted $\mathrm{MoS}_{2}$ and WS $\mathrm{WS}_{2}$ catalysts under medium pressure conditions", Journal of Catalysis, 1976, vol. 42, pp. 467-470.

[9] H. Farag, K. Sakanishi, M. Kouzu, A. Matsumura, Y. Sugimoto, and I. Saito, "Dibenzothiophene hydrodesulfurization over synthesized $\mathrm{MoS}_{2}$ catalysts", Journal of Molecular Catalysis A: Chemical, 2003, vol. 206, pp. 399-408.

[10] Y. Sun, H. Wang, and R. Prins, "Hydrodesulfurization with classic $\mathrm{Co}-\mathrm{MoS}_{2}$ and $\mathrm{Ni}-\mathrm{MoS}_{2} / \mathrm{Y}-\mathrm{Al}_{2} \mathrm{O}_{3}$ and new Pt-Pd on mesoporous zeolite catalysts", Catalysis Today, 2010, vol. 150, pp. 213-217. 
[11] I. Efeoglu, Ö. Baran, F. Yetim, and S. Altintaş, "Tribological characteristics of $\mathrm{MoS}_{2}$ - $\mathrm{Nb}$ solid lubricant film in different tribo-test conditions", Surface and Coatings Technology, 2008, vol. 203, pp. 766-770.

[12] P. D. Fleischauer and J. R. Lince, "Comparison of oxidation and oxygen substitution in $\mathrm{MoS}_{2}$ solid film lubricants", Tribology International, 1999, vol. 32, pp. 627-636.

[13] Y. Xing, J. Deng, Z. Wu, and Y. Lian, "Friction and wear behavior of textured $\mathrm{Al}_{2} \mathrm{O}_{3} / \mathrm{TiC}$ ceramic surface filled with $\mathrm{MoS}_{2}$ solid lubricants," vol. 229-231, ed. Kuala Lumpur, 2012, pp. 35-39.

[14] B. Pourabbas and B. Jamshidi, "Preparation of $\mathrm{MoS}_{2}$ nanoparticles by a modified hydrothermal method and the photo-catalytic activity of $\mathrm{MoS}_{2} / \mathrm{TiO}_{2}$ hybrids in photo-oxidation of phenol", Chemical Engineering Journal, 2008, vol. 138, pp. 55-62.

[15] P. Raybaud, J. Hafner, G. Kresse, S. Kasztelan, and H. Toulhoat, "Ab initio study of the $\mathrm{H}_{2}-\mathrm{H}_{2} \mathrm{~S} / \mathrm{MoS}_{2}$ gas-solid interface: The nature of the catalytically active sites", Journal of Catalysis, 2000, vol. 189, p. 129.

[16] L. F. Seivane, H. Barron, S. Botti, M. A. L. Marques, Á. Rubio, and $X$. López-Lozano, "Atomic and electronic properties of quasi-one-dimensional $\mathrm{MoS}_{2}$ nanowires", Journal of Materials Research, 2013, vol. 28, pp. 240-249.

[17] T. F. Jaramillo, K. P. Jørgensen, J. Bonde, J. H. Nielsen, S. Horch, and I. Chorkendorff, "Identification of active edge sites for electrochemical $\mathrm{H}_{2}$ evolution from $\mathrm{MoS}_{2}$ nanocatalysts", Science, 2007, vol. 317, pp. 100-102.

[18] D. Kong, H. Wang, J. J. Cha, M. Pasta, K. J. Koski, J. Yao, and Y. Cui, "Synthesis of $\mathrm{MoS}_{2}$ and $\mathrm{MoSe}_{2}$ films with vertically aligned layers", Nano Letters, 2013, vol. 13, pp. 1341-1347.

[19] Z. Chen, J. Kibsgaard, and T. F. Jaramillo, "Nanostructuring $\mathrm{MoS}_{2}$ for photoelectrochemical water splitting," San Diego, CA, 2010.

[20] J. Bonde, P. G. Moses, T. F. Jaramillo, J. K. Nørskov, and I. Chorkendorff, "Hydrogen evolution on nano-particulate transition metal sulfides", Faraday Discussions, 2008, vol. 140, pp. 219-231.

[21] B. Hinnemann, P. G. Moses, J. Bonde, K. P. Jørgensen, J. H. Nielsen, S. Horch, I. Chorkendorff, and J. K. Nørskov, "Biomimetic hydrogen evolution: $\mathrm{MoS}_{2}$ nanoparticles as catalyst for hydrogen evolution", Journal of the American Chemical Society, 2005, vol. 127, pp. 5308-5309. 
[22] D. Merki, H. Vrubel, L. Rovelli, S. Fierro, and X. Hu, "Fe, Co, and Ni ions promote the catalytic activity of amorphous molybdenum sulfide films for hydrogen evolution", Chemical Science, 2012, vol. 3, pp. 2515-2525.

[23] M. Nguyen, P. D. Tran, S. S. Pramana, R. L. Lee, S. K. Batabyal, N. Mathews, L. H. Wong, and M. Graetzel, "In situ photo-assisted deposition of $\mathrm{MoS}_{2}$ electrocatalyst onto zinc cadmium sulphide nanoparticle surfaces to construct an efficient photocatalyst for hydrogen generation", Nanoscale, 2013, vol. 5, pp. 1479-1482.

[24] S. Y. Chou, P. R. Krauss, W. Zhang, L. Guo, and L. Zhuang, "Sub-10 nm imprint lithography and applications", Journal of Vacuum Science and Technology B: Microelectronics and Nanometer Structures, 1997, vol. 15, pp. 2897-2904.

[25] M. D. Austin, H. Ge, W. Wu, M. Li, Z. Yu, D. Wasserman, S. A. Lyon, and S. Y. Chou, "Fabrication of $5 \mathrm{~nm}$ linewidth and $14 \mathrm{~nm}$ pitch features by nanoimprint lithography", Applied Physics Letters, 2004, vol. 84, pp. 5299-5301.

[26] N. G. Cha, T. Kanki, and H. Tanaka, "Direct fabrication of integrated 3D epitaxial functional transition metal oxide nanostructures using extremely small hollow nanopillar nano-imprint metal masks", Nanotechnology, 2011, vol. 22,

[27] N. G. Cha, B. K. Lee, T. Kanki, H. Y. Lee, T. Kawai, and H. Tanaka, "Direct fabrication of integrated 3D Au nanobox arrays by sidewall deposition with controllable heights and thicknesses", Nanotechnology, 2009, vol. 20,

[28] A. N. Hattori, A. Ono, and H. Tanaka, "Position-, size-, and shape-controlled highly crystalline ZnO nanostructures", Nanotechnology, 2011, vol. 22,

[29] T. R. Hendricks and I. Lee, "Wrinkle-free nanomechanical film: Control and prevention of polymer film buckling", Nano Letters, 2007, vol. 7, pp. 372-379.

[30] A. W. Maijenburg, E. J. B. Rodijk, M. G. Maas, M. Enculescu, D. H. A. Blank, and J. E. ten Elshof, "Hydrogen generation from photocatalytic silver|zinc oxide nanowires: Towards multifunctional multisegmented nanowire devices", Small, 2011, vol. 7, pp. 2709-2713.

[31] A. W. Maijenburg, A. George, D. Samal, M. Nijland, R. Besselink, B. Kuiper, J. E. Kleibeuker, and J. E. ten Elshof, "Electrodeposition of micropatterned $\mathrm{Ni} \mid \mathrm{Pt}$ multilayers and segmented $\mathrm{Ni}|\mathrm{Pt}| \mathrm{Ni}$ nanowires", Electrochimica Acta, 2012, vol. 81, pp. 123-128. 


\section{Summary}

This thesis is entitled "Templated electrodeposition of functional nanostructures: nanowires, nanotubes and nanocubes". Templated electrodeposition is the synthesis technique that was used throughout this thesis, and it comprises the use of a template with specific shape and dimensions for the formation of different types of nanostructures. Throughout this thesis, three different nanostructures were made: nanowires (Chapters 2 to 6), nanotubes (Chapters 2 and 5) and nanocubes (Chapters 7 and 8). Since electrodeposition can be used for the synthesis of many different types of materials, like metals (Chapters 2-5, 7, 8), metal oxides (Chapters 2, 4-7) and metal sulphides (Chapter 8), different types of functionalities can be given to these nanostructures. Throughout this thesis, photocatalytic $\mathrm{H}_{2}$ formation was the functionality that was studied most (Chapters 2, 4-7), but electrocatalytic $\mathrm{H}_{2}$ formation (Chapter 8) and magnetic properties (Chapter 3 ) were also studied. 
In Chapter 1, a theoretical introduction into (templated) electrodeposition and photocatalysis is given. Electrodeposition is an easy and cost-effective method for the deposition of a wide range of metals, semiconductors and conductive polymers on a conductive substrate. This process involves reduction of ions in solution, called the electrolyte, in order to form a solid material. When a template is applied on top of the conductive substrate, the deposited material can mimic the inverse shape of the template used. Photocatalysis is a technique that can be used for the synthesis of different types of chemicals from (sun)light using a semiconductor as photocatalyst. When the band edges of the valence band and conduction band of the semiconductor are positioned favourably, water can be split into $\mathrm{H}_{2}$ and $\mathrm{O}_{2}$ gas. At the end of Chapter 1, a multifunctional nanowire containing six different segments ( $\mathrm{Pt}|\mathrm{Au}| \mathrm{Pt}|\mathrm{Ni}| \mathrm{Ag} \mid \mathrm{ZnO}$ ) is presented, which could be used for autonomous movement $(\mathrm{Pt}|\mathrm{Au}| \mathrm{Pt})$, magnetic steering $(\mathrm{Ni})$ and photocatalytic $\mathrm{H}_{2}$ formation ( $\mathrm{Ag} \mid \mathrm{ZnO}$ ).

Chapter 2 describes the most essential experimental procedures that were used throughout this thesis. The first part of this chapter explains the experimental procedures that should be applied when using templated electrodeposition for the synthesis of axially segmented $\mathrm{Ag} \mid \mathrm{ZnO}$ and coaxial $\mathrm{TiO}_{2}$ - $\mathrm{Ag}$ nanowires. Very important during templated electrodeposition is isolation of the backside of the membrane so that deposition will exclusively take place inside the membrane pores. It is also very important to take the deposition order of the desired metal and metal oxide phases into account, since $\mathrm{ZnO}$ can dissolve in the acidic electrolyte used for $\mathrm{Ag}$ deposition, and a coaxial structure can only be made when one of the phases forms a nanotube, which needs to be deposited first. The second part of this chapter describes an easy method for semi-quantitative detection of $\mathrm{H}_{2}$ gas formed during photocatalytic water splitting, for which a $\mathrm{Pd}$-based $\mathrm{H}_{2}$ sensor was used. By placing the sensor in the gas phase above the solution, the output signal of this sensor changes when $\mathrm{H}_{2}$ is formed during photocatalytic $\mathrm{H}_{2}$ formation. 
In Chapter 3, it is shown that the galvanic replacement reaction can be suppressed by increasing the overpotential used for electrodeposition of the noble metal. The galvanic replacement reaction is responsible for the replacement of a less noble metal for a noble metal when the noble metal is deposited on top of the less noble one via electrodeposition. In the case of $\mathrm{Pt}$ deposition on top of $\mathrm{Ni}$, this can be accomplished by using a more negative potential for Pt deposition ( $-0.6 \mathrm{~V}$ instead of $-0.3 \mathrm{~V} \mathrm{vs}$. $\mathrm{Ag} / \mathrm{AgCl})$. This opens up the possibility to form (micro- and nanopatterned) Ni|Pt multilayers and $\mathrm{Ni}|\mathrm{Pt}| \mathrm{Ni}$ nanowires by (templated) electrodeposition. The combination of $\mathrm{Ni}$ and $\mathrm{Pt}$ can be beneficial in several magnetic applications. In the case of micropatterned $\mathrm{Ni}$ Pt multilayers, double hysteresis loop behaviour was observed, which was induced by the formation of a small layer of ferromagnetic $\mathrm{Ni}_{3} \mathrm{Pt}$ at the Ni-Pt interface.

Chapter 4 presents an axially segmented nanowire system containing $\mathrm{Ag}$ and $\mathrm{ZnO}$ segments that finds application in photocatalytic water splitting. The main advantage of using segmented nanowires compared to conventional photoelectrochemical cells is that no external circuit needs to be applied since these nanowires are capable of splitting water autonomously. By comparing the shape of $I-V$ curves measured along the length of the nanowires, it was found that a Schottky barrier had formed at the Ag-ZnO interface, while single component $\mathrm{Ag}$ and $\mathrm{ZnO}$ nanowires exhibited ohmic and semiconducting behaviour, respectively. The Schottky barrier at the $\mathrm{Ag} \mid \mathrm{ZnO}$ interface allows electron transfer from the $\mathrm{ZnO}$ phase to the Ag phase leading to electron-hole separation and is therefore responsible for the photocatalytic activity of these nanowires. After UV illumination for $17 \mathrm{~min}$ of an 80 vol\% aqueous methanol solution containing $0.1 \mathrm{~g} \mathrm{Ag} \mid \mathrm{ZnO}$ nanowires, it was estimated that $\sim 0.2$ vol\% $\mathrm{H}_{2}$ had formed in the gas volume above the solution. This corresponds to a $\mathrm{H}_{2}$ formation rate of $\sim 6.9 \mu \mathrm{mol} / \mathrm{h} \cdot \mathrm{g}$. 
In Chapter 5, $\mathrm{TiO}_{2}$ nanotubes are demonstrated that were formed by the electrochemically induced sol-gel method. The formation of nanotubes via this method opens up the possibility to form coaxial nanowires with a $\mathrm{Ag}$ core as presented in this chapter. These coaxial $\mathrm{TiO}_{2}-\mathrm{Ag}$ nanowires were also used for autonomous water splitting, with the advantage that the semiconductor-metal interface in these nanowires was much larger compared with the $\mathrm{ZnO}-\mathrm{Ag}$ interface in Chapter 4. This was also visible in the amount of $\mathrm{H}_{2}$ that was formed during water splitting experiments. Next to the formation of coaxial $\mathrm{TiO}_{2}-\mathrm{Ag}$ nanowires, this chapter also presents a method for the formation of $\mathrm{Ag}$ nanoparticles incorporated in $\mathrm{TiO}_{2}$ nanotubes $\left(\mathrm{TiO}_{2} / \mathrm{Ag}\right.$ nanotubes) by drying the $\mathrm{TiO}_{2}$ gel at $100{ }^{\circ} \mathrm{C}$ overnight with subsequent $\mathrm{Ag}$ electrodeposition. Thermal annealing at $650{ }^{\circ} \mathrm{C}$ for $2 \mathrm{~h}$ resulted in the formation of coaxial $\mathrm{TiO}_{2}-\mathrm{Ag}$ nanowires. In this chapter, the photocatalytic activity of coaxial $\mathrm{TiO}_{2}-\mathrm{Ag}$ nanowires made via the electrochemically induced sol-gel method was also compared with bare $\mathrm{TiO}_{2}$ nanotubes, $\mathrm{TiO}_{2} / \mathrm{Ag}$ nanotubes and coaxial $\mathrm{TiO}_{2}-\mathrm{Ag}$ nanowires in which the $\mathrm{TiO}_{2}$ shell was made via atomic layer deposition (ALD). Of all these one-dimensional $\mathrm{TiO}_{2}$ nanostructures, coaxial $\mathrm{TiO}_{2}$-Ag nanowires made via the electrochemically induced sol-gel method showed the highest $\mathrm{H}_{2}$ formation rate: $1.2 \pm 0.3 \mathrm{mmol} / \mathrm{h} \cdot \mathrm{g}$.

Chapter 6 presents a photocatalytic nanowire system in which a $p$-n photoelectrochemical diode is responsible for the photocatalytic activity instead of a Schottky barrier. The advantage of using a photoelectrochemical diode is the possibility to carry out electrochemical reactions with an up conversion in energy. For the realization of this photoelectrochemical diode, $\mathrm{p}$ - and n-type $\mathrm{Cu}_{2} \mathrm{O}$ were combined within single nanowires, in which the use of a homojunction has the unique advantage that both phases have a comparable (if not identical) chemical reactivity, resulting in a $\mathrm{p}$ - $n$ interface with enhanced chemical and mechanical stability. It was found that local diffusion and mixing of $\mathrm{Cu}^{+}$ interstitials and $\mathrm{Cu}^{0}$ donors near the interface created an intrinsic interface layer with Ohmic properties, creating the photoelectrochemical diode. Using nanowires with $2 \mathrm{p}$ - and $2 \mathrm{n}$-type segments in a solution containing phosphate, $\mathrm{H}_{2}$ gas was formed at a rate of $2.2 \pm 0.5 \mathrm{mmol} / \mathrm{h} \cdot \mathrm{g}$. 
Chapter 7 presents a method for the formation of nanocubes via templated electrodeposition inside a template containing a cubic hole pattern. Nano imprint lithography (NIL) was used for template preparation, which resulted in a PMMA template containing the desired cubic hole pattern. $\mathrm{Ni}$ and $\mathrm{p}-\mathrm{Cu}_{2} \mathrm{O}$ nanocubes were deposited inside these templates, perfectly adopting the negative replica of the template. The roughness of the top surface of these nanocubes was estimated with the root mean square (rms) method and was found to be $5 \pm 1 \mathrm{~nm}$, which is in the same range as the rms value of a $\mathrm{Ni}$ film made by electrodeposition ( $\sim \mathrm{nm})$. The $p-\mathrm{Cu}_{2} \mathrm{O}$ nanocubes are composed of smaller crystallites compared with planar films, which suggests that the nucleation of $\mathrm{Cu}_{2} \mathrm{O}$ in the nano-sized template takes place more easily than without template. The photocatalytic properties of $\mathrm{p}-\mathrm{Cu}_{2} \mathrm{O}$ nanocubes were measured and it was found that the photocurrent of the nanocubes was doubled to $\sim 3.0 \mathrm{~mA} / \mathrm{cm}^{2}$ compared with the planar films. In addition, also segmented $\mathrm{Ni} \mid \mathrm{p}-\mathrm{Cu}_{2} \mathrm{O}$ nanobars were made as a proof-of-concept to show the possibility of making multisegmented nanocubes, which is a unique advantage of this technique.

In Chapter 8, Au nanocube structures with a PMMA core made by a combination of NIL and sidewall deposition were used as an alternative template for deposition of $\mathrm{MoS}_{2}$, Pt and Ni nanocube structures. Using this technique, the electrodeposited material was conformally deposited on top of the template instead of inside the template. By high resolution Transmission Electron Microscopy (TEM), it was found that the individual layers inside the electrodeposited $\mathrm{MoS}_{2}$ film were preferentially aligned parallel to the underlying Au substrate. Due to this preferential alignment of $\mathrm{MoS}_{2}$ planes, catalytically active Mo (1010) and S (1010) edge sites became available at the corners of the nanocube structures. Using linear sweep voltammetry (LSV), it was found that the activity of these $\mathrm{MoS}_{2}$ nanocube structures for $\mathrm{H}_{2}$ evolution was higher than that of planar $\mathrm{MoS}_{2}$ films, which was quantified by a shift in overpotential that is needed to reach a current density of $-5 \mathrm{~mA} / \mathrm{cm}^{2}$ from $387 \mathrm{mV}$ for planar films to $320 \mathrm{mV}$ for the nanocube structures. 


\section{Samenvatting}

De titel van mijn proefschrift is "Templated electrodeposition of functional nanostructures: nanowires, nanotubes and nanocubes". Vertaald in het Nederlands zou dit "Elektrodepositie van functionele nanostructuren in een mal: nanodraadjes, nanobuisjes en nanokubusjes" worden. Hierbij was elektrodepositie de techniek die ik gedurende mijn promotie heb gebruikt om het gewenste materiaal te maken, en door elektrodepositie specifiek in een mal met een bepaalde vorm en afmetingen te laten plaatsvinden, heb ik verschillende typen nanostructuren gemaakt. In een mal met een cilindrische vorm kunnen nanodraadjes (Hoofdstuk 2 tot 6) en nanobuisjes (Hoofdstuk 2 en 5) worden gemaakt, en door een mal met een vierkante vorm te gebruiken, heb ik laten zien dat het ook mogelijk is om nanokubusjes (Hoofdstuk 7 en 8 ) te maken. Door het gebruik van verschillende soorten vloeistoffen voor de elektrodepositie, kunnen verschillende soorten materialen (metalen (Hoofdstuk 2-5, 7, 8), metaaloxiden (Hoofdstuk 2, 4-7) en metaalsulfiden (Hoofdstuk 8)) worden gemaakt, die elk andere eigenschappen of functies hebben. Tijdens mijn promotie heb ik vooral gekeken naar de vorming van waterstof met behulp van fotokatalyse (Hoofdstuk 2, 4-7), maar elektrokatalyse (Hoofdstuk 8) en magnetische eigenschappen (Hoofdstuk 3) zijn ook kort aan bod gekomen. De vetgedrukte woorden zullen in de rest van deze samenvatting uitgebreider worden uitgelegd. 
Zoals gezegd, is elektrodepositie de techniek die ik gebruikt heb om mijn nanostructuren te maken. De opstelling voor elektrodepositie is schematisch weergegeven in Figuur 1 en bestaat uit een oplossing, genaamd elektrolyt, waarin de ionen zijn opgelost die nodig zijn voor de depositie van een bepaald materiaal, en drie elektroden die in de elektrolyt worden gehangen: de werkelektrode, referentie-elektrode en tegenelektrode. Door een spanningsverschil aan te leggen tussen de werkelektrode en de referentie-elektrode, worden er elektronen naar de werkelektrode gestuurd. Op de werkelektrode zullen deze negatief geladen elektronen reageren met de positief geladen ionen uit de oplossing, waardoor een vaste stof wordt gevormd.

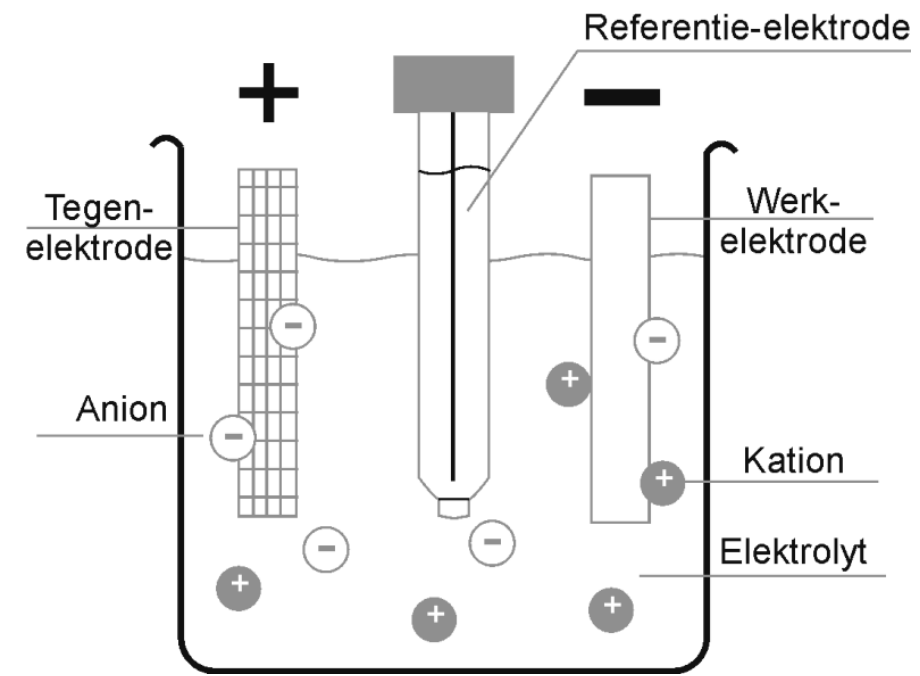

Figuur 1: Opstelling gebruikt voor elektrodepositie met werkelektrode, referentie-elektrode en tegenelektrode.

Over het algemeen worden vlakke elektroden gebruikt, waardoor er een gladde laag wordt gedeponeerd. Maar door het aanbrengen van een mal op de werkelektrode, zal de depositie worden beperkt tot de dimensies van de mal. Hierdoor zal het gedeponeerde materiaal een exacte negatieve replica van de mal vormen. Het proces dat ik hiervoor gebruikte is schematisch weergegeven in Figuur 2. De achterkant van het membraan is geïsoleerd, zodat de depositie specifiek plaatsvindt in de poriën van de mal. 


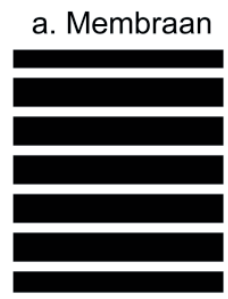

\section{d. Depositie}

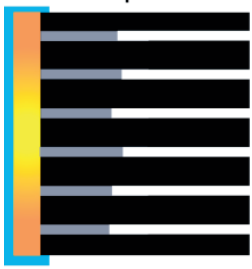

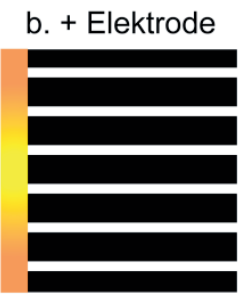

e. Stop

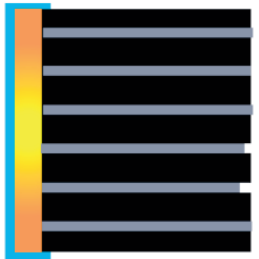

c. + Isolatie

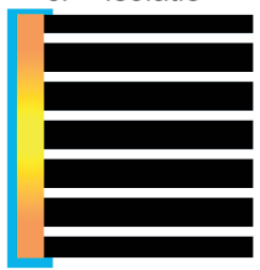

f. Oplossen

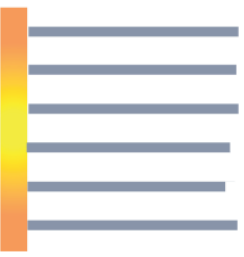

g. Afbreken

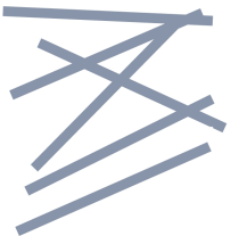

h. Isolatie voor AAO

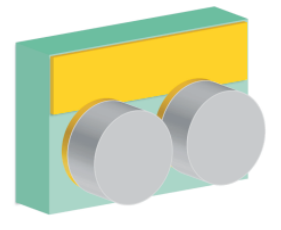

Figuur 2: Schematische weergave van de verschillende stappen in het proces van elektrodepositie in een mal: (a) het gebruikte membraan, (b) het sputteren van een Au laag als elektrode, (c) het isoleren van de achterkant van de elektrode, (d) depositie van het gewenste materiaal, (e) het stoppen van de depositie zodra de gewenste lengte is bereikt, (f) het oplossen van de mal, (g) het breken van de binding tussen de nanostructuren en de Au elektrode, en (h) een alternatieve isolatie voor geanodiseerde aluminium oxide (AAO) membranen.

Voor het maken van nanodraadjes heb ik polycarbonaat (PCTE) of geanodiseerde aluminium oxide (AAO) membranen gebruikt als mal, welke cylindrische poriën bevatten. Door het gebruik van verschillende membranen met elk hun eigen poriediameter en -lengte, heb ik nanodraadjes gemaakt met een diameter variërend van 50 tot $500 \mathrm{~nm}$ (een nanometer is $10^{-9}$ meter) en een lengte variërend van 2 tot $40 \mu \mathrm{m}$ (een micrometer is $10^{-6}$ meter). Door het achtereenvolgens deponeren van verschillende materialen in hetzelfde membraan kunnen eigenschappen worden gecombineerd, of kunnen nanodraadjes worden gemaakt met nieuwe eigenschappen. Deze nanowires bestaande uit een combinatie van verschillende materialen worden gesegmenteerde nanowires genoemd. 
Voor de nanobuisjes die ik heb gemaakt, heb ik AAO membranen met een poriediameter van $200 \mathrm{~nm}$ en een porielengte van 40 tot $60 \mu \mathrm{m}$ gebruikt. Tijdens de thermische behandeling die nodig is om kristallijn $\mathrm{TiO}_{2}$ te maken, verdampt water uit de structuur waardoor deze krimpt. Wanneer dit in een mal met een diameter van $200 \mathrm{~nm}$ of meer gebeurt, wordt het materiaal tegen de wand van de mal gedrukt tijdens het drogen, waardoor nanodraadjes met een holle binnenkant ontstaan: nanobuisjes. Het grote voordeel van het maken van nanobuisjes in plaats van nanodraadjes, is dat deze buisjes met een tweede materiaal kunnen worden gevuld voor het vormen van coaxiale nanodraadjes, zoals ik in Hoofdstuk 5 heb gedaan. Het belangrijkste voordeel van deze coaxiale nanodraadjes voor de fotokatalytische watersplitsing is dat het contactoppervlak tussen beide materialen veel groter is.

Door het ontwikkelen van een nieuw soort mal, heb ik aangetoond dat het ook mogelijk is om nanokubusjes te maken in plaats van cilindrische nanodraadjes en -buisjes. In samenwerking met collega's uit Japan hebben we een kubische afdruk gemaakt in een polymeerlaag, waarbij de bodem van de kubische poriën op een goudlaag zitten. Deze goudlaag doet dienst als werkelektrode. Het grote voordeel van het maken van nanokubusjes met behulp van elektrodepositie in een mal ten opzichte van andere synthesetechnieken is dat de gemaakte nanokubusjes een relatief klein verschil in grootte hebben en dat ze van veel verschillende materialen kunnen worden gemaakt. In Hoofdstuk 7 laat ik zien dat deze techniek goed werkt voor het maken van $\mathrm{Ni}$ en $\mathrm{p}-\mathrm{Cu}_{2} \mathrm{O}$ nanokubusjes, en in Hoofdstuk 8 heb ik $\mathrm{MoS}_{2}$ nanokubusjes gemaakt met behulp van elektrodepositie op een "mal" van polymere kubusjes die zijn bedekt met een dun laagje Au.

Fotokatalyse is een techniek die kan worden gebruikt voor het laten plaatsvinden van verschillende chemische reacties onder invloed van licht. Aangezien zonlicht hier ook voor kan worden gebruikt, is deze techniek de laatste jaren sterk in opkomst voor het goedkoper maken van vele chemische processen. Een voorbeeld hiervan is fotokatalytische watersplitsing voor de productie van waterstofgas als schone energiebron. De basis voor fotokatalytische watersplitsing is het gebruik van een 
halfgeleider met een gunstige ligging van de zogeheten valentie- en conductieband (Figuur 3), waarbij de valentieband het hoogste energieniveau van het materiaal is waarin elektronen zich nog net bevinden, en de conductieband is het laagste energieniveau waarin zich geen elektronen meer bevinden. Door de interactie van een halfgeleider met (zon)licht worden enkele elektronen uit de valentieband aangeslagen zodat ze in de conductieband terechtkomen. Hierdoor krijgen deze elektronen extra energie, waardoor verschillende chemische reacties kunnen worden uitgevoerd aan het oppervlak van de halfgeleider. Tijdens mijn promotie heb ik drie verschillende materialen $\left(\mathrm{ZnO}, \mathrm{TiO}_{2}\right.$ en $\left.\mathrm{Cu}_{2} \mathrm{O}\right)$ gebruikt als fotokatalytische nanodraadjes (Hoofdstukken 4, 5 en 6) en heb ik $\mathrm{p}-\mathrm{Cu}_{2} \mathrm{O}$ nanokubusjes gebruikt als foto-elektrode (Hoofdstuk 7).

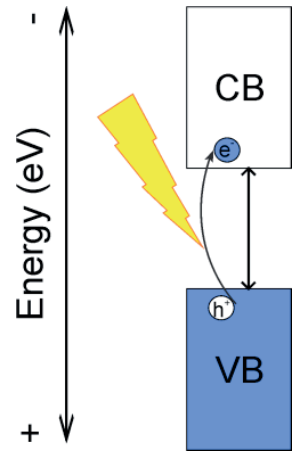

Figuur 3: Schematische weergave van de bandenstructuur van een halfgeleider. VB is de valentieband en CB is de conductieband.

Met behulp van elektrokatalyse kunnen ook een heleboel chemische reacties (in oplossing) worden uitgevoerd, waarbij een soortgelijke opstelling wordt gebruikt als voor elektrodepositie (Figuur 1). Het elektrokatalytische karakter van deze reacties zit in het gebruik van een geschikt katalysatormateriaal voor de werkelektrode, waarbij de benodigde spanning die moet worden aangelegd om de reactie op gang te krijgen (de zogeheten overpotentiaal) zo klein mogelijk is. Veel onderzoek op het gebied van elektrokatalyse wordt dan ook uitgevoerd om deze overpotentiaal te verlagen. In Hoofdstuk 8 van mijn proefschrift heb ik $\mathrm{MoS}_{2}$ nanokubusjes gemaakt die de overpotentiaal voor waterstofevolutie verlagen ten opzichte van vlakke $\mathrm{MoS}_{2}$ lagen. 


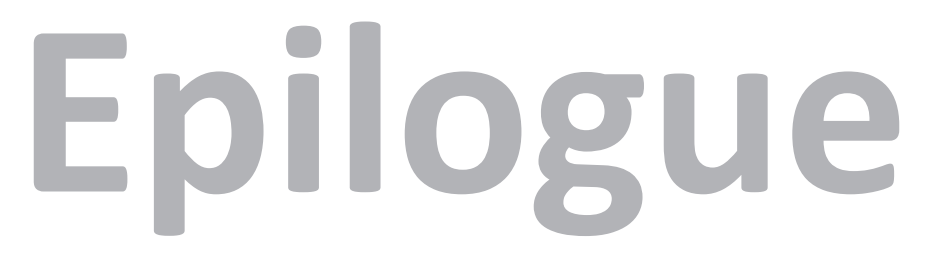

After four years of performing research focused on templated electrodeposition of functional nanostructures, I feel it is appropriate to reflect on where we started four years ago, how this thesis developed its contents and what could be interesting future research strategies on these topics. 
Four years ago I was hired on a proposal entitled "Towards self-assembled inorganic mesostructures", which was granted in the TOP framework of the Netherlands Organization for Scientific Research (NWO). The main aim of this proposal was to "develop strategies, which combines synthesis and (self) assembly of nanosized particles to produce mesoscale materials" with the goal that "these hierarchical structures can show unique properties that are not found in the individual building blocks". Within this project, I worked on the chemical aspects, Bouwe Kuiper worked on the physical aspects, and Maarten Nijland worked on the physicochemical aspects combining chemistry and physics.

When thinking about self-assembly, the term self-assembled monolayers directly comes into mind, in which organic molecules with a thiol group at one end of the chain are used to bind the molecules to a Au surface. This approach was also pursued in Chapter 3 for patterned electrodeposition. By functionalization of the other end of these organic molecules, the Au surface can specifically be functionalized [1]. Another large research field incorporating self-assembly is DNA origami, in which the order of base pairs within DNA strands are arranged so that specific two- and three-dimensional shapes can be formed upon hybridization of the base pairs [2]. But in addition to these organic building blocks, inorganic nanoparticles can also be used as building blocks in self-assembly processes via e.g. magnetic interactions or the use of organic linker molecules [3]. Using nanowires for self-assembly processes, complementary DNA strands are often used as linker molecules in order to self-assemble nanowires in a side-by-side or end-to-end fashion, or to couple nanowires with nanospheres [4-6]. In order to incorporate a more regular arrangement within these self-assembled nanostructures, an open cubic mesostructure was envisaged as shown in Figure 1. In this open cubic mesostructure, the ends of axially segmented nanowires are coupled to the six sides of nanocubes, in which the use of a metallic phase for the end of a nanowire and an oxidic phase for the middle part of the nanowires should enable specific binding to the metallic nanocubes via thiol chemistry. 


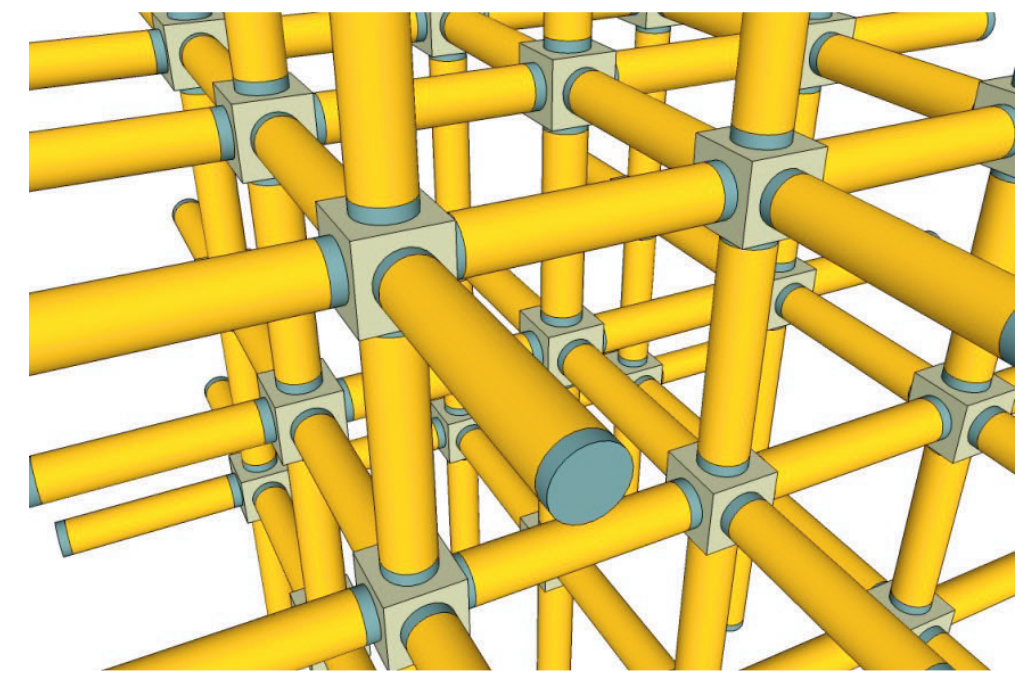

Figure 1: Envisaged self-assembled open cubic mesostructures.

Templated electrodeposition is a widely used method for the deposition of axially segmented nanowires with variable diameter, length and composition, and a small size distribution $[7,8]$. Therefore, a suitable method for the synthesis of the required nanowires was quickly found. On the other hand, such a reliable technique was not yet available for the deposition of nanocubes. Therefore we searched for a template with a cubic hole pattern, which was eventually found through a collaboration with Osaka University in Japan. The results of this collaboration were presented in Chapters 7 and 8.

In the meantime, another research pathway was started in order to find an interesting application for the open cubic mesostructure. With the world's increasing energy demand and the depletion of fossil fuels, we need to adapt to the use of renewable energy sources with the most abundant renewable energy source being solar radiation. One of the ways in which solar energy can be used for future energy supply is photocatalytic water splitting for the formation of $\mathrm{H}_{2}$ gas as a renewable solar fuel. In this respect, three different nanowire systems were introduced in Chapters 4, 5 and 6 for autonomous water splitting, which means that no external circuit is needed to connect the photocathode and (photo)anode.

In the end, little research was devoted to the self-assembly of inorganic nanostructures into three-dimensional mesostructures like the envisaged open cubic mesostructure. Even though the realization of such structures 
would still be very interesting from a research point of view, I believe that the original vision of emerging properties within the self-assembled mesostructure can already be achieved using templated electrodeposition only. Since it is very straightforward to combine different materials within the same nanowire or nanocube, different functionalities can be combined within a single nanostructure. A beautiful example of this can be found in Figure 1.6 of the introduction, which shows a nanowire containing 6 segments and 3 different functionalities, but other examples can be found throughout this thesis. For example, in Chapters 4 and 5, templated electrodeposition was used for the synthesis of nanowires containing a photocatalytically active metal oxide phase and a metallic co-catalyst that were used for autonomous water splitting. $\mathrm{No}_{2}$ formation was observed when only one of the two phases was used, but templated electrodeposition enabled the combination of both phases within a single nanowire and the emerging photocatalytic activity.

It is noted that the examples presented in this thesis do not possess any three-dimensional mesoscale architecture. But with the availability of templates for the electrodeposition of interconnected three-dimensional nanowire networks [9], it will be possible to form three-dimensional mesostructures with spatial control over combined functionalities in the near future. With the use of a relatively simple and cost-effective technique like templated electrodeposition, it is not needed to rely on the entropic chance that the envisaged structure is formed as would be the case with self-assembly.

Almost every chapter in this thesis contains some interesting ideas for further research on the specific topics, and they also open up possibilities for the use of the presented research strategies using different types of materials for other types of applications. One interesting outlook for further research I would like to point out here is the use of templated electrodeposition for the synthesis of nanocubes containing different materials, as was suggested in Chapter 7. Until now, we have shown the use of this technique for the synthesis of $\mathrm{Ni}$ and $\mathrm{p}-\mathrm{Cu}_{2} \mathrm{O}$ nanocubes, but $\mathrm{I}$ believe that this technique can also be used for the synthesis of nanocubes of many more materials after fine-tuning of the different electrodeposition parameters. Especially the possibility to synthesize noble metal nanocubes $(\mathrm{Au}, \mathrm{Pt}, \mathrm{Ag}$ ) would be interesting for the realization of the open cubic mesostructure as proposed in Figure 1. 
In Chapters 2, 4, 5 and 6, the use of photocatalytic nanowire systems for autonomous water splitting and $\mathrm{H}_{2}$ formation was presented. Although the main advantage of these nanowire systems is that no external circuit is required, as opposed to photoelectrochemical cells, these systems are not able to provide any quantitative information about the degree of efficiency enhancement that is obtained by nanostructurization of the photocatalytic material into nanowires, nor if this efficiency enhancement is solely encompassed by the increased surface area, or that there are also other effects playing a role. I have tried different strategies to obtain mechanically stable nanowire arrays so that photocurrent measurements could be performed, but I found that this was not possible with the use of commercial templates. Therefore, an interesting approach for further research on the use of photocatalytic nanowires for water splitting and $\mathrm{H}_{2}$ formation would be to use different types of templates for the synthesis of mechanically stable one-dimensional nanostructures, e.g. interconnected nanowire networks and nanocones (Figure 2) $[9,10]$.

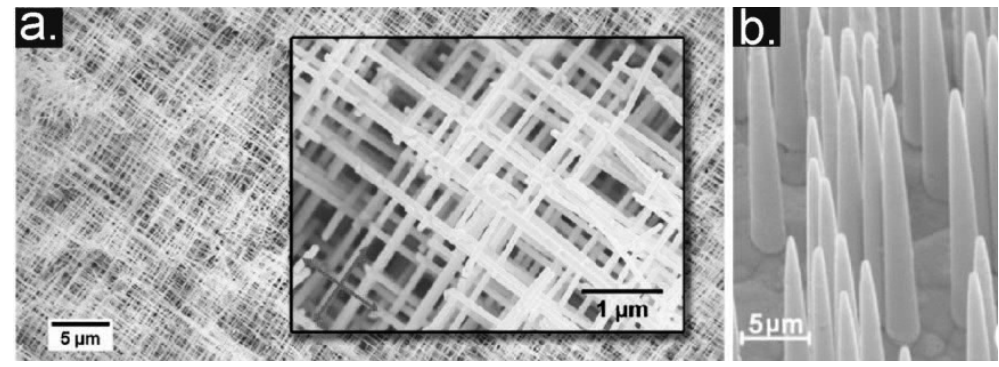

Figure 2: (a) Pt nanowire network structure and $\mathrm{Cu}$ nanocones. Reprinted with permission from references $[9,10]$. 


\section{References}

[1] J. J. Gooding, F. Mearns, W. Yang, and J. Liu, "Self-assembled monolayers into the 21st century: Recent advances and applications", Electroanalysis, 2003, vol. 15, pp. 81-96.

[2] B. Saccà and C. M. Niemeyer, "DNA origami: The art of folding DNA", Angewandte Chemie - International Edition, 2012, vol. 51, pp. 58-66.

[3] S. C. Glotzer and M. J. Solomon, "Anisotropy of building blocks and their assembly into complex structures", Nature Materials, 2007, vol. 6, pp. 557-562.

[4] D. Fava, Z. Nie, M. A. Winnik, and E. Kumacheva, "Evolution of self-assembled structures of polymer-terminated gold nanorods in selective solvents", Advanced Materials, 2008, vol. 20, pp. 4318-4322.

[5] B. Pan, L. Ao, F. Gao, H. Tian, R. He, and D. Cui, "End-to-end self-assembly and colorimetric characterization of gold nanorods and nanospheres via oligonucleotide hybridization", Nanotechnology, 2005, vol. 16, pp. 1776-1780.

[6] R. D. Robinson, B. Sadtler, D. O. Demchenko, C. K. Erdonmez, L. W. Wang, and A. P. Alivisatos, "Spontaneous superlattice formation in nanorods through partial cation exchange", Science, 2007, vol. 317, pp. 355-358.

[7] S. J. Hurst, E. K. Payne, L. Qin, and C. A. Mirkin, "Multisegmented one-dimensional nanorods prepared by hard-template synthetic methods", Angewandte Chemie - International Edition, 2006, vol. 45, pp. 2672-2692.

[8] R. M. Penner and C. R. Martin, "Preparation and electrochemical characterization of ultramicroelectrode ensembles", Analytical, 1987, vol. 59, pp. 2625-2630.

[9] M. Rauber, I. Alber, S. Muöller, R. Neumann, O. Picht, C. Roth, A. Schoökel, M. E. Toimil-Molares, and W. Ensinger, "Highly-ordered supportless three-dimensional nanowire networks with tunable complexity and interwire connectivity for device integration", Nano Letters, 2011, vol. 11, pp. 2304-2310.

[10] P. Serbun, F. Jordan, A. Navitski, G. Müller, I. Alber, M. E. Toimil-Molares, and C. Trautmann, "Copper nanocones grown in polymer ion-track membranes as field emitters", EPJ Applied Physics, 2012, vol. 58, 


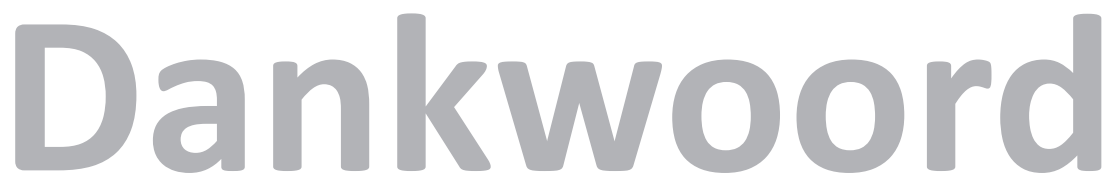

Promoveren doe je nooit alleen, en in mijn geval heb ik het geluk gehad dat ik de afgelopen jaren met veel verschillende mensen heb mogen samenwerken. Ere wie ere toekomt, dus vandaar dit dankwoord. 
Als eerste wil ik André bedanken dat hij mij de kans heeft gegeven om op dit super interessante project te mogen werken. Ik vond het erg fijn dat je me in dit project zoveel vrijheid hebt gegeven, waardoor het echt mijn project is geworden en ik me de afgelopen jaren heb kunnen ontwikkelen tot een expert in deze interessante gebieden: templated elektrodepositie en water splitsing. Daarnaast kijk ik met plezier terug op de discussies die we de afgelopen jaren hebben gehad, waarbij ik dankzij jouw ervaring steeds weer een stapje verder kon komen binnen de verschillende projecten. BEDANKT!!

Secondly I would like to thank Kyoung-Shin for giving me the opportunity to visit her lab in the fall of 2011 for an important collaboration. Of course I learned a lot in this period about the topics of photocatalysis and photoelectrochemistry, and the materials we can make for these purposes using electrodeposition, but also personally this was an experience I will never forget. Therefore I'm very thankful for being part of your group during this period, and also for the nice Skype discussions we've had the past months about Chapters 6, 7 and 8. Also I would like to take this chance to thank everybody else from the Choi lab for the nice collaborations and all the fun we had: Jason, Ken, Colleen, Bobby, Morrisa, James, Yiseul, Donghyeon, John, Kristin and Joe, THANKS!!

Maar dichter bij huis zijn er binnen mijn eigen groep IMS natuurlijk ook verschillende mensen die een speciale vermelding verdienen. Dave, helaas zagen we je de laatste jaren steeds minder bij IMS, maar daarom vind ik het misschien juist wel een extra grote eer dat je mijn copromotor wilt zijn. Jouw charismatische karakter en uitgebreide kennis van nanomaterialen zullen altijd een grote inspiratie blijven. Rogier en Maarten, de keuze voor jullie als paranimfen was snel gemaakt, want met jullie in de buurt is er altijd genoeg te beleven. Vier jaar lang met Rogier samen op één kantoor zitten lijkt misschien onmogelijk voor sommige mensen, maar ik heb me al die jaren prima vermaakt, en je blijft me nog steeds verbazen! Maarten ken ik al sinds ik in 2004 zijn doegroeppapa mocht zijn, maar tijdens onze periode bij IMS is wel gebleken hoe vaak we op één lijn zitten, en dan is het natuurlijk extra fijn om met zo'n TOPper in hetzelfde project te zitten! 
Verder ben ik Michiel en Eddy, de nanowire-pioniers van IMS, zeer dankbaar voor alles wat zij op dit gebied hadden bereikt voor en tijdens mijn afstuderen. Zonder jullie hulp had ik nooit zo'n snel begin kunnen maken met mijn promotie, en ik heb nog steeds erg veel aan jullie ontdekkingen! Antony, thank you very much for the best collaborations I've had within IMS and the nice trips we've made: Why not! En de rest van de Chemische broeders niet te vergeten: Sjoerd, Pablo, Huiyu, Gerard, Tomek, Nicolas, Ole, Suresh, Ronald, Sajid, Wouter en Petra bedankt voor alle lol en gezellige gesprekken die we in het lab hebben gehad de afgelopen jaren! En de rest van IMS wil ik ook bedanken voor de goede mix van gezellige koffiepauzes en andere uitstapjes aan de ene kant en de serieuze wetenschappelijke vorming aan de andere kant. Bernard, Guus, Gertjan, Mark, Henk, José, Dominic, Marion, Peter, Alim, Nirupam, Bouwe, Josée, Muhammad, David, Michelle, Brian, Kurt, Ruud, Rik, Tom, Werner, Anirban, Kenan, Deba, Minh, Anuj, Evert, Ben, Tjeerd, Zhaoliang, Xin, Peter, Hans, Oktay and Gerwin: Bedankt!

Verder wil ik mijn studenten ook nog even speciaal bedanken, want jullie inzet en gezelligheid heb ik altijd erg gewaardeerd, en ik hoop dat jullie met veel plezier terugkijken op jullie opdrachten. Janneke, ik heb veel geluk gehad met jou als eerste bachelorstudent en zonder jouw opdracht weet ik niet of mijn proefschrift, en speciaal Hoofdstuk 5, er zo uit zou zien als nu. Roy, bedankt voor de belangrijke stappen die je hebt gezet voor Hoofdstuk 5 zodat we ook daadwerkelijk coaxiale structuren konden maken. Robbert en Victor, bedankt voor jullie uitgebreide inzet om nanowire arrays op een substraat te laten staan zonder polymeertroep. Ondanks dat het niet zo goed lukte als verwacht, hebben jullie projecten mij wel veel kennis opgeleverd. Liz, bedankt voor al het geweldige werk dat je voor Hoofdstuk 6 hebt gedaan, en wat fijn dat je tijdens je vakantie ook nog hard kon doorwerken om het verhaal af te krijgen. Joren, jij ook bedankt voor de inzichten die je ons hebt gegeven op het gebied van zelf-assemblerende nanowires, een interessant onderwerp waar ik altijd nog eens iets mee wilde doen maar nooit tijd voor had. Bedankt!! 
Without collaborations, I wouldn't have been able to obtain so many nice results during my PhD. Without the close collaboration with Kyoung-Shin, Jason, Colleen and Morrisa my knowledge about photocatalytic, photoelectrochemical and electrocatalytic materials would be minimal. Without the cubic templates from Azusa and Hidekazu, I wouldn't have been able to make nanocubes by templated electrodeposition. Without the dendritic AAO templates from Helmut and Martin, the deposition of coaxial $\mathrm{TiO}_{2}$-Ag nanowires would have taken much more time. Zonder de vele uren die Michel en Guido hebben gestoken in het betrouwbaarder maken van de multicell setup, zou het onmogelijk zijn geweest om verschillende fotokatalytische nanowire systemen met elkaar te kunnen vergelijken. Without the help from Moreno, Roel and Bernard I wouldn't have been able to perform photocurrent measurements within the Netherlands. Without Jürgen, I wouldn't have been able to include the nice I- $\mathrm{V}$ measurements on $\mathrm{p} \mid \mathrm{n}-\mathrm{Cu}_{2} \mathrm{O}$ nanowires. Mark, Rico en Gerard wil ik graag bedanken voor de vele uren SEM en TEM waar ik de afgelopen jaren gebruik van heb gemaakt. Kirsten, bedankt voor je interesse in onze magnetische nanowires, ik vond het erg gezellig om hier samen met jou aan te werken! En als laatste wil ik Antony, Sjoerd, Huiyu, Maarten, Bouwe, Josée, Rogier en Deba nogmaals bedanken voor jullie hulp met patterning, XRD, XPS, FTIR en VSM metingen en interpretatie.

I have to admit that I was quite nervous when I went to my first conference without knowing anybody a few years ago, but quickly I learned that there is a special atmosphere at conferences where everybody is interested in each other's work and friends are easily made. And two years later, I even chaired the first Gordon Research Seminar on Electrodeposition, for which I would like to thank Leah, Andy and Kyoung-Shin for their organizational help. Furthermore, I would like to thank Martin, Aljosa, Mojca, Noi, Veronika, Jason, Carrie, Ken, Colleen, Kristina, Rakesh, Zhen, Walther, Ben, André, Kornelius, Eugenia, Sudipta, Laurent, Laura, Alexandra, Ilaria, Ege, Martín, Pablo, Veronika, Svenja, Bobby, James, Morrisa, Yiseul, Brian, Tim, Olga, Cristina, Marco, Mike, Mieke, Petra, Monika and Thalluri for making all the conferences I visited so awesome, and I'm also happy that I was able to enjoy some nice after conference trips with some of you. Thanks!! 
Naast werken, heb ik de afgelopen jaren gelukkig ook genoeg tijd gehad voor ontspanning, waarvan ik toch wel redelijk wat tijd in of naast het korfbalveld van Vakgericht heb doorgebracht. Hiervoor wil ik mijn bestuursgenootjes Floris, Janneke en Martijn bedanken voor alle gezellige vergaderingen, en natuurlijk mijn teamgenootjes van Vakgericht 2 (Roel, Peter, Edwin, Tjalling, Hayo, Jurgen, Kylie, Jorinde, Rike, Linda, Mirjam, Adriënne, Wilmer, Anouk, Wytse, Wouter, Lisette, Daan, Taco, Kelly, Mariëlle en Yorick) bedanken voor de gezellige wedstrijden en trainingen. En de rest van Vakgericht natuurlijk ook bedankt voor alle gezelligheid!

Daarnaast stonden een aantal goede vrienden ook altijd garant voor de nodige ontspanning. Jessica bedankt voor alle gezellige etentjes en serie-kijkavonden. Sandra onder andere bedankt voor de gezellige oud en nieuw vieringen. En Ramon, Soubhik en Miriam bedankt voor alle gezellige oud-bestuursuitstapjes met Veronique en Jeroen.

En als laatste, maar absoluut niet de minsten: papa, mama, Sander, oma, oma, ooms en tantes bedankt voor alle steun en interesse de afgelopen jaren!!!

Zo, hier laat ik het bij KLAAR! 
